\title{
The Effects of Fuel Additives on Diesel Engine Emissions during Steady State and Transient Operation
}

John P. Nuszkowski

West Virginia University

Follow this and additional works at: https://researchrepository.wvu.edu/etd

\section{Recommended Citation}

Nuszkowski, John P., "The Effects of Fuel Additives on Diesel Engine Emissions during Steady State and Transient Operation" (2008). Graduate Theses, Dissertations, and Problem Reports. 2730.

https://researchrepository.wvu.edu/etd/2730

This Dissertation is protected by copyright and/or related rights. It has been brought to you by the The Research Repository @ WVU with permission from the rights-holder(s). You are free to use this Dissertation in any way that is permitted by the copyright and related rights legislation that applies to your use. For other uses you must obtain permission from the rights-holder(s) directly, unless additional rights are indicated by a Creative Commons license in the record and/ or on the work itself. This Dissertation has been accepted for inclusion in WVU Graduate Theses, Dissertations, and Problem Reports collection by an authorized administrator of The Research Repository @ WVU.

For more information, please contact researchrepository@mail.wvu.edu. 
The Effects of Fuel Additives on Diesel Engine Emissions during Steady State and Transient Operation

\author{
John P. Nuszkowski
}

\begin{abstract}
Dissertation submitted to the College of Engineering and Mineral Resources

at West Virginia University in partial fulfillment of the requirements

for the degree of
\end{abstract}

Doctor of Philosophy

in

Mechanical Engineering

Dr. Gregory J. Thompson, Chair

Dr. Nigel N. Clark

Dr. Mridul Gautam

Dr. Scott Wayne

Dr. John Zondlo

Department of Mechanical and Aerospace Engineering

Morgantown, West Virginia

2008

Keywords: Additives, Emissions, Diesel Engines, Heat Release 


\section{Abstract \\ The Effects of Fuel Additives on Diesel Engine Emissions during Steady State and Transient Operation John P. Nuszkowski}

Internal combustion engines have propelled society's transportation and power needs for the last century. However, with the regulatory demand to reduce air pollution, internal combustion engines are a major focus to reduce the emissions from these engines. Compression ignition or diesel engines are a major contributor to NOx and PM pollution. However, the life of these engines is much longer than that of their spark-ignited counterparts, causing the fleet of diesel engines to consist of a significant number of old, higher polluting engines. Fuel additives are one method of reducing emissions and/or enhancing performance in these older diesel engines without the need for technology upgrades (new engines/aftertreatment). Although diesel fuel additives' ability to reduce harmful emissions is well known in the literature, the mechanism as to how these additives work is not well understood.

To explore the mechanism, three cetane improvers (2-EHN, DTBP, and ODA) were investigated on a 1992 DDC Series 60 engine and 2004 EGR-equipped Cummins ISM370 engine incorporating sensors for in-cylinder pressure measurement and analysis. The engines were tested on the heavy-duty FTP cycle and the steady state SET test. The cetane improvers, depending on the additive, treat rate, and base fuel (excluding the biodiesel blends), showed significant reduction in NOx (2.2-4.9\%) on the 1992 DDC engine and no change or significant increase (1.3-1.4\%) on the 2004 Cummins engine when exercised over the transient FTP cycle. In the SET tests, low loads produced a NOx decrease (up to 8\%) and high loads a NOx increase (up to $1.8 \%$ ) with cetane improvers on the 1992 DDC engine. The 2004 Cummins engine showed little NOx decrease (up to $1 \%$ ) or a NOx increase (up to 6.1\%) with cetane improvers compared to the base fuel on the SET test. The biodiesel blends showed a similar trend with the additized neat fuel with decreased NOx at low load and increased NOx at high load on the 1992 DDC engine, suggesting a cetane effect due to the high cetane number of biodiesel.

The heat release parameters showed that the change in NOx was due to the change in maximum cylinder pressure, maximum cylinder gas temperature, premix fraction, and pressure at the start of combustion on the 1992 DDC engine. Overall, the fuel additives reduced the premix fraction of the heat release on the 1992 DDC engine at all loads and reduced the premix fraction at low 
load (25-50\% load) on the 2004 Cummins engine. The 2004 Cummins engine had higher boost pressure, compression ratio, and manifold air temperature, which may have created the low premix fraction. A phenomenological combustion model was developed to provide local NOx formation characteristics. The combustion model and heat release correlations showed that reducing the ignition delay with cetane improvers shifted the global heat release rate and produced the NOx change on the 1992 DDC engine. The reduced ignition delay with cetane improvers created an earlier start of combustion that shifted the in-cylinder pressure and temperature, which resulted in the NOx increase at high load and NOx decrease at low load. 


\section{Table of Contents}

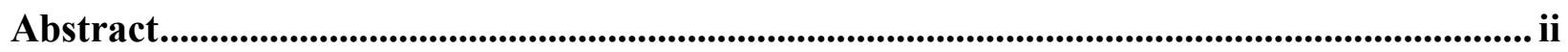

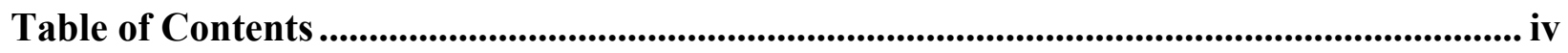



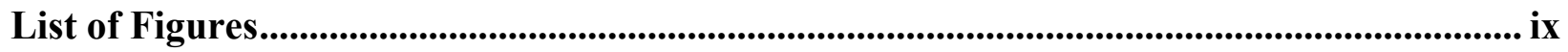

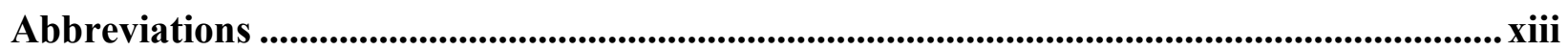



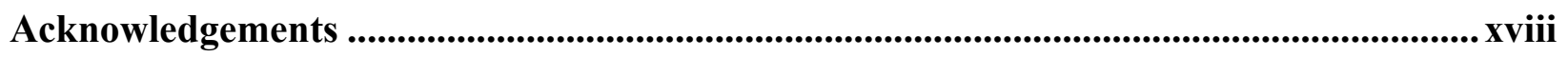

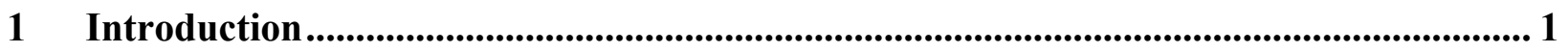

2 Background n................................................................................................................ 5

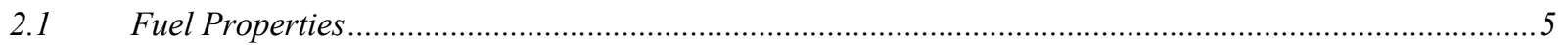



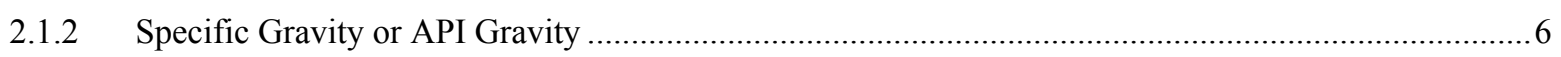

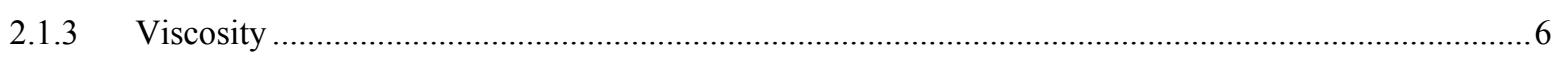





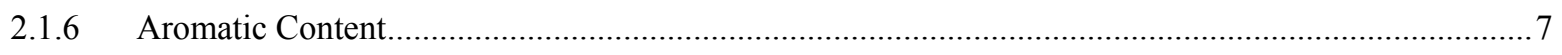

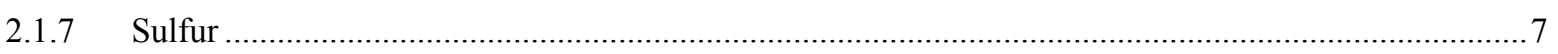



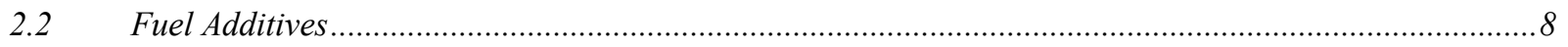



2.3.1 Water Emulsion Diesel Fuel …….......................................................................................... 10

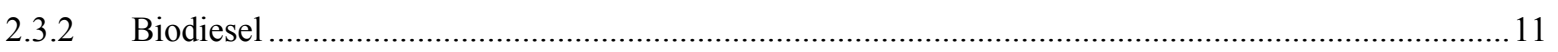

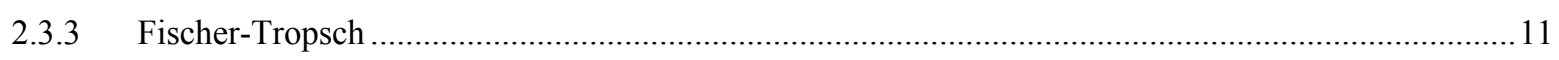

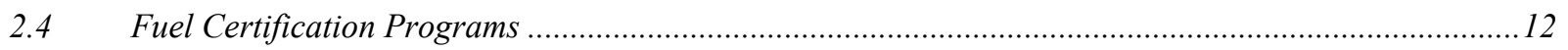

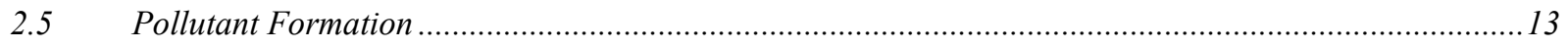

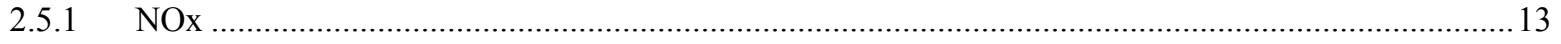

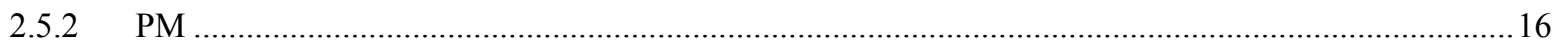





2.5.5 $\mathrm{HC}$

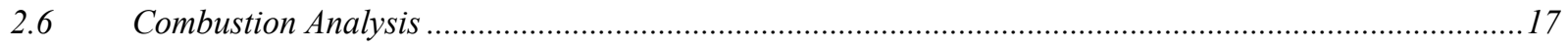



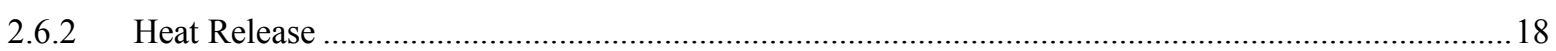




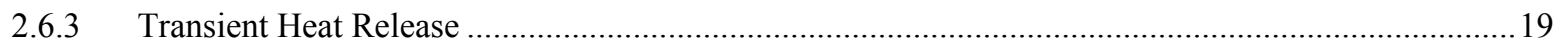

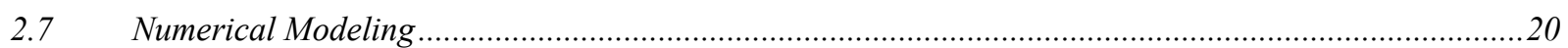

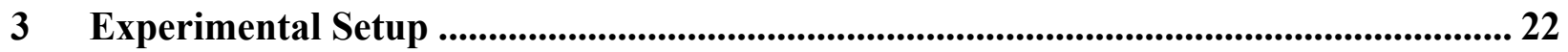





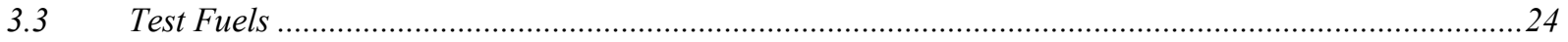



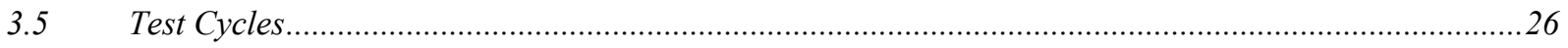



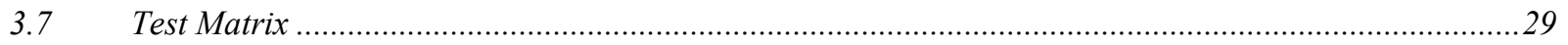

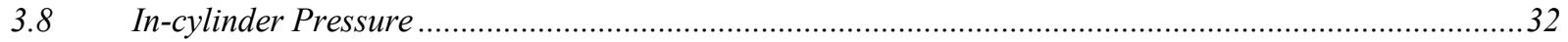

3.8.1 Measured and Calculated Parameters ..................................................................................................

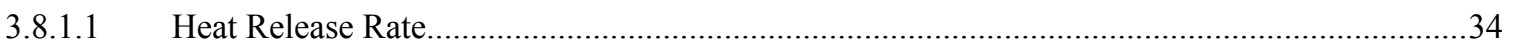

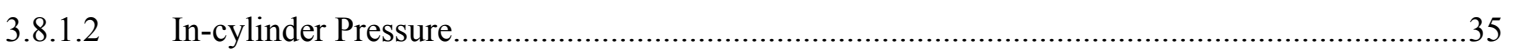









3.8.1.7 Indicated Mean Effective Pressure ...................................................................................... 37

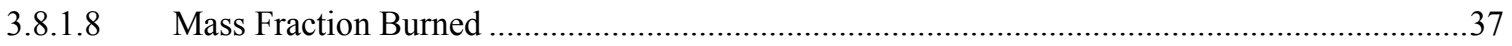

3.8.1.9 In-Cylinder Gas Temperature





3.8.1.12 Ratio of Pressure at Exhaust Valve Opening to Intake Valve Closing.......................................39



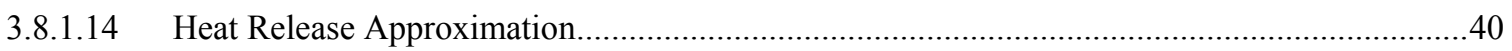



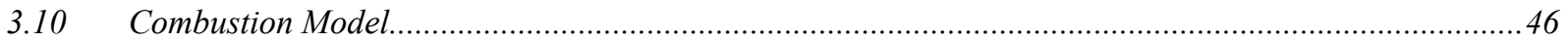

$4 \quad$ Results and Discussions ....................................................................................................... 51

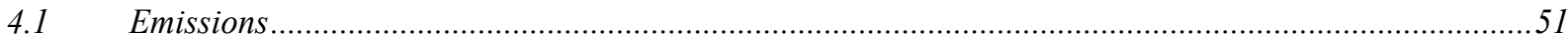

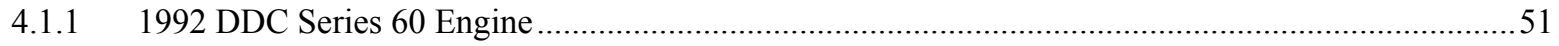

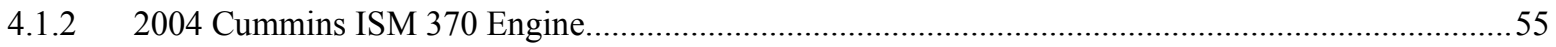

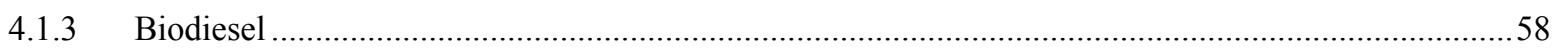

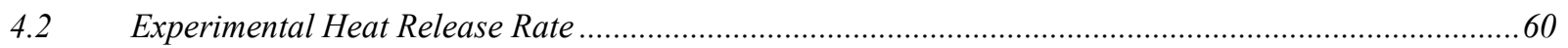



4.2.2 2004 Cummins ISM 370 Engine Heat Release ..............................................................................65

4.2.3 Comparison of Heat Release Between Engines ................................................................................... 70 


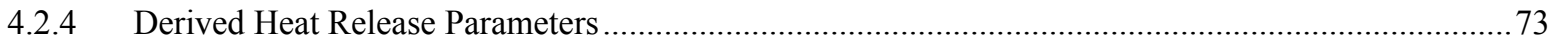

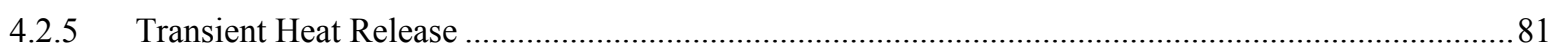

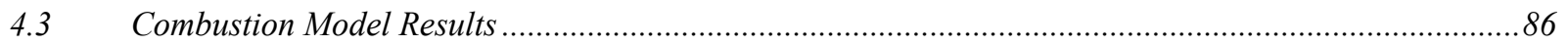

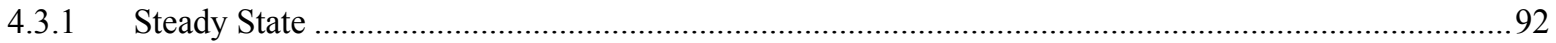

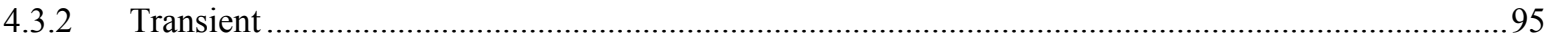

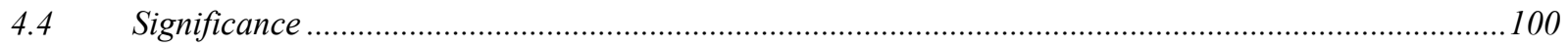

5 Conclusions and Recommendations .............................................................................. 102

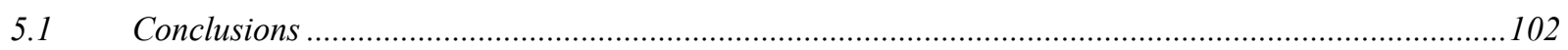



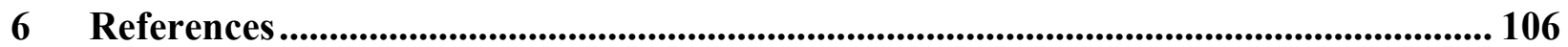

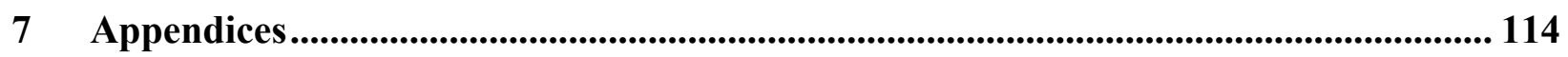




\section{List of Tables}

Table 2-1 US EPA Heavy Duty Diesel Truck Engine Emissions Standards, g/bhp-hr [16] ........ 5

Table 2-2 Influence of Fuel Properties on Heavy-Duty Diesel NOx and PM Emissions from

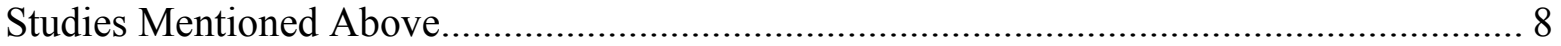

Table 2-3 ASTM-D975-05 Diesel Fuel Specification in the US [44] ................................... 10

Table 2-4 Reference and Candidate Fuel Specification for CARB [7] ................................. 13

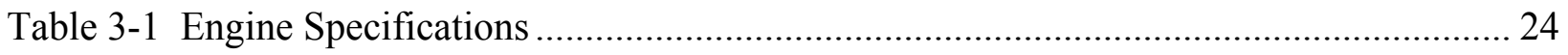

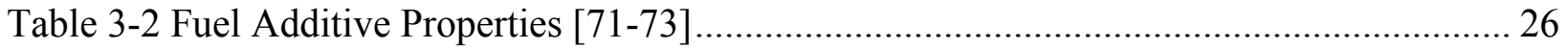

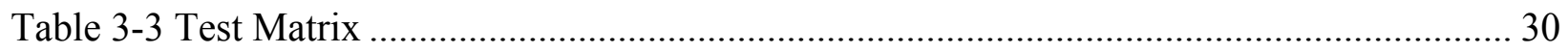

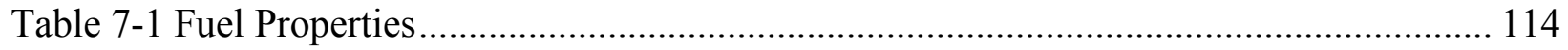

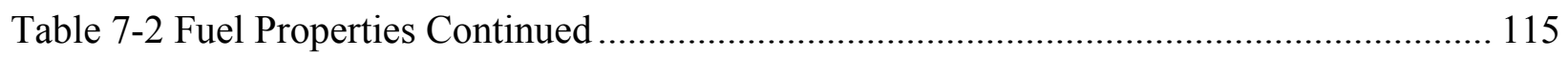

Table 7-3 In-Cylinder Pressure Transducer Specifications .................................................. 116

Table 7-4 The Average Combustion Parameter Correlation Coefficients for NOx and CO



Table 7-5 Correlation Coefficients for Change in Combustion Parameters and Change in NOx and CO Emissions for Low Cetane Fuel with 8ml/gal 2-EHN Fuel Compared to Low Cetane Fuel................................................................................................... 118

Table 7-6 The Average Combustion Parameter Correlation Coefficients for NOx and CO from 1 SET Tests on the 2004 Cummins Engine ........................................................... 119

Table 7-7 Correlation Coefficients for Change in Combustion Parameters and Change in NOx and CO Emissions for CP Cert Fuel with 12ml/gal 2-EHN Fuel Compared to CP Cert Fuel

Table 7-8 Repeatability of Heat Release Parameters from 11 SET Tests: Parameters (range/average), Ratios (range/average), Time (range in ms), and Crank Angle (range in deg)

Table 7-9 January 2007 FTP Results for the 1992 Detroit Diesel Series 60 .......................... 123

Table 7-10 June 2007 FTP Results for the 1992 Detroit Diesel Series 60 .............................. 124

Table 7-11 July 2007 FTP Results for the 1992 Detroit Diesel Series 60 ............................ 125

Table 7-12 February 2007 FTP Results for the 2004 Cummins ISM 370 ............................. 126

Table 7-13 January 2007 SET Results for the 1992 Detroit Diesel Series 60 ........................ 127

Table 7-14 June 2007 SET Results for the 1992 Detroit Diesel Series 60 ............................ 131

Table 7-15 July 2007 SET Results for the 1992 Detroit Diesel Series 60............................. 135 
Table 7-16 February 2007 SET Results for the 2004 Cummins ISM 370............................. 139 


\section{List of Figures}

Figure 2-1 Emissions from a Typical Fuel Spray [57] ……….............................................. 15

Figure 2-2 Typical Heat Release Rate Curve …………......................................................... 19

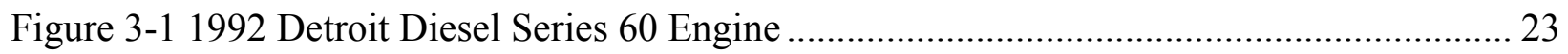

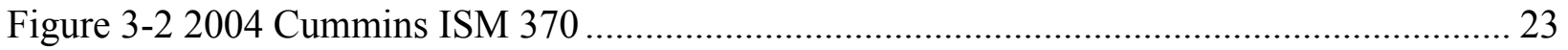

Figure 3-3 Biodiesel Fuels from Left to Right: Soy, Tallow, and Cottonseed Derived ............... 25

Figure 3-4 Heavy Duty Diesel FTP Test Cycle on the 1992 Series 60 DDC ............................... 27

Figure 3-5 Supplemental Emissions Test, Numbers in the Circles Represent the Test Order ..... 28

Figure 3-6 In-Cylinder Pressure Transducers (Not to Scale): Left, 6125B and Right, 6061B

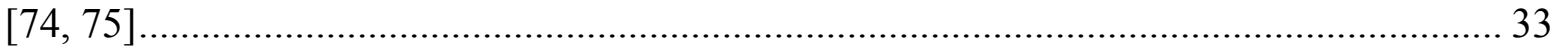

Figure 3-7 In-Cylinder Pressure / Heat Release Analysis Software ............................................. 34

Figure 3-8 Influence of Specific Heat Ratio on the Heat Release Curve for Mode 2 (100\%

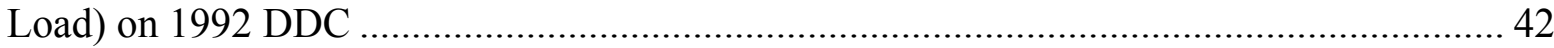

Figure 3-9 Influence of Specific Heat Ratio on the Heat Release Curve for Mode 2 (100\% Load) on 2004 Cummins ISM ........................................................................................ 43

Figure 3-10 Steady State Combustion Derived Fuel Flow Compared to Laboratory Fuel



Figure 3-11 Steady State Combustion Derived Intake Air Flow Compared to Laboratory Intake Air Flow for the 1992 DDC Engine

Figure 3-12 Steady State Combustion Derived Fuel Flow Compared to Laboratory Fuel

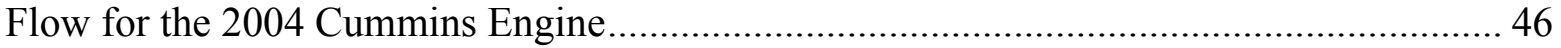

Figure 3-13 The Phenomenological Combustion Model with 10 Fuel Packages.......................... 47

Figure 3-14 Energy Equation for Fuel Packages and Unburned Zone ......................................... 49

Figure 4-1 Change in Brake Specific NOx for Grad Ref Fuel Additized with 16ml/gal ODA Compared to Neat Fuel for Steady State Modes on the 1992 DDC (No Column indicates no significant difference). NOx - Primary NOx Analyzer, NOx2 - Secondary NOx Analyzer, NO - From Secondary NO Analyzer ................................................................ 52

Figure 4-2 Change in the Brake Specific NOx for Low Cetane Fuel with Three Treat Rates of 2-EHN Compared to Neat Fuel for Steady State Modes on the 1992 DDC (Idle not shown).

Figure 4-3 Change in the Brake Specific NOx for Low Cetane Fuel with Three Cetane Improvers Compared to Neat Fuel for Steady State Modes on the 1992 DDC (Idle not shown). 
Figure 4-4 Change in the Brake Specific NOx for CP Cert Fuel with Two Cetane Improvers and a Repeat Neat Fuel Compared to the Neat Fuel for Steady State Modes on the 2004 Cummins ISM 370 (Idle and Mode 2 not shown).

Figure 4-5 Change in the Brake Specific NOx for Grad Ref Fuel Additized with 16ml/gal ODA with Enabled and Disabled EGR Compared to the Neat Fuel with Enabled and Disabled EGR for Steady State Modes on the 2004 Cummins ISM 370 .....

Figure 4-6 Change in the Brake Specific NOx for Low Cetane Fuel with B20 Cottonseed, Repeat Low Cetane Fuel, and Additized B20 Cottonseed Blend Compared to the Neat Fuel for Steady State Modes on the 1992 DDC Engine

Figure 4-7 Change in the Brake Specific NOx for CP Cert Fuel with B20 Soy Blend and Additized B20 Soy Blend Compared to the Neat Fuel for Steady State Modes on the 2004 Cummins ISM 370.

Figure 4-8 Heat Release for Mode 8 (100\% Load) with Varying Amounts of 2-EHN on the 1992 DDC Engine.

Figure 4-9 Heat Release for Mode 9 (25\% Load) with Varying Amounts of 2-EHN on the 1992 DDC Engine.

Figure 4-10 Shifted In-Cylinder Gas Temperature for Mode 8 (100\% Load) with Varying Amounts of 2-EHN on the 1992 DDC Engine....

Figure 4-11 Shifted In-Cylinder Gas Temperature for Mode 9 (25\% Load) with Varying Amounts of 2-EHN on the 1992 DDC Engine....

Figure 4-12 Heat Release for Mode 8 (100\% Load) with Varying Amounts of 2-EHN on the 2004 Cummins ISM 370 Engine

Figure 4-13 Heat Release for Mode 9 (25\% Load) with Varying Amounts of 2-EHN on the 2004 Cummins ISM 370 Engine

Figure 4-14 Shifted In-Cylinder Gas Temperature for Mode 9 (25\% Load) with Varying Amounts of 2-EHN on the 2004 Cummins ISM 370 Engine.

Figure 4-15 Heat Release for Mode 8 (100\% Load) and Mode 9 (25\% Load) on the 2004 Cummins ISM 370 Engine with and without EGR

Figure 4-16 Calculated In-cylinder Gas Temperature for Mode 8 (100\% Load) on the 2004 Cummins ISM 370 Engine with and without EGR

Figure 4-17 Calculated In-cylinder Gas Temperature for Mode 9 (25\% Load) on the 2004 Cummins ISM 370 Engine with and without EGR

Figure 4-18 Comparison of Calculated In-cylinder Gas Temperature for Mode 8 (100\% Load) on the 1992 DDC and 2004 Cummins ISM 370 Engines on CP Cert Fuel

Figure 4-19 Comparison of Calculated In-cylinder Gas Temperature for Mode 9 (25\% Load) on the 1992 DDC and 2004 Cummins ISM 370 Engines on CP Cert Fuel. 
Figure 4-20 Calculated In-cylinder Pressure Curve without Combustion with MAP $=302 \mathrm{kPa}$ and MAT $=300 \mathrm{~K}$ on the 1992 DDC, 2004 Cummins ISM 370, and 1991 DDC Engines .... 72

Figure 4-21 In-cylinder Temperature Curve without Combustion with $\mathrm{MAP}=302 \mathrm{kPa}$ and MAT $=300 \mathrm{~K}$ on the 1992 DDC, 2004 Cummins ISM 370, and 1991 DDC Engines

Figure 4-22 Change in NOx with Additized Fuels Compared to a Change in the Peak Pressure for the Steady State Modes on the 1992 DDC (Error Bars show An Approximate One Standard Deviation Based on Repeat Tests with the Guttman Fuel)...... 76

Figure 4-23 Change in NOx with Additized Fuels Compared to a Change in the Peak Gas Temperature for the Steady State Modes on the 1992 DDC (Error Bars show An Approximate One Standard Deviation Based on Repeat Tests with the Guttman Fuel)...... 77

Figure 4-24 Change in NOx with Additized Fuels Compared to a Change in the Premix Fraction for the Steady State Modes on the 1992 DDC (Error Bars show An Approximate One Standard Deviation Based on Repeat Tests with the Guttman Fuel)...... 78

Figure 4-25 Change in NOx with Additized Fuels Compared to a Change in the Pressure at the Start of Combustion for the Steady State Modes on the 1992 DDC (Error Bars show An Approximate One Standard Deviation Based on Repeat Tests with the Guttman Fuel)

Figure 4-26 Change in CO with Additized Fuels Compared to a Change in NOx for the Steady State Modes on the 1992 DDC (Error Bars show An Approximate One Standard Deviation Based on Repeat Tests with the Guttman Fuel)

Figure 4-27 Percent Change in NOx with Additized Fuels Compared to a Percent Change in the Premix Fraction for the Steady State Modes on the 2004 Cummins ISM 370.

Figure 4-28 Change in NOx and Gross Indicated Mean Effective Pressure during Transient Operation for the 1992 DDC (Error Bars show One Standard Deviation from the Mean Based on the Three Hot Start FTPs for Each Fuel)

Figure 4-29 Change in NOx from a change in the Premix Fraction during Transient Operation for the 1992 DDC (Error Bars show One Standard Deviation from the Mean Based on the Three Hot Start FTPs for Each Fuel, For Error Bars on NOx, see Figure 4-28)

Figure 4-30 Change in NOx from a change in Peak Gas Temperature during Transient Operation for the 1992 DDC (Error Bars show One Standard Deviation from the Mean Based on the Three Hot Start FTPs for Each Fuel, For Error Bars on NOx, see Figure 4-28)

Figure 4-31 Change in NOx from change in Peak Cylinder Pressure over Transient and Steady State Operation for the 1992 DDC

Figure 4-32 Global Cylinder Gas Temperature Predicted by Combustion Model and Calculated from In-Cylinder Pressure using the Ideal Gas Law ....................................... 88

Figure 4-33 Cylinder Volume Predicted by Combustion Model and Actual 
Figure 4-34 Influence of Mixing Constant and Local Equivalence Ratio on NOx

Figure 4-35 Model $\mathrm{CO}_{2}$ and Laboratory Based $\mathrm{CO}_{2}$ for Low Cetane Fuel with and without Additive

Figure 4-36 Model NOx and Laboratory Based NOx for Low Cetane Fuel with and without Additive

Figure 4-37 Percent Reduction in Exhaust NOx with Additized Low Cetane Fuel from Model and Laboratory

Figure 4-38 NOx Formation Between Low Cetane Fuel (LC) and Additized Low Cetane Fuel (LCA) for Mode 7 (25\% Load)

Figure 4-39 NOx Formation Between Low Cetane Fuel (LC) and Additized Low Cetane Fuel (LCA) for Mode 4 (75\% Load) ...................................................................... 95

Figure 4-40 Mass Emissions of the Experimental $\mathrm{CO}_{2}$ and Combustion $\mathrm{Model} \mathrm{CO}_{2}$ for a 45-

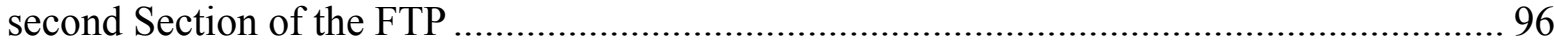

Figure 4-41 Mass Emissions of the Experimental NOx and Combustion Model NOx for a 45-second Section of the FTP

Figure 4-42 NO Formation Rates for a 45-second Section of the FTP (Top: Low Cetane Fuel, Bottom: Low Cetane Fuel with 8ml/gal 2-EHN) ............................................... 98

Figure 4-43 Cylinder Fuel Flow Rate (Top), Air Flow Rate (Middle), and Ratio of Cylinder Pressure at EVO to IVO for a 45-second Section of the FTP

Figure 4-44 NOx Reduction from the FTP cycle with 2-EHN on the 1992 DDC and 2004 Cummins 100 


\section{Abbreviations}

2-EHN

ACT

ATDC

BDC

BSFC

BTDC

CAFEE

CARB

CFD

CFR

$\mathrm{CO}$

$\mathrm{CO}_{2}$

CP

CR

CVS

DDC

DMC

DME

DMM

DPF

DTBP

ECU

EGR

EOC

EPA

ER

EVO

FBP

FT
2-Ethylhexyl Nitrate

Apparent Combustion Time

After Top Dead Center

Bottom Dead Center

Brake-Specific Fuel Consumption

Bottom Dead Center

Center for Alternative Fuels, Engines, and Emissions

California Air Resources Board

Computational Fluid Dynamics

Code of Federal Regulations

Carbon Monoxide

Carbon Dioxide

Chevron Phillips

Compression Ratio

Constant Volume Sampler

Detroit Diesel Corporation

Dimethyl Carbonate

Dimethyl Ether

Dimethoxy Methane

Diesel Particulate Filter

Di-Tertiary Butyl Peroxide

Engine Control Unit

Exhaust Gas Recirculation

End of Combustion

Environmental Protection Agency

Equivalence Ratio

Exhaust Valve Opening

Final Boiling Point

Fisher-Tropsch 


\begin{tabular}{|c|c|}
\hline FTP & Federal Test Procedure \\
\hline $\mathrm{H}$ & Hydrogen \\
\hline $\mathrm{H}_{2} \mathrm{O}$ & Water \\
\hline $\mathrm{HC}$ & Hydrocarbon \\
\hline HFID & Heat Flame Ionization Detector \\
\hline HMN & Heptamethylnonane \\
\hline IMEP & Indicated Mean Effective Pressure \\
\hline IMEPg & Gross Indicated Mean Effective Pressure \\
\hline IVC & Intake Valve Closing \\
\hline LANF & Los Angeles Non-Freeway \\
\hline LAFY & Los Angeles Freeway \\
\hline $\mathrm{LC}$ & Low Cetane \\
\hline LFE & Laminar Flow Element \\
\hline LHV & Lower Heating Value \\
\hline MAP & Manifold Air Pressure \\
\hline MAT & Manifold Air Temperature \\
\hline MFB & Mass Fraction Burned \\
\hline MTBE & Methyl Tertiary Butyl Ether \\
\hline $\mathrm{N}_{2}$ & Diatomic Nitrogen \\
\hline NDIR & Non-Dispersive Infrared \\
\hline NMHC & Non-Methane Hydrocarbons \\
\hline $\mathrm{N}_{2} \mathrm{O}$ & Nitrous Oxide \\
\hline NO & Nitric Oxide \\
\hline $\mathrm{NO}_{2}$ & Nitrogen Dioxide \\
\hline NOx & Oxides of Nitrogen \\
\hline NYNF & New York Non-Freeway \\
\hline $\mathrm{O}$ & Molecular Oxygen \\
\hline $\mathrm{O}_{2}$ & Diatomic Oxygen \\
\hline ODA & Organic Derived Additive \\
\hline $\mathrm{OH}$ & Hydroxyl \\
\hline PAH & Polycyclic Aromatic Hydrocarbons \\
\hline
\end{tabular}




$\begin{array}{ll}\text { PM } & \text { Particulate Matter } \\ \text { RME } & \text { Rapeseed Methyl Ether } \\ \mathrm{SET} & \text { Supplemental Emissions Test } \\ \mathrm{SO}_{2} & \text { Sulfur Dioxide } \\ \mathrm{SOC} & \text { Start of Combustion } \\ \mathrm{TDC} & \text { Top Dead Center } \\ \mathrm{THC} & \text { Total Hydrocarbons } \\ \text { TxLED } & \text { Texas Low Emission Diesel } \\ \text { WVU } & \text { West Virginia University } \\ \text { VGT } & \text { Variable Geometry Turbocharger }\end{array}$




\section{List of Symbols}

$\Delta \Theta_{\mathrm{d}}$

$\Delta \Theta_{\mathrm{P}}$

$\Theta$

$\Theta_{\text {SOC,d }}$

$\Theta_{\text {SOC,P }}$

$\mu$

$\rho_{\mathrm{a}}$

a

A

C

$\mathrm{h}_{\text {air }}$

$\mathrm{K}(\mathrm{z})$

$\mathrm{m}_{\mathrm{d}}$

$\mathrm{m}_{\text {fuel }}$

$\dot{m}_{\text {fuel }}$

$\mathrm{m}_{\mathrm{p}}$

$\dot{m}_{z}$

$\mathrm{n}$

$\mathrm{n}_{\text {eff }}$

$\mathrm{n}_{\mathrm{S}}$

$\mathrm{n}_{\mathrm{V}}$

$\mathrm{P}$

$\mathrm{P}_{\odot}$

$\mathrm{P}_{\text {IVC }}$

$\mathrm{P}_{\mathrm{STD}}$

Q

$\mathrm{Q}_{\mathrm{d}}$

$\mathrm{Q}_{\mathrm{fv}}$

Q Gross
Length of Diffusion Combustion in Crank Angle Degrees

Length of Premix Combustion in Crank Angle Degrees

Crank Angle

Start of Diffusion Combustion

Start of Premix Combustion

Average

Density of Charge Mass in Cylinder

Conversion Efficiency Parameter

Mixing Factor

Constant

Enthalpy of Unburned Zone

Constant for Package z

Diffusion Shape Factor

Fuel Injected

Fuel Flow Rate

Premix Shape Factor

Mass Flow of Air into Package Z

Polytropic Constant

Fuel Conversion Efficiency

Engine Speed

Volumetric Efficiency

Pressure

Pressure at Crank Angle $\Theta$

Pressure at IVC

Standard Pressure

Heat Released

Heat Released during Diffusion

Energy to Evaporate Fuel

Gross Heat Released 


\begin{tabular}{|c|c|}
\hline$\dot{Q}_{\text {Intake }}$ & Intake Flow Rate \\
\hline $\mathrm{Q}_{\mathrm{p}}$ & Heat Released during Premix \\
\hline $\mathrm{Q}_{\mathrm{w}, \mathrm{z}}$ & Wall Heat Transfer for Package z \\
\hline $\mathrm{Q}_{\mathrm{w}, \mathrm{ub}}$ & Wall Heat Transfer for Unburned Zone \\
\hline $\mathrm{R}$ & Gas Canstant \\
\hline $\mathrm{R}_{\mathrm{Est}}$ & Estimated Range \\
\hline $\mathrm{R}_{\mathrm{S}}$ & Revolutions Per Combustion Event \\
\hline $\mathrm{R} / \mathrm{A}$ & Range over Average \\
\hline $\mathrm{T}$ & Torque \\
\hline $\mathrm{T}_{\Theta}$ & Temperature at Crank Angle $\Theta$ \\
\hline$t_{\text {comb }}$ & Combustion Time for Package z \\
\hline$T_{f / p}$ & Friction and Pumping Torque \\
\hline $\mathrm{T}_{\mathrm{IVC}}$ & Temperature at IVC \\
\hline$t_{\text {mix }}$ & Mixing Time for Package z \\
\hline $\mathrm{T}_{\mathrm{STD}}$ & Standard Temperature \\
\hline $\mathrm{u}_{\mathrm{o}}$ & Injection Velocity \\
\hline $\mathrm{U}_{\mathrm{ub}}$ & Internal Energy of Unburned Zone \\
\hline $\mathrm{U}_{\mathrm{Z}}$ & Internal Energy of Package z \\
\hline $\mathrm{V}$ & Volume \\
\hline $\mathrm{V}_{\Theta}$ & Volume at Crank Angle $\Theta$ \\
\hline$V_{D}$ & Displacement Volume \\
\hline $\mathrm{V}_{\mathrm{IVC}}$ & Volume at IVC \\
\hline $\mathrm{V}_{\mathrm{S}}$ & Sweep Volume \\
\hline $\mathrm{W}_{\mathrm{z}}$ & Work from Package z \\
\hline $\mathrm{W}_{\mathrm{ub}}$ & Work from Unburned Zone \\
\hline $\mathrm{X}$ & Molar Fraction \\
\hline $\mathrm{Y}$ & Mode Variable such as BSFC or NOx \\
\hline $\mathrm{z}$ & Fuel Package z \\
\hline
\end{tabular}




\section{Acknowledgements}

I would like to express gratitude to several key individuals who influenced my professional development and contributed to the completion of this dissertation. First, I would like to thank Dr. Gregory Thompson for taking a chance on hiring me as a graduate research assistant. I cannot thank you enough for your guidance, support, and faith in me throughout my graduate education. I also appreciate the expertise and insight provided by my committee members, Dr. Nigel Clark, Dr. Mridul Gautam, Dr. Scott Wayne, and Dr. John Zondlo. I am grateful for the help and support provided by Thomas Spencer. I would also like to express appreciation to Byron Rapp, Bradley Ralston, Ray Tincher, Wesley Hardin, Michael Ursic, and Kevin Flaim for all those long hours spent in the engine lab. Finally, I would like to thank my family who never questioned my desire or ability to obtain an advanced degree.

This dissertation is dedicated to my wife for standing by me through my long work hours and delaying her own graduation so we could continue living together in Morgantown. 


\section{Introduction}

Alternative energy sources to hydrocarbon-based fuels have been at the forefront of the United States and other countries, but hydrocarbon-based combustion continues to be a major source of energy in the US. An effect of combustion is that some resultant products are hazardous and regarded as pollution by regulatory agencies. The US air pollution of carbon monoxide (CO), oxides of nitrogen (NOx), volatile organic compounds (VOC), sulfur dioxide $\left(\mathrm{SO}_{2}\right)$, particular matter (PM), and lead have decreased 48, 17, 51, 52, 34, and 98\%, respectively, from 1970 to 2002 [1]. Even with these reductions, about 160 million tons of pollution from all sources is emitted each year in the US alone [1].

The diesel engine is a widely used power plant due to its durability, high thermal efficiency, and high fuel efficiency compared to other types of internal combustion engines. With no reliable cost effective alternative method of power production with the same advantages, diesel engines will continue to be used in the near future. Pollutants are a major issue of diesel engines, with NOx and airborne PM of primary concern. These pollutants, and others in diesel exhaust, have been linked to adverse health effects [2,3]. To reduce air pollution, the U.S. Environmental Protection Agency (US EPA) and other regulatory agencies worldwide are tightening diesel emission regulations continuously.

Current emission standards rely on laboratory testing using an engine dynamometer with a standard test procedure. Results are reported as an integrated value for emissions from a transient set of engine speed and load conditions over a length of time or a set of prescribed speed-load points. However, on-road heavy-duty diesel engines operate at different conditions and the emissions produced are dependent on the speed, load, acceleration, and environment [4]. Therefore, researchers that utilize emission results from engine dynamometer testing to predict "real-world" emissions of all diesel engines, such as emission inventories are therefore bound by the limitations of these tests. Diesel engine manufacturers have also used devices that defeat emission regulations by producing higher NOx and lower fuel consumption during real world operation, but lower emissions when the engine is being certified on a dynamometer. As a result of these defeat devices, the US Federal Government, in 1998, required six engine manufacturers 
to fund emissions reduction research with a portion of the funding going to in-use emissions testing [5].

The fleet of diesel engines typically consists of legacy, higher polluting engines. Due to the high reliability of diesel engines, it is common for on-road heavy-duty diesel engines to last 1,000,000 miles [6]. Assuming a modest truck operation of 100,000 miles a year, a diesel engine may be operational for ten years. Compared to a 2008 model year on-road heavy-duty diesel engine, a 1998 model year on-road heavy-duty diesel engine emits 20 and 10 times the amount of NOx and PM pollution, respectively.

Reduction of the emissions produced by diesel engines may be achieved by different methods. Replacing the current older technology diesel engine fleet with newer engines incorporating emission reduction hardware is one high cost method. However, the impact of newer technology will be overestimated if new engines from model years 1990-2000 (with defeat devices) are used, considering the emissions inventory models utilize emissions from certification testing. Utilization of aftertreatment devices can reduce emissions from older technology engines; however, the engines were not designed to operate with aftertreatment devices and the cost of these devices would be the responsibility of the consumer.

Diesel fuel properties have been shown to effect emissions and by altering these properties, emissions reduction can be achieved. Fuel properties can be changed by costly refinery modification or with the addition of fuel additives (higher consumer cost). Most fuel additives are developed and tested on a limited number of engines, so the overall effect of emissions on the fleet of diesel engines is unknown. Consumer based reduction strategies, which require acceptance of drivers and truck company owners to optimize engine use (such as minimizing idle times and maximizing the use of cruise control) are being considered. Inspection and maintenance programs periodically test engines and detect high polluters in need of repair. However, this requires consumer acceptance because of the increased inspection and repair cost. Each method of emissions reduction provides an additional element to the current system of diesel engine operation, thus incurring an additional cost. This highlights the need for economical incremental emissions reduction strategies. 
State programs such as TxLED and CARB look to reduce the state inventory emissions beyond the US EPA's requirements by reducing the sulfur content, reducing the aromatic content, and increasing the cetane number of the diesel fuel [7]. TxLED and the CARB certified alternative diesel fuel provide a means for showing emission equivalency to the certification diesel fuel with $10 \%$ aromatics and a minimum cetane number of 48 . By using a fuel additive, fuel suppliers have an unobtrusive method of meeting the required standards set by environmental agencies and without the costly modification to refineries.

Cetane improvers, combustion improvers, and oxygenates are three types of fuel additives which have been reported to result in emission changes. Mixed engine performance and emission results have been reported with each additive type. In particular, cetane improver additives have been shown to reduce NOx [8,9], show no NOx benefit [10], and increase NOx [11] by different researchers. Cetane improvers reduce the time from the start of fuel injection to the start of combustion, known as the ignition delay. Researchers have shown strong correlations between the reduction in ignition delay and NOx created by cetane improvers [12-15]. However, there exists limited understanding on why NOx shows no benefit or a NOx increase for some engines, fuels, and additives.

In combustion studies, an important parameter is the premix combustion fraction. The premixed fraction is the fraction of the heat released from the fuel injected before the start of combustion to the total heat released. The premix portion is thought to be important to NOx formation [10]. An increase in the cetane number (for example, by adding a cetane improver) of a fuel causes a shorter ignition delay, which has the effect of less fuel being injected before the start of combustion and decreases the premix fraction [12-15].

The objective of this project was to investigate the combustion characteristics of fuel additives as an emission reduction strategy. Specifically, 2-Ethylhexyl Nitrate (2-EHN), Di-Tertiary Butyl Peroxide (DTBP), and a propriety additive were investigated at several concentration levels. Two engines (1992 DDC Series 60 and 2004 Cummins ISM 370) were instrumented with an incylinder pressure transducer during steady state and transient testing. The emissions of $\mathrm{CO}_{2}, \mathrm{CO}$, 
NOx, THC, and TPM were collected. A statistical analysis using a T-test was performed to determine when emission changes due to the additives were statistically significant. From the measured in-cylinder pressure data, the heat release curve and heat release parameters were calculated or measured to investigate the combustion characteristics. The heat release parameters such as maximum in-cylinder pressure, maximum in-cylinder temperature, and premix fraction were investigated for emission changes due to the addition of fuel additives. Correlation coefficients were used to determine the strength of the relationship between heat release parameters and emission changes. A phenomenological combustion model was subsequently developed to explore how the shift in the heat release curve (caused by the cetane improvers) affected NOx emissions. 


\section{Background}

In 1970, the Clean Air Act was put into action to establish the US EPA to implement and institute regulations to limit pollution. As time progressed, the US EPA put increasingly austere emissions standards into effect. The US EPA emissions standard of heavy-duty on-road engines has reduced NOx from 10.7 to $0.2 \mathrm{~g} / \mathrm{bhp}-\mathrm{hr}$ and PM from 0.6 to $0.01 \mathrm{~g} / \mathrm{bhp}$-hr from 1988 to 2007, which amounts to approximately $98 \%$ decrease from the 1988 standards (Table 2-1). For the implementation of the 2007 standards, ultra-low sulfur diesel was required to initiate the use of aftertreatment devices. The fuel types and properties therefore have an impact on emissions and emissions reduction technology.

Table 2-1 US EPA Heavy Duty Diesel Truck Engine Emissions Standards, g/bhp-hr [16]

\begin{tabular}{|l|c|c|c|c|c|c|}
\hline Year & HC & CO & NOx & PM & NMHC + NOx & NHMC \\
\hline 1988 & 1.3 & 15.5 & 10.7 & 0.6 & $\mathrm{n} / \mathrm{a}$ & $\mathrm{n} / \mathrm{a}$ \\
\hline 1990 & 1.3 & 15.5 & 6 & 0.6 & $\mathrm{n} / \mathrm{a}$ & $\mathrm{n} / \mathrm{a}$ \\
\hline 1991 & 1.3 & 15.5 & 5 & 0.25 & $\mathrm{n} / \mathrm{a}$ & $\mathrm{n} / \mathrm{a}$ \\
\hline 1994 & 1.3 & 15.5 & 5 & 0.1 & $\mathrm{n} / \mathrm{a}$ & $\mathrm{n} / \mathrm{a}$ \\
\hline 1998 & 1.3 & 15.5 & 4 & 0.1 & $\mathrm{n} / \mathrm{a}$ & $\mathrm{n} / \mathrm{a}$ \\
\hline $2004^{*}(1)$ & 1.3 & 15.5 & $\mathrm{n} / \mathrm{a}$ & 0.1 & 2.4 & $\mathrm{n} / \mathrm{a}$ \\
\hline \multicolumn{1}{|c|}{ or $(2)$} & 1.3 & 15.5 & $\mathrm{n} / \mathrm{a}$ & 0.1 & 2.5 & 0.5 \\
\hline 2007 & 1.3 & 15.5 & 0.2 & 0.01 & $\mathrm{n} / \mathrm{a}$ & 0.14 \\
\hline
\end{tabular}

${ }^{*} 2004$ standards were in effect in October 2002

This section discusses the previous research and background into the influence of fuel properties, fuel additives, fuel types, pollutant formation, and combustion characteristics of diesel engines.

\subsection{Fuel Properties}

Each fuel has specific macroscopic properties such as cetane number, API gravity, energy content, viscosity, aromatic content, volatility, and sulfur content. These properties are interdependent, meaning that when one property is changed, others are affected. Although fuel properties are interdependent, difficult to isolate, and vary independently, generalities can be made about the influence of a specific fuel property on emissions.

\subsubsection{Cetane Number}

The cetane number designated for each fuel is based on the ignition quality. The current method for determining a fuel's cetane number is based on the percentage of n-cetane and Heptamethylnonane $(\mathrm{HMN})$ in a reference fuel blend to obtain the equivalent compression ratio 
of the tested fuel in a cetane engine [17]. An increase in cetane number causes a shorter ignition delay, which has the effect of less fuel being injected during the premix burn and more during the diffusion burn portion (this will be discussed in Section 2.6), thus reducing cylinder pressure rise, which may result in lower cylinder temperatures. At the same time, a higher cetane fuel advances ignition timing because of the shorter ignition delay, which increases combustion pressures and temperatures. The emission effects of cetane number are engine dependent. Cetane number has a greater effect on emissions in older engine technology, since newer technology optimizes combustion for diffusion burning [10].

\subsubsection{Specific Gravity or API Gravity}

Specific gravity is the ratio of fuel density to the density of water, when both are at the same temperature and pressure. The specific gravity of petroleum products is usually given as the API gravity, which is an arbitrary scale that is inversely related to the specific gravity. The density of the fuel affects the combustion in a diesel engine physically. For example, a lower density fuel requires longer injection duration for the same fuel mass to be injected. Although density is a physical effect, research has found that a higher density fuel increases PM $[18,19,20]$ and NOx $[19,21]$.

\subsubsection{Viscosity}

The viscosity is a property defining the resistance of the fuel to shearing (flow) and is based on the molecular structure and temperature. At higher temperatures, the viscosity of a diesel fuel is lower than the viscosity of the same fuel at a lower temperature. If the viscosity is too low, leaking can occur through the seals in the fuel injection system. The viscosity affects the fuel injection system, since an accurate amount of fuel is needed for injection. Likewise, spray pattern is also influenced by the viscosity [22]. With a high viscosity fuel, potentially less fuel could be injected. Density and viscosity are generally interrelated and studies generally use density as the modeled parameter.

\subsubsection{Energy Content}

The energy content of fuel is the amount of energy per unit of mass or volume given when

combusted. While a high-density fuel will have greater energy content per unit volume than a low-density fuel, the low-density fuel has greater energy content per unit mass than a high- 
density fuel. Fuels of different energy contents will give different power outputs on the same engine unless the fuel injection is individually optimized for each fuel.

\subsubsection{Volatility}

The volatility, usually given as T50, T90, or T95 is the temperature at which $50 \%, 90 \%$, or $95 \%$, respectively, of a fuel sample, by volume, is evaporated and then condensed in a separate container. A high T95 temperature (low volatility), can signify that the fuel is difficult to burn. Some studies have shown an increase in PM emissions with increasing T90 or Final Boil Point (FBP) [23, 24], while other studies have shown the distillation has no influence on PM emissions $[20,25]$ and the influence should be attributed to the density. Some studies show an influence of the fuel volatility for other emissions such as NOx $[21,25,26]$ and $\mathrm{HC}[21,25]$.

\subsubsection{Aromatic Content}

An aromatic hydrocarbon is a hydrocarbon with a conjugated double bond carbon ring with benzene being the most common. One ring is a monocyclic aromatic and more than one ring is a PAH compound. The double bonds may make an aromatic hydrocarbon more difficult to break, thus requiring greater temperature to initiate combustion. Some studies have shown that aromatics have no effect on PM [27], while others showed that decreasing aromatics decreases PM $[28,29,30]$ and NOx [29, 30] emissions. Kidoguchi et al. [30] suggested that a higher flame temperature is required for a higher aromatic content fuel and high flame temperatures lead to greater NOx formation.

\subsubsection{Sulfur}

The use of a low-sulfur diesel fuel has been shown to reduce PM emissions in diesel engines by reducing the sulfates formed, which are a component of the PM emissions. The sulfates produced by the sulfur in the fuel are measured as PM in the exhaust and can have a negative effect on aftertreatment devices and engine components. Most fuel sulfur forms oxides of sulfur (SOx). Typically, only $1-3 \%$ of the sulfur in the fuel is converted to sulfates in the PM measurement [31] and this may be greater with an aftertreatment device. For the 2007 and later heavy-duty on-road engines, emissions standards of $0.01 \mathrm{~g} / \mathrm{bhp}-\mathrm{hr} \mathrm{PM}$, and $0.2 \mathrm{~g} / \mathrm{bhp}-\mathrm{hr}$ NOx, and a less than $15 \mathrm{ppm}$ sulfur content in fuel have been implemented to enable catalytic DPFs, 
NOx adsorbers, and limit sulfate PM. At this low sulfur level, sulfur is not seen as a significant portion of the PM formation.

\subsubsection{Summary}

Table 2-2 shows a summary of the effect of fuel properties on NOx and PM emissions in table form from the studies mentioned above. Typically, increased cetane number, reduced total aromatics, reduced density, or reduced T95 decreases NOx emissions. The strength of the effect varies between engines, but in general, follows these trends. PM emissions reduce with reduced fuel sulfur, reduced total aromatics, reduced density, or reduced T95. Modern engines (post 2004) have been shown to be less influenced by fuel properties.

Table 2-2 Influence of Fuel Properties on Heavy-Duty Diesel NOx and PM Emissions from Studies Mentioned Above

\begin{tabular}{|l|l|l|}
\hline & NOx & \multicolumn{1}{|c|}{ PM } \\
\hline Reduced Sulfur & $\mathbf{0}$ & $\mathbf{\downarrow}^{*}$ \\
\hline Increased Cetane Number & $\mathbf{\downarrow}^{*}$ & $\mathbf{0}$ \\
\hline Reduced Total Aromatics & $\mathbf{\downarrow}^{*}$ & $\mathbf{\downarrow}^{*}$ \\
\hline Reduced Density & $\mathbf{\downarrow}^{*}$ & $\mathbf{\downarrow}^{*}$ \\
\hline Reduced T95 & $\mathbf{\downarrow}^{*}$ & $\mathbf{\downarrow}^{*}$ \\
\hline${ }^{*}$ Maybe less significant on modern engines & \multicolumn{2}{|l}{} \\
\hline
\end{tabular}

\subsection{Fuel Additives}

Diesel fuels require certain properties for in-use engines. As the requirements for fuel properties change, fuel suppliers can use fuel additives to obtain these properties without the high cost of refinery modification. Some types of fuel additives are ignition, oxygenate, lubricity, combustion, flow, wax anti-settling, anti-foam, detergents, and anti-corrosion additives. Detergents and anti-corrosion additives help to maintain the integrity of the engine fuel system, the emission levels, and fuel economy over the life of the engine. Flow improvers and wax antisettling additives provide enhanced fuel properties for cold climates where heavy hydrocarbons can settle out and clog fuel lines. The blended fuels must also meet the requirements of cetane number, percentage aromatics, and sulfur level.

An ignition improver allows the fuel to ignite earlier during fuel injection, shortening the ignition delay. As mentioned above, a higher cetane number fuel has a shorter ignition delay, shortening the premix combustion, which can lead to lower NOx emissions. Two common ignition 
improver additives are a nitrate-based 2-EHN and peroxide-based additive DTBP. Higgins and colleagues [32] used a constant volume combustion system to show that the primary effect of 2EHN on diesel combustion is an accelerated pre-ignition radical pool with greater effect at low temperatures and low cylinder air densities. Previous diesel emission studies have shown mixed results of NOx reduction using 2-EHN or DTBP with some having up to $8 \%$ reduction in NOx $[8,9]$ while others showing no benefit [10] or an increase in NOx [11]. McCormick et al. [33] effectively blended biodiesel with DTBP and 2-EHN to reduce NOx and maintain the PM emissions reduction from the use of biodiesel. Modern engines have shown lower reductions in NOx from cetane improvers. Fuel injection in modern engines is optimized for shorter premixed combustion, and this can be attributed to the lower influence of shortening the ignition delay [10].

Oxygenate additives raise the air-to-fuel ratio, thus resulting in increased oxygen at locations of fuel burning and providing a greater opportunity for soot oxidation. Some oxygenate additives are Methyl Tertiary Butyl Ether (MTBE), Butylal (an acetal compound, $\mathrm{C}_{9} \mathrm{H}_{20} \mathrm{O}_{2}$ ), Dimethyl Carbonate (DMC), Dimethoxy Methane (DMM), and bio-diesel. Previous studies [34, 35, 36] have shown a greater than $4 \%$ reduction of PM for each $1 \%$ wt oxygen addition to the fuel. With an increase in oxygen content using a biodiesel compound (RME) or glycol ethers, Zannis et al. [37] reported a decrease in soot, $\mathrm{CO}$, and $\mathrm{HC}$ emissions with an increase in NOx emissions and Brake Specific Fuel Consumption (BSFC) on a single cylinder engine operating at $2000 \mathrm{rpm}$ and three different loads. Using a blend of DMC with diesel at an oxygen content of $15 \%$, Lu and colleagues [38] found that smoke decreased by $75 \%$ and NOx emissions decreased by $15-20 \%$. The oxygenate chemical structure seems to effect the soot reduction with glycol ethers (linear structure) showing greater reduction of soot than with dioxolane (ring structure) [39].

Lubricity additives are used to enhance the lubricating qualities of fuels. Low lubricity fuels can damage the fuel injection system by high wear on the components. Fuel with low aromatics and low sulfur content such as Fischer Tropsch as well as oxygenated fuels tend to have low lubricity $[33,40]$. Esters have been shown to be good lubricity additives [41]. 
Metal-based additives, called combustion improvers, have shown an up to $9 \%$ reduction of BSFC [42] and up to a $25 \%$ reduction of PM [43]. An ultra low dosage (4-8ppm) of a platinum/cerium additive was used by Valentine et al. [43]. The bimetallic additive lowered PM by up to $25 \%$ alone, up to $50 \%$ with an oxidation catalyst, and up to $95 \%$ with an oxidation catalyst and DPF.

\subsection{Diesel Fuel Types}

The diesel fuel type affects the fuel properties such as cetane number, percent aromatics, viscosity, and these then effect the combustion process and emissions as stated in Section 2.1. While fuel types and refineries each have different chemical composition and properties, the requirements for grade 1-D and 2-D specific diesel fuels in the US as specified by the ASTMD975-05 are listed in Table 2-3. A minimum of 40 cetane number and either a minimum 40 cetane index or a maximum $35 \%$ (by volume) aromatics is required to be considered a grade 1-D or 2-D diesel. Some properties, such as lubricity, are for the consideration of engine components and wear.

Table 2-3 ASTM-D975-05 Diesel Fuel Specification in the US [44]

\begin{tabular}{|c|c|c|c|c|}
\hline Fuel Property & Test Method & Unit & Grade 1-D & Grade 2-D \\
\hline Cetane Number & D613 & & $40(\min )$ & $40(\min )$ \\
\hline Either (1) Cetane Index & D976 / D4737 & & $40(\min )$ & $40(\min )$ \\
\hline Or (2) Aromatics & D5186 & $\%$ (vol.) & 35 (max) & 35 (max) \\
\hline Cloud Point & $\mathrm{D} 2500$ & ${ }^{\circ} \mathrm{C}$ & location based & location based \\
\hline Distillation 90\% (vol.) & $\overline{D 86}$ & ${ }^{\circ} \mathrm{C}$ & 288 (max) & $282-338$ \\
\hline Total Sulfur & D2622 & $\%$ (wt.) & $0.05(\max )^{*}$ & $0.05(\max )^{*}$ \\
\hline Flashpoint & $\mathrm{D} 93$ & ${ }^{\circ} \mathrm{C}$ & $38(\min )$ & $52(\min )$ \\
\hline Kinematic Viscosity @ 40 $\mathrm{C}$ & D445 & $\mathrm{mm}^{2} / \mathrm{s}$ & $1.3-2.4$ & $1.9-4.1$ \\
\hline Water \& Sediment & D2709 & $\%$ (vol.) & 0.05 (max) & $0.05(\max )$ \\
\hline Ramsbottom Carbon on $10 \%$ Residue & D4530 & $\%$ (wt.) & $0.15(\max )$ & 0.35 (max) \\
\hline Ash & D482 & $\%$ (wt.) & $0.01(\max )$ & $0.01(\max )$ \\
\hline Copper Strip Corrosion & $\mathrm{D} 130$ & & No. $3(\max )$ & No. 3(max) \\
\hline Lubricity, HFRR @60 & D6079 & microns & $520 \max$ & $520 \max$ \\
\hline
\end{tabular}

* Effective mid 200615 ppm (wt.) sulfur limit (max) for highway diesel fuel

\subsubsection{Water Emulsion Diesel Fuel}

One type of fuel emissions reduction technology is water emulsion fuels [45]. These consist of water mixed with diesel fuel. Water particles are suspended in the diesel fuel using an emulsifier, which poses problems since water and diesel have different densities and physical 
properties and are usually not miscible. The emulsified fuel has a length of time before the mixture separates. During combustion, the water in the diesel creates lower temperatures in the cylinder of the engine, which decreases NOx. The lower NOx is achieved even with the improved mixing obtained, which result in higher peak pressures and peak heat release rates than the base diesel fuel. This specific type of fuel has been shown in previous testing to decrease NOx by up to $20 \%$ and have conflicting results on PM. The emulsified fuel requires longer fuel injection duration than typical diesel fuel for the same amount of fuel energy due to the addition of water to the fuel.

\subsubsection{Biodiesel}

Some research has focused on biodiesel, which is derived from vegetable oil or animal fat. Biodiesel, since it is a renewable energy source, benefits in the reduction of life cycle emissions. Some main advantages of biodiesel are the higher cetane rating, no aromatics, and low or no sulfur content [46]. Although suffering from having lower energy content and higher NOx emissions (up to 13\%) compared to D2 fuel, the emissions of $\mathrm{HC}, \mathrm{CO}$, and PM have been shown to decrease $13.6-63.2 \%, 10.1-42.7 \%, 8.3-55 \%$, respectively [46, 47], depending on blending ratio, fuel type, and test cycle. Szybist et al. [48] showed that the higher bulk modulus (compressibility) of biodiesel increased the start of injection (0.1-0.3 crank angle degrees) resulting in a phase shift of the maximum cylinder temperature and maximum heat release. The most influential trends of NOx production were the location of maximum temperature and heat release as opposed to the values of the maximum temperature and heat release. Recent studies have offset the increase in NOx emissions of biodiesel by the addition of a cetane improver [33, 48] or the lowering the iodine number (degree of unsaturation) [48]. The use of waste cooking oil is also a potential biodiesel fuel with a high viscosity that requires heating to prevent fuel filter clogging. Bari and colleagues [49] showed that by reducing the head loss through the fuel filter by raising the fuel tank level, the $10 \%$ power loss with use of waste cooking oil was reduced to $5 \%$.

\subsubsection{Fischer-Tropsch}

Fischer-Tropsch, a synthetic diesel, is produced from any carbon containing raw material by means of the Fisher-Tropsch process. The most popular feedstock materials for creating FT fuel are natural gas or coal. The main advantages of FT fuel are high cetane number, low aromatic 
content, low sulfur content, and the ability to blend with other diesels. While FT does suffer from having low lubricity and cold flow properties, additives can be used to alleviate these issues. A study done by Atkinson et al. [50] on a Navistar T444E engine showed average reductions of $12 \%, 21 \%, 4.9 \%, 20 \%, 31 \%$, for $\mathrm{HC}, \mathrm{CO}, \mathrm{CO}_{2}, \mathrm{NOx}$, and $\mathrm{PM}$, respectively, with FT fuel compared to D2 fuel. The reductions were explained by the lower peak cylinder

pressure, burn rate, and exhaust temperatures. A study on an unmodified single cylinder by Youngcheng et al. [51] showed reductions on average of $17 \%$ for NOx and $40 \%$ for smoke emissions using FT fuel compared to conventional diesel fuel.

\subsection{Fuel Certification Programs}

Current programs such as the TxLED and the CARB certified alternative diesel fuel provide means for showing emission equivalency to a certification diesel fuel with $10 \%$ aromatics and a minimum cetane number of 48 [7]. The testing is done on a Detroit Diesel Series 60 engine, which is representative of the post 1990-model year engines and tested in accordance with the guidelines given by CARB or Texas. The candidate fuel is tested against the reference fuel and the specifications for each of these fuels are shown in Table 2-4. Any fuel that meets the requirements as a certified CARB diesel meets the requirements for the TxLED program. 
Table 2-4 Reference and Candidate Fuel Specification for CARB [7]

\begin{tabular}{|l|c|c|}
\hline \multicolumn{1}{|c|}{ Fuel Property } & $\begin{array}{c}\text { Reference Fuel } \\
\text { Specifications }\end{array}$ & $\begin{array}{c}\text { Candidate Fuel } \\
\text { Specifications }\end{array}$ \\
\hline Sulfur Content & $15 \mathrm{ppm}$ max. & $15 \mathrm{ppm}$ max. \\
\hline Aromatic Hydrocarbon & $10 \%$ max. & - \\
Content, Vol. \% & $1.4 \%$ max. & - \\
\hline $\begin{array}{l}\text { Polycyclic Aromatic } \\
\text { Hydrocarbon }\end{array}$ & & \\
content, Wt. \% & 10 ppm max. & - \\
\hline Nitrogen Content & 48 minimum & - \\
\hline Natural Cetane & & $33-39$ \\
Number & $33-39$ & $2.0-4.1$ \\
\hline Gravity, API ${ }^{*}$ & $2.0-4.1$ & 130 \\
\hline Viscosity at 40 ${ }^{\circ} \mathrm{C}, \mathrm{cSt}$ & 130 & \\
\hline Flash point, ${ }^{\circ} \mathrm{F},(\mathrm{min})$. & & $340-420$ \\
\hline Distillation, ${ }^{\circ}{ }^{* *}$ & $340-420$ & $400-490$ \\
IBP & $400-490$ & $470-560$ \\
10\% REC. & $470-560$ & $550-610$ \\
50\% REC. & $550-610$ & $580-660$ \\
\hline 90\% REC. & $580-660$ & \\
EP & &
\end{tabular}

${ }^{*}$ No more than $3 \mathrm{API}$ difference between fuels

${ }^{* *}$ No more than $45^{\circ} \mathrm{F}$ difference between fuels

\subsection{Pollutant Formation}

When trying to reduce emissions, understanding the way in which each pollutant is formed is important and helps to understand what combustion characteristics to optimize. As a result of a chemical reaction, products are formed. Some common products of combustion for a hydrocarbon fuel are $\mathrm{CO}_{2}, \mathrm{CO}, \mathrm{NOx}, \mathrm{N}_{2}, \mathrm{O}_{2}, \mathrm{HC}, \mathrm{H}_{2} \mathrm{O}$, and carbon particles. The current regulated emissions in the US for on-road heavy-duty diesel engines are NOx, CO, PM, and total hydrocarbons (and/or NMHC).

\subsubsection{NOx}

Due to environmental restrictions, oxides of nitrogen are being reduced to meet regulations. NOx is a difficult emission to control in a diesel engine, since higher combustion temperatures are linked to higher NOx formation and lower fuel consumption. With diesel engines, combustion is primarily operated lean and NOx reducing after-treatment devices are expensive, whereas in a gasoline vehicle the operation occurs in stoichiometric to rich conditions allowing the use of a catalytic converter. Another main concern is that PM regulations are strict for diesel 
engines and usually a reduction in NOx coincides with an increase in PM, which is called the NOx-PM trade-off.

Understanding how NOx forms in the combustion process provides the basis for NOx control and reduction. NOx consists primarily of nitric oxide (NO), which represents greater than 70$90 \%$ of the total NOx. At temperatures $1200 \mathrm{~K}$ and below, nitrogen dioxide $\left(\mathrm{NO}_{2}\right)$ forms from the NO in the exhaust and constitutes the rest of the total NOx emitted from a diesel engine. Typically, four formation mechanisms are attributed for NOx: thermal, fuel, nitrous oxide, and prompt [52]. From atmospheric $\mathrm{N}_{2}$, the thermal NOx formation occurs by the well-known extended Zeldovich mechanism (Equation 2-1, Equation 2-2, and Equation 2-3). This mechanism is a simplification of many elementary reactions. At high temperatures, $\mathrm{N}_{2}$ and $\mathrm{O}_{2}$ can dissociate into their atomic states and contribute in the thermal NOx formation (Figure 2-1). Due to the strength of the triple bond in $\mathrm{N}_{2}$, reaction 1 (Equation 2-1) has high activation energy and thus requires a high temperature for the reaction to begin $(>\sim 1800 \mathrm{~K})$. Fuel-borne NOx is formed by nitrogen in the fuel, when the nitrogen is oxidized, typically through the prompt mechanism. The nitrous oxide $\left(\mathrm{N}_{2} \mathrm{O}\right)$ mechanism consists of molecular nitrogen and oxygen forming $\mathrm{N}_{2} \mathrm{O}$, which then reacts with oxygen to form NO. This mechanism has previously been a minor contributor to NOx emissions, but is influenced less by temperature than thermal NOx formation and may be a major contributor in modern engines. The fourth mechanism, prompt $\mathrm{NOx}$, is the formation of NOx in the earliest stages of combustion by $\mathrm{N}_{2}$ reacting with radicals of the fuel producing molecules that are then oxidized into NOx. Prompt NOx formation is believed to be less temperature dependent.

$$
\begin{aligned}
& O+N_{2} \Leftrightarrow N O+N \\
& N+O_{2} \Leftrightarrow N O+O \\
& N+O H \Leftrightarrow N O+H
\end{aligned}
$$



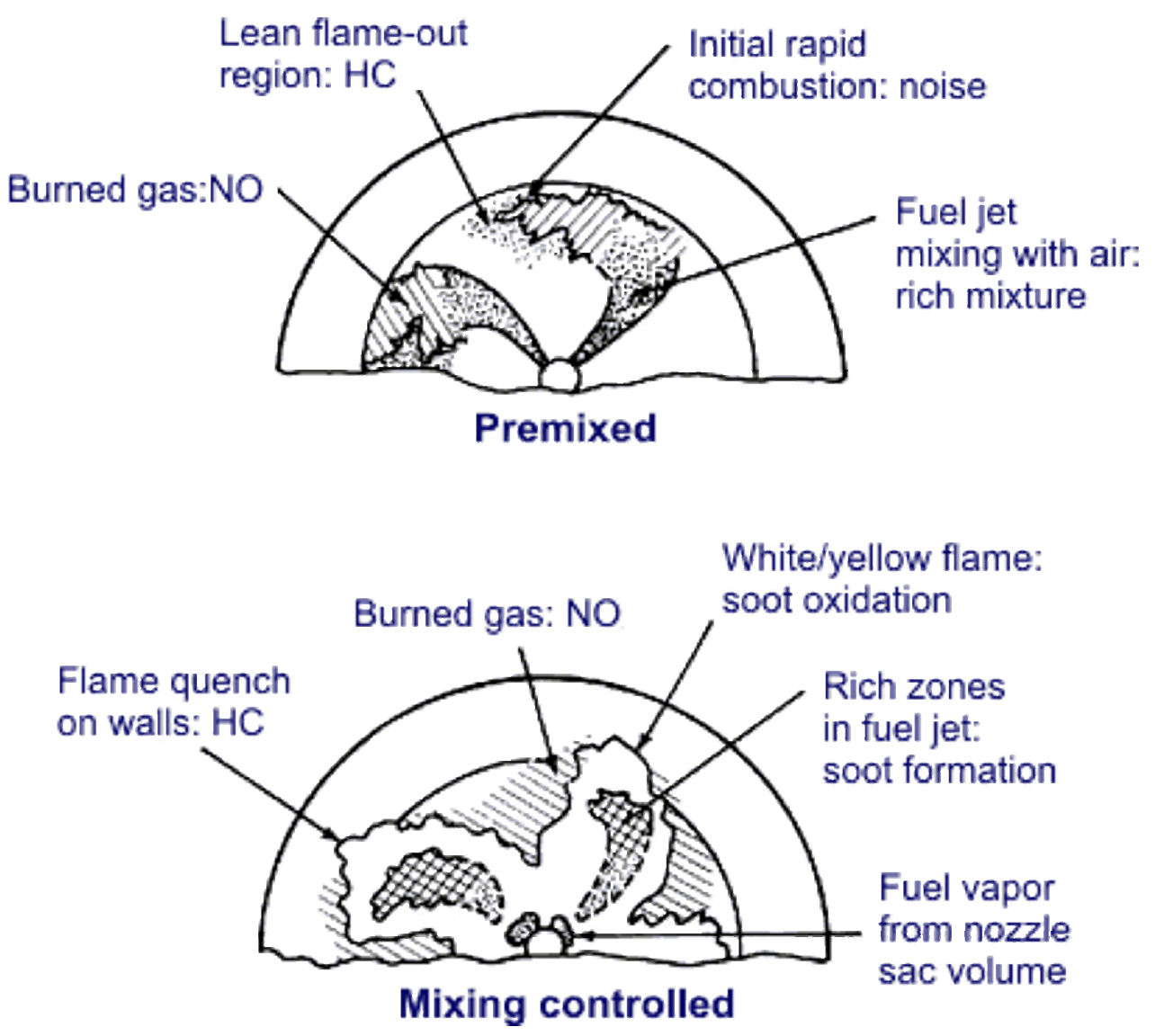

Figure 2-1 Emissions from a Typical Fuel Spray [57]

When studying combustion by means of the heat release, theories of NOx formation have been suggested. The formation of NOx is a function of temperature. As the temperature increases, NOx formation increases. The temperature in combustion varies spatially and therefore, the formation is linked to the local temperature. A lower average cylinder temperature suggests lower local temperatures at locations where NOx forms. A major contribution to the understanding of NOx formation was the study of Dec $[53,54]$. These studies showed that NOx was formed during the diffusion portion of the heat release, which is stoichiometric to lean, and not during the premix portion, which is rich. Dec [53, 54] studied medium to high load conditions and not low load, where combustion is primarily premix combustion. There are many explanations for the change in NOx emissions based on the heat release curve from previous researchers. Some accepted explanations for changes in NOx are:

- An increase in the heat released during the premix portion corresponds to a rapid increase in the cylinder pressure and temperature compressing the diffusion flame where NOx is formed; resulting in higher NOx [53, 54]. 
- A decrease in the heat released during the premix portion of the heat release creates an increased amount of burning during the diffusion flame where NOx is produced; resulting in higher NOx [53, 54, 56].

- A shift in the heat release toward top dead center has higher compression during combustion, which causes higher temperatures and pressures that lead to higher NOx formation rates $[53,54]$.

- A long ignition delay leads to a uniform lean equivalence ratio due to better mixing. This typically occurs with high EGR (>30\%). The combustion will be then be closer to homogeneous charge compression ignition ( $\mathrm{HCCI}$ ), which decreases NOx due to lean combustion [55].

\subsubsection{PM}

Small particles, called particulate matter, emitted by diesel engines have been linked to health effects and are therefore regulated [58]. The US EPA defines particulate matter as the part of exhaust that when diluted below $125^{\circ} \mathrm{F}$ is trapped on a sample filter. PM consists of a solid portion (carbon and ash), soluble organic fraction, and sulfates. The SOF is hydrocarbons (mostly heavy hydrocarbons) that have condensed on the carbon particles. The solid carbon portion and soluble organic fraction are formed by incomplete combustion of the fuel. This occurs at low air-fuel ratios such as high load and during transient events when boost pressure is limited. High cylinder temperatures and the availability of oxygen increase the oxidization of the solid carbon particles and hydrocarbons to carbon monoxide and carbon dioxide (Figure 2-1). The sulfates are formed from reactions with the sulfur in the fuel, and fuel sulfur levels have been reduced to combat this. High sulfur content in the lube oil will also contribute to sulfates.

\subsubsection{CO}

The formation of $\mathrm{CO}$ is attributed to the fuel oxidation from combustion. The major contributor to $\mathrm{CO}$ formation is insufficient time and oxygen for the oxidation of $\mathrm{CO}$ to $\mathrm{CO}_{2}$. $\mathrm{CO}$ emissions follow with PM emissions, since the main contributor to PM, carbon, is formed during low airto-fuel ratio such as acceleration and high loads. Since diesel engines run lean, the levels of CO are relatively low and generally far below current regulations. 


\subsection{4 $\mathrm{CO}_{2}$}

A direct product of combustion from a hydrocarbon fuel is $\mathrm{CO}_{2}$. Global warming has been attributed to $\mathrm{CO}_{2}$, which is considered a green house gas [59]. Any increase in fuel consumption increases the $\mathrm{CO}_{2}$ emissions. Currently in the US, $\mathrm{CO}_{2}$ emissions are not regulated, but may be regulated in the future.

\subsubsection{HC}

The hydrocarbons in the exhaust are formed by incomplete combustion, as well as the heavy hydrocarbons from engine oil on the cylinder walls. Zones that are either too lean or rich for combustion are spots for hydrocarbon formation (Figure 2-1). Any fuel from injection that contacts the cylinder walls or piston surface can have a quenching effect and become hydrocarbon emissions. Another method of hydrocarbon emissions can occur from a late injection of fuel when temperature and pressure are not high enough for combustion. Bad nozzle seating can cause a late injection.

\subsection{Combustion Analysis}

By measuring the in-cylinder pressure, the combustion characteristics described by start of ignition, ignition delay, combustion duration, heat release rate, and mass fraction burned can be calculated. By measuring the exhaust emissions and making a comparison with the combustion parameters mentioned above, an insight into the pollutant formation can be obtained.

\subsubsection{In-cylinder Pressure}

Measuring in-cylinder pressure provides the means to analyze the heat release and determine the characteristics of combustion. A piezoelectric pressure transducer allows the measurement of dynamic pressure at a fast rate to measure the in-cylinder pressure. During the typical compression and expansion strokes, the in-cylinder pressure increases during the compression stroke. When fuel is injected, a delay occurs before combustion and then a sudden increase in pressure greater than the motoring curve indicates the pressure created by combustion. The motoring pressure is the pressure generated by compressing the volume of charge gas without fuel injection. 


\subsubsection{Heat Release}

A well-known and highly utilized method for analyzing combustion characteristics is the heat release rate in the combustion chamber [60]. Utilizing the first law of thermodynamics and assuming a uniform pressure, uniform temperature, and ideal gas with the substitution of the specific heat ratio $(\gamma)$ and the substitution of crank angle for time reduces to an expression for the gross heat release rate (Equation 2-4). By combining the heat transfer to the walls with the gross heat release rate, the equation becomes the net heat release rate, given as Equation 2-5. A relationship for the heat transfer to the walls is required when using the gross heat release rate. The well-known Woshni equation [61] is generally used and was used for this study. For this study, the gross heat release rate will be utilized for the total heat released, which will provide a more accurate mass fraction burned. The wall heat transfer may be up to $15 \%$ of the gross heat transfer [62].

$$
\begin{aligned}
& {\left[\frac{d Q}{d \theta}\right]_{g r o s s}=\left(\frac{\gamma}{\gamma-1}\right) * P * \frac{d V}{d \theta}+\left(\frac{1}{\gamma-1}\right) * V * \frac{d P}{d \theta}+\left[\frac{d Q}{d \theta}\right]_{h t}} \\
& {\left[\frac{d Q}{d \theta}\right]_{n e t}=\left(\frac{\gamma}{\gamma-1}\right) * P * \frac{d V}{d \theta}+\left(\frac{1}{\gamma-1}\right) * V * \frac{d P}{d \theta}}
\end{aligned}
$$

The heat release rate has three regions: premixed, diffusion (rate-controlled), and late combustion (Figure 2-2). The diffusion and late combustion regions are combined into solely the diffusion combustion region in this study. The premixed burn portion is the characteristic spike at the beginning of combustion and important to NOx formation as mentioned above. The diffusion portion and then late combustion follow the premix portion and are usually more gradual. Because of cycle-to-cycle combustion variation, multiple (50-300) steady state cycles are normally collected after the engine has reached thermal equilibrium to provide for an average cylinder pressure trace before the heat release analysis is performed. 




Figure 2-2 Typical Heat Release Rate Curve

\subsubsection{Transient Heat Release}

The application of heat release analysis in steady state applications has proven to be a useful tool in engine research, but on-road heavy-duty diesel engines operate in a transient environment. More research using heat release analysis on transient test cycles is needed. In 2000 [63] and 2001 [64], combustion studies at a constant engine speed during a step-change in load were performed. Assanis and coworkers [63] performed their analysis on a series 60 Detroit Diesel engine looking at cylinder equivalence ratio, cylinder fuel flow, and combustion characteristics. During the load change, the turbocharger lag produced more prominent premix combustion from the relatively high equivalence ratio. Bermudez et al. [64] performed a transient combustion analysis on exhaust opacity and showed that optimizing injection pressure and duration during a transient can reduce opacity. It is noted that it is difficult to obtain repeated transient data because of thermal history effects. 


\subsection{Numerical Modeling}

The understanding of engine combustion from experimental testing is limited due to the multiple processes effecting the resulting engine performance and emissions. Although not as accurate as experimental testing, numerical modeling provides details about the fuel evaporation, mixing, chemical formation, and local temperature. Numerical modeling may provide a quicker and less expensive method than experimental testing when examining a large parametric study. Typically, numerical modeling is separated into three categories based on the detail level with each level requiring greater computation time. Thermodynamic (zero dimensional) modeling assumes a homogeneous mixture to determine the heat release rate and has no chemical formation details. Phenomenological (quasi-dimensional) models have physical and chemical submodels that solve the energy and mass equations. Computational Fluid Dynamics (CFD) models (multi-dimensional) solve the mass, energy, and momentum equations with detailed physical and chemical submodels. The accuracy of a model is typically based on a graphical comparison of the numerical and experimental pressure and zero-dimensional heat release rate $[65,66]$.

The level of detail used for the chemical formation submodel varies between studies. Some combustion research assumes the chemical reactions to be at equilibrium for each time step. The assumption of equilibrium has been shown to inaccurately model NOx formation [67,68], with NOx approaching zero as the gas temperature reduces after combustion. The use of kinetics to model chemical formation in diesel combustion provides greater accuracy since chemical formation typically does not have sufficient time to reach equilibrium and "freeze" below certain temperatures. This freezing occurs for NOx with temperatures below 1800K; the NOx formation rate approaches zero [67]. The chemical formation submodel depends on the assumed number of species and reactions. A greater number of species and reactions increase the computation time. Using the Zeldovich mechanism for NOx tends to achieve an accuracy of $+/-$ 20\% [65]. A phenomenological combustion model by Hernandez et al. [68], which included 59 reactions and 27 chemical species, agreed within $30 \%$ of experimental NOx. Three combustion submodels were studied with a CFD model by Singh and colleagues [66] with 30 species and 65

reactions. The models agreed within $50 \%$ of the experimental NOx. For both the phenomenological combustion model [68] and the CFD model (with three different combustion 
submodels) [66], the predicted NOx trends agreed with the experiment NOx trends. Using NOx formation as an example, a greater number of species and reactions provides more details on chemical formation, but does not necessarily mean greater accuracy. 


\section{Experimental Setup}

\subsection{Introduction}

The objective of this work was to investigate the combustion characteristics during steady state and transient cycles using fuel additives as an emission reduction strategy. The steady state and transient cycles were tested at the WVU Engine Research Center. The capabilities of the testing center have been documented extensively elsewhere [69]. This section will focus on the experimental setup of the engines, fuels, and combustion analysis system.

\subsection{Test Engines}

The alternative diesel fuel programs, such as CARB and TxLED, specify the use of a engine representative of the post 1990 model year diesel engine fleet for certification testing. A 1992 DDC Series 60 engine was acquired by WVU in poor condition (actual in-use engine from an over-the-road truck) and required an engine re-build (Figure 3-1). A newer 2004 Cummins ISM 370 engine from prior WVU research was used to study the effects of fuel additives on more modern diesel engines (Figure 3-2). Both engines are 4-stroke, turbocharged, intercooled, and electronically controlled. The Cummins engine used cooled exhaust gas recirculation and a variable geometry turbocharger to meet the 2004 emissions standards (Table 3-1). The 1992 DDC Series 60 engine was selected as part of the test matrix since this engine is specifically listed by the CARB and TxLED programs. The 2004 Cummins engine was selected because of availability and this engine represented a more modern on-road heavy-duty diesel engine. 


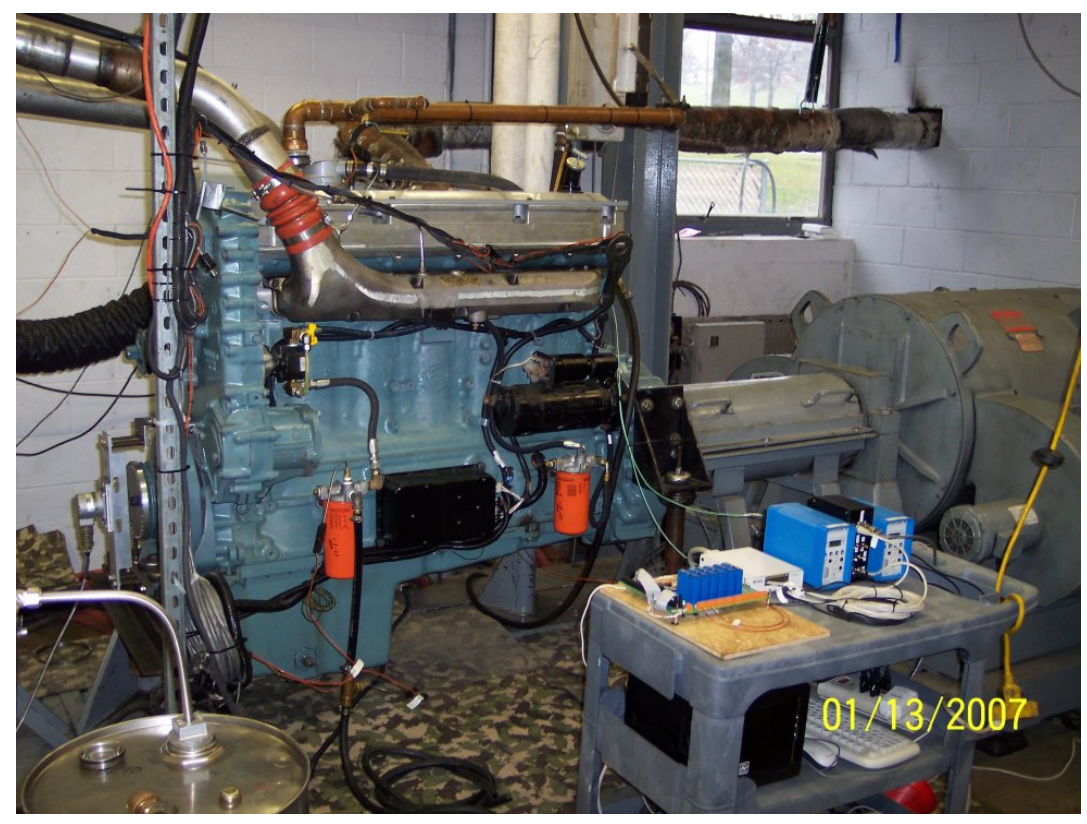

Figure 3-1 1992 Detroit Diesel Series 60 Engine



Figure 3-2 2004 Cummins ISM 370 
Table 3-1 Engine Specifications

\begin{tabular}{|l|c|c|}
\hline Manufacturer & Detriot Diesel & Cummins \\
\hline Model & DDC S60 & ISM 370 \\
\hline Year & 1992 & 2004 \\
\hline Cylinders & 6 & 6 \\
\hline Displacement (L) & 12.7 & 10.8 \\
\hline Power Rating (hp) & $360 @ 1810 \mathrm{rpm}$ & 370 @ 2100rpm \\
\hline Torque Rating (ft-lbs) & $1450 @ 1200 \mathrm{rpm}$ & $1450 @ 1200 \mathrm{rpm}$ \\
\hline Bore (mm) x Stroke (mm) & $130 \times 160$ & $125 \times 147$ \\
\hline Connecting Rod Length (mm) & 269.3 & 218 \\
\hline Compression Ratio & 15.0 & 16.1 \\
\hline Intake & $\begin{array}{c}\text { Turbocharged \& } \\
\text { Intercooled }\end{array}$ & $\begin{array}{c}\text { Turbocharged, } \\
\text { Intercooled, \& } \\
\text { EGR }\end{array}$ \\
\hline
\end{tabular}

The DDC engine was fitted with two in-cylinder pressure transducers (cylinder No. 3 and 5) located in the engine head and fitted by the Detroit Diesel Corporation. The Cummins engine was already fitted with an in-cylinder pressure transducer on cylinder number six from a previous project. An encoder provided the timing for data acquisition with a low to high voltage at every crank angle (every $0.25 \mathrm{deg}$ for the $1992 \mathrm{DDC}$ engine and $0.1 \mathrm{deg}$ for the 2004 Cummins engine) of the drive shaft, and this voltage change triggered the DAQ card to acquire an in-cylinder pressure measurement. The encoder was attached to the drive shaft of the engine through the main shaft front pulley. On the DDC engine, one fuel injector (cylinder No. 3) was fitted with a needle lift sensor to obtain the start and end of fuel injection.

\subsection{Test Fuels}

Five base fuels (Grad Ref, Grad Cand, CP Cert, Low Cetane, and Guttman fuel) were studied, with ranging fuel properties (Table 7-1 and Table 7-2). These fuels were selected since they represent a wide range of fuels that may be found in use. The most extensive testing on the 1992 DDC was with the Low Cetane (LC) fuel since a greater change in additized emissions levels and the heat release rate were observed due to the relatively low cetane number (46) compared to the other base fuels (48-61). The main fuel utilized on the 2004 Cummins, due to availability, was the CP Cert fuel, which had a cetane number of 50 . Three biodiesel B20 blends ( $80 \%$ neat fuel and $20 \%$ biodiesel, by volume) were investigated and represented neat biodiesel types available in the marketplace. The three biodiesel fuels were derived from soy, tallow (animal fat), and cottonseed (Figure 3-3). On the 2004 Cummins engine, the range of the total aromatics 
in the CP Cert (the neat fuel) and the three B20 blends was 33-33.4. The total aromatics, on the 1992 DDC engine, for the LC (neat fuel) and the three biodiesel blends had a range of 38.5-40.4. Biodiesel typically has near zero aromatics and the total aromatics did not change significantly between the neat fuel and biodiesel blends. Therefore, the total aromatics measurement for the biodiesel blends was suspect. On the 1992 DDC and 2004 Cummins, the LC B20 Cottonseed and CP Cert B20 Soy, respectively, were additized to investigate the influence of additives on biodiesel blends. The oxygen content in the biodiesel blends was calculated by assuming the difference between the combined carbon and hydrogen weight from B20 blends and the neat diesel was the oxygen weight added by the biodiesel fuel.



Figure 3-3 Biodiesel Fuels from Left to Right: Soy, Tallow, and Cottonseed Derived

\subsection{Test Additives}

Three additives of the ignition improver type were investigated: the nitrate-based 2-EHN, the peroxide-based DTBP, and a proprietary organic derived additive (ODA). The 2-EHN and DTBP additives provided a link to prior studies and the ODA provided insight into a new additive. Although cetane improvers are frequently used in diesel fuel, the reasons for favorable emissions on some engines and unfavorable on others are unknown. A study showed that DTBP is $85-95 \%$, on an equal mass basis, as effective at changing the cetane number as 2-EHN [70]. Therefore, a greater amount of DTBP was added to the neat fuel to obtain comparable cetane number improvements as the 2-EHN additive. The properties of the fuel additives are shown in Table 3-2. The ODA was a proprietary additive and therefore the composition and chemical structure was not reported. 
Table 3-2 Fuel Additive Properties [71-73]

\begin{tabular}{|c|c|c|c|c|}
\hline Physical Property & $\begin{array}{c}\text { Unit of } \\
\text { Measurement }\end{array}$ & $\begin{array}{c}\text { 2-Ethylhexyl } \\
\text { Nitrate } \\
(2-E H N)\end{array}$ & $\begin{array}{l}\text { Di-tertiary- } \\
\text { Butyl Peroxide } \\
\text { (DTBP) }\end{array}$ & $\begin{array}{c}\text { Organic } \\
\text { Derived } \\
\text { Additive } \\
\text { (ODA) }\end{array}$ \\
\hline Molecular Weight & - & 175.23 & 206.3 & \multirow{14}{*}{$\begin{array}{l}\text { Proprietary } \\
\text { Information }\end{array}$} \\
\hline Flash Point & ${ }^{\circ} \mathrm{C}$ & 70 & 10 & \\
\hline Freezing Point & ${ }^{\circ} \mathrm{C}$ & -45 & -40 & \\
\hline Boiling Point & ${ }^{\circ} \mathrm{C}$ & 100 & 111 & \\
\hline Vapor Pressure @ 20 C & $\mathrm{Pa}$ & 27 & 2600 & \\
\hline Vapor Pressure @ $40^{\circ} \mathrm{C}$ & $\mathrm{Pa}$ & $40-53$ & $\mathrm{~N} / \mathrm{A}$ & \\
\hline Vapor Pressure @ $82^{\circ} \mathrm{C}$ & $\mathrm{kPa}$ & 1.33 & $\mathrm{~N} / \mathrm{A}$ & \\
\hline Density @ $20^{\circ} \mathrm{C}$ & $\mathrm{g} / \mathrm{mL}$ & 0.96 & $\mathrm{~N} / \mathrm{A}$ & \\
\hline Kinematic Viscosity @ 20 C & $\mathrm{cSt}$ & 1.8 & $\mathrm{~N} / \mathrm{A}$ & \\
\hline Solubility in Water @ $20^{\circ} \mathrm{C}$ & $\mathrm{mg} / \mathrm{L}$ & 12.6 & insoluble & \\
\hline Heat of Vaporization & $\mathrm{kJ} / \mathrm{kg}$ & 368 & $\mathrm{~N} / \mathrm{A}$ & \\
\hline Heat of Decomposition & $\mathrm{J} / \mathrm{g}$ & 2100 & $\mathrm{~N} / \mathrm{A}$ & \\
\hline Auto / Self Ignition Temperature & ${ }^{\circ} \mathrm{C}$ & 130 & 80 & \\
\hline Decomposition Temperature & ${ }^{\circ} \mathrm{C}$ & 100 & 111 & \\
\hline
\end{tabular}

\subsection{Test Cycles}

The test cycles were computer controlled using engine speed and engine load (torque) as input values. After a test, the measured engine speed and engine load points were compared to the engine speed and load input values. The measured engine speed and load points must meet a regression analysis to be considered a valid test. An engine testing sequence consisted of a warm-start heavy-duty federal test procedure (FTP) test followed by three hot-start FTP tests (see Figure 3-4). The warm start test was used to bring the engine to normal operating conditions. In between each test was a 20-minute soak period used for zeroing and spanning the analyzers and changing PM filters. The heavy-duty FTP engine dynamometer cycle was developed in the 1970s for engine and fuel certification testing of heavy-duty diesel engines. The test cycle has four sections: the New York Non-Freeway (NYNF), Los Angeles Non-Freeway (LANF), Los Angeles Freeway (LAFY), and a repeat of the New York Non-Freeway (NYNF). The NYNF section simulates light city traffic with frequent stops and starts. The LANF models heavy city traffic with infrequent stops, while the LAFY section models highway driving with heavy traffic. 


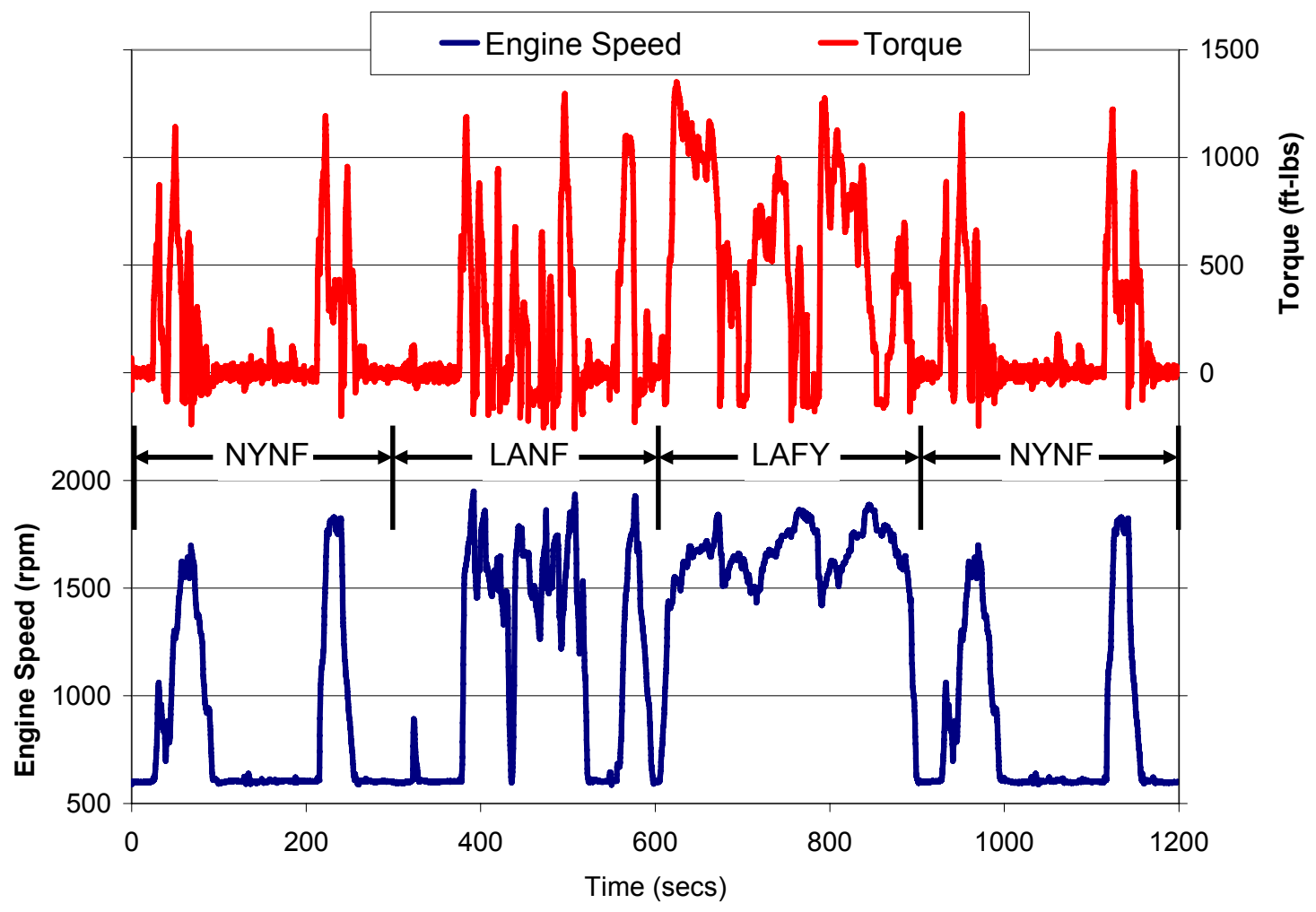

Figure 3-4 Heavy Duty Diesel FTP Test Cycle on the 1992 Series 60 DDC

After the last hot-start FTP data collection, a steady state test was started. The steady state test was the Supplemental Emissions Test (SET). This test is required as part of the engine certification procedure for new on-road heavy-duty diesel engines in the United States. Additionally, the SET provides a link to prior additive research literature performed at steady state. The SET consists of idle and four loads at three different engine speeds with the duration of idle lasting four minutes and 12 other modes lasting two minutes (Figure 3-5). The numbers in Figure 3-5 indicate the order in which the steady state points are tested. These numbers are used as the mode number referenced in this research. The engine speeds A, B, and C are determined from the engine power curve and represent low, intermediate, and high speed, respectively. Typically, the SET emissions are reported as an averaged weighted value based on published weighting factors for each mode. For this study, the mass emissions during each mode were more important and were addressed separately. 


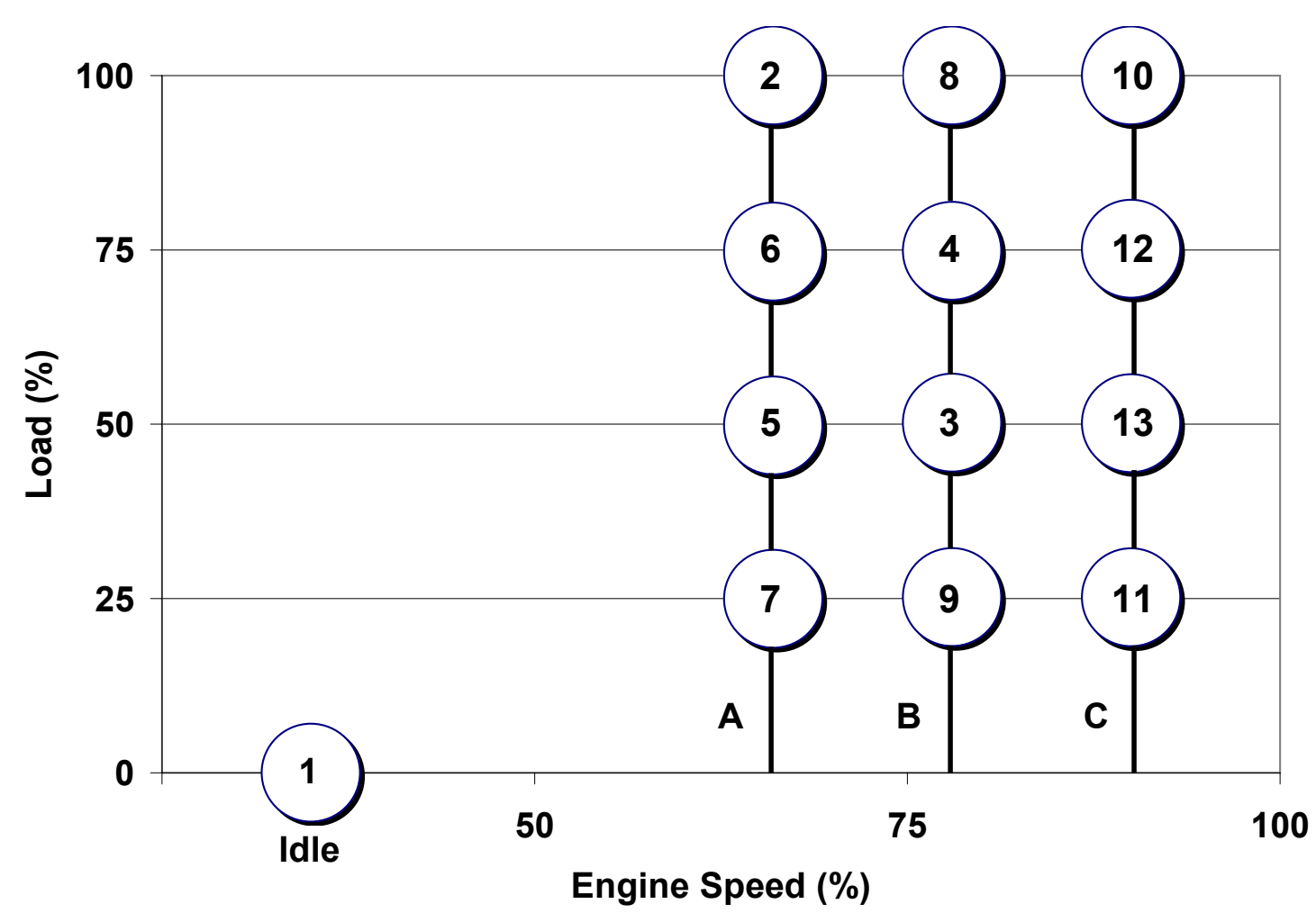

Figure 3-5 Supplemental Emissions Test, Numbers in the Circles Represent the Test Order

\subsection{WVU Engines Research Center}

The WVU Engines Research Center was used for the engine testing performed in this research, which has a full-scale dilution tunnel. The ERC included an engine dynamometer capable of absorbing and providing power. The full scale dilution and constant volume system (CVS) employed in the test cell was designed based on Title 40 CFR Part 86 Subpart N requirements. A critical flow venturi was used as the method of measuring the diluted exhaust. The dilute exhaust analyzers consisted of a Rosemount Analytical Model 402 heated flame ionization detector (HFID), Horiba FIA 236 HFID, Rosemount Model 955 Chemiluminescent, Horiba Model AIA210LE Non-Dispersive Infrared (NDIR), and Horiba Model AIA-210 Non-Dispersive Infrared (NDIR) to measure THC (January and February 2007 testing), THC (June and July 2007 testing), NOx, CO, and $\mathrm{CO}_{2}$, respectively. An Eco Physics CLD 844CMh was used as a secondary NOx analyzer for $\mathrm{QA} / \mathrm{QC}$ and it provided the ability to measure NOx and NO and through subtraction, $\mathrm{NO}_{2}$. For the July 2007 testing, a CAI 600 HCLD-C was substituted for the Eco Physics CLD $844 \mathrm{CMh}$ as the secondary NOx analyzer due to availability. Unlike the Eco Physics NOx analyzer, the CAI 600 HCLD-C only measured total NOx. The PM was gravimetrically 
measured in accordance with Title 40 CFR Part 86 Subpart N requirements using proportional sampling of the diluted exhaust through a pair of Pallflex 70mm diameter Model T60A20 fluorocarbon-coated glass microfiber filters in series. For more detail information on the facility and testing, see reference [69].

\subsection{Test Matrix}

The investigated base fuels and additive concentrations are shown as Table 3-3. The 1992 DDC engine was tested with base fuels of Grad Ref, Grad Cand, CP Cert, Low Cetane, and Low Cetane B20 Cottonseed. The base fuels tested on the 2004 Cummins engine were the Grad Ref, Grad Cand, CP Cert, and CP Cert B20 Soy. The multiple base fuels were tested to investigate whether the base fuel properties had any large influence on additive performance. There was also a limited quantity of each base fuel. Cetane improvers were chosen as the studied additives due to the need for an improved understanding of their emissions performance. The literature only speculates on reasons for the varied NOx reductions/increases based on engine conditions (load and speed) and type (manufacturer, model, and year) [10-15]. The additive concentrations ranged from 3 to $24 \mathrm{ml} /$ gal and every combination of additive, concentration, and fuel type was not tested on both engines. The wide range of additive concentrations was due to testing the engine and base fuel responses to the additive and then later applying this knowledge to other base fuels and additive concentrations. That is, an ad hoc test plan was used in this program. Due to limited change in the NOx emissions with the cetane improvers on the 2004 Cummins engine, higher concentrations of each additive were evaluated than with the 1992 DDC engine. One main difference between the two engines was the 2004 Cummins engine had cooled EGR, where as the 1992 DDC did not have EGR at all. To determine whether the EGR had an influence on the effectiveness of the cetane improvers, the EGR valve was disabled with and without additive utilizing the Grad Ref fuel. This would also give an indication of the emissions if an EGR failure occurred on a modern engine (model year 2004 or later) with cetane-improved fuel. 
Table 3-3 Test Matrix

\begin{tabular}{|c|c|c|c|c|c|}
\hline Engine & Fuel & $\begin{array}{l}\text { Testing Month of } \\
2007\end{array}$ & Additive / Blend & $\begin{array}{l}\text { Number of } \\
\text { FTP Tests }\end{array}$ & $\begin{array}{l}\text { Number of } \\
\text { SET Tests }\end{array}$ \\
\hline \multirow[t]{33}{*}{1992 DDC } & \multirow[t]{2}{*}{ Grad Ref } & \multirow[t]{2}{*}{ January } & Neat & 4 & 3 \\
\hline & & & $16 \mathrm{ml} / \mathrm{gal}$ ODA & 4 & 3 \\
\hline & \multirow[t]{7}{*}{ Grad Cand } & \multirow[t]{7}{*}{ January } & Neat & 4 & 2 \\
\hline & & & $8 \mathrm{ml} / \mathrm{gal} 2 \mathrm{EHN}$ & 3 & 2 \\
\hline & & & $16 \mathrm{ml} / \mathrm{gal}$ ODA & 3 & 2 \\
\hline & & & $16 \mathrm{ml} / \mathrm{gal}$ ODA $2 \mathrm{x}$ & 3 & 2 \\
\hline & & & Neat & 3 & 1 \\
\hline & & & $10 \mathrm{ml} / \mathrm{gal}$ DTBP & 3 & 2 \\
\hline & & & $6 \mathrm{ml} / \mathrm{gal}$ ODA & 3 & 2 \\
\hline & \multirow[t]{4}{*}{ CP Cert } & \multirow[t]{2}{*}{ January } & Neat & 4 & 1 \\
\hline & & & $12 \mathrm{ml} / \mathrm{gal}$ ODA & 3 & 1 \\
\hline & & \multirow[t]{2}{*}{ July } & Neat & 3 & 1 \\
\hline & & & $12 \mathrm{ml} / \mathrm{gal}$ ODA & 3 & 1 \\
\hline & \multirow[t]{18}{*}{ Low Cetane } & \multirow[t]{11}{*}{ June } & Neat & 3 & 1 \\
\hline & & & $7.5 \mathrm{ml} / \mathrm{gal}$ DTBP & 3 & 1 \\
\hline & & & $3 \mathrm{ml} / \mathrm{gal} 2-\mathrm{EHN}$ & 3 & 1 \\
\hline & & & $6 \mathrm{ml} / \mathrm{gal} 2-\mathrm{EHN}$ & 3 & 1 \\
\hline & & & $8 \mathrm{ml} / \mathrm{gal} 2-\mathrm{EHN}$ & 3 & 1 \\
\hline & & & $6 \mathrm{ml} / \mathrm{gal}$ ODA3 & 3 & 1 \\
\hline & & & $12 \mathrm{ml} / \mathrm{gal}$ ODA3 & 3 & 1 \\
\hline & & & $16 \mathrm{ml} / \mathrm{gal}$ ODA3 & 3 & 1 \\
\hline & & & $3.88 \mathrm{ml} / \mathrm{gal}$ ODANS & 3 & 1 \\
\hline & & & $7.75 \mathrm{ml} / \mathrm{gal}$ ODANS & 3 & 1 \\
\hline & & & $10.33 \mathrm{ml} / \mathrm{gal}$ ODANS & 3 & 1 \\
\hline & & \multirow[t]{7}{*}{ July } & Neat & 3 & 1 \\
\hline & & & $6 \mathrm{ml} / \mathrm{gal} 2-\mathrm{EHN}$ & 3 & 1 \\
\hline & & & $12 \mathrm{ml} / \mathrm{gal}$ ODA3 & 3 & 1 \\
\hline & & & B20 Soy & 3 & 1 \\
\hline & & & B20 Mineral & 3 & 1 \\
\hline & & & B20 Cottonseed & 3 & 1 \\
\hline & & & Neat & 3 & 1 \\
\hline & \multirow[t]{2}{*}{ LC B20 Cottonseed } & \multirow[t]{2}{*}{ July } & $6 \mathrm{ml} / \mathrm{gal} 2-\mathrm{EHN}$ & 3 & 1 \\
\hline & & & $12 \mathrm{ml} / \mathrm{gal}$ ODA3 & 3 & 1 \\
\hline \multirow[t]{18}{*}{2004 Cummins } & \multirow[t]{2}{*}{ Grad Ref } & \multirow[t]{2}{*}{ February } & Neat & 3 & 1 \\
\hline & & & $16 \mathrm{ml} / \mathrm{gal}$ ODA & 3 & 1 \\
\hline & \multirow[t]{2}{*}{ Grad Ref w/o EGR } & \multirow[t]{2}{*}{ February } & Neat & 3 & 1 \\
\hline & & & $16 \mathrm{ml} / \mathrm{gal}$ ODA & 0 & 1 \\
\hline & \multirow[t]{2}{*}{ Grad Cand } & \multirow[t]{2}{*}{ February } & Neat & 3 & 1 \\
\hline & & & $6 \mathrm{ml} / \mathrm{gal}$ ODA & 3 & 1 \\
\hline & CP Cert & February & Neat & 3 & 1 \\
\hline & & & $12 \mathrm{ml} / \mathrm{gal}$ ODA & 3 & 1 \\
\hline & & & $6 \mathrm{ml} / \mathrm{gal} 2 \mathrm{EHN}$ & 3 & 1 \\
\hline & & & $12 \mathrm{ml} / \mathrm{gal} 2 \mathrm{EHN}$ & 3 & 1 \\
\hline & & & $24 \mathrm{ml} / \mathrm{gal}$ ODA & 3 & 1 \\
\hline & & & $15 \mathrm{ml} / \mathrm{gal}$ DTBP & 3 & 1 \\
\hline & & & B20 Soy & 3 & 1 \\
\hline & & & B20 Mineral & 3 & 1 \\
\hline & & & B20 Cottonseed & 3 & 1 \\
\hline & & & Neat & 3 & 0 \\
\hline & & & Neat & 3 & 1 \\
\hline & CP Cert B20 Soy & February & 10ml/gal DTBP & 3 & 1 \\
\hline
\end{tabular}


To determine whether the change in emissions between the additized and neat fuel over the FTP cycle or for a mode in the SET was significant and not by chance, the T-test was used. A p-value (probability) $<0.05$ (typically used in statistical studies) was used to establish statistical significance between the means with different variances. When a p-value $<0.05$ occurred between the means of the additive and neat fuel tests, there was a probability of less than $5 \%$ that the difference occurred by chance. This also states that differences deemed "statistically significant" had a $5 \%$ probability that they occurred by chance and were false positives.

For the SET tests, fuel and additive combinations with two or more repeats used the T-test. For fuel and additive combinations with only one SET test, a T-test could not be performed, and a different approach was used for significance. For each mode, if the difference between the additized and neat fuel NOx emission, for example, was greater than the approximate range of the neat fuel plus the approximate range of the additized fuel, this was deemed a significant difference. The approximate range for each additive and fuel combination was found from 11 SET tests on the Guttman fuel with the 1992 DDC engine at three different dilution air humidity settings (3 SETs at dry, 4 SETs at $\sim 60 \%$, and 4 SETs at saturated conditions) from another study. From the range over average (similar to a covariance, Equation 3-1) of the work, BSFC, and emissions from the three dilution air humidity settings, the maximum range over average was determined for each mode. Then for each fuel and additive combination with only one SET test, each maximum range over average from the Guttman fuel was multiplied by the value from the fuel and additive combination to find an approximate range (Equation 3-2). The range was used instead of the standard deviation because the range would reduce the number of false positive determinations of statistical significance. For the 2004 Cummins engine, the difference between the repeat SET tests on the CP Cert fuel over the average of the repeats was utilized. This range over average was then used as mentioned above for the 1992 DDC engine to determine a significant difference on the 2004 Cummins engine.

$$
\begin{aligned}
& R / A=\frac{\text { Range }}{\text { Average }}=\left(\frac{\text { Max }- \text { Min }}{\mu}\right)_{\text {Guttman }} \\
& R_{E s t}=(R / A)_{\text {Guttman }} * Y_{\text {Fuel }}
\end{aligned}
$$


To find a relationship between the heat release parameters (see Section 3.8.1) and emissions of the additized and neat fuel, the Pearson product-moment correlation coefficient was used. The correlation coefficient is a measure of the linear relationship between two variables and ranges from -1 to 1 , with " -1 " being a "perfect" negative linear relation, and " +1 " being a "perfect" positive linear relationship, and zero having no linear relationship. Therefore, higher correlation

coefficients indicate a stronger relationship between variables, but not necessarily a cause and effect relationship. It should be noted that plots of the heat release parameters and the emissions were observed to determine if any outlier(s) might have caused a low or high correlation; no outliers were found.

\subsection{In-cylinder Pressure}

The pressure transducers were of the piezoelectric type, which measures dynamic pressure. A static pressure measurement is required to "peg" or provide a reference point. The pressure transducer connects to a charge amplifier, which converts the charge provided by the pressure transducer to an amplified voltage. This voltage can then be read by a data acquisition system.

The 1992 DDC engine and the 2004 Cummins utilized Kistler quartz pressure transducer models 6125B and 6061B, respectively (Figure 3-6). The model 6061B pressure transducer utilizes cooling water to minimize any temperature influences such as thermal shock and sensitivity. The manufacturer specifications for the transducers are provided in the Appendix as Table 7-3. A low-pass filter was applied to the measured in-cylinder pressure to minimize fluctuations caused by the pressure wave. A low-pass filter with cut-off frequencies of $2500 \mathrm{~Hz}$ and $1500 \mathrm{~Hz}$ was applied to the in-cylinder pressure of the 1992 DDC engine and 2004 Cummins engine, respectively, to reduce the high frequency combustion noise. The 2004 Cummins engine had greater combustion noise, so a lower cut-off frequency was required. The low-pass filter is a type of averaging filter, which unfortunately causes a reduction in the premix spike. It was assumed that since this averaging was applied to all data equally, the relative differences between fuels should not be impacted significantly. 

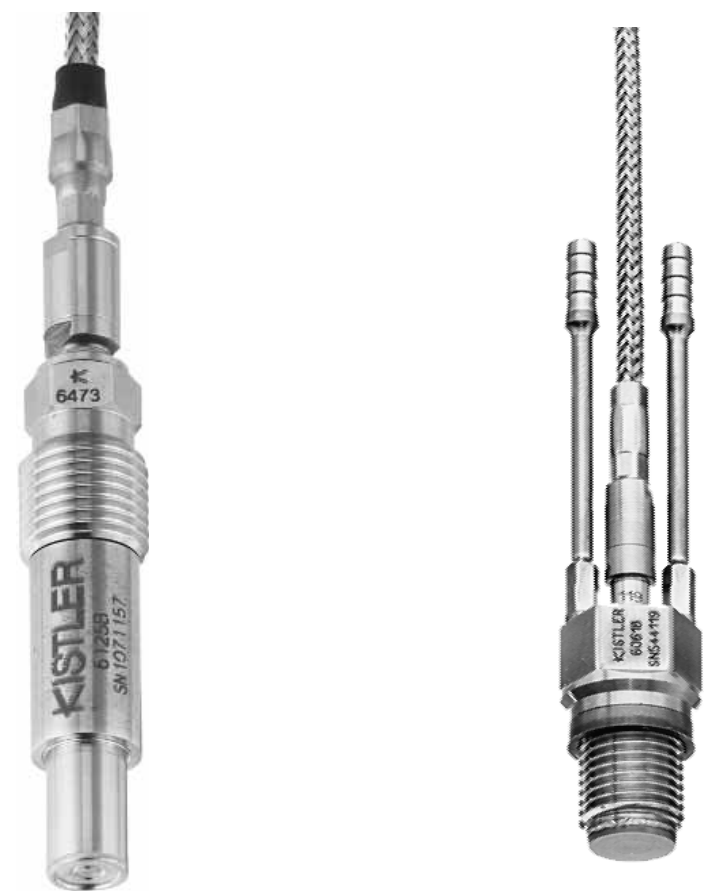

Figure 3-6 In-Cylinder Pressure Transducers (Not to Scale): Left, 6125B and Right, 6061B [74, 75]

To acquire the transient in-cylinder pressure measurement, data acquisition software was developed. The software currently developed allows real-time processing of the acquired pressure data into the heat release and the derived combustion characteristics with a graphical display of the current heat release (Figure 3-7). The calculated combustion characteristics can then be recorded. The combustion acquisition and analysis system used a stand-alone computer from the existing laboratory DAQ system because of computational requirements and easy adaptation to the current laboratory. 




Figure 3-7 In-Cylinder Pressure / Heat Release Analysis Software

\subsubsection{Measured and Calculated Parameters}

Although the software above provided some measured and calculated parameters, a Matlab program was written to reanalyze the acquired pressure data. The parameters that were directly measured or calculated are displayed in the Appendix as Table 7-4. Most parameters were calculated using the in-cylinder pressure. The engine speed and temperature during the exhaust stroke were measured parameters that were not based on the in-cylinder pressure signal. The engine speed was used to align the measured and calculated parameters during a transient test to the laboratory data.

\subsubsection{Heat Release Rate}

From the heat release rate data (Equation 2-4), the maximum heat release rate, location of the maximum heat release rate, net heat released over the combustion period, gross heat release calculated over the combustion period, and fuel flow were calculated. Researchers [48] have used the maximum heat release rate as an indication of NOx emissions, with a higher heat 
release rate correlating to higher NOx. The net and gross heat released (Equation 3-3 and Equation 3-4) is the summation of the heat released during each crank angle resolution from the start of combustion (SOC) to the end of combustion (EOC). From the gross heat released, lower heating value of the fuel (LHV), and engine speed (rpm), the fuel flow in the cylinder with incylinder pressure measurement was calculated. By multiplying the fuel flow in one cylinder by the number of cylinders, an estimation for the total fuel consumption of the engine was obtained, assuming all cylinders have the same fuel flow (Equation 3-5).

$$
\begin{aligned}
& Q_{\text {net }}=\sum_{S O C}^{E O C} d Q_{\text {net }} \\
& Q_{\text {gross }}=\sum_{S O C}^{E O C} d Q_{\text {gross }} \\
& \dot{m}_{\text {fuel }}=\frac{Q_{\text {gross }} * n_{s} * \frac{1}{2} \frac{\text { cycle }}{\text { LHV }}}{\text { rev }}
\end{aligned}
$$

\subsubsection{In-cylinder Pressure}

With the direct measurement of in-cylinder pressure, the maximum pressure and the location of maximum pressure were calculated. The maximum pressure provides an indication of the engine load and the in-cylinder temperature. Higher pressure typically indicates higher loads and incylinder gas temperatures.

Since the piezoelectric transducer provided dynamic pressure, the pressure signal needed referencing each cycle to give an absolute pressure. The two most common methods are using the manifold air pressure or assuming a constant polytropic constant [76]. The method used for this study was a constant polytropic constant. This method has been recommended by Brunt et al. [76] for combustion studies since the measurement of manifold air pressure is not required, which can be inaccurate with tuned intake manifolds. The corrected pressure was the average of the calculated corrected pressures over a 40 crank angle degree window during the compression stroke between 120 and 60 degrees BTDC. Since the laboratory intake manifold air pressure (MAP) was not used in the pressure correction, the MAP was obtained from the in-cylinder pressure trace at the location of intake valve closing and compared to the laboratory MAP. 
Obtaining the MAP from the pressure trace removed the dependency of another sensor and the need for interpolation of the laboratory MAP pressure during transient tests.

\subsubsection{Needle Lift}

A needle lift sensor was installed inside a single injector on the 1992 DDC Series 60 engine by Wolff Controls. The sensor was a Hall Effect sensor, which provided a voltage signal proportional to height of the fuel injection needle at a frequency response of $25 \mathrm{kHz}$. From the needle lift, the start and end of the fuel injection was obtained.

\subsubsection{Start of Combustion}

The start of combustion is defined here, as the first measurable quantity of combustion in the cylinder (Figure 2-2). When comparing two fuels on the same engine at the same set points of engine speed and load, the start of combustion is an indication of ignition delay if the start of ignition was the same. Other researchers have used the point at which the pressure deviates from the motoring curve [50] or the point at which $10 \%$ of the mass fraction has burned [77].

\subsubsection{Ignition Delay}

The time from the start of fuel injection to the start of combustion is the ignition delay. Ignition delay provides an indication of the combustibility of the fuel injected and the mixing of the fuel and air. A longer ignition delay indicates the need for higher pressures and temperatures for the fuel to combust. A higher cetane fuel has a smaller ignition delay and therefore more fuel is injected during the diffusion burn, potentially resulting in lower NOx emissions.

\subsubsection{Estimated End of Combustion}

The duration of combustion is from the start of combustion to the end of combustion. With the injection of more fuel, the duration of combustion can be longer. Long combustion duration might indicate that too much fuel is injected as the cylinder cools down during the expansion stroke, potentially causing incomplete combustion. The end of combustion was estimated from the maximum heat released over ten crank angle degrees and adding twenty degrees. After the end of combustion the heat released should maintain the same level for tens of degrees [78], thus over estimation of the end of combustion should be a better assumption than under estimation, especially when the mass fraction burned is of concern. 


\subsubsection{Indicated Mean Effective Pressure}

A useful combustion parameter was the indicated mean effective pressure (IMEP), which is the cylinder work normalized by the cylinder displaced volume. A study done by Brunt and Emtage [79] explored five methods of calculating the IMEP, and the method least effected by experimental error was used here (Equation 3-6). The gross IMEP is the IMEP over the compression and expansion strokes only and gross IMEP was used in this study. The gross engine torque (Equation 3-7) may be calculated from the IMEP, displacement volume of the engine $\left(V_{D}\right)$, and the number of revolutions per combustion cycle $\left(R_{S}\right)$. The friction and pumping torque (Equation 3-8) was approximated from a polynomial of engine speed and intake air flow [80]. Subtracting friction/pumping torque from the gross torque yielded the brake torque. The polynomial coefficients for the friction/pumping torque relationship were fit using the gross torque from the combustion parameters and the brake torque from the dynamometer during steady state testing. Using the brake torque and engine speed from the combustion program, the engine power may be calculated for each combustion cycle during transient testing.

$$
\begin{aligned}
& \text { imep }=\frac{\Delta \theta}{V_{D}} \sum_{i=B D C}^{i=B D C} P(i) * \frac{d V(i)}{d \theta} \\
& T=\frac{V_{D} * \text { imep }}{R_{S}} \\
& T_{f / p}=a_{o}+a_{1} * n_{S}+a_{2} * n_{S}^{2}+\left(a_{3}+a_{4} * n_{S}\right) * m_{a}
\end{aligned}
$$

\subsubsection{Mass Fraction Burned}

The mass fraction burned (MFB) gives the percentage of injected fuel that burned at a particular crank angle. Common values of interest are the durations of 10, 50, and 90\% MFB [78]. The duration, in crank angle, of start of combustion to $10 \%$ or $50 \%$ MFB indicates the intensity of premix combustion, while from 50 to $90 \%$ MFB indicates the strength of the diffusion burn. The equation for the mass fraction burned used in this research was from the first law of thermodynamics and calculated by normalizing the cumulative gross heat release at each crank angle to the total heat released (Equation 3-9). 
$m f b_{\theta}=\frac{\sum_{i=S O C}^{i=\theta} d Q_{i, \text { gross }}}{Q_{\text {gross }}}$

\subsubsection{In-Cylinder Gas Temperature}

The uniform or mean gas temperature in the cylinder can be calculated at each crank angle by making the ideal gas assumption with a known reference location and temperature such as at inlet valve closure. Since pollutant formation, especially NOx, is a function of temperature, the mean cylinder temperature was a useful variable to analyze. Szybist and coworkers [48] showed a relationship between NOx emissions and the location of maximum cylinder temperature that was not dependent on fuel type when testing conventional diesel, biodiesel (B20, B40, and B100), or FT fuels (FT20, FT40, FT100).

The method for calculation of the mean cylinder gas temperature was done by rearranging the ideal gas equation for any crank angle with gas temperature on the left side (Equation 3-10). The ideal gas equation at inlet valve closure was rearranged to give Equation 3-11. By assuming that the molecular weight does not vary significantly during combustion, the two equations (Equation 3-10 and Equation 3-11) are combined into Equation 3-12, resulting in the mean cylinder gas temperature being a function of known quantities.

$$
\begin{aligned}
& T_{\theta}=P_{\theta} * V_{\theta} *\left(\frac{1}{n * R}\right) \\
& \frac{T_{I V C}}{P_{I V C} * V_{I V C}}=\left(\frac{1}{n * R}\right) \\
& T_{\theta}=P_{\theta} * V_{\theta} *\left(\frac{T_{I V C}}{P_{I V C} * V_{I V C}}\right)
\end{aligned}
$$

\subsubsection{Premix Fraction}

As mentioned in the Literature review section, the heat release rate may be divided into two parts: the premix and diffusion sections. Particular interest with combustion studies has been the premix section. The end of the premix section has been defined as the dip after the premix spike 
leading to the diffusion section (Figure 2-2). The summation of the heat released during the premix section to the total heat released was the premix fraction.

\subsubsection{Air Flow Rate}

Fuel-to-air ratio strongly influences combustion conditions. From the intake air flow and the fuel flow, a fuel-to-air ratio was calculated. The combustion-based intake air flow (Equation 3-13) was compared to the laboratory laminar flow element (LFE) measured (Equation 3-14) intake air flow as a quality check. The in-cylinder pressure-based engine intake flow at standard conditions was calculated, assuming a volumetric efficiency $\left(n_{v}\right)$, with engine speed $\left(C_{E}\right)$, engine displacement $\left(V_{D}\right)$, MAP, and manifold air temperature (MAT) using Equation 3-13. The revolutions per cycle $\left(R_{S}\right)$ is a conversion for the number of revolutions per combustion cycle. For a 4-stroke engine, the $\mathrm{R}_{\mathrm{S}}$ value is two, and for a 2-stroke engine, the value is one. The LFE consisted of a tube bundle creating laminar flow (low Reynolds number). The pressure drop across the element was measured and corrected to standard conditions. The LFE (Equation 3-14) has constants $\mathrm{B}$ and $\mathrm{C}$ with known standard conditions ( $\mu_{\text {std }}, \mathrm{P}_{\text {std }}$, and $\left.\mathrm{T}_{\text {std }}\right)$ and measured fluid conditions $\left(\mathrm{P}_{\mathrm{f}}, \mathrm{T}_{\mathrm{f}}\right.$, and $\mu_{\mathrm{f}}$ calculated from $\left.\mathrm{T}_{\mathrm{f}}\right)$.

$$
\begin{aligned}
& \dot{Q}_{\text {intake }}=\frac{n_{V} * n_{S} * V_{D}}{R_{S}} *\left(\frac{M A P}{P_{\text {std }}}\right) *\left(\frac{T_{\text {std }}}{M A T}\right) \\
& \dot{Q}_{\text {intake }}=\left(B * d P+C * d P^{2}\right) *\left(\frac{\mu_{\text {std }}}{\mu_{f}}\right) *\left(\frac{P_{f}}{P_{\text {std }}}\right) *\left(\frac{T_{\text {std }}}{T_{f}}\right)
\end{aligned}
$$

\subsubsection{Ratio of Pressure at Exhaust Valve Opening to Intake Valve Closing}

The boost pressure provided by the turbocharger changes the pressure inside the cylinder, which alters the created power. The turbocharger provides greater boost as the exhaust pressure increases. When the engine transitions from low to high load, the exhaust pressure is low, but the engine is commanded to increase the power. Large amounts of fuel are injected and the exhaust pressure increases, creating higher turbocharger speeds and more boost, but a time delay, or turbocharger "lag," is created from the sudden engine demand of the turbocharger to the actual boost created. The ratio of the exhaust pressure at exhaust valve opening to intake valve closing (or MAP in this study's case) showed the current boost ratio. The boost ratio provided an indication of load change. Steady state conditions and transient operation at the same engine 
speed and load condition may have different boost ratios due to the turbocharger lag. The cylinder boost ratio provided another parameter based on the heat release.

\subsubsection{Fuel Conversion Efficiency}

To investigate whether the cetane improver additives used in this study changed the efficiency of combustion, the fuel conversion efficiency was calculated (Equation 3-15). The fuel conversion efficiency provided how much power was converted from the energy in the fuel for each combustion event. The fuel flow and power were from the in-cylinder combustion-based parameters.

$n_{\text {eff }}=\frac{\text { Power }}{\dot{m}_{\text {fuel }} * L H V}$

\subsubsection{Heat Release Approximation}

Mathematical representations of the heat release curve include the double Weibe function [81] and the polygon-hyperbola combustion profile [82]. This study used the double Weibe function, since this function includes combustion parameters studied in this work as shown in Equation 3-16. By fitting the experimental heat release curve to the double Weibe function using a least squares method, a continuous curve was reduced to six constants. The equation includes a premix and a diffusion portion. With $\mathrm{a}=6.908$, this assumes a conversion efficiency of $99.9 \%$ of the fuel energy to heat. The eight fitting parameters are the premix portion heat released $\left(\mathrm{Q}_{\mathrm{p}}\right)$, shape parameter $\left(\mathrm{m}_{\mathrm{p}}\right)$, start of combustion $\left(\theta_{\mathrm{soc}, \mathrm{p}}\right)$, length of combustion $\left(\Delta \theta_{\mathrm{p}}\right)$, diffusion portion heat released $\left(\mathrm{Q}_{\mathrm{d}}\right)$, shape parameter $\left(\mathrm{m}_{\mathrm{d}}\right)$, start of combustion $\left(\theta_{\mathrm{soc}, \mathrm{d}}\right)$, and length of combustion $\left(\Delta \theta_{\mathrm{d}}\right)$. The start of combustion $\left(\theta_{\mathrm{soc}, \mathrm{p}}\right.$ and $\left.\theta_{\mathrm{soc}, \mathrm{d}}\right)$ was determined before the least square approximation routine, resulting in six fitting parameters.

$$
\begin{aligned}
& {\left[\frac{d Q}{d \theta}\right]_{\text {gross }}} \\
& =a Q_{p}\left(m_{p}+1\right)\left(\frac{\theta-\theta_{s o c, p}}{\Delta \theta_{c, p}}\right)^{m_{p}} \exp \left[-a\left(\frac{\theta-\theta_{s o c, p}}{\Delta \theta_{c, p}}\right)^{m_{p}+1}\right] \\
& +a Q_{d}\left(m_{d}+1\right)\left(\frac{\theta-\theta_{s o c, d}}{\Delta \theta_{c, d}}\right)^{m_{d}} \exp \left[-a\left(\frac{\theta-\theta_{s o c, d}}{\Delta \theta_{c, d}}\right)^{m_{d}+1}\right]
\end{aligned}
$$




\subsection{Experimental Heat Release Accuracy}

Some consideration was taken in obtaining accurate experimental heat release measurements to minimize the measurement and calculation errors created. A variable of concern in the heat release analysis was the specific heat ratio; recent research focuses on improving the accuracy [83-86]. The global specific heat ratio depends on the concentrations of the combustion products at each crank angle resolution. Predicting the combustion products requires a sophisticated combustion model, which can be computationally intensive. Early researchers have used a constant specific heat ratio, a linear model based on the cylinder gas temperature [85] and a polynomial based on the cylinder gas temperature $[85,86]$. More recently, models based on the equivalence ratio and/or two-zone model with an unburned and burned zone [83-85] have been implemented. Another study has utilized an equilibrium combustion model as the basis for fitting the polynomials based on equivalence ratio [85]. This requires a new curve fit for each fuel tested since fuels may differ, especially in studies considering fuel with oxygen, such as biodiesel.

For the research presented here, a two-zone model was chosen with unburned and burned zones. The molar concentrations $\left(\mathrm{CO}_{2}, \mathrm{H}_{2} \mathrm{O}, \mathrm{O}_{2}\right.$, and $\left.\mathrm{N}_{2}\right)$ in the burned zone were solved assuming complete combustion, a reasonable assumption for properly functioning diesel engines, which operate lean. The 1992 DDC and 2004 engines generally operated with 1.4 to 5 times the stoichiometric air required. From the molar concentrations, a burned zone specific heat ratio at the cylinder gas temperature was developed. The molar concentrations in the unburned zone were dependent on the EGR ratio (Equation 3-17). The MFB was used to combine the unburned and burned zones into the global specific heat ratio (Equation 3-18).

$$
\begin{aligned}
& \gamma_{u}=Y_{E G R} * \gamma_{b}+\left(1-Y_{E G R}\right) * \gamma_{A i r} \\
& \gamma=M F B * \gamma_{b}+(1-M F B) * \gamma_{u}
\end{aligned}
$$

The influence of the chosen method used for the specific heat ratio on the experimental heat released is shown in Figure 3-8 and Figure 3-9. The results of the method give virtually identical results as a more sophisticated method utilizing an equilibrium combustion model. The "Brunt" method is a polynomial fit of the global specific heat ratio as a function of cylinder gas temperature. Differences in the global heat release rate and heat released were noticed between 
the "Brunt" method and the two-zone method used for this study. Larger differences would be noticed between the methods shown and a constant specific heat ratio method.



Figure 3-8 Influence of Specific Heat Ratio on the Heat Release Curve for Mode 2 (100\% Load) on 1992 DDC 




Figure 3-9 Influence of Specific Heat Ratio on the Heat Release Curve for Mode 2 (100\% Load) on 2004 Cummins ISM

During steady state testing, for each mode, 200 pressure cycles were averaged to reduce combustion noise. The heat release rate and combustion characteristics were then calculated. As a quality assurance check, the combustion-derived fuel flow and intake air flow were compared with the laboratory-measured values. The fuel flow and intake air flow for eleven SET tests using the same Guttman fuel are shown in Figure 3-10 and Figure 3-11. For comparison to the laboratory, the combustion derived fuel flow assumed all six cylinders are equivalent to the measured cylinder. A linear regression constrained to pass through the origin showed good agreement with a $\mathrm{R}^{2}$ greater than 0.99 for the fuel and intake flows. The zero-dimensional heat release model was $97-99 \%$ of the measured laboratory fuel flows, which included a fuel meter, $\mathrm{CO}_{2}$ based fuel flow, and ECU fuel flow. This was determined to be adequate for this study. The combustion derived air flow was $4 \%$ higher than the laboratory measured intake air (using a LFE). Idle (Mode 1) and Mode 2 were the least repeatable and were disregarded during later analyses due to changes in engine control. 


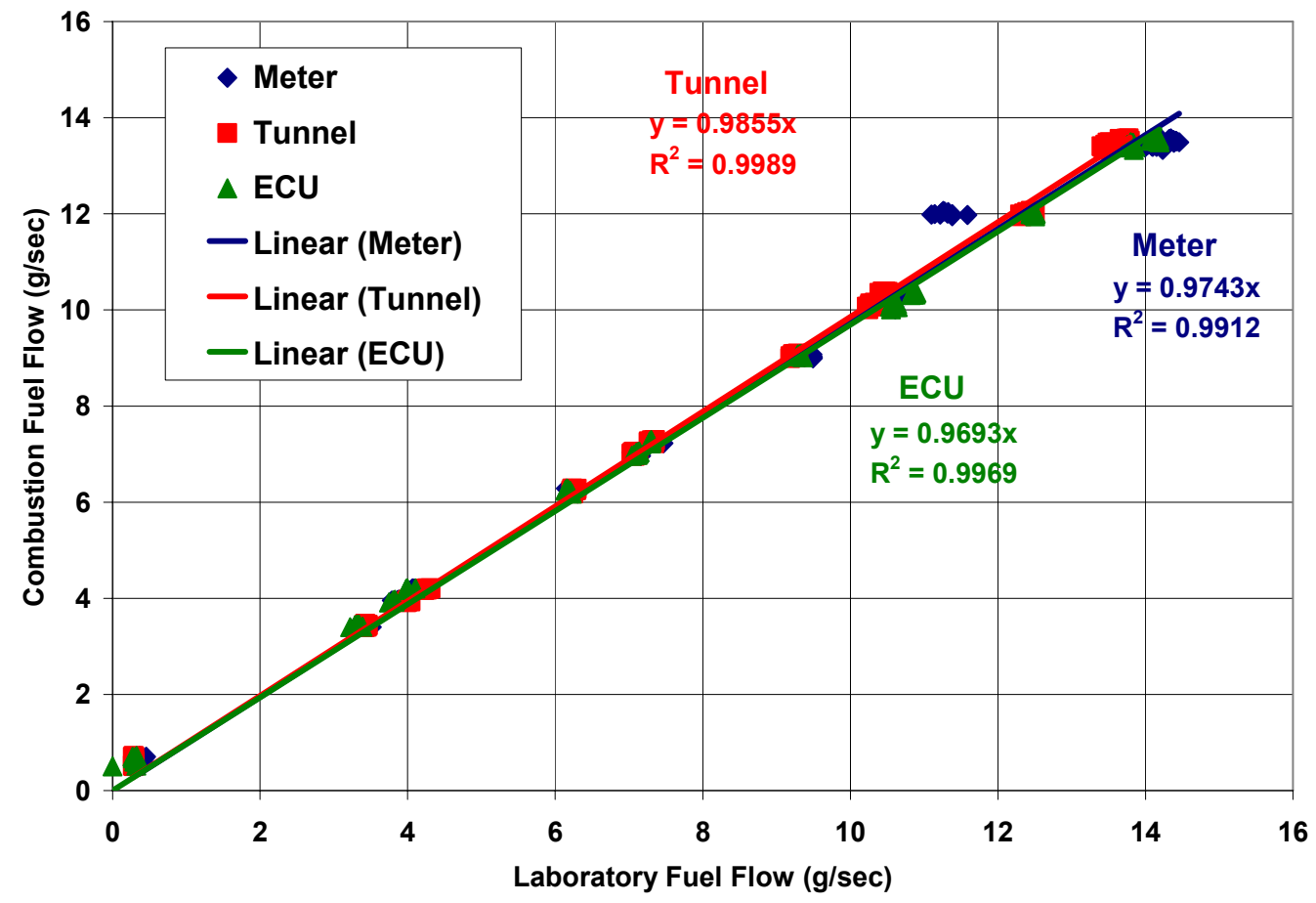

Figure 3-10 Steady State Combustion Derived Fuel Flow Compared to Laboratory Fuel Flow for the 1992 DDC Engine

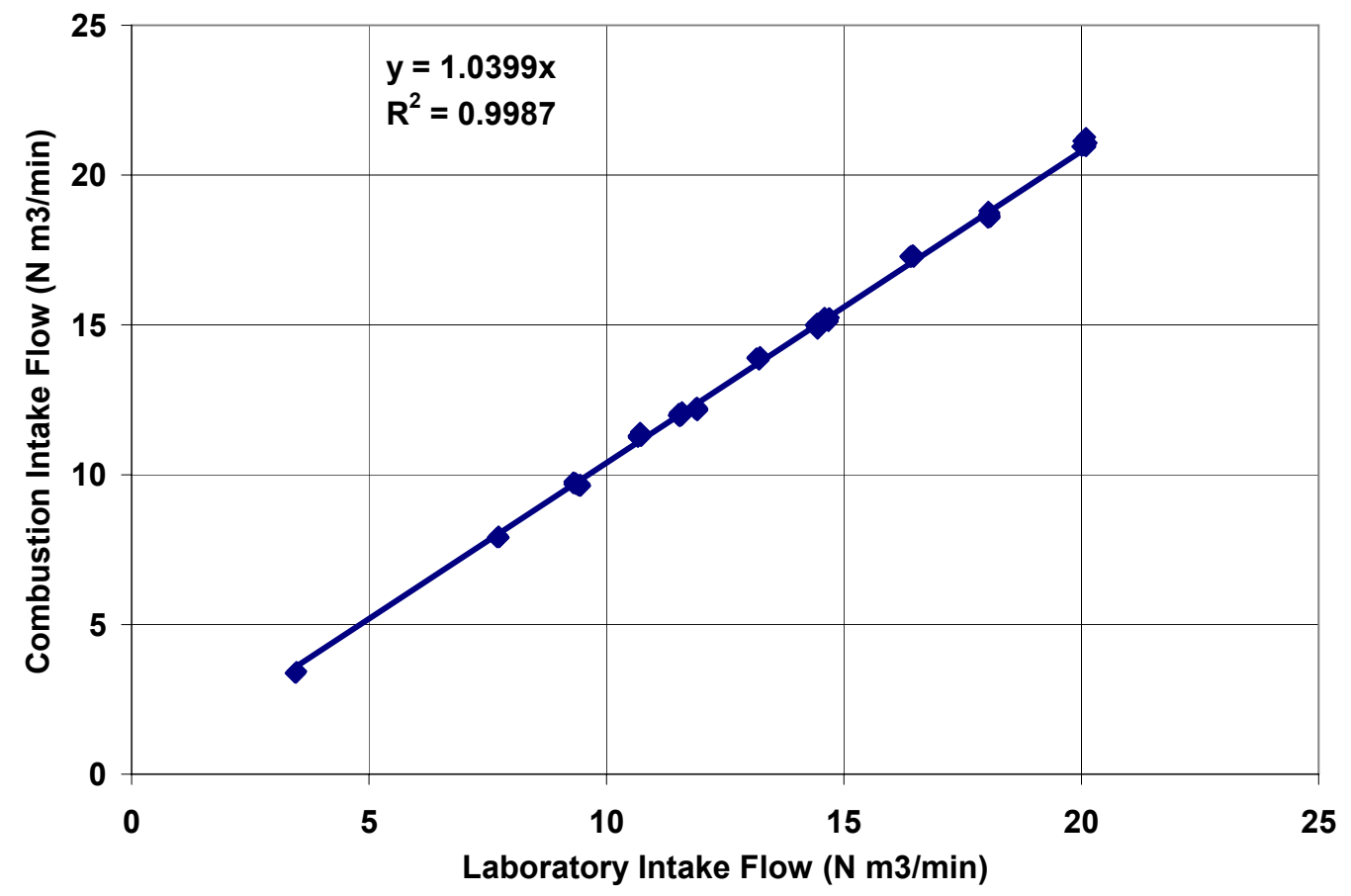

Figure 3-11 Steady State Combustion Derived Intake Air Flow Compared to Laboratory Intake Air Flow for the 1992 DDC Engine 
The combustion derived engine torque and engine speed measured with the encoder agreed to the laboratory measured torque and engine speed with a slope and $\mathrm{R}^{2}$ of virtually one. It should be noted that the combustion-derived torque used the laboratory torque to derive the friction and pumping torque as mentioned in Section 3.8.1.7. For the 11 SET tests conducted on the Guttman fuel, the in-cylinder derived combustion parameters were measured and/or calculated. Table 7-8, in the Appendix, provides the resulting repeatability found for each parameter. The range (maximum - minimum) of parameters in crank angle degrees or milliseconds was used to signify repeatability. The SOC had a maximum range of 0.25 degrees, which was the resolution of the encoder. Other parameters are shown as the range over the average. Since comparisons were made between fuels with only one SET, the range provided a better determination of a significant difference than the covariance. The maximum cylinder pressure, maximum cylinder temperature, and premix fraction had maximum range over average values of $1.3 \%, 2.2 \%$, and $7.3 \%$, respectively.

For the twenty SET tests conducted using the 2004 Cummins engine, the linear regression between the combustion derived fuel flow and the ECU fuel flow had a slope of 1.03 and an $\mathrm{R}^{2}$ greater than 0.99 (Figure 3-12). The heat release analysis showed greater variation on the 2004 Cummins than on the 1992 DDC due to high frequency oscillations in the measured in-cylinder pressure. The 2004 Cummins engine utilized cooled EGR and a variable geometry turbocharger. With more engine components affecting combustion, the cycle-to-cycle combustion had greater variation. The continuous NOx emissions showed an oscillation that followed the oscillation in the EGR fraction due to the stepper motor controlling the EGR flow. With EGR, the heat release analysis had greater variation in the intake conditions (MAP, MAT, and EGR fraction), which affected the combustion characteristics. These variations highlight the fact that to study fundamental combustion phenomenon, the use of single cylinder engines with tightly controlled parameters is paramount to obtain repeatable data. However, the data to be presented will illustrate that newer engines (post 2002), with additional control parameters, result in variations in the control algorithm and hence variation in the combustion and the emissions generated. 


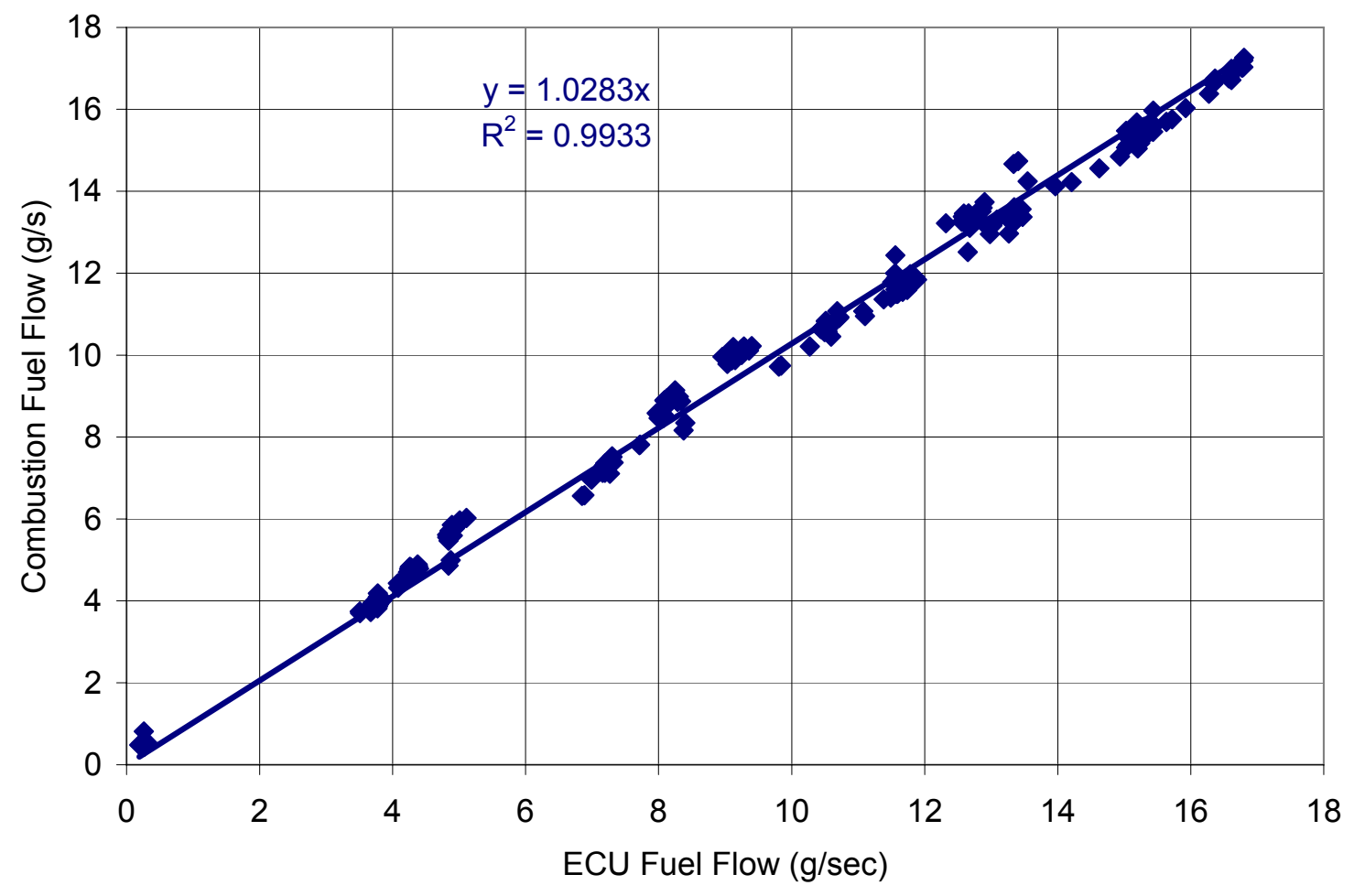

Figure 3-12 Steady State Combustion Derived Fuel Flow Compared to Laboratory Fuel Flow for the 2004 Cummins Engine

\subsection{Combustion Model}

For this study, a phenomenological combustion model was developed based on the global heat release rate to investigate the formation of NOx emissions. A phenomenological model provides some emission formation information due to mixing without the need for a full spatial (3D, CFD) analysis. For the model developed in this study, the fuel injected into the cylinder was broken into a number of fuel packages (Figure 3-13). The number of fuel packages was based on the length of combustion and the crank angle step length ( 2 degrees crank angle). It should be noted that the needle lift signal was used to derive the fuel injection profile because a constant injection velocity was assumed. There will be some error with this assumption, but the error should be minimal when comparing differences between neat and additized fuels. 




Figure 3-13 The Phenomenological Combustion Model with 10 Fuel Packages

An equation for the evolution of the equivalence ratio of fuel package $\mathrm{z}$ was developed assuming an inverse relationship with the mixing time. Equation 3-19 has two constants, $C$ and $A$. The constant A was termed the mixing constant. When a fuel package leaves the fuel injector, the equivalence ratio is infinite, since no mixing has occurred yet. As the fuel package travels in the combustion chamber, the amount of air in the package increases due to mixing with stoichiometric conditions (assumed) occurring at combustion, which is indicated by the global heat release rate. Mixing continues after initial combustion until the equivalence ratio of the package equals the global equivalence ratio of the cylinder.

$E R(z, t)=\frac{C}{t_{m i x}(z, t)^{A}}$

Using the boundary condition that the local equivalence ratio at the time of combustion has a value of one, the constant $C$ in Equation 3-19 becomes the combustion time raised to the mixing constant. Substituting the solution for constant $C$ back into Equation 3-19, results in Equation 3-20. A model for the apparent combustion time (ACT) was developed by Arrègle et al. [87, 88]. The ACT for a packet of fuel was the time from injection to combustion indicated by the 
global heat release (Equation 3-21). Equation 3-21 was modified assuming constant injector hole diameter and injection velocity. The ACT for each fuel package was a function of the mixing time, density of air in the cylinder, and oxygen concentration. Substituting the combustion time (Equation 3-21) into the previously developed relationship for the local equivalence ratio (Equation 3-20) results in the relationship used in this study (Equation 3-22). The only constant left to solve for in Equation 3-22 was $K(z)$. At the time of combustion, the mixing time was equal to the time of combustion, and the local equivalence ratio was assumed unity. The global density of air in the cylinder was solved from the ideal gas law and oxygen concentration from equilibrium relationships. A mixing constant of two, which was chosen for this study, based on a NOx combustion study by Hernandez et al. [68] that utilized the same local ER ratio relationship (Equation 3-22).

$$
\begin{aligned}
& E R(z, t)=\left(\frac{t_{\text {comb }}(z)}{t_{\text {mix }}(z, t)}\right)^{A} \\
& t_{\text {comb }}(z)=A C T(z)=K *\left[\overline{\rho_{a}^{0.5} * u_{o} * O_{2}^{0.5}} * \phi^{-1}\right]^{-1} \\
& E R(z, t)=\left(\frac{K(z)}{t_{\text {mix }}(z, t) * \rho_{a}^{0.5}(t) * O_{2}^{0.5}(t)}\right)^{A}
\end{aligned}
$$

The fuel packages were considered burned zones after the time of combustion. The air in the cylinder not yet mixed with a fuel package was considered the unburned zone. The number of burned zones depended on the time step chosen. The conservation of energy equation was used to solve the temperature for each zone at each time step. The derived conservation of energy equation for the fuel packages is shown as Equation 3-23 and on the left side of Figure 3-14. At the time of combustion for a fuel package, the energy equation included the chemical heat energy $\left(\mathrm{dQ}_{\mathrm{c}}\right)$ and energy required to evaporate the fuel $\left(\mathrm{dQ}_{\mathrm{fv}}\right)$; at all other times these are zero. Some work was produced $(\mathrm{dW})$ and there was a loss of heat energy to the walls $\left(\mathrm{dQ}_{\mathrm{w}}\right)$ at each time step. Due to the changing ER of each package, more air enters the fuel package and the associated enthalpy of this additional air was taken into account. The unburned zone (Equation 3-24 and on the right of Figure 3-14) has no chemical energy produced or fuel evaporation and depends on the work, heat transfer to the walls, and the enthalpy loss from air mass exiting the unburned zone and entering the burned zones. An iterative approach was used to solve the package product temperature and chemical composition. The exhaust was assumed to consist 
only of $\mathrm{CO}_{2}, \mathrm{H}_{2} \mathrm{O}, \mathrm{N}_{2}, \mathrm{O}_{2}, \mathrm{O}, \mathrm{CO}, \mathrm{H}_{2}, \mathrm{H}, \mathrm{OH}$, and $\mathrm{NO}$. Using the conservation of carbon, hydrogen, oxygen, nitrogen, total moles, and six chemical equilibrium equations (Equation 3-25 to Equation 3-30), the products were solved [89]. The conservation of energy for a particular zone (Equation 3-23) should result in zero. Any deviation from zero resulted in changing the product temperature and recalculating the product concentrations. This iterating continued until the difference in product temperature between two consecutive iterations was less than $1^{\circ} \mathrm{C}$. The extended Zeldovich model was used to predict the NOx formation. References $[65,67]$ provide more details on the reaction kinetics and the extended Zeldovich mechanism used. High levels of NO were predicted with the extended Zeldovich mechanism. An empirical modifier (function of the cylinder pressure) was applied to the forward reaction rate of reaction 1 (Equation 2-1) as used by Miller et al. [90], which helps to incorporate the pressure effects on NOx that are not included with the assumed equilibrium reactions.

$$
\begin{aligned}
& 0=-d U_{z}+d Q_{c, z}-d Q_{w, z}-d Q_{f v}-d W_{z}+\dot{m}_{z} h_{a i r} \\
& 0=-d U_{u b}-d Q_{w, u b}-d W_{u b}-\left(\sum \dot{m}_{z}\right) h_{a i r}
\end{aligned}
$$
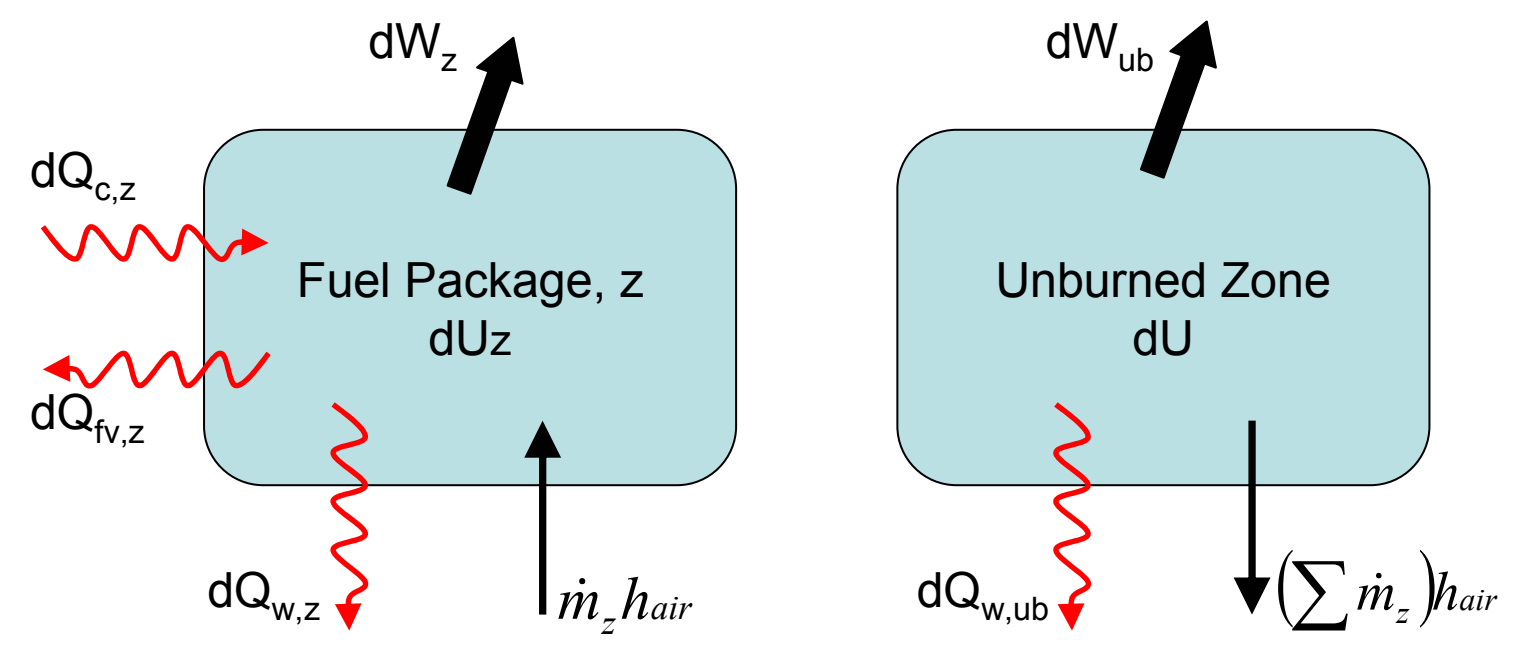

Figure 3-14 Energy Equation for Fuel Packages and Unburned Zone

$$
\begin{array}{ll}
\frac{1}{2} H_{2} \leftrightarrow H & K_{1}=\frac{X_{H} P^{0.5}}{X_{H_{2}}^{0.5}} \\
\frac{1}{2} O_{2} \leftrightarrow O & K_{2}=\frac{X_{O} P^{0.5}}{X_{O_{2}}{ }^{0.5}}
\end{array}
$$




$$
\begin{aligned}
\frac{1}{2} \mathrm{H}_{2}+\frac{1}{2} \mathrm{O}_{2} \leftrightarrow \mathrm{OH} & K_{3}=\frac{X_{\mathrm{OH}}}{X_{\mathrm{H}_{2}}{ }^{0.5} X_{\mathrm{O}_{2}}^{0.5}} \\
\frac{1}{2} \mathrm{O}_{2}+\frac{1}{2} \mathrm{~N}_{2} \leftrightarrow \mathrm{NO} & K_{4}=\frac{X_{\mathrm{NO}}}{X_{\mathrm{N}_{2}}^{0.5} X_{\mathrm{O}_{2}}^{0.5}} \\
\mathrm{H}_{2}+\frac{1}{2} \mathrm{O}_{2} \leftrightarrow \mathrm{H}_{2} \mathrm{O} & K_{5}=\frac{X_{\mathrm{H}_{2} \mathrm{O}}}{X_{\mathrm{H}_{2}} X_{\mathrm{O}_{2}}^{0.5} P^{0.5}} \\
\mathrm{CO}+\frac{1}{2} \mathrm{O}_{2} \leftrightarrow \mathrm{CO}_{2} & K_{6}=\frac{X_{\mathrm{CO}_{2}}}{X_{\mathrm{CO}} X_{\mathrm{O}_{2}}{ }^{0.5} P^{0.5}}
\end{aligned}
$$




\section{Results and Discussions}

This research examined the combustion characteristics and resulting emissions formation of fuels with additives from heavy-duty diesel engines through in-cylinder pressure analysis and emission measurement. The emissions results consisted of modal steady state tests and integrated transient tests. In-cylinder pressure was collected for each mode during steady state testing and for each combustion cycle during transient testing. Using the heat release calculated from the in-cylinder pressure, a combustion model of the emissions formation was developed to aid the understanding of the significance of the change in global heat release due to additizing neat fuels. These results will be presented in this section. The data presentation has been divided between the two different engines and by different test campaigns.

\subsection{Emissions}

The three additives tested were 2-EHN, DTBP, and ODA. Multiple concentrations of the additives were tested with different base fuels. To compare different fuel-additive combinations, a T-test with a p-value $<0.05$ was used to establish statistical significance between the means with difference variances. The FTP test typically consisted of a sample size of three hot starts per fuel; although some tests had up to five repeat runs. Repeat steady state testing was limited due to fuel constraints, so a sample size of one was typical for the steady state testing. Some steady state tests had repeats (two tests). Only one base fuel and one additized fuel had three tests, allowing a statistical significance for each mode. These tests were used to draw statistical significance criteria. The single steady state tests were used for trends or possible conclusions, but without the confidence of a statistical analysis. The focus was on NOx emissions due to the difficulty of reducing NOx, while maintaining the same fuel economy. Typically, reducing NOx means lower combustion temperatures, which result in lower fuel economy.

\subsubsection{DDC Series 60 Engine}

For the January 2007 testing on the 1992 DDC engine, CP Cert, Grad Ref, and Grad Cand were the three base fuels tested. A NOx reduction was achieved on the FTP cycle with the use of additives (Table 7-9). For each additized base fuel, a statistical significant NOx reduction (2.2$3.6 \%$ ) was noticed. The emissions of $\mathrm{CO}, \mathrm{HC}$, and TPM were significantly reduced as well. The 
achieved reductions were 5.8-9.3\%, 10.9-19.8\%, and 4.3-6.6\%, for CO, $\mathrm{HC}$, and TPM, respectively. For the CP Cert fuel additized with $12 \mathrm{ml} /$ gal ODA, a $1 \%$ increase in TPM was found.

For the Grad Ref fuel additized with $16 \mathrm{ml} / \mathrm{gal}$ ODA, three repeat SET tests were conducted allowing a Student's T-test for statistical significance (Figure 4-1) for NO and NOx. Mode 0 was the cycle weighted emissions and mode $1^{*}$ was the mass emissions at idle (grams/hr). At $100 \%$ load (modes 2, 8, and 10), NOx increased by $1.3-1.6 \%$ with respect to the neat fuel, while at $25 \%$ load (modes 7,9 , and 11$)$, NOx decreased by $4.2-5.6 \%$.

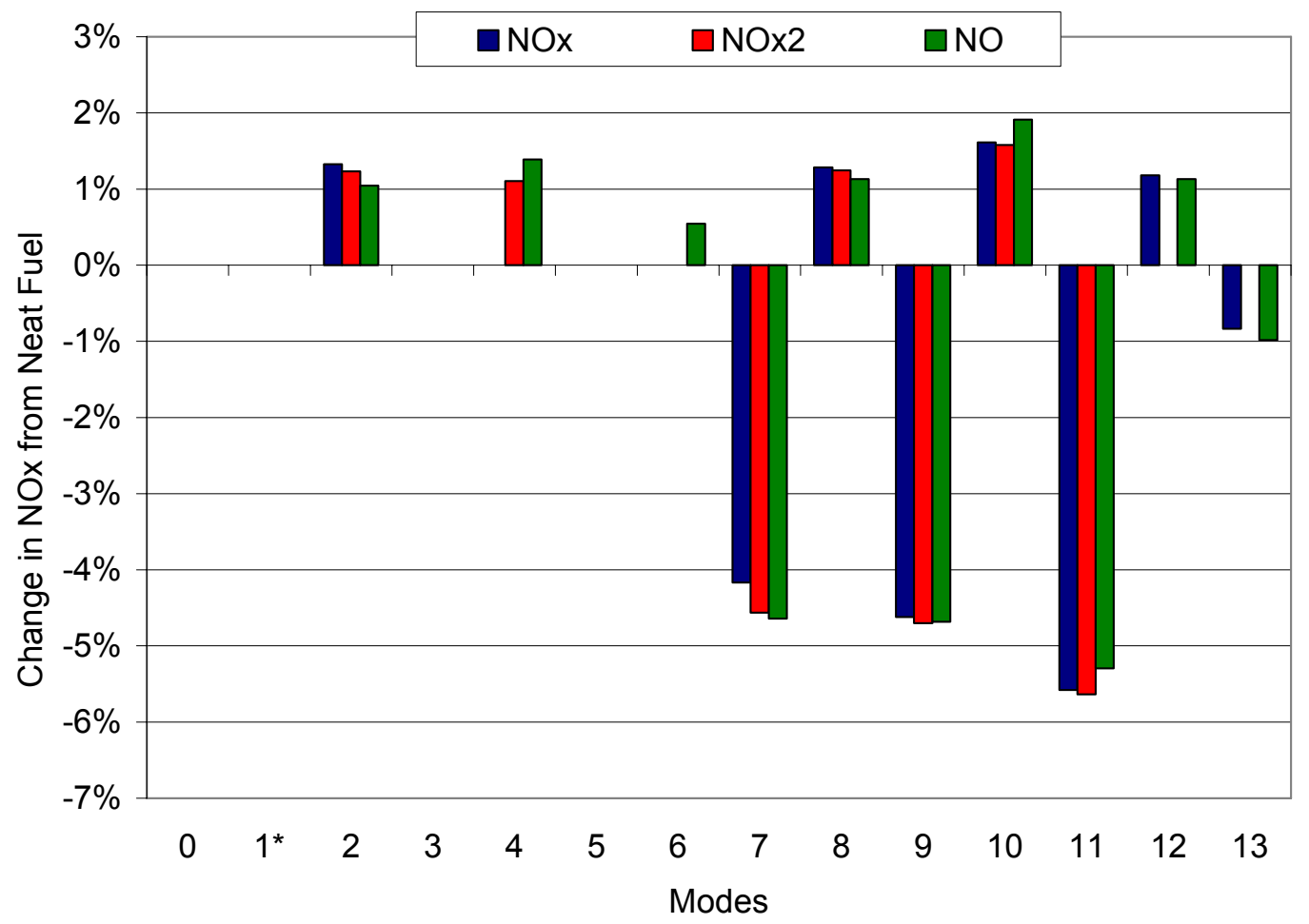

Figure 4-1 Change in Brake Specific NOx for Grad Ref Fuel Additized with 16ml/gal ODA Compared to Neat Fuel for Steady State Modes on the 1992 DDC (No Column indicates no significant difference). NOx -

Primary NOx Analyzer, NOx2 - Secondary NOx Analyzer, NO - From Secondary NO Analyzer

The FTP test consists of the engine being exercised over many different speeds and loads, as mentioned in Section 3.5, with the emissions integrated over the entire cycle. Depending on the mode, as shown in Figure 4-1, NOx decreased or increased. The percent reductions of emissions from the additized fuel results are then dependent on the test cycle. With the FTP test cycle primarily at low load, NOx would show a greater reduction than for a high load test cycle. As 
illustrated in Figure 4-1, the two NOx analyzers demonstrated similar changes. The NO reduction was comparable to the NOx reduction, indicating that there is no significant $\mathrm{NO}_{2}$ production due to the additive.

Based on the outcome from the January 2007 tests, additional testing was conducted in June 2007, with one base fuel, named Low Cetane, which indicated the lowest cetane number (46.2) of the base fuels tested. A single treat rate of DTBP and three different treat rates of 2-EHN, ODA3 (ODA version 3), and ODANS (ODA with a new formulation) were tested. On the FTP cycle, all treat rates and additives showed a significant difference in $\mathrm{CO}, \mathrm{NOx}$, and $\mathrm{HC}$ compared to the neat fuel. The emissions of $\mathrm{CO}$ decreased 5-8.9\%, NOx decreased 2.6-4.9\%, and HC decreased 16.7-37\% (Table 7-10). Statistically significant differences in work, BSFC, and $\mathrm{CO}_{2}$ were noticed for some tests, although the changes were small (less than $0.5 \%$ ).

With increasing treat rates from 3 to $8 \mathrm{ml} / \mathrm{gal}$, 2-EHN showed a NOx decrease at 25\% load of approximately $3.1 \%$, while at $100 \%$ load a NOx increase of $0.6 \%$ was found (Figure $4-2$ ). The primary mechanism of increasing 2-EHN concentrations on NOx reduction was prominent at low load with less influence at high load. Idle (Mode $1^{*}$ ) was not shown in the figure, due to the low accuracy of the sampling system and variability of combustion (no fuel injected into the cylinder) for this mode. For Mode 2, the Low Cetane fuel had low NOx on the primary NOx analyzer, which then caused a high percent NOx increases for Mode 1 and the weighted emissions (Mode 0). It should be noted that the June 2007 testing only consisted of a single SET test. The Student's T-test requires at least two tests, so a statistical analysis was not performed. 


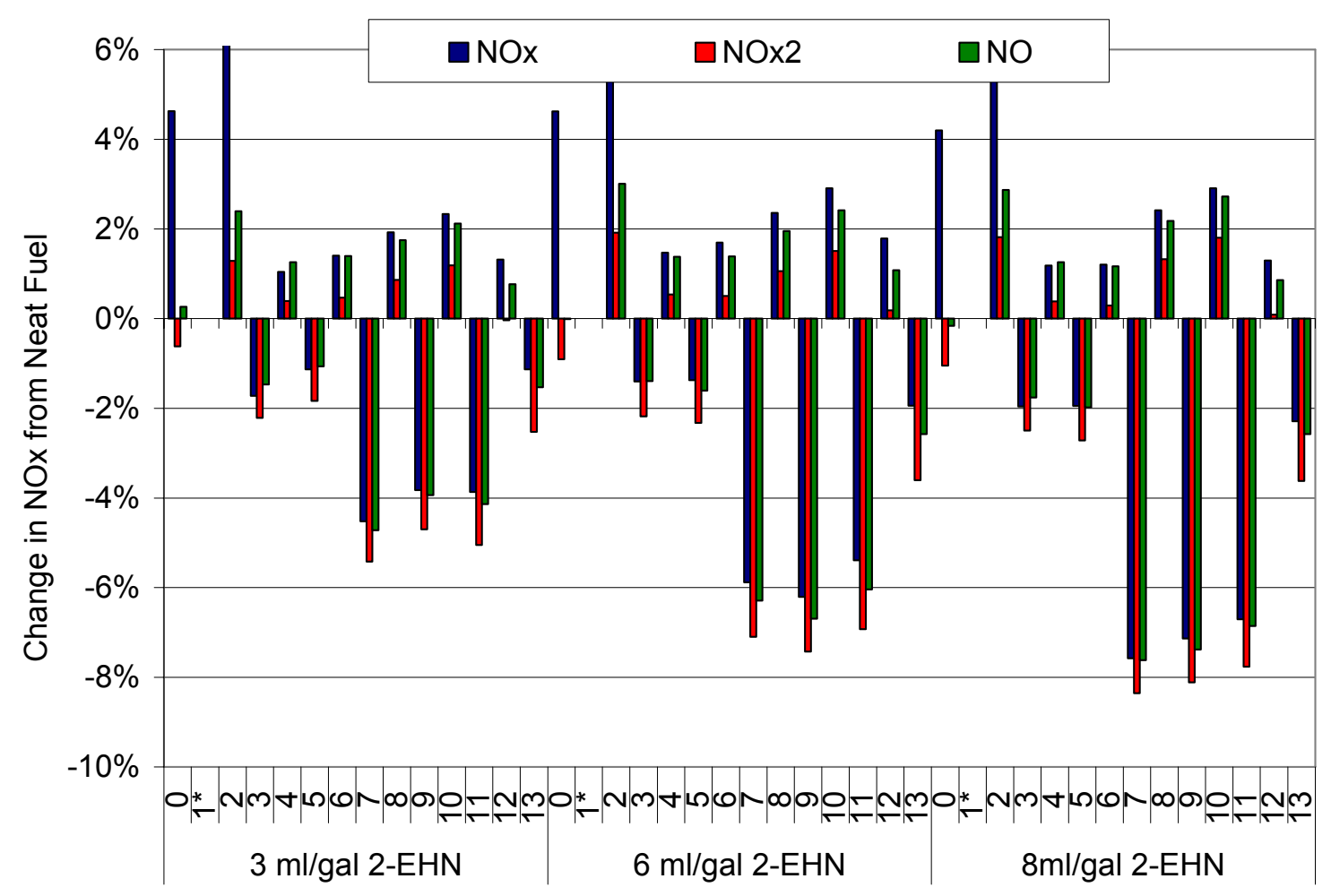

Figure 4-2 Change in the Brake Specific NOx for Low Cetane Fuel with Three Treat Rates of 2-EHN Compared to Neat Fuel for Steady State Modes on the 1992 DDC (Idle not shown)

As illustrated in the data, as the concentration of 2-EHN increases, the NOx reduction increases (percent difference is going more negative) for the low power modes, and the NOx production increases (the percent difference is going more positive) for the higher power modes. Treat rates of $7.5 \mathrm{ml} / \mathrm{gal}$ DTBP, $6 \mathrm{ml} / \mathrm{gal} 2-\mathrm{EHN}$, and $12 \mathrm{ml} / \mathrm{gal}$ ODA3 had NOx reductions of 3.8-4.4\% for the FTP cycle. The three additives showed similar behavior, with NOx reductions noticed at low load and a NOx increase at high load. From the steady state testing, $7.5 \mathrm{ml} / \mathrm{gal}$ DTBP showed less NOx increase at high load and less NOx decrease at low load than $6 \mathrm{ml} / \mathrm{gal} 2-\mathrm{EHN}$ and $12 \mathrm{ml} / \mathrm{gal}$ ODA3. Therefore, the exact chemical mechanisms between additives may be different, but the load effect on NOx was similar. It should be noted that Mode 2 for the primary NOx analyzer again had low NOx and resulted in high percent NOx increases for the additives. More testing was done in July 2007 and the results were similar to the January and June 2007 testing (Appendix, Table 7-11). The SET results for all studies are provided in the Appendix as Table 7-13 through Table 7-15. 


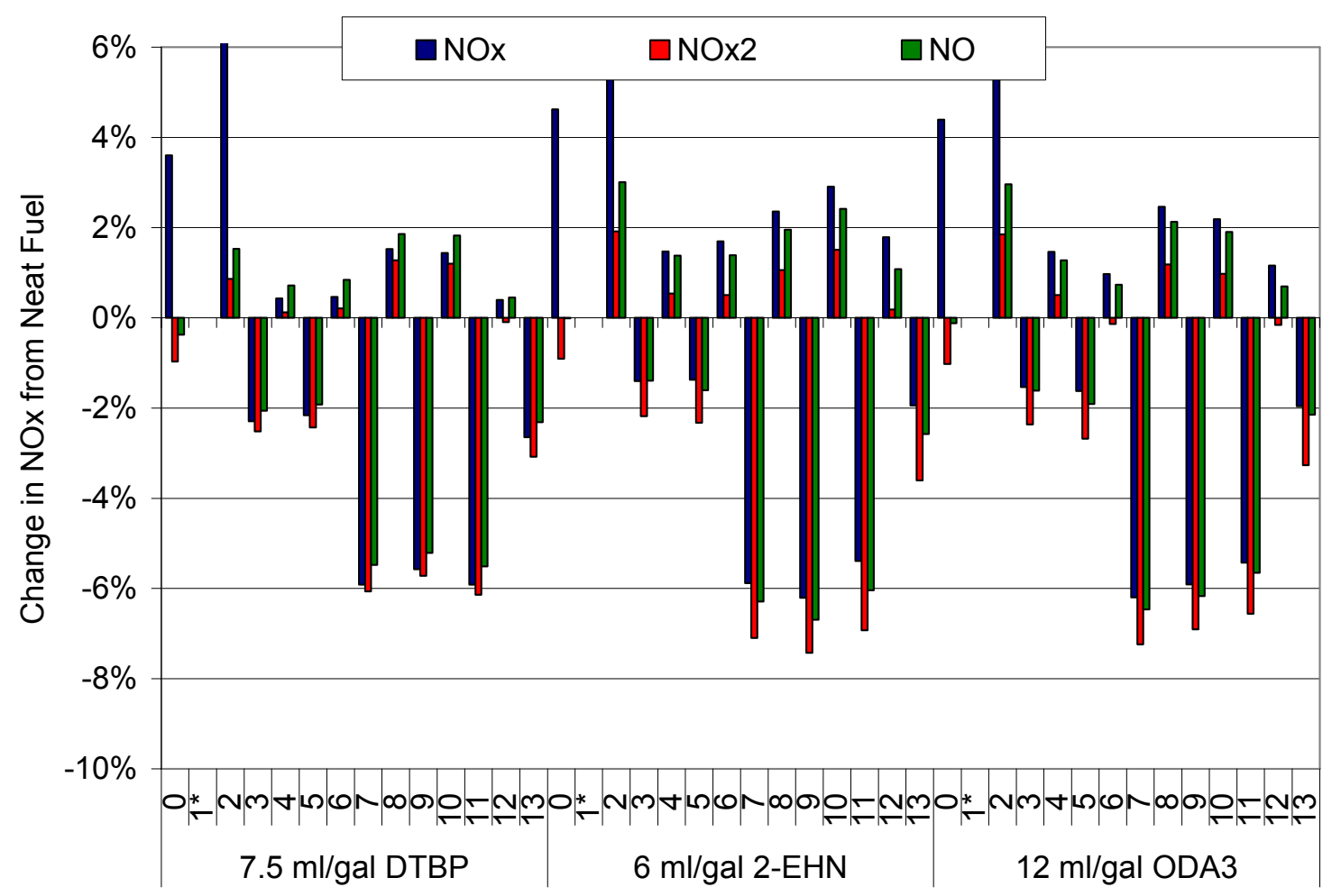

Figure 4-3 Change in the Brake Specific NOx for Low Cetane Fuel with Three Cetane Improvers Compared to Neat Fuel for Steady State Modes on the 1992 DDC (Idle not shown)

\subsubsection{Cummins ISM 370 Engine}

The 2004 Cummins ISM 370 engine showed no significant difference or a NOx increase with the additives. The higher treat rates of $12 \mathrm{ml} / \mathrm{gal} 2-\mathrm{EHN}$ and $24 \mathrm{ml} / \mathrm{gal}$ ODA on the CP Cert fuel showed a $1.3 \%$ and $1.4 \%$ NOx increase, respectively. With the CP Cert fuel, the additives showed a CO decrease of 7.3-14.7\% and no significant difference in HC and TPM.

The 2004 Cummins ISM 370 engine was operated with and without EGR to determine the level of influence the EGR had on the NOx emissions. The EGR was disabled by disconnecting the wiring at EGR valve, which resulted in the EGR valve being in the closed position. It should be noted that the injection timing was changed by the ECU between EGR enabled and disabled conditions. The MAP was lower during the disabled EGR condition than the enabled EGR condition. Without EGR, the NOx and PM emissions were comparable to a 1994 model year onroad heavy-duty diesel engine. Utilizing Grad Ref fuel, without EGR, on the 2004 Cummins engine, the brake-specific NOx over the FTP cycle was $4.75 \mathrm{~g} / \mathrm{bhp}-\mathrm{hr}$, while the 1992 DDC 
engine had 4.70g/bhp-hr NOx. With EGR, emissions of CO, NOx, HC, and TPM decreased $11.9 \%, 54.1 \%, 3.6 \%$, and $12.8 \%$, respectively, compared to the condition of no EGR. The BSFC and emission of $\mathrm{CO}_{2}$ increased $6.5 \%$ and $4.8 \%$, respectively, compared to no EGR. The addition of EGR significantly lowered NOx due to lower combustion temperatures, but had a fuel consumption penalty due to reduced fuel efficiency and lower power output.

For the steady state testing, only a single SET was evaluated for each additive. The percent changes in NOx from the base fuel for $12 \mathrm{ml} / \mathrm{gal} 2-\mathrm{EHN}, 15 \mathrm{ml} / \mathrm{gal} \mathrm{DTBP}$, and a repeat of the CP Cert fuel during SET testing are shown in Figure 4-4. The columns for modes 1 and 2 were removed due to engine control changing between tests, such as different EGR mass fractions (mode 2) and turning on and off fuel injection (idle). The high variability of the results for the 2004 Cummins was noticed by observing the repeat CP Cert SET test with changes up to 6\% in NOx observed. The data highlights the fact that modern (post Oct. 2002) on-road heavy-duty diesel engines with VGT and EGR (now aftertreatment) have become complex machines that are not necessarily repeatable. 


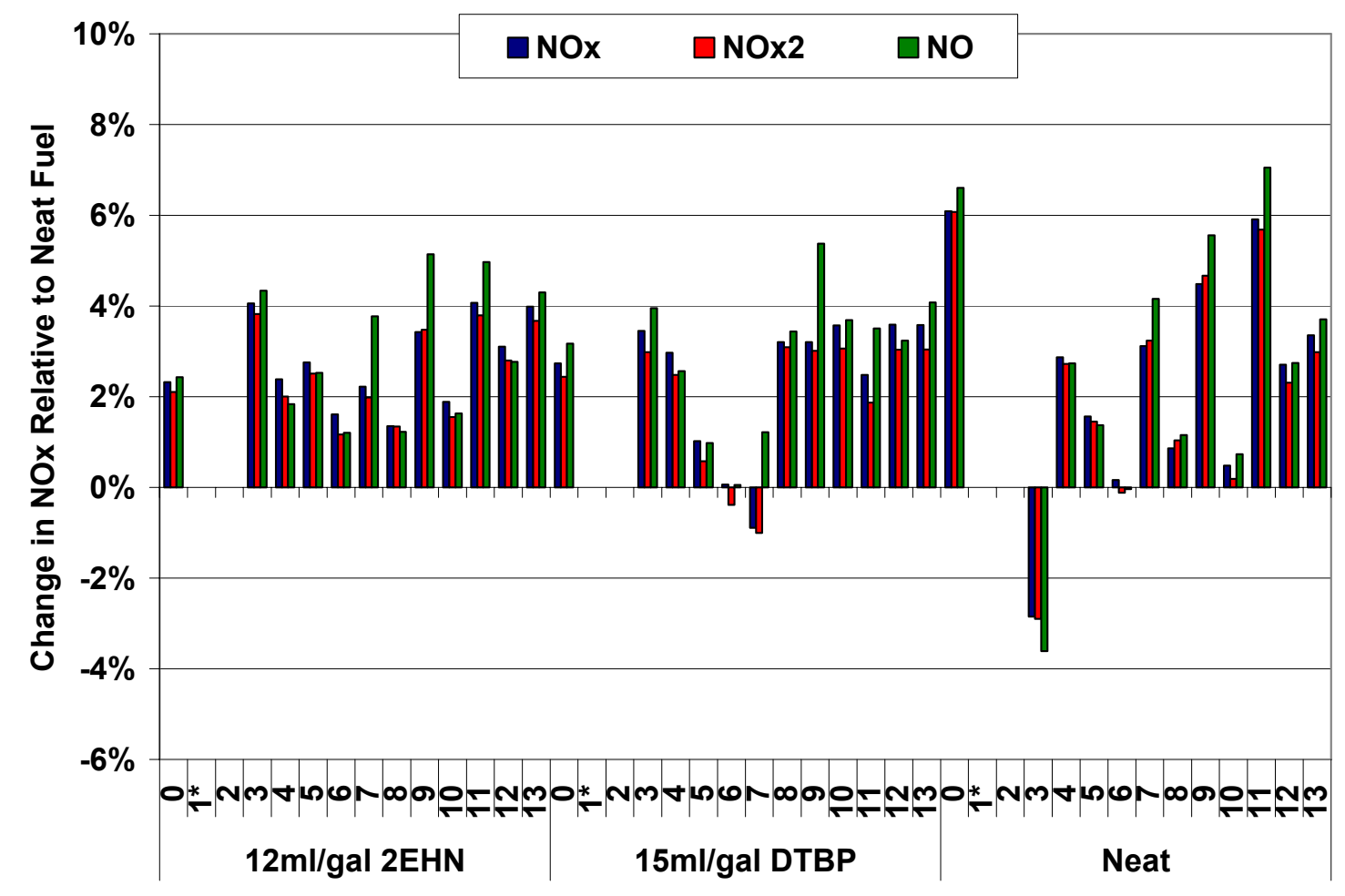

Figure 4-4 Change in the Brake Specific NOx for CP Cert Fuel with Two Cetane Improvers and a Repeat Neat Fuel Compared to the Neat Fuel for Steady State Modes on the 2004 Cummins ISM 370 (Idle and Mode 2 not shown)

To test the influence of EGR on the additive, the EGR valve was enabled and disabled for the neat and additized Grad Ref fuels (Figure 4-5). On average, the NOx increased approximately $1.7 \%$ with the EGR enabled, with most modes showing a NOx increase of up to $4 \%$. With the EGR disabled, NOx had no change, but some modes showed a slight NOx increase $(\sim 1 \%)$ and others a slight NOx decrease $(\sim 1 \%)$. With disabled EGR, the neat fuel produced emissions similar to the 1992 DDC Series 60 engine, but the addition of cetane improver had little influence on emissions. It should be noted that other research done at WVU on a 1999 Cummins engine also showed little response to cetane improvers [69]. The 1999 Cummins did not have EGR. 


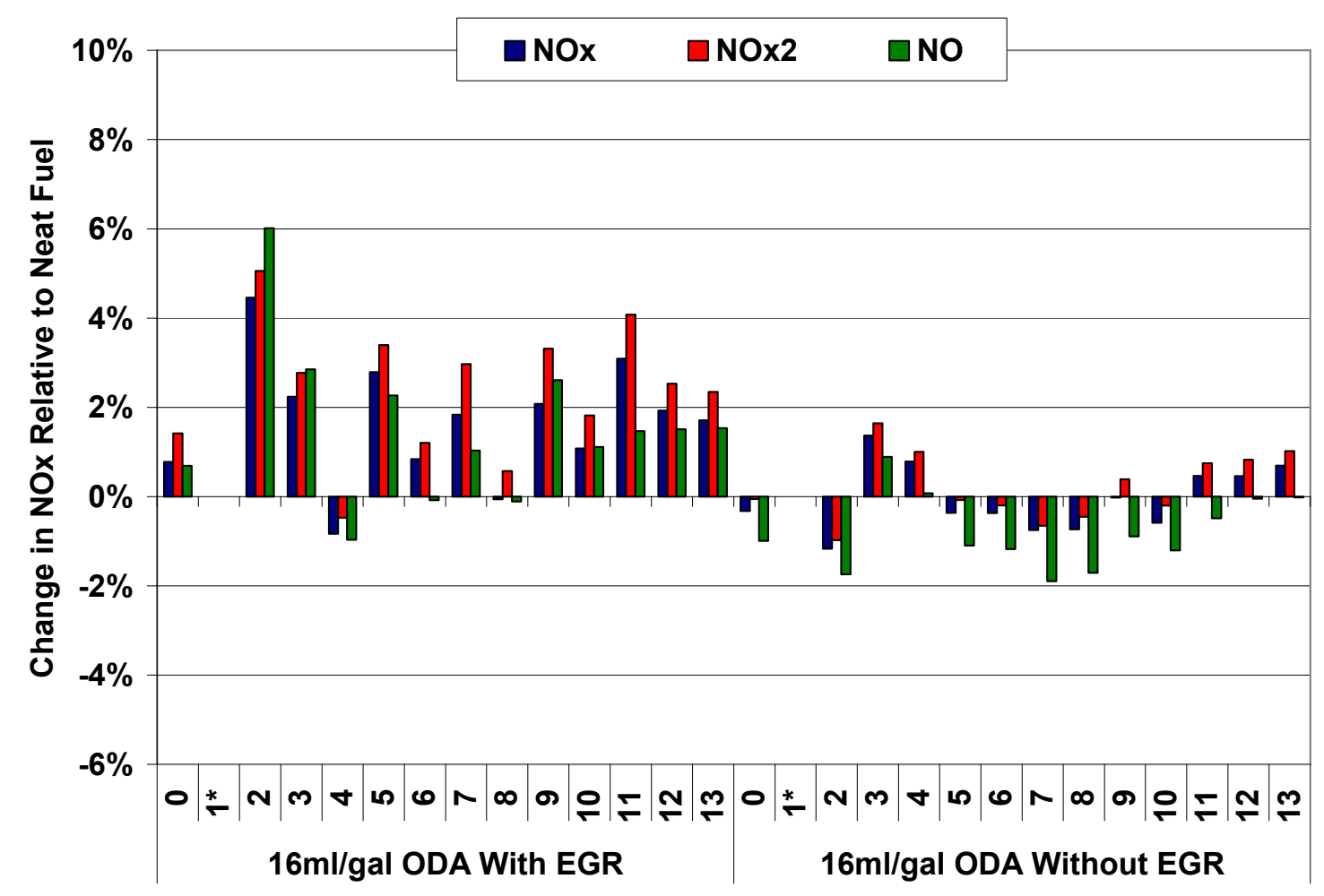

Figure 4-5 Change in the Brake Specific NOx for Grad Ref Fuel Additized with 16ml/gal ODA with Enabled and Disabled EGR Compared to the Neat Fuel with Enabled and Disabled EGR for Steady State Modes on the 2004 Cummins ISM 370

\subsubsection{Biodiesel}

Due to increases in NOx with biodiesel blends, cetane improvers have been investigated to offset the NOx penalty $[33,48]$. Therefore, the influence of additives on the biodiesel blends was investigated on the 1992 DDC engine and the 2004 Cummins engine. Using the Low Cetane fuel as the base fuel, B20 blends ( $80 \%$ neat and $20 \%$ biodiesel, by volume) of soy, tallow, and cottonseed were investigated on the 1992 DDC engine. The B20 blends of tallow and cottonseed had significantly different NOx (2.1-2.2\% decrease) than the neat fuel. The NOx decrease was not typical of biodiesel blends and was attributed to a cetane effect due to the use of low cetane fuel as the base fuel, since biodiesel has a high cetane number. All biodiesel blends had a significant reduction of the brake-specific emissions of CO (13.8-14.4\%), HC (23.6-34.2\%), and TPM (23.4-24\%). With the addition of cetane improvers, the B20 cottonseed fuel significantly reduced NOx (0.7-0.9\%). The additives had no influence on TPM. During steady state testing, the B20 blends showed similar trends as the additized fuels with an increase in NOx at high 
loads and a decrease in NOx at low loads (Figure 4-6). By adding 6ml/gal 2-EHN to the B20 cottonseed fuel, the NOx increase and decrease for each mode was greater in magnitude, relative to the unadditized B20 cottonseed fuel.

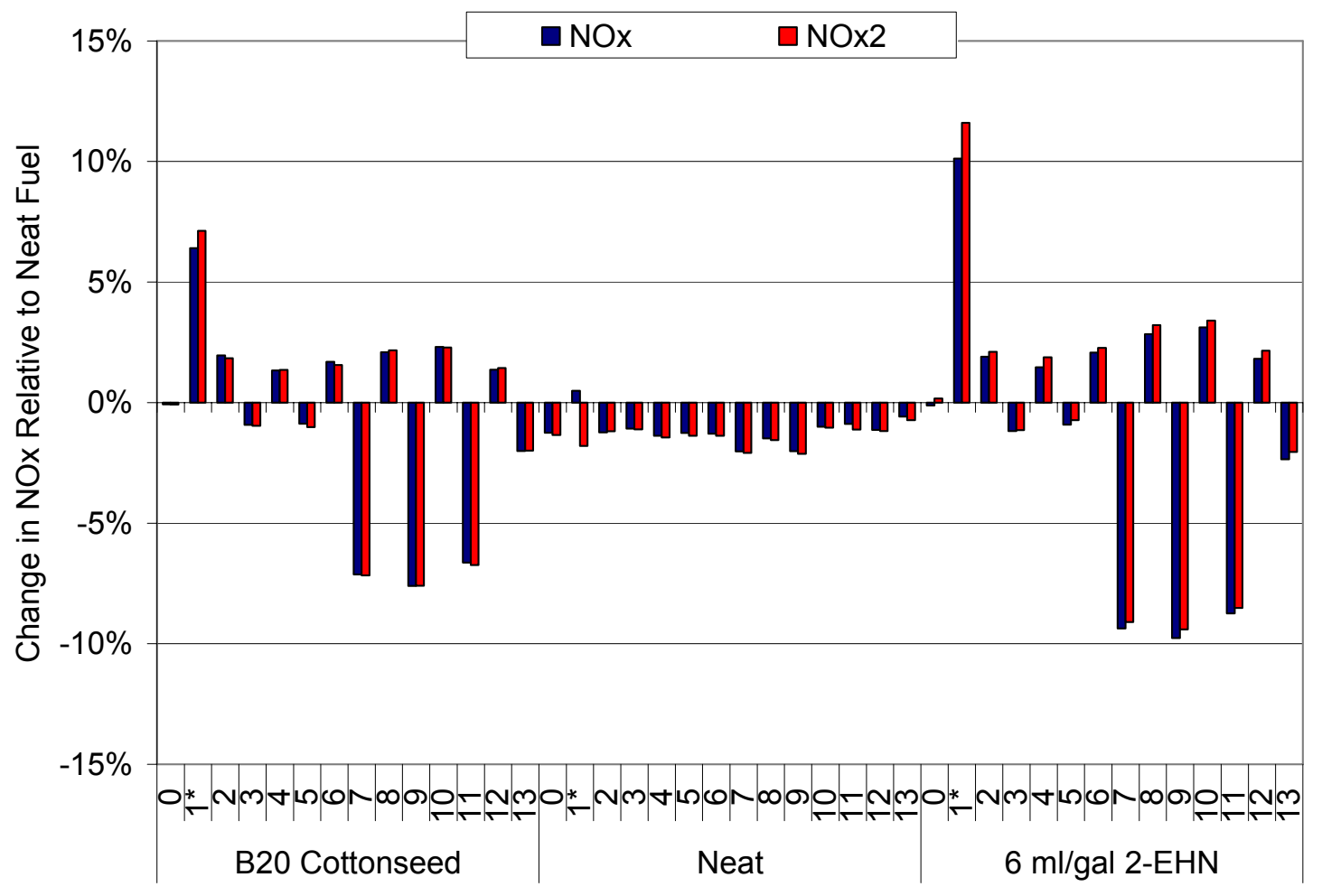

Figure 4-6 Change in the Brake Specific NOx for Low Cetane Fuel with B20 Cottonseed, Repeat Low Cetane Fuel, and Additized B20 Cottonseed Blend Compared to the Neat Fuel for Steady State Modes on the 1992 DDC Engine

With the 2004 Cummins ISM 370 engine results, Table 7-12in Appendix, the B20 blends significantly increased NOx (2.8-4.3\%) and decreased CO (9.8-10.7\%), HC (12-14.3\%), and TPM (23.2-34.7\%) compared to the neat fuel. Both the 1992 DDC and the 2004 Cummins had decreased CO, HC, and TPM, while NOx decreased for the 1992 DDC and increased for the 2004 Cummins. The base diesel fuel used on the B20 blends for the 2004 Cummins was the CP Cert fuel, which had a cetane number of 49.9. The Low Cetane fuel used as the base fuel on the 1992 DDC engine had a cetane number of 46.2. Another difference between the engines was their cetane response. The addition of cetane improvers had little effect on the 2004 Cummins engine. For the biodiesel blends, NOx showed an increase relative to the neat fuel during each mode, as seen in Figure 4-7. The addition of $10 \mathrm{ml} / \mathrm{gal}$ DTBP to the B20 soy showed no significant difference in NOx on the FTP cycle compared to the B20 Soy. The steady state 
results of $10 \mathrm{ml} / \mathrm{gal}$ DTBP showed levels of NOx increasing and decreasing relative to the B20 soy, but NOx was still greater than with the neat fuel. It is the author's belief that fuel differences are more difficult to discern with the 2004 Cummins due to more sophisticated engine control with the addition of EGR and higher-pressure injection than the 1992 DDC engine.

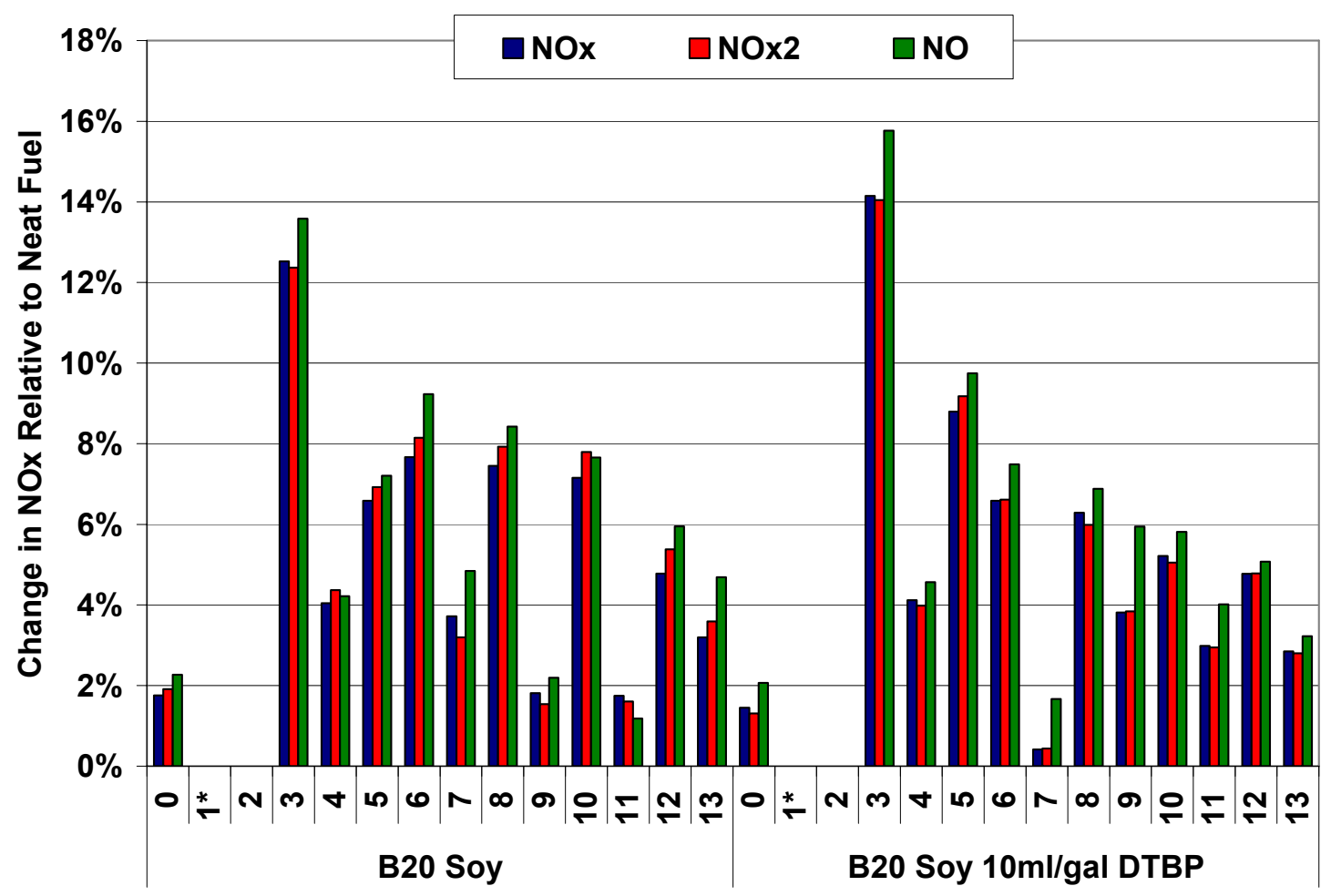

Figure 4-7 Change in the Brake Specific NOx for CP Cert Fuel with B20 Soy Blend and Additized B20 Soy Blend Compared to the Neat Fuel for Steady State Modes on the 2004 Cummins ISM 370

\subsection{Experimental Heat Release Rate}

The experimental heat release curve and heat release parameters were calculated and/or measured for each combustion cycle during steady state and transient testing. The heat release rate curve provided a macroscopic (or global) view of combustion in the diesel engines. An investigation into the global parameters, such as in-cylinder pressure and calculated in-cylinder gas temperature, helped to understand whether the changes in emissions with additives was a global (macroscopic) or local (microscopic) effect. 


\subsubsection{DDC Engine Heat Release}

From the experimental heat release rate curve during steady state testing, the ignition improver decreases ignition delay and the premix spike. Figure 4-8 and Figure 4-9 show a high and low load mode, respectively, with increasing levels of 2-EHN. At low load, the premix spike was more substantial than at high load, and referring back to the prior NOx emission plots, low load was where NOx reduction was noticed. At the high loads, either no NOx change or an increase in NOx was observed. The noticeable differences between neat fuel and additized fuels occurred earlier in the heat release rate with the later section of diffusion burning being close to identical. After 15 crank angle degrees from the SOC, the heat release rate curves were identical between additized and neat fuels for mode 9 and after 25 degrees for mode 8. The premix spike is related to the amount of fuel injected before the start of combustion. With cetane improvers causing an earlier SOC, the premix spike was reduced, although the premix fraction may be similar between the neat and additized fuel. The reduction of the premix fraction provided by cetane improvers (or natural cetane) has been demonstrated by other researchers [12-15].

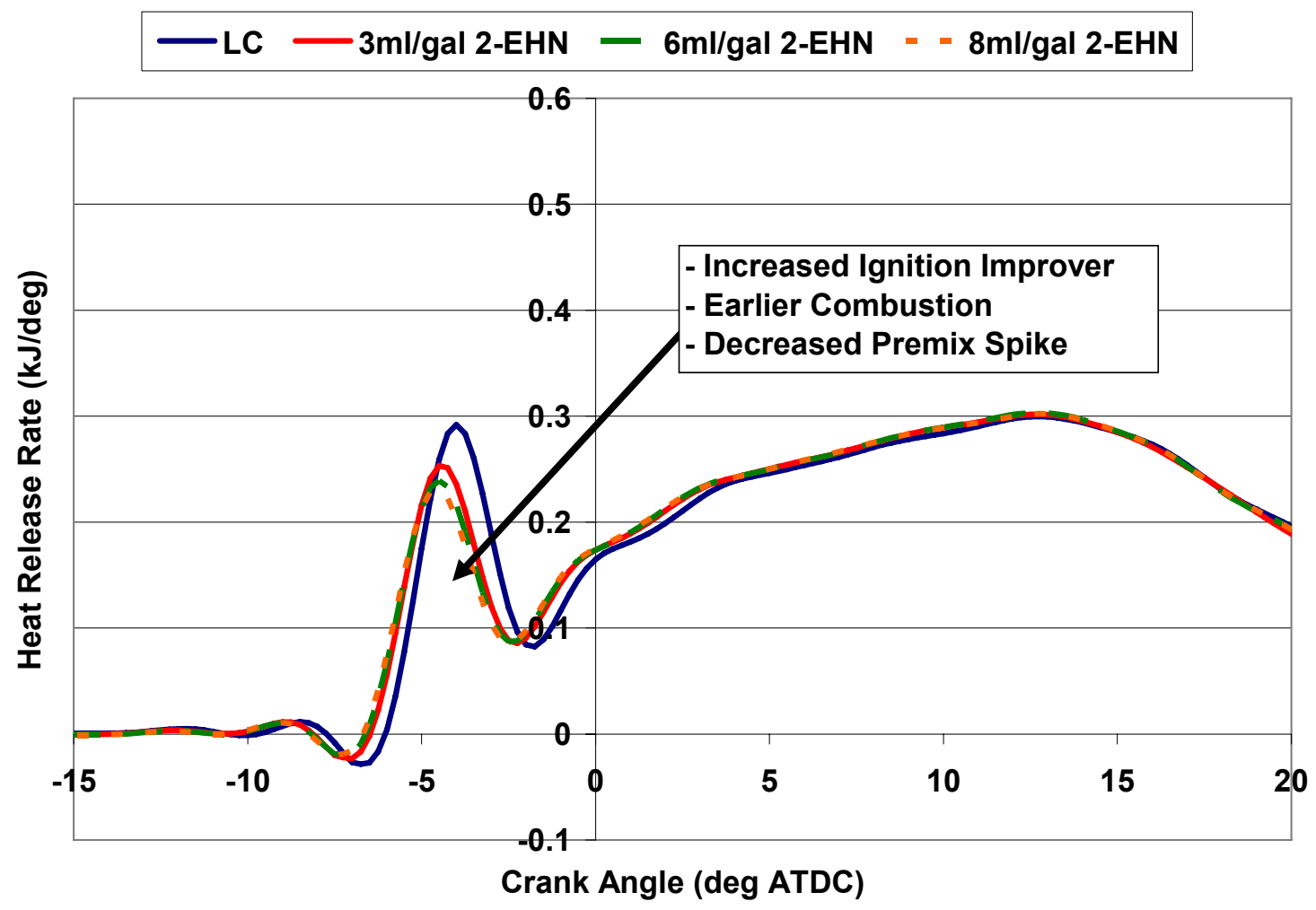

Figure 4-8 Heat Release for Mode 8 (100\% Load) with Varying Amounts of 2-EHN on the 1992 DDC Engine 




Figure 4-9 Heat Release for Mode 9 (25\% Load) with Varying Amounts of 2-EHN on the 1992 DDC Engine

Thermal NO formation is strongly effected by temperature and molar concentrations as shown in the Zeldovich mechanism, with NOx formation occurring above $\sim 1800 \mathrm{~K}$. Figure 4-10 and Figure 4-11 show the shifted temperature profiles of mode 8 and mode 9, respectively, on the 1992 DDC. The temperature profiles of the additized fuel were shifted to the start of combustion of the neat fuel. A noticeable decrease in temperature compared to the neat fuel was noticed on mode 9 (low load) from SOC to 21 degrees for the additized fuel. After 21 degrees ATDC, the additized fuels had a greater temperature than the neat fuel, but the cylinder was starting to cool down. At high load (mode 8) with the additized fuel, a lower temperature was again noticed early (from SOC to 21 degrees), which was followed by a higher temperature (after 21 degrees ATDC). It should be noted that the maximum temperature of the additized fuels are approximately the same in a given mode, although the rate of change of temperature was lower with increased 2-EHN, as seen in Figure 4-11. The higher temperature in Figure 4-10 and Figure 4-11 for the additized fuel during the later part of combustion is for the shifted temperature profiles. When observing the unshifted temperature profiles, the temperature between the additized and neat fuel differs less than $3 \mathrm{~K}$ during the later part of the expansion stroke. This 
small change in temperature between the additized fuel and neat fuel was observed in the exhaust (post-turbocharger) and the exhaust manifold, which had measured changes of less than $2 \mathrm{~K}$.

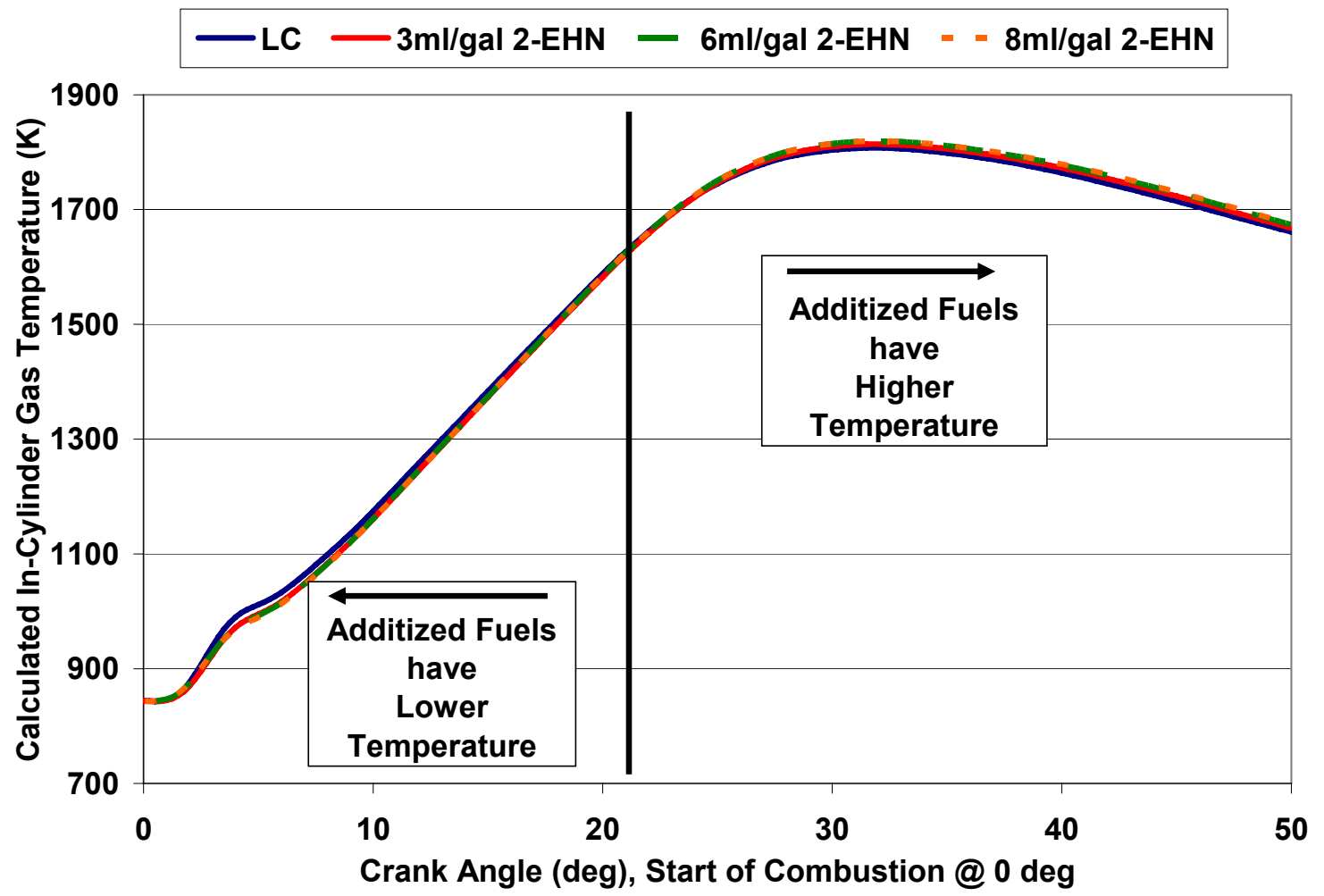

Figure 4-10 Shifted In-Cylinder Gas Temperature for Mode 8 (100\% Load) with Varying Amounts of 2-EHN on the 1992 DDC Engine 


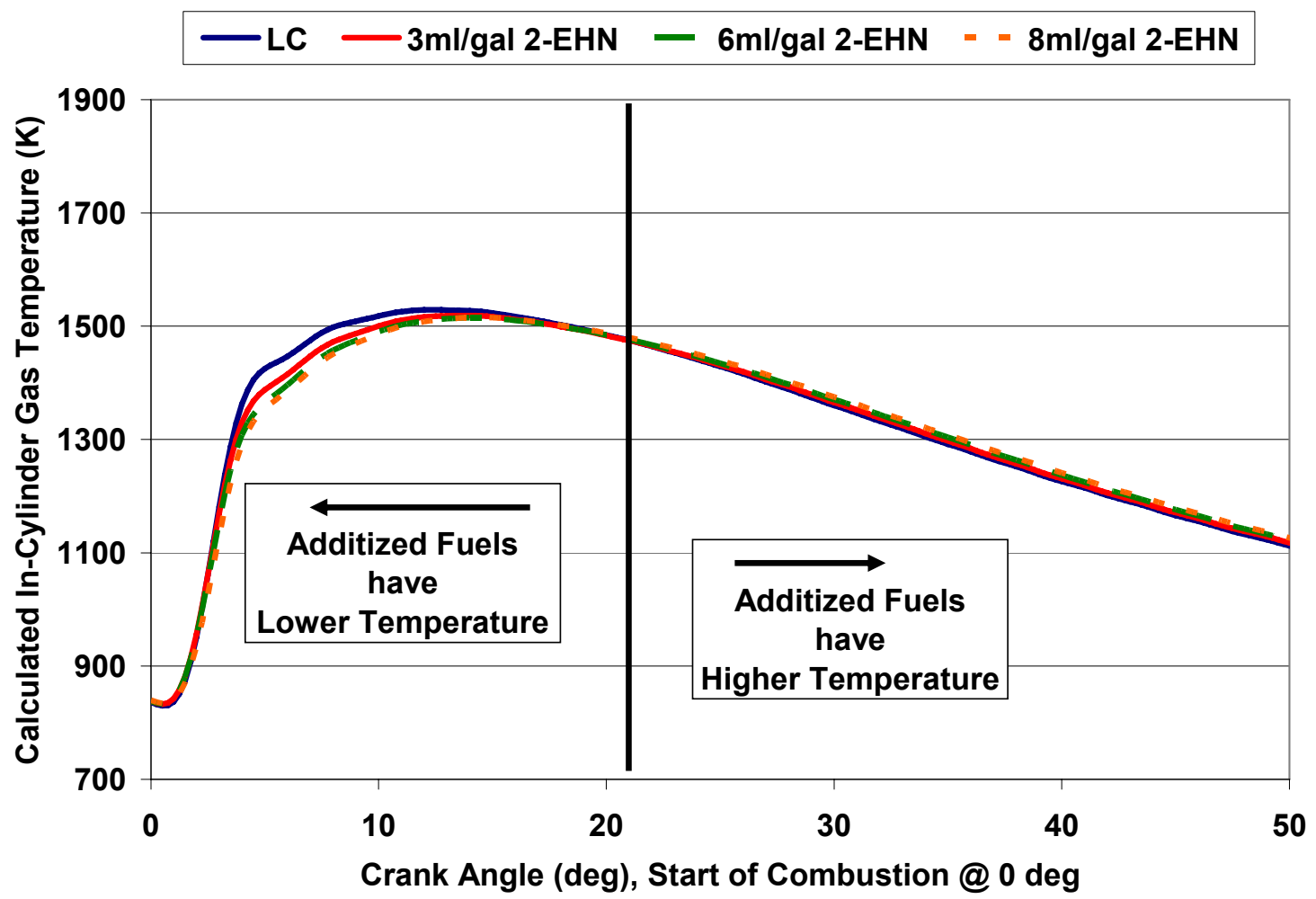

Figure 4-11 Shifted In-Cylinder Gas Temperature for Mode 9 (25\% Load) with Varying Amounts of 2-EHN on the 1992 DDC Engine

Although the temperature profiles shown are for the global temperature in the cylinder, the author believes insight can be made into the local flame temperature. The difficulty with the global temperature is determining when the local flame temperature was above $1800 \mathrm{~K}$, which is conducive for NOx formation. The local flame temperatures directly after the SOC should be greater than $1800 \mathrm{~K}$, since the adiabatic flame temperatures of diesel are typically $\sim 2500 \mathrm{~K}$. For high loads, more fuel was injected creating longer combustion durations and therefore local flame temperatures greater than $1800 \mathrm{~K}$ for longer periods than with low loads. Due to the increasing combustion duration, for increasing loads, the higher global temperature after 21 degrees (after SOC) with additized fuels becomes more important for NOx formation than the reduced global temperatures before 21 degrees (after SOC). This might explain the no change or increase in NOx for high loads and the decrease in NOx for low loads. The effect of the NOx emissions due to load from the global heat release rate and temperature was studied in detail with the use of a combustion model (Section 4.3). 


\subsubsection{Cummins ISM 370 Engine Heat Release}

In-cylinder pressure was obtained on a 2004 Cummins engine. Overall, in-cylinder pressure on the 2004 Cummins engine had higher variation than on the 1992 DDC engine due to the mounting location of the in-cylinder pressure transducer (pressure waves from passage) and/or combustion noise. The accuracy of the in-cylinder pressure data becomes an issue when observing the heat release curves. Figure 4-12 and Figure 4-13 show the heat release rate for mode 8 and mode 9 , respectively. At high loads (mode 8 and 10), no significant difference was noticed between the heat release rates of the additized and neat fuel. At low loads (modes 7, 9, and 11), there was a difference with increasing concentrations of the additive leading to shorter ignition delays, which caused lower premix spikes. Figure 4-12 and Figure 4-13 show a repeat of the neat diesel (CP), which occurred five days after the first test, and give an indication of the heat release rate repeatability for the 2004 Cummins engine. NOx is a strong function of temperature. Shown in Figure 4-14 is the shifted temperature for the neat and additized diesel fuels for mode 9. The additized and repeat neat fuel temperature curves were shifted to the SOC for the first neat fuel test. The early start of combustion for the additized fuel caused lower temperatures at the beginning of combustion, but after 17 degrees, the additized fuels had higher temperatures. The global cylinder temperature was much lower for the 2004 Cummins ISM 370 compared to the 1992 DDC Series 60 due a greater heat capacity, which slowed the combustion rate. The higher heat capacity was due to increased charge air (fresh air mass + EGR mass), since EGR increased the intake pressure with higher boost pressure. 




Figure 4-12 Heat Release for Mode 8 (100\% Load) with Varying Amounts of 2-EHN on the 2004 Cummins ISM 370 Engine



Figure 4-13 Heat Release for Mode 9 (25\% Load) with Varying Amounts of 2-EHN on the 2004 Cummins ISM 370 Engine 




Figure 4-14 Shifted In-Cylinder Gas Temperature for Mode 9 (25\% Load) with Varying Amounts of 2-EHN on the 2004 Cummins ISM 370 Engine

The 2004 Cummins ISM 370 utilized cooled EGR. By disabling the EGR valve, the EGR flow into the intake manifold was removed. When $16 \mathrm{ml} / \mathrm{gal}$ ODA was added to the Grad Ref fuel, the engine control changed between the EGR enabled and disabled conditions (Figure 4-15). For mode 8 (high load), fuel injection was delayed. For mode 9 (low load), fuel injection was advanced. The change in fuel injection timing limits the conclusions that may be drawn. For mode 8 , the heat release curve was virtually identical with and without the additive for cases of EGR enabled/disabled. For mode 9 with the additive, the ignition delay was reduced creating a smaller spike in the premix portion in the heat release. The premix spike was increased for mode 9 with the EGR disabled compared to the EGR enabled case. The higher premix spike may be from the higher oxygen concentration or from combustion occurring closer to TDC leading to the increased combustion rate. 


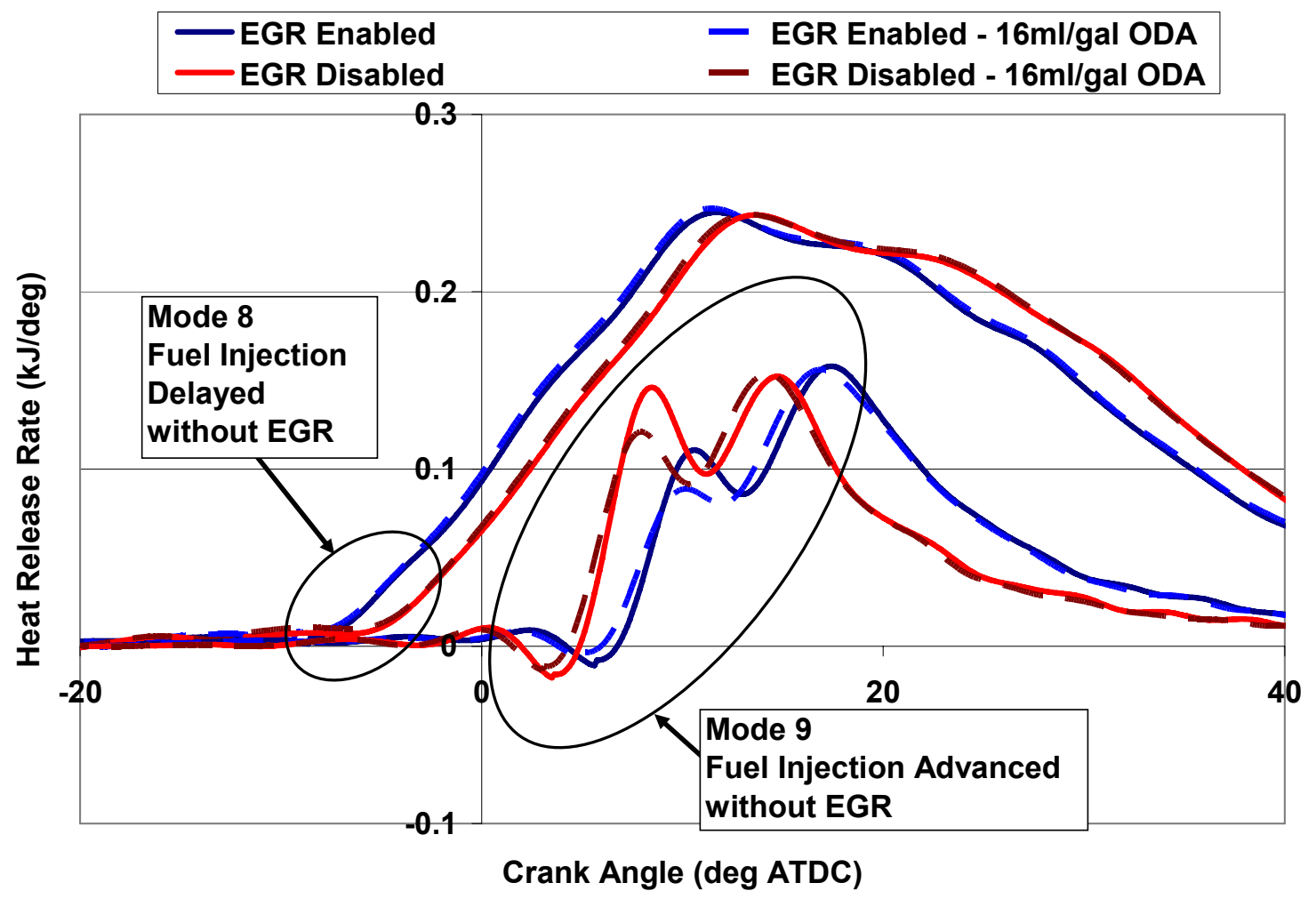

Figure 4-15 Heat Release for Mode 8 (100\% Load) and Mode 9 (25\% Load) on the 2004 Cummins ISM 370 Engine with and without EGR

The global in-cylinder temperature with EGR was higher compared to having the EGR disabled for modes 8 and 9 (Figure 4-16 and Figure 4-17). Although with the EGR enabled, local temperatures decreased creating a reduction in NOx, the global temperature was greater because of the high temperatures in the intake manifold. The higher peak gas temperature with EGR was not the case for all modes, since it was dependent on the intake conditions. High EGR flow created higher intake manifold pressure, which increased the intake flow, but high EGR also created higher intake manifold temperatures decreasing mass flow. The cylinder peak gas temperature was greater with the EGR enabled for modes 8 and 9, however, NOx was half the amount. The global heat release characteristics are therefore limited and should only be used simultaneously with the knowledge of other engine conditions such as intake conditions and local chemical effects. The EGR had a significant impact on the emissions, although the heat release curve may have behaved similarly without EGR. 


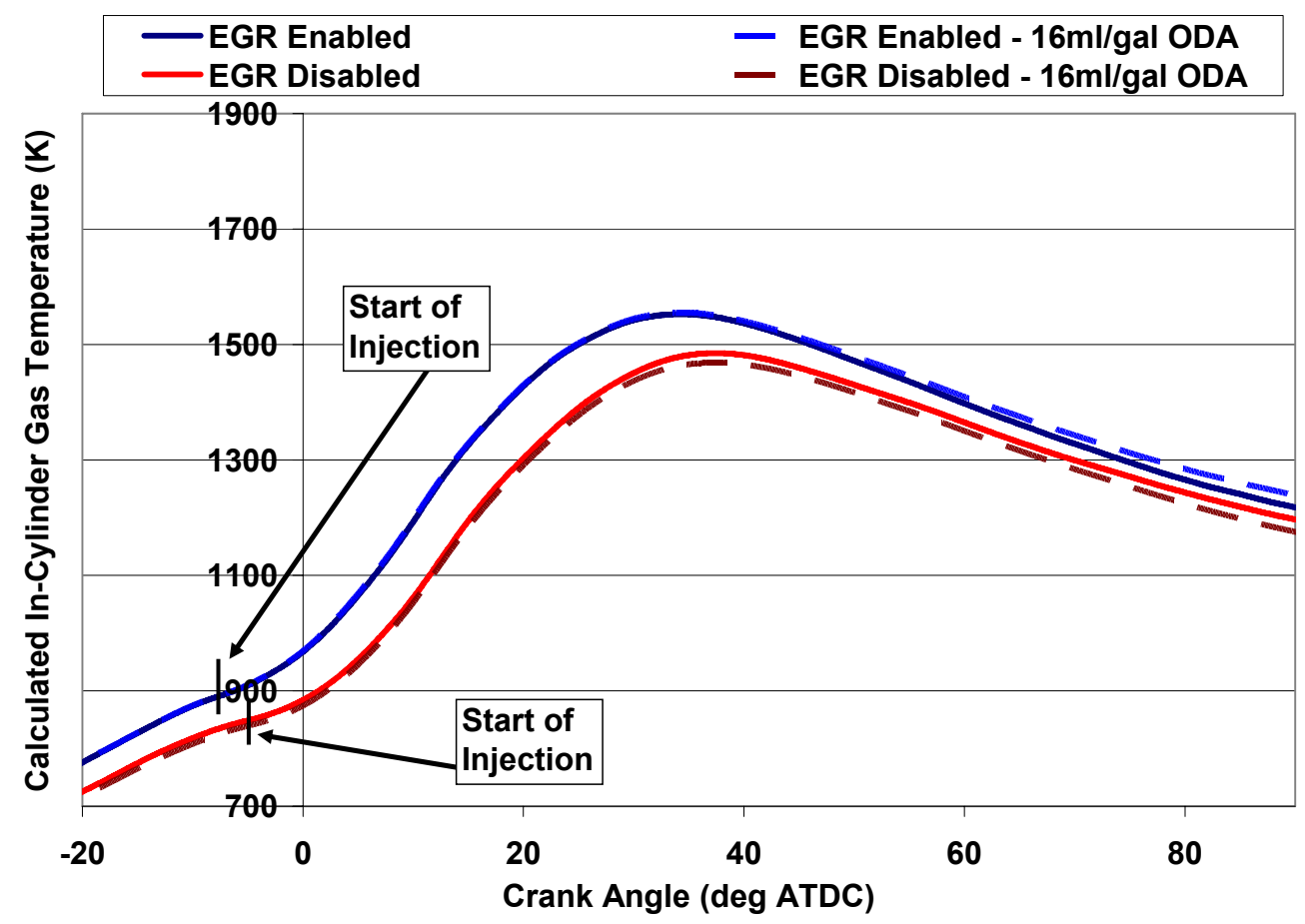

Figure 4-16 Calculated In-cylinder Gas Temperature for Mode 8 (100\% Load) on the 2004 Cummins ISM 370 Engine with and without EGR

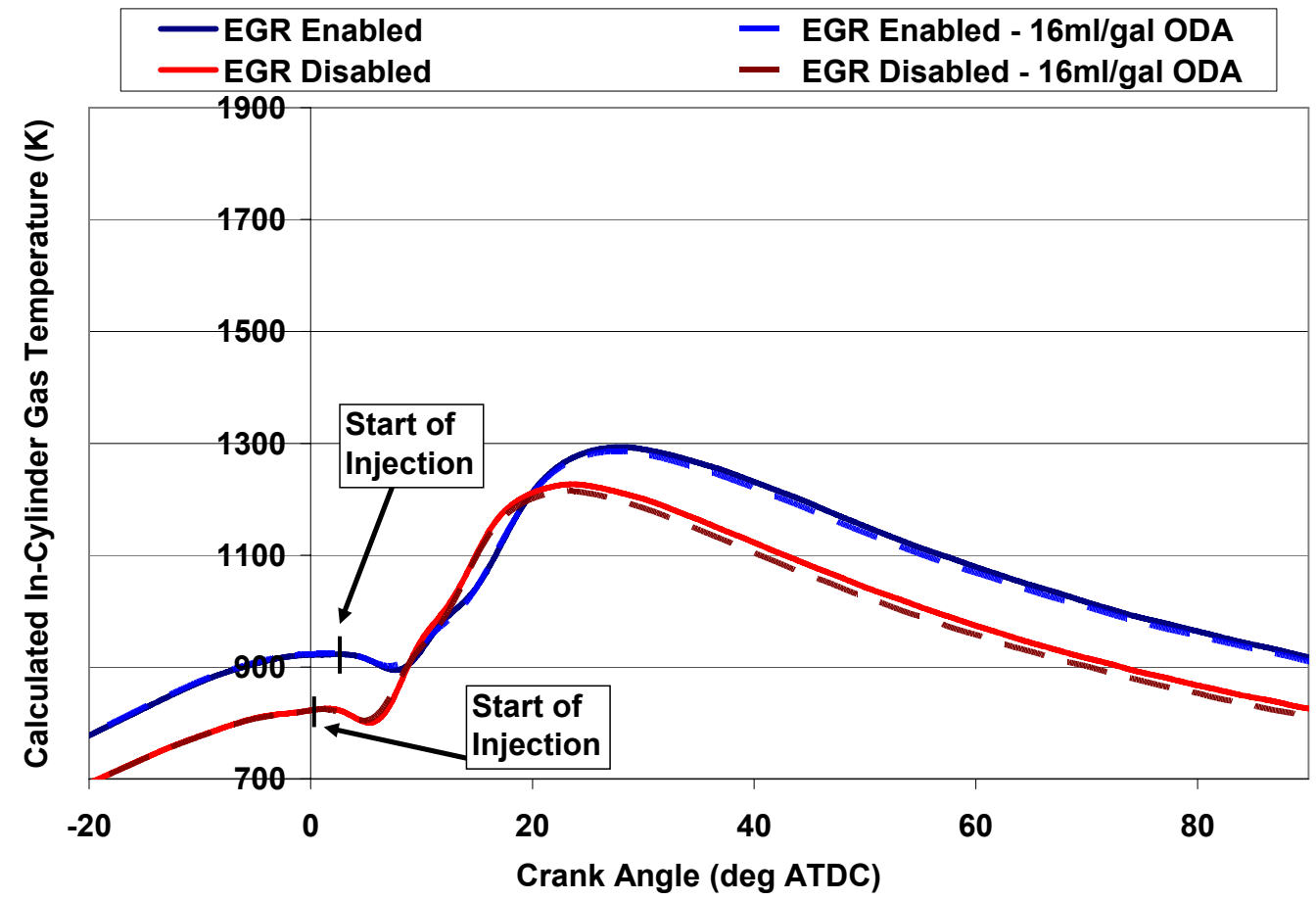

Figure 4-17 Calculated In-cylinder Gas Temperature for Mode 9 (25\% Load) on the 2004 Cummins ISM 370 Engine with and without EGR 


\subsubsection{Comparison of Heat Release Between Engines}

The two engines showed very different responses to the fuel additives in respect to the heat release curve and NOx emissions. The 2004 Cummins engine had greater cylinder temperatures at the start of injection (Figure 4-18 and Figure 4-19), which may have led to shorter ignition delay $[32,91]$ due to improved evaporation, atomization, and higher reaction rates. A lower combustion rate was noted on the 2004 Cummins with the heat release curve and cylinder gas temperature increasing less rapidly than on the 1992 DDC engine. The peak gas temperature was lower with 2004 Cummins due to the EGR and increased charge mass in the cylinder. The increased charge mass and EGR created a high thermal capacity, which absorbed more heat, reducing the cylinder gas temperature. Figure 4-18 and Figure 4-19 shows the cylinder gas temperatures for Modes 8 and 9, respectively, of both engines. A higher temperature of approximately 50K was noted at the SOC for the 2004 Cummins engine. However, its peak gas temperature was less than the 1992 DDC engine's due to the increased charge mass.



Figure 4-18 Comparison of Calculated In-cylinder Gas Temperature for Mode 8 (100\% Load) on the 1992 DDC and 2004 Cummins ISM 370 Engines on CP Cert Fuel 


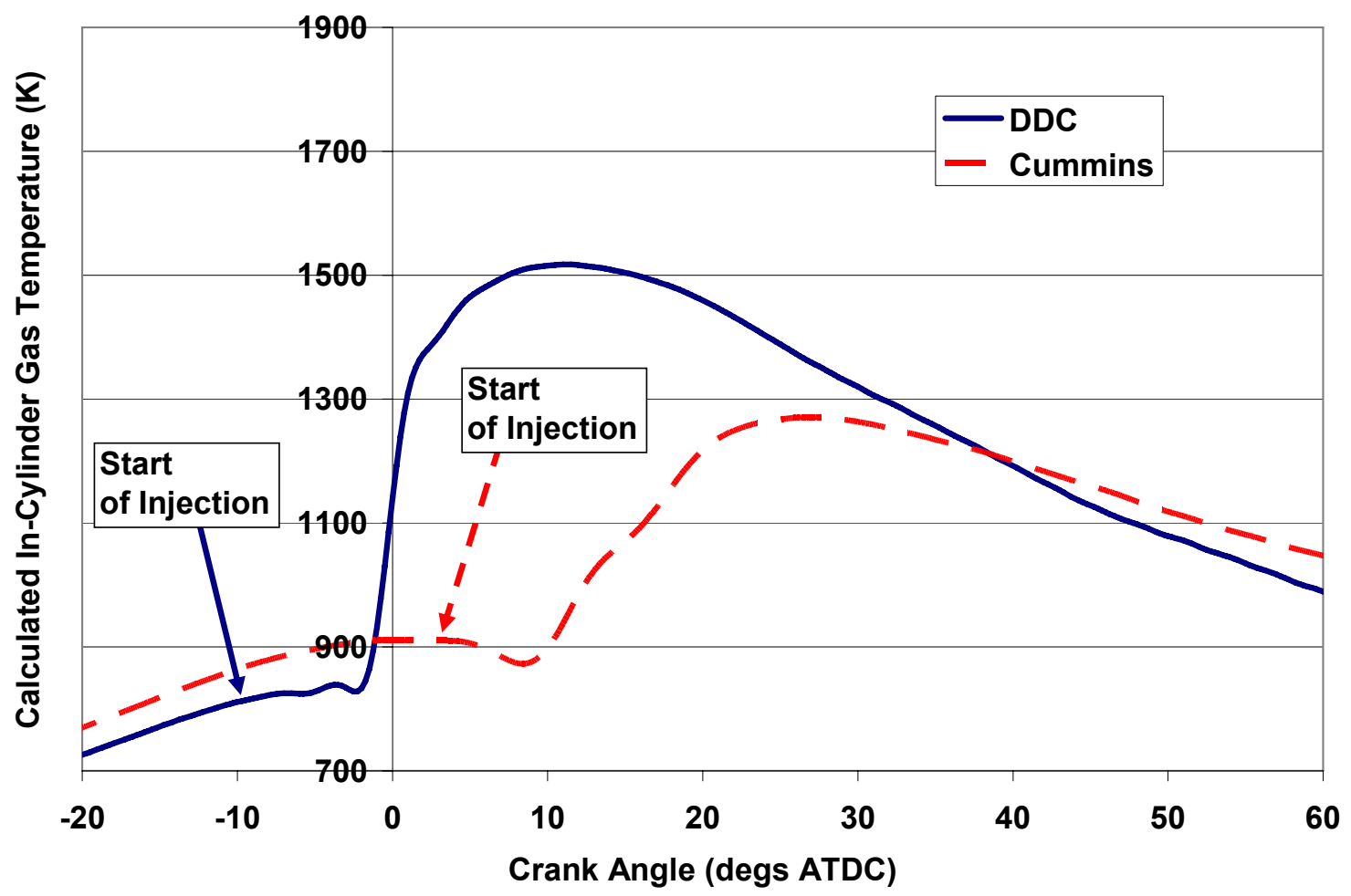

Figure 4-19 Comparison of Calculated In-cylinder Gas Temperature for Mode 9 (25\% Load) on the 1992 DDC and 2004 Cummins ISM 370 Engines on CP Cert Fuel

Engines have different designs between engine manufacturers and models. The 1992 DDC Series 60 engine and the 2004 Cummins engine had a different bore, stroke, connection rod length, displacement, and compression ratio (CR). All of these parameters influenced the pressure, temperature, and heat release profile. The $\mathrm{CR}$ is the ratio of cylinder volume at BDC to the cylinder volume at TDC. With higher CRs, a greater pressure is obtained at TDC. The 1992 DDC engine had a CR of 15, while the 2004 Cummins was 16.1. Using the polytropic relationship, $\mathrm{P}=\mathrm{Pivc}^{*}(\mathrm{~V} / \mathrm{Vivc})^{\mathrm{n}}$, with assumed quantities of MAP (pressure at inlet valve closing), volume at inlet valve closing, and polytropic constant (1.4), a pressure curve for each engine was developed when combustion would not be occurring (Figure 4-20). A difference of $\sim 1 \mathrm{MPa}$ at TDC between the engines was calculated. The 1991 DDC engine, shown in Figure 4-20, was used in another study at WVU and had very little (2\%), if any, NOx reduction with the additives used here [69]. The $1991 \mathrm{DDC}$ had a 11.1L displacement compared to the 12.7L of the 1992 DDC. The 1991 DDC engine had an increase of $\sim 1.5 \mathrm{MPa}$ over the 1992 DDC engine at TDC due to the high CR of 16.5. It should be noted that the MAP of the 2004 Cummins engine 
during engine testing was typically 1.1-1.4 times greater than the 1992 DDC engine's, which created even larger differences in the cylinder pressure at TDC. With the higher CR for the 2004 Cummins engine, the motoring temperature was $\sim 25 \mathrm{~K}$ higher than for the 1992 DDC engine (Figure 4-21) at TDC for the assumed conditions. The MAT was typically $\sim 25$ to 50 Kelvin higher with the 2004 Cummins engine than with the 1992 DDC engine due to high temperature of the EGR flow. Note that the EGR cooler does not reduce the temperature down to that of the fresh intake air before it is introduced into the intake manifold.



Figure 4-20 Calculated In-cylinder Pressure Curve without Combustion with $M A P=302 \mathrm{kPa}$ and MAT=300K on the 1992 DDC, 2004 Cummins ISM 370, and 1991 DDC Engines 


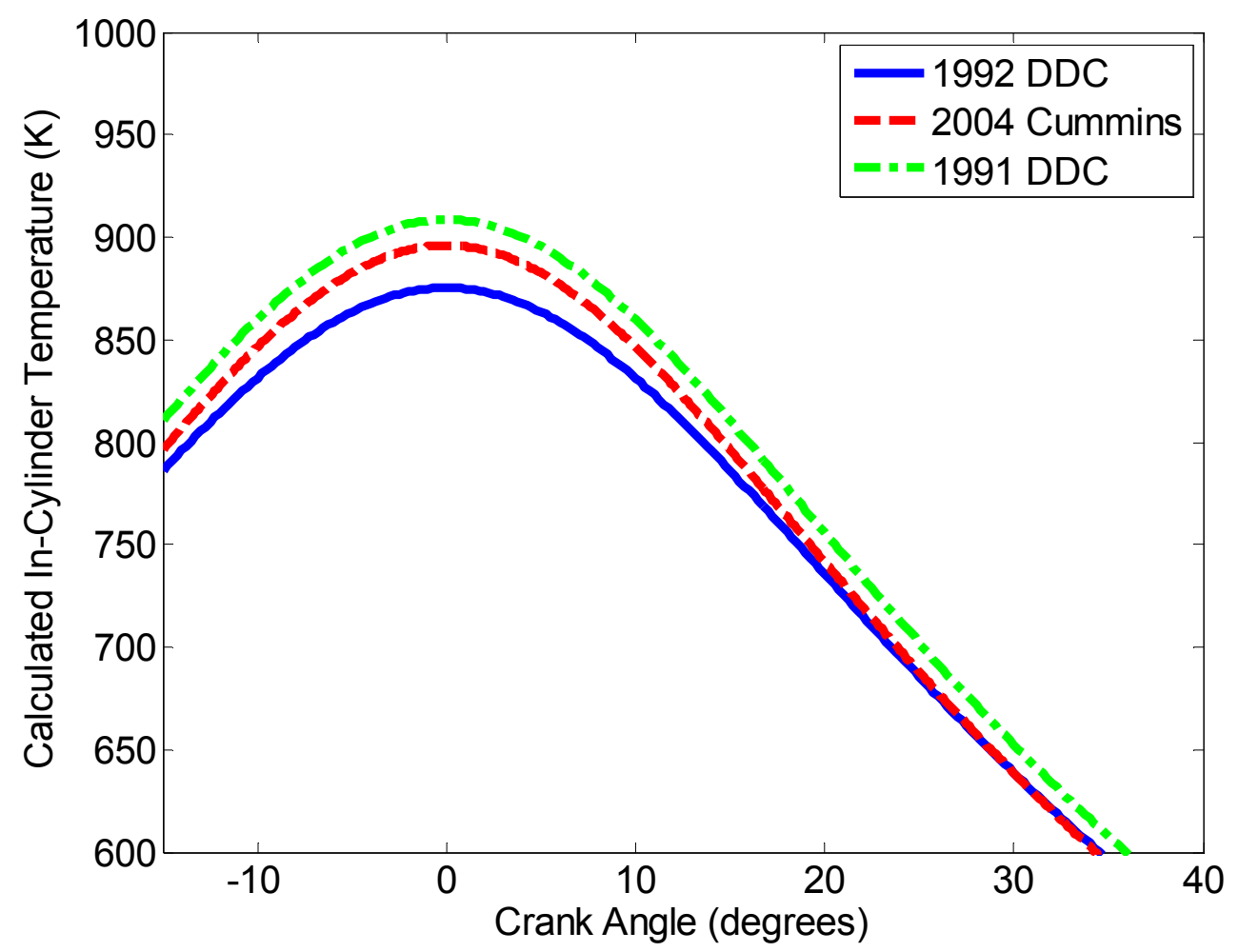

Figure 4-21 In-cylinder Temperature Curve without Combustion with $\mathrm{MAP}=302 \mathrm{kPa}$ and $\mathrm{MAT}=300 \mathrm{~K}$ on the 1992 DDC, 2004 Cummins ISM 370, and 1991 DDC Engines

The higher temperatures and pressures in the 2004 Cummins engine due to the CR, MAP, and MAT should create different combustion characteristics, such as a shorter ignition delay [32, 91] and smaller premix spike [92, 93]. It is plausible that since the 2004 Cummins engine implements higher injection pressures, mixing was enhanced, and shorter ignition delays were created [91]. Studies with high boost pressures create reduced ignition delays, and the heat release profile approaches the injection profile $[92,93]$.

\subsubsection{Derived Heat Release Parameters}

To improve understanding of the NOx and PM formation from the heat release curve, the correlation between modal NOx and the combustion measured or calculated parameters from the steady state testing were examined. Table 7-4 in the Appendix shows each combustion parameter and the correlation coefficient for NOx and CO on the 1992 DDC engine. The CO measurement was used as a surrogate for PM measurement [94]. The correlation coefficient is a measure of the linear relationship between two variables and ranges from -1 to 1, with "-1" being 
a "perfect" negative linear relation, and " +1 " being a "perfect" positive linear relationship, and zero having no linear relationship. Multiple units were used for NOx and $\mathrm{CO}$, since studies vary on the method used to represent the emissions. The brake-specific emissions ( $\mathrm{g} / \mathrm{bhp}-\mathrm{hr})$, mass emission rate (g/s), mass emission normalized by the fuel injected (EI, $g / g$ of fuel injected), and the exhaust concentration (ppmv) have been used in combustion correlation studies. The modal exhaust concentration was used to understand the NOx formation. Using the mass based NOx instead of the exhaust concentration for correlations with the heat release parameters showed correlations related to engine load and intake flow such as cumulative heat released and/or cylinder pressure at bottom dead center. The mass flow rate of NOx (from the dilution tunnel) was divided by the density of $\mathrm{NO}_{2}$ ( $\mathrm{NOx}$ assumed to be all $\mathrm{NO}_{2}$ as in the Code of Federal Regulations) and the exhaust flow rate (assumed to be the intake flow) to obtain an approximate exhaust NOx concentration. This was likewise done for CO. The mass flow rate of NOx from the dilution tunnel had a humidity correction factor applied. Therefore, the NOx in the dilution tunnel and the calculated exhaust NOx concentration were normalized to an intake humidity of $75 \mathrm{gr} / \mathrm{lb}$.

The correlations based on the exhaust concentrations of NOx are relatively low (absolute value $\leq$ 0.72) compared to the correlations between the heat release parameters and the brake-specific NOx, mass flow rate of NOx, and EINOx (absolute value $\leq 1.0$ ). Some of these correlations have been shown in other research, such as peak pressure, maximum heat release rate, peak gas temperature, and location of peak gas temperature [48]. To understand if any heat release parameters showed correlations with the change in NOx using additives, the change in the emissions with and without additives were correlated with the change in heat release parameters with and without additives. Table 7-5 in the Appendix provides the correlation coefficients for Low Cetane with $8 \mathrm{ml} / \mathrm{gal}$ 2-EHN. Lower correlation coefficients with the change in emissions compared to absolute emissions were observed overall. The highest correlations for NOx were with peak pressure (0.92-0.97), location of $90 \%$ MFB ( -0.81 to -0.84$)$, location of peak gas temperature (-0.83 to -0.86$)$, premix fraction (0.94-0.99), pressure at the SOC (-0.82 to -0.92$)$, and the premix heat released $(0.88-0.92)$. Note that the combustion characteristics were probably correlated with one another but these inter-correlations were not studied here. The change in ignition delay showed a correlation of $0.65-0.80$, while the change in start of combustion had a 
correlation of $0.76-0.85$. The ignition delay is the time difference between the start of injection and the start of combustion. Previous researchers have stated that the ignition delay changes the premix fraction [81], which may change NOx [54].

The change in peak pressure and change in exhaust NOx concentration are shown in Figure 4-22. A high correlation was noticed, with increased pressure causing a NOx increase and reduced pressure causing a NOx reduction. Higher pressure typically means higher temperature, which may then create a higher NOx formation rate. For Figure 4-22 through Figure 4-26, the error bars shown are an approximate one standard deviation. The error bars for the heat release parameters are based on 11 repeat tests with the Guttman fuel. The error bars for the exhaust constituents are based on four repeat tests with the Guttman fuel. For more details on calculating the approximate standard deviation, see Section 3.7, which showed how the approximate range was calculated. 


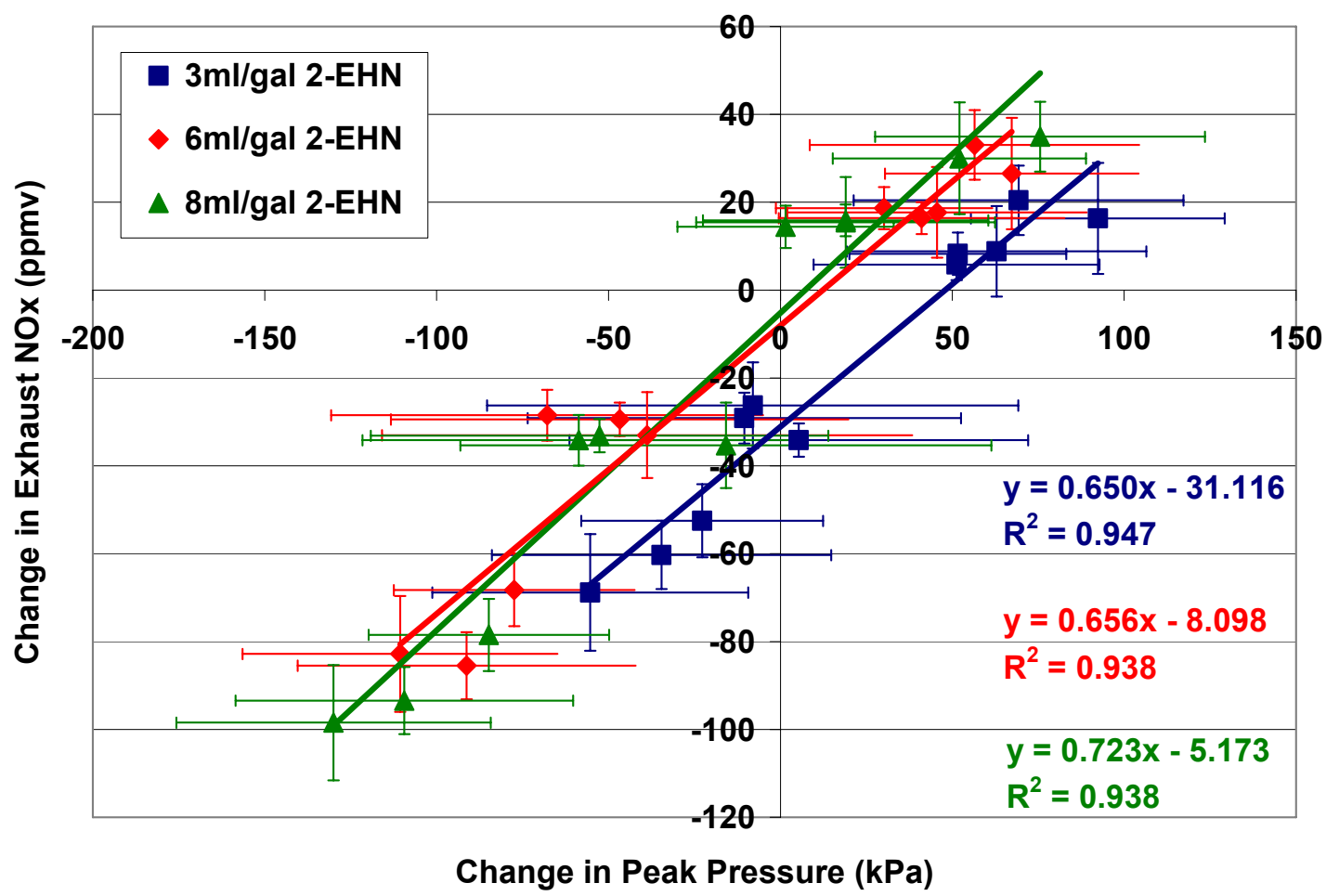

Figure 4-22 Change in NOx with Additized Fuels Compared to a Change in the Peak Pressure for the Steady State Modes on the 1992 DDC (Error Bars show An Approximate One Standard Deviation Based on Repeat Tests with the Guttman Fuel)

Since higher temperatures create more thermal NOx, the change in peak gas temperature and change in exhaust NOx concentration is shown in Figure 4-23. A lower $\mathrm{R}^{2}$ was noticed with this correlation, although the general trend shows an increase in NOx with increased peak gas temperatures and a decrease in NOx with a decrease in the peak gas temperature. The peak gas temperature only provides a single characteristic and not the length of combustion time that occurred at high temperatures. The length of time at high temperatures with and without additives may play a greater role than the peak gas temperature. The peak gas temperature used in Figure 4-23 was from the calculated cylinder temperature, which gave an indication of NOx production, but NOx formation depends on the local flame temperature and the residence time of combustion zones at high local temperatures. The combustion model in Section 4.3 addressed the NOx formation dependence on local temperature and the residence time of combustion zones at high local temperatures. 


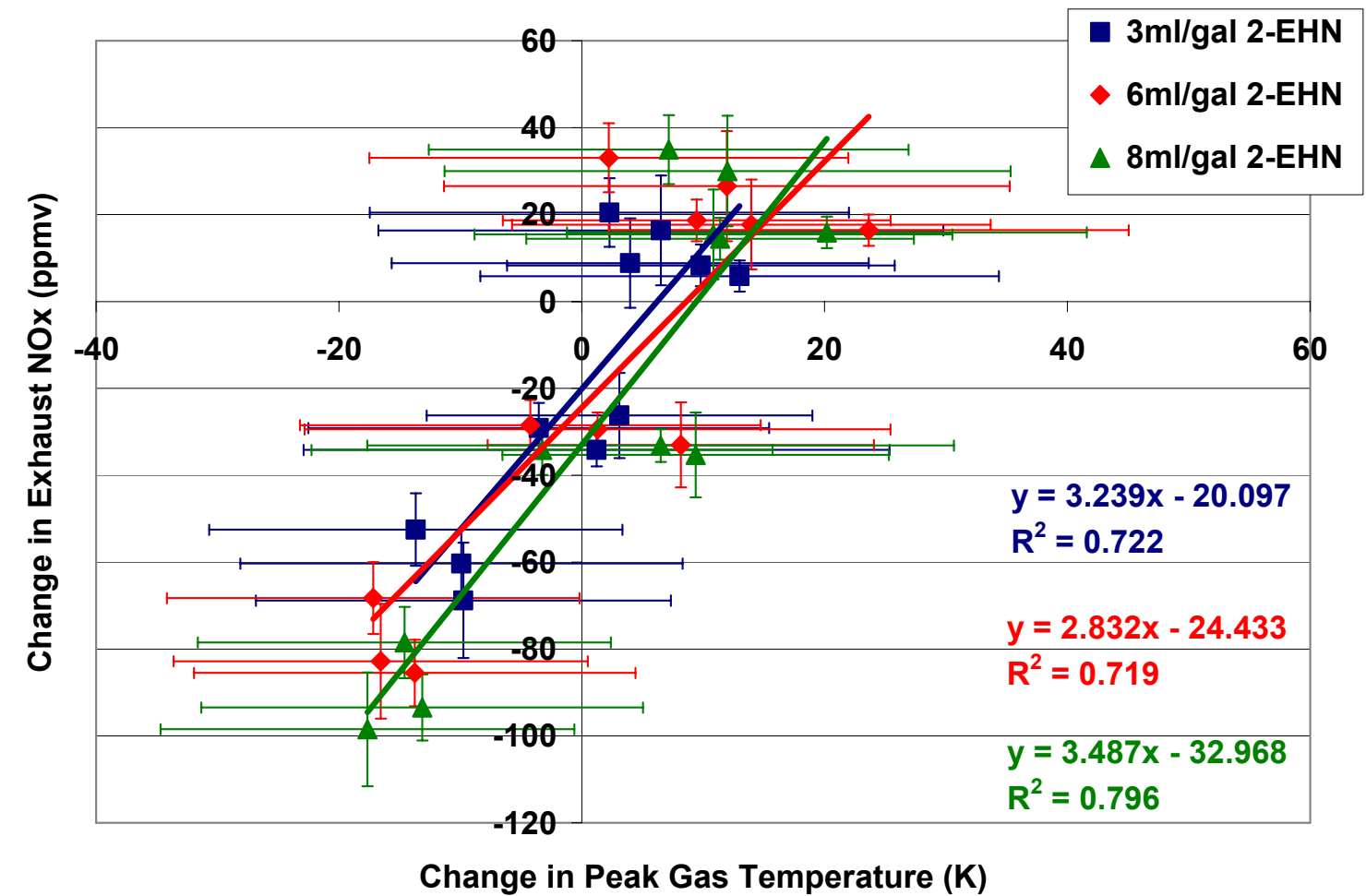

Figure 4-23 Change in NOx with Additized Fuels Compared to a Change in the Peak Gas Temperature for the Steady State Modes on the 1992 DDC (Error Bars show An Approximate One Standard Deviation Based on Repeat Tests with the Guttman Fuel)

A high correlation was observed between the change in premix fraction and the change in the exhaust NOx concentration (Figure 4-24). The premix fraction decreased for all modes, although a NOx increase was observed at high loads. This leads the author to believe that the change in premix fraction does not cause the change in NOx, but leads to a change in other parameters such as temperature and pressure. 


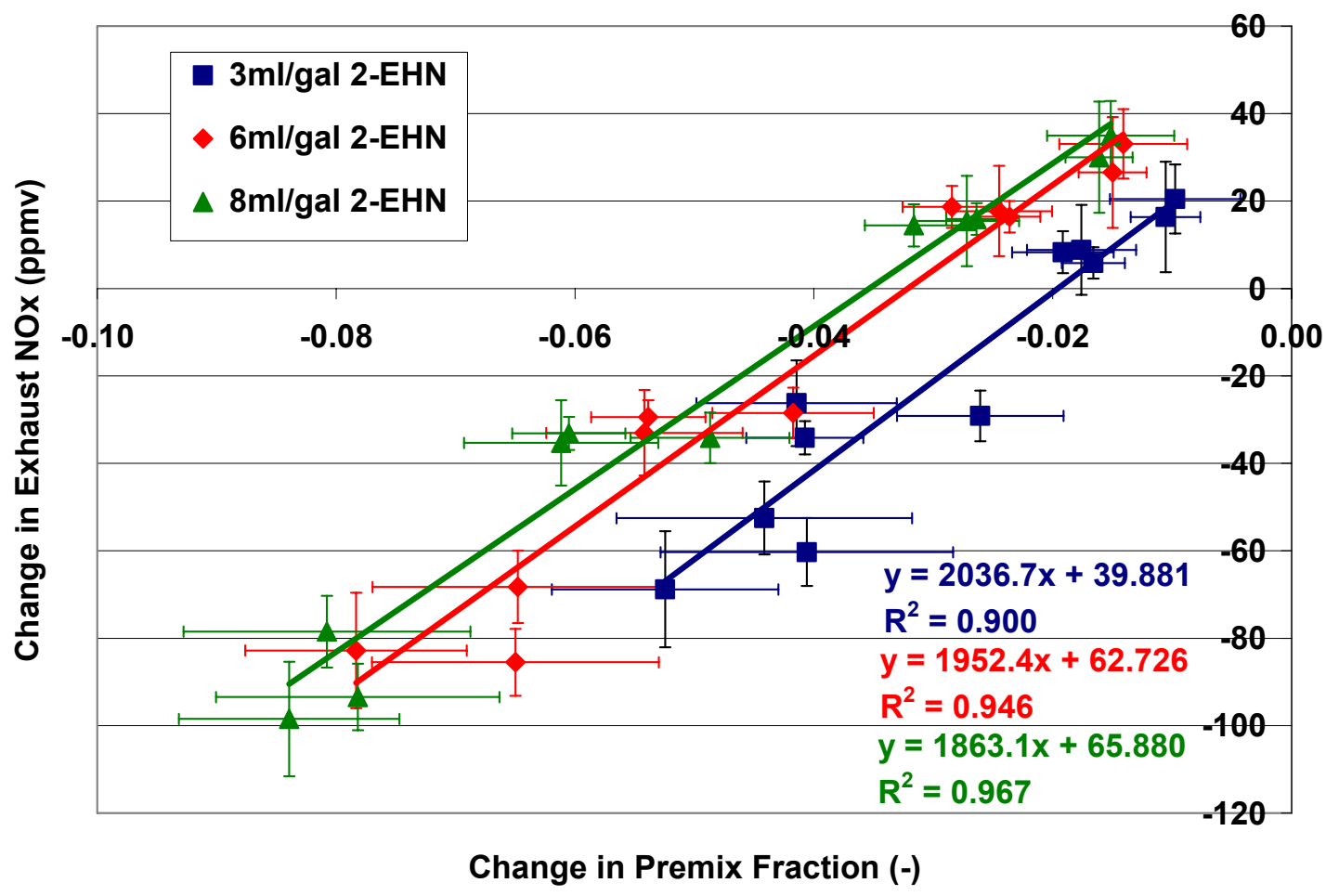

Figure 4-24 Change in NOx with Additized Fuels Compared to a Change in the Premix Fraction for the Steady State Modes on the 1992 DDC (Error Bars show An Approximate One Standard Deviation Based on Repeat Tests with the Guttman Fuel)

A decrease in ignition delay caused by the additives would change the pressure at which combustion occurred. If combustion occurred on the compression stroke, a decrease in the ignition delay would make the pressure at the SOC decrease. On the expansion stroke, a decrease in ignition delay would cause an increase in pressure at SOC. The greater NOx reduction was observed with lower SOC pressure changes, which has combustion occurring near TDC (Figure 4-25). The pressure at SOC typically decreased, with greater decreases having a NOx increase. At high loads compared to low loads, the same percent reduction in pressure at SOC (with and without additive) would have higher-pressure changes due to higher boost creating greater compression pressure. 


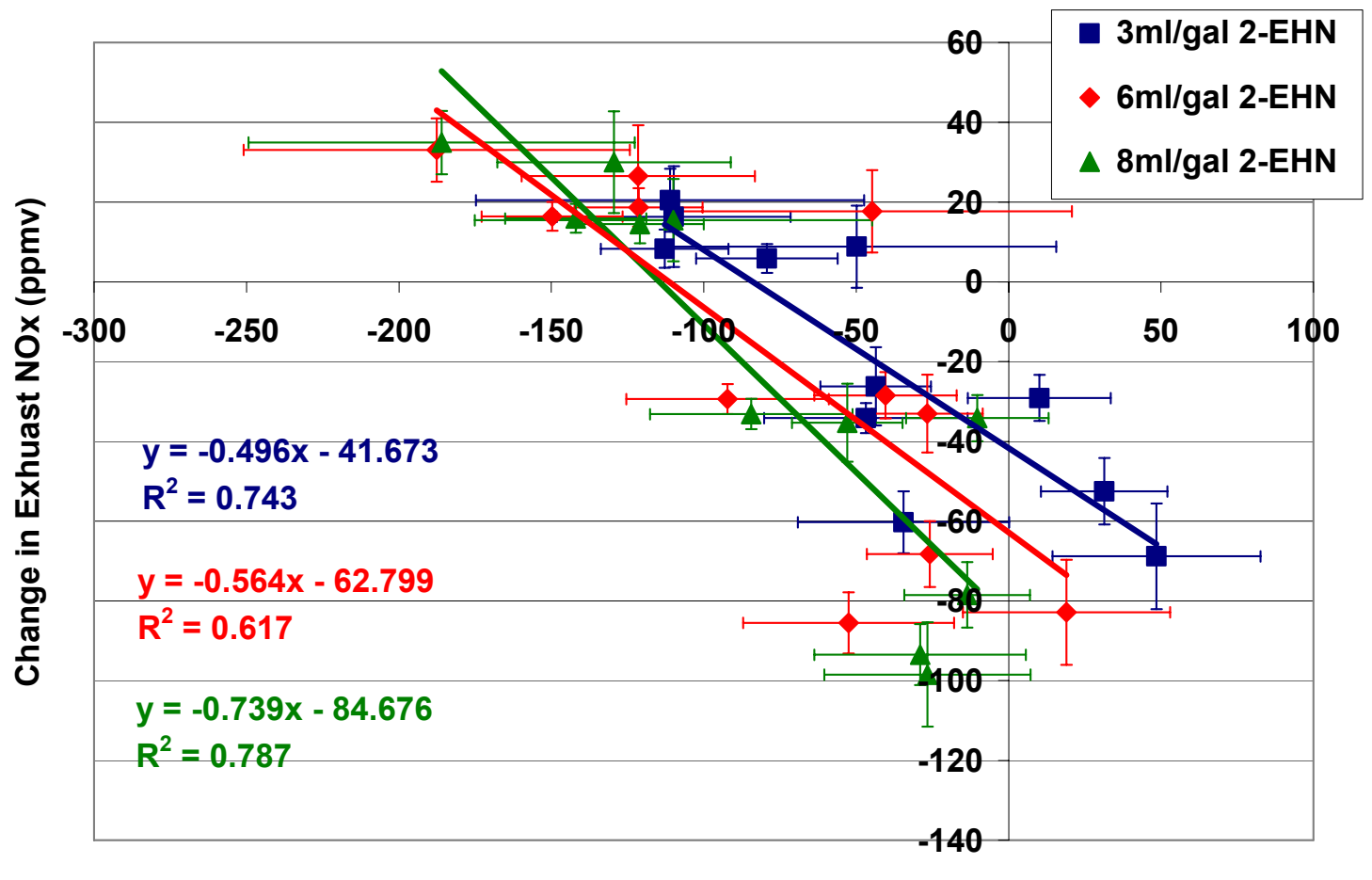

Change in Pressure at the SOC (kPa)

Figure 4-25 Change in NOx with Additized Fuels Compared to a Change in the Pressure at the Start of Combustion for the Steady State Modes on the 1992 DDC (Error Bars show An Approximate One Standard Deviation Based on Repeat Tests with the Guttman Fuel)

For $\mathrm{CO}$, the correlations were less favorable. The highest correlation coefficients were with the $10 \%$ MFB (-0.73 to -0.90$)$. This relationship would suggest that an increase in the burning time at the beginning of the heat release would decrease $\mathrm{CO}$ (and PM). An increase in burning time would suggest an increase in the oxidization rate of $\mathrm{CO}$, which would decrease $\mathrm{CO}$, which is contrary to the correlation found. This high correlation may be due to an interrelated cause. A high degree of scatter was also noticed with this relationship. The additives caused a decrease in $\mathrm{CO}$ during all modes with greater reductions occurring at high load, which was when the NOx increase occurred. Figure 4-26 illustrated a NOx/CO trade-off like the typical NOx/PM trade-off shown in the literature. The increased radical pool caused by the ignition improvers may increase local oxidation of $\mathrm{CO}$ and $\mathrm{PM}$. 




Figure 4-26 Change in CO with Additized Fuels Compared to a Change in NOx for the Steady State Modes on the 1992 DDC (Error Bars show An Approximate One Standard Deviation Based on Repeat Tests with the Guttman Fuel)

For the 2004 Cummins engine, lower correlations were observed for heat release parameters with the absolute $\mathrm{NOx} / \mathrm{CO}$ and change in NOx/CO compared to the 1992 DDC engine (Table 7-6 and Table 7-7, in the Appendix). Although the change in maximum cylinder pressure and maximum cylinder gas temperature due to the cetane improvers showed good correlation on the 1992 DDC engine, the 2004 Cummins engine did not have high correlations (-0.51 to 0.11$)$. The absolute NOx emissions did correlate well with the absolute maximum cylinder pressure (0.67-0.97) and maximum cylinder gas temperature (0.15-0.8). The change in premix fraction had a correlation coefficient of 0.66 with the change in exhaust NOx (ppmv) at the higher treat rates of $12 \mathrm{ml} / \mathrm{gal}$ 2-EHN and $15 \mathrm{ml} / \mathrm{gal}$ DTBP. This correlation was due to the change in the exhaust NOx levels and not reductions due to the additives. Figure 4-27 shows the percent change in premix fraction and the percent change in exhaust NOx. Overall, with changes in premix fraction (except for $15 \mathrm{ml} /$ gal DTBP), the exhaust NOx increased $0-4.2 \%$ with the fuel additives. The change in exhaust NOx due to the additives could not be explained with the 2004 Cummins engine, if any change occurred. The FTP tests only showed a $1.3 \%$ and $1.4 \%$ increase in brake-specific NOx 
for the $12 \mathrm{ml} / \mathrm{gal} 2-\mathrm{EHN}$ and $24 \mathrm{ml} / \mathrm{gal}$ ODA, and no significant difference was observed with the lower treat rates or the $15 \mathrm{ml} /$ gal DTBP. The author believes multiple repeat SET tests need to be conducted for each treat rate to determine whether the percent change in NOx at each load is statistically significant or due to fluctuating engine control and accuracy for the 2004 Cummins (or any newer engine with EGR, VGT, or similar hardware).



Change in Premix Fraction (\%)

Figure 4-27 Percent Change in NOx with Additized Fuels Compared to a Percent Change in the Premix Fraction for the Steady State Modes on the 2004 Cummins ISM 370

\subsubsection{Transient Heat Release}

For the transient tests, the combustion parameters were acquired for each combustion cycle, while the emissions data were acquired at $5 \mathrm{~Hz}$ on different computers. The combustion parameters were time aligned using engine speed, which was collected on both computers and converted to $5 \mathrm{~Hz}$. A time delay occurred between the combustion created emissions and the measured emissions. The exhaust concentrations of $\mathrm{NOx}$ and $\mathrm{CO}$ were time aligned to the indicated mean effective pressure from the combustion parameters, although the effect of transient EGR and boost on NOx might introduce a bias in this correlation. The continuous heat release parameters from the three FTP hot-starts were then averaged and a 9-point moving 
average was done to minimize variation when comparing to the laboratory obtained emissions data. In Figure 4-28 through Figure 4-30, the error bars show one standard deviation from the mean based on the three hot start FTPs for each fuel.

Figure 4-28 shows the LAFY section of the FTP as an example to describe the transient incylinder data analysis. The IMEPg and difference in exhaust NOx concentration between the LC fuel and the LC fuel with $8 \mathrm{ml} / \mathrm{gal}$ 2-EHN are shown. During idle sections and the beginning of the idle to load transition, large differences in parameters and exhaust NOx concentration were noticed due to the high combustion variation at idle and misalignments from time aligning the data. For any IMEPg less than $450 \mathrm{kPa}$, the combustion parameters and NOx differences were set equal to zero to minimize this effect. The choice of $450 \mathrm{kPa}$ for IMEPg corresponded approximately to $20 \%$ load, which was slightly less than the $25 \%$ load points (lowest loads) in the SET tests. At IMEPg less than $\sim 1250 \mathrm{KPa}$, a NOx decrease was noticed. No NOx change or a NOx increase occurred at an IMEPg greater than $\sim 1250 \mathrm{kPa}$. This behavior of NOx with load was observed with the SET testing and previously shown in the steady state testing section. 


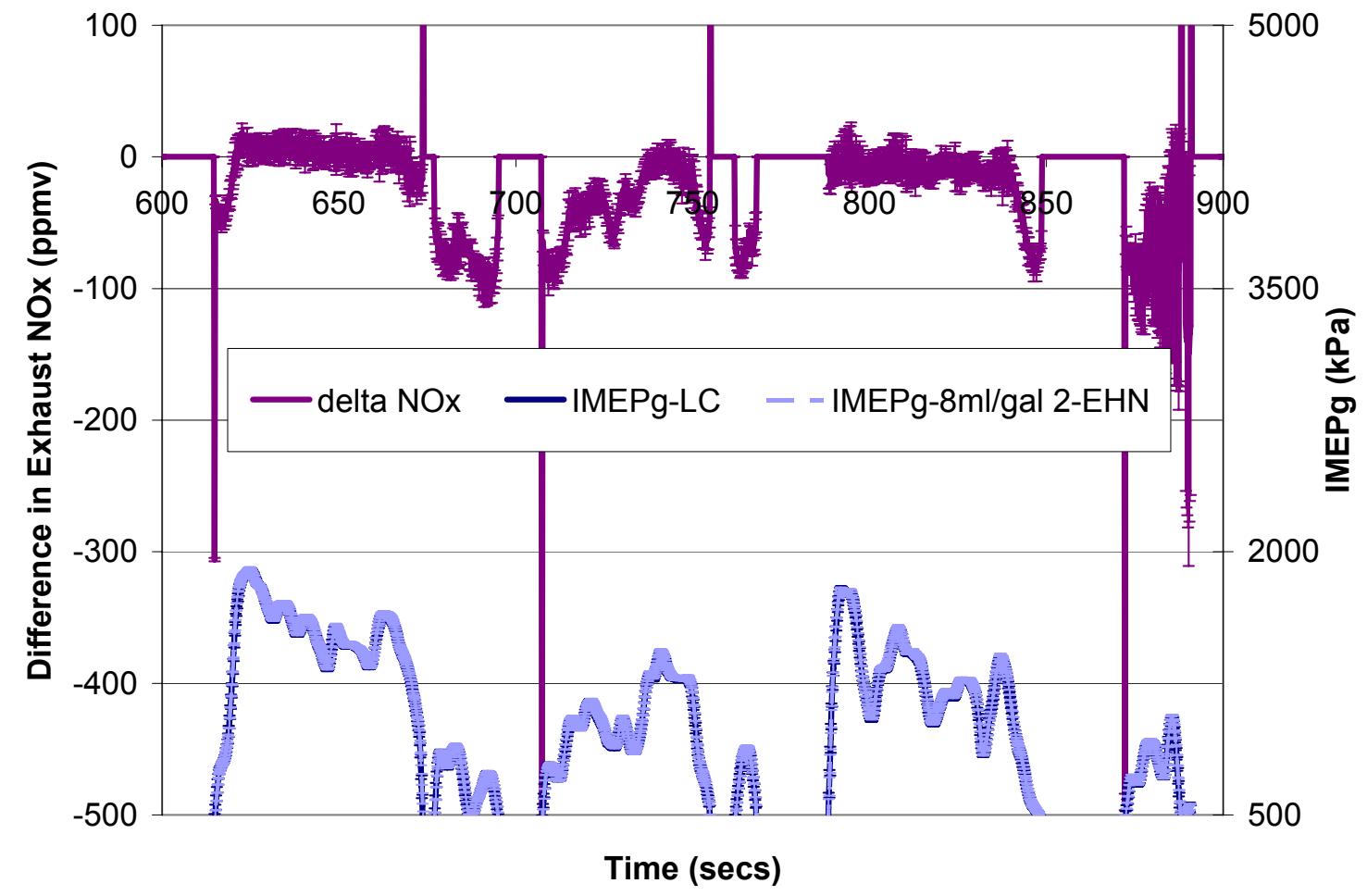

Figure 4-28 Change in NOx and Gross Indicated Mean Effective Pressure during Transient Operation for the 1992 DDC (Error Bars show One Standard Deviation from the Mean Based on the Three Hot Start FTPs for Each Fuel)

During acceleration from low to high load, the premix fraction increases in the lower loads and then decreases at higher loads. Assanis and coworkers [63] showed that during a load change, the turbocharger lag produced more prominent premix combustion from the relatively high equivalence ratio. A correlation was observed between the change in premix fraction and the change in NOx from the steady state testing. Figure 4-29 shows the continuous premix fraction for the Low Cetane fuel and additized Low Cetane fuel. The change in NOx was again plotted. A predicted change in NOx (labeled "delta NOx model"), using a linear relationship fitted from the change in NOx to the change in premix from the steady state testing, was added to explore whether the steady state correlation translates to the transient tests. At high premix values, the NOx decreased with the additive. At low premix values, the NOx showed either no change or a NOx increase. The predicted change in NOx from the delta NOx model had higher increases and decreases than actual. This may be due to the noticed change in injection timing strategy between the steady state tests and the transient tests. The transient tests had delayed injection timing compared to the steady state tests. The engine utilized a method to pass emission 
regulations on the FTP cycle, but allowed lower fuel consumption (increased NOx) during relatively steady state operation [5].



Figure 4-29 Change in NOx from a change in the Premix Fraction during Transient Operation for the 1992 DDC (Error Bars show One Standard Deviation from the Mean Based on the Three Hot Start FTPs for Each Fuel, For Error Bars on NOx, see Figure 4-28)

The continuous change in peak gas temperature showed a relationship with the change in NOx. The continuous peak gas temperature might give an indication of the thermal NOx, which is considered the main contributor to NOx formed in diesel combustion. A linear model was again developed, based on steady state results, to predict the change in NOx during transient testing. The levels of change in NOx agreed well (Figure 4-30), although the predicted NOx values had greater variation. This may be attributed to the sensitive response of this relationship to changes in temperature. The transient peak cylinder gas temperature was calculated cycle by cycle and had larger variation than the steady state peak cylinder gas temperature, which had 200 pressure cycles averaged. 




Figure 4-30 Change in NOx from a change in Peak Gas Temperature during Transient Operation for the 1992 DDC (Error Bars show One Standard Deviation from the Mean Based on the Three Hot Start FTPs for Each Fuel, For Error Bars on NOx, see Figure 4-28)

The levels of change in NOx predicted by the change in premix fraction from the linear relationship were off to some degree, while the predicted levels of NOx change from the change in peak gas temperature had better agreement, although injection timing changed. This shows that the effect of the premix fraction on NOx is a function of the injection strategy, while the effect of the peak gas temperature on NOx is not. The effect of the change in peak pressure on the change in exhaust NOx was different between transient and steady state operation (Figure 4-31). Typically, a decrease in peak pressure was noticed during the transient cycle, while during steady state operation, four modes had an increase in peak pressure. This may be due to the delayed injection timing used for transient operation, which had combustion occurring later in the expansion stroke that caused cooling of the combustion contents. With high loads during steady state and advanced injection timing, the reduced premix fraction creates an increased diffusion fraction, which had increased pressure near TDC. The increased cooling of the combustion chamber with delayed injection had the diffusion fraction occurring later in the 
combustion cycle, which may reduce the burning rate; allowing less opportunity for NOx reduction.

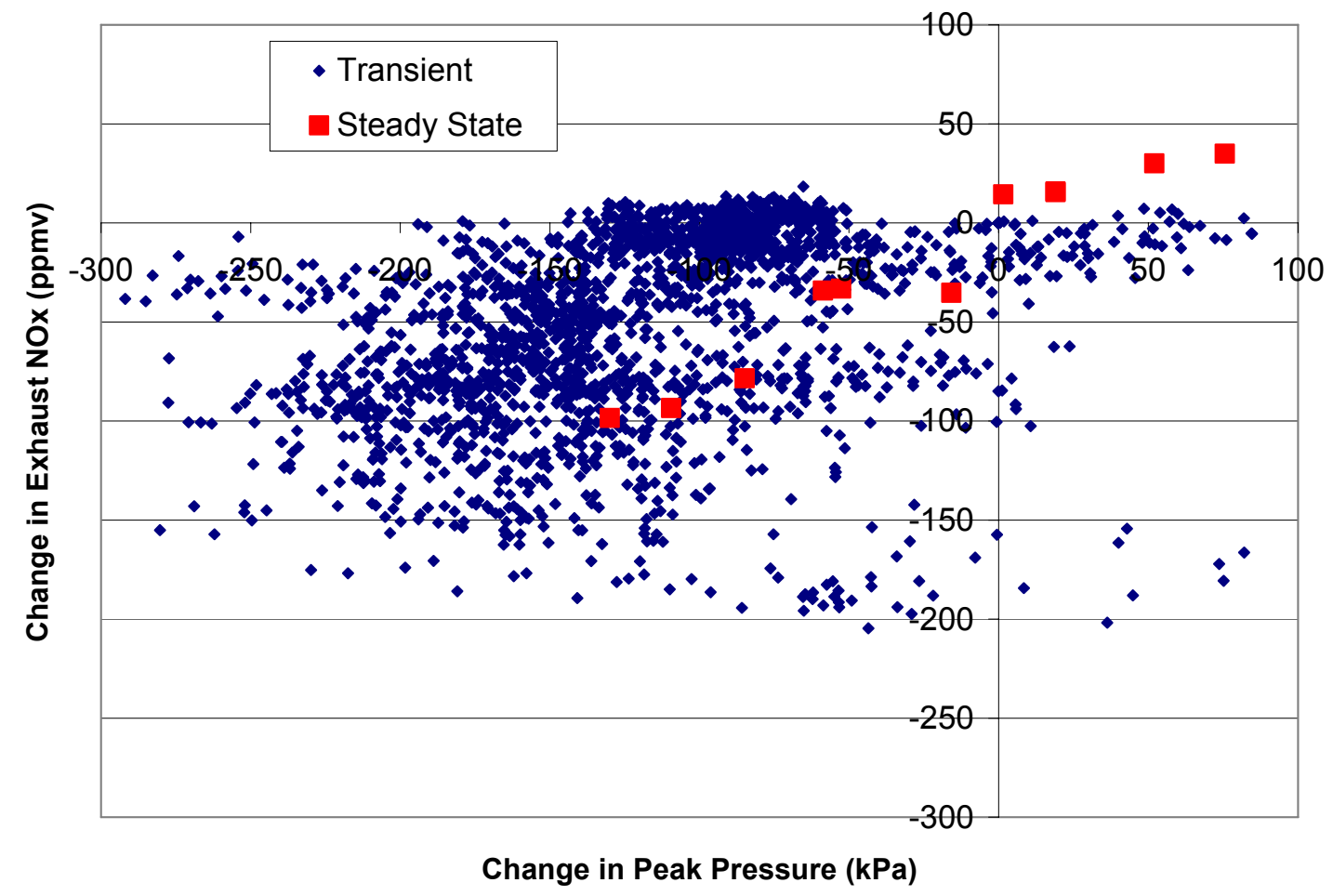

Figure 4-31 Change in NOx from change in Peak Cylinder Pressure over Transient and Steady State Operation for the 1992 DDC

\subsection{Combustion Model Results}

For the fuel additives used in this study, a change in the global heat release rate was observed with the 1992 DDC engine. The fuel additives increased or decreased NOx depending on the mode. A more in depth analysis of the how the global heat release rate curve effects the NOx emissions was needed. The combustion model shown in Section 3.10 was applied to the 1992 DDC engine. The model utilized the global heat release rate, a mixing model, and the extended Zeldovich mechanism to investigate how the change in the global heat release with additive effected the NOx formation.

The conceptual combustion model produced by Dec [53, 54] from Laser-Sheet Imaging found the premix portion of the heat release to have a high ER (3-4). Based on this, the ER for the combusting fuel packages during the premix portion was investigated with a setting of two for 
the combustion model. Using the high ER during the premix portion produced very low NOx at $25 \%$ load, which had a high premix fraction (0.6-0.7) and high NOx (1000-1200ppmv). The heat release curves investigated by Dec were visually similar to those of $50 \%$ and $75 \%$ load on the 1992 DDC engine. Improved accuracy occurred when solving for ER with the developed mixing relationship (Equation 3-22) without using a high ER for the premix portion.

Mode 8, with Low Cetane fuel, was used extensively to understand the model parameters (mixing constant, local ER, and internal EGR) on the predicted emissions. The predicted cylinder volume and cylinder gas temperature was used as a quality check for the combustion model. The mass-averaged cylinder temperature from the combustion model was compared to the calculated cylinder gas temperature from the ideal gas equation (Figure 4-32). Although, the ideal gas law loses accuracy at high pressures, a real gas approaches an ideal gas at high temperatures. When checking the real gas effects, the worst-case compressibility factor was 0.95 for pure water vapor at the measured in-cylinder pressures and calculated temperatures. The compressibility factor was 1.0-1.02 for the mixtures and this shows the assumption of an ideal gas was acceptable. 


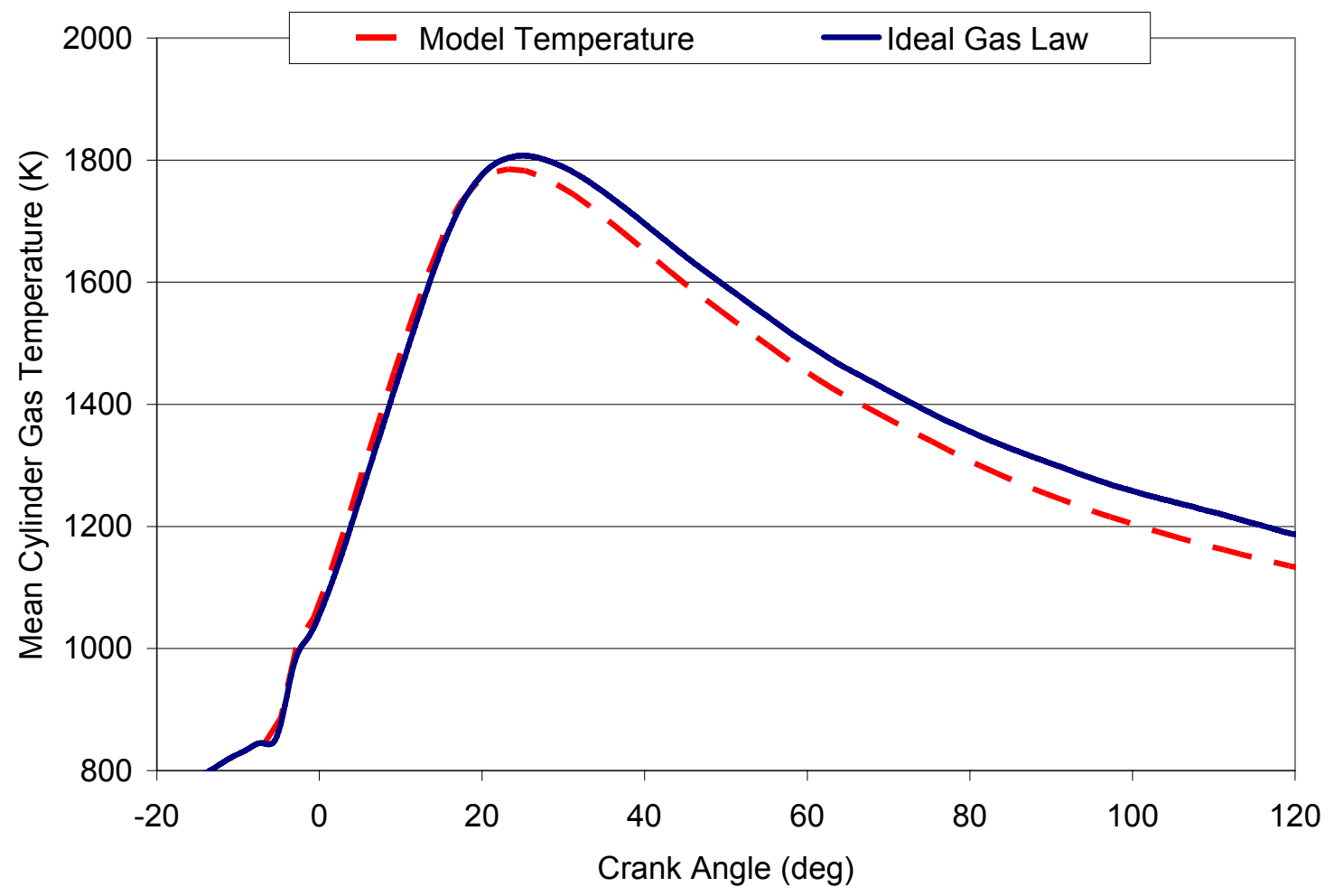

Figure 4-32 Global Cylinder Gas Temperature Predicted by Combustion Model and Calculated from In-

Cylinder Pressure using the Ideal Gas Law

The gas temperature predicted by the combustion model was $30 \mathrm{~K}$ lower at the peak than the cylinder gas temperature calculated from the in-cylinder pressure. This was deemed acceptable since the calculated model temperature depended on the properties (enthalpy, internal energy, and higher heating value) used for the diesel fuel, the mixing model, heat transfer model, and the assumed product species. The trend from the calculated temperature was followed by the model temperature. The model predicted volume was compared to the actual cylinder volume (Figure 4-33). After 90 degrees ATDC, the combustion model predicted a lower cylinder volume than actual; this may come from the temperature disagreement. Combustion duration was typically shorter than 60 degrees ATDC, and NOx formation was quenched before 90 degrees ATDC. 


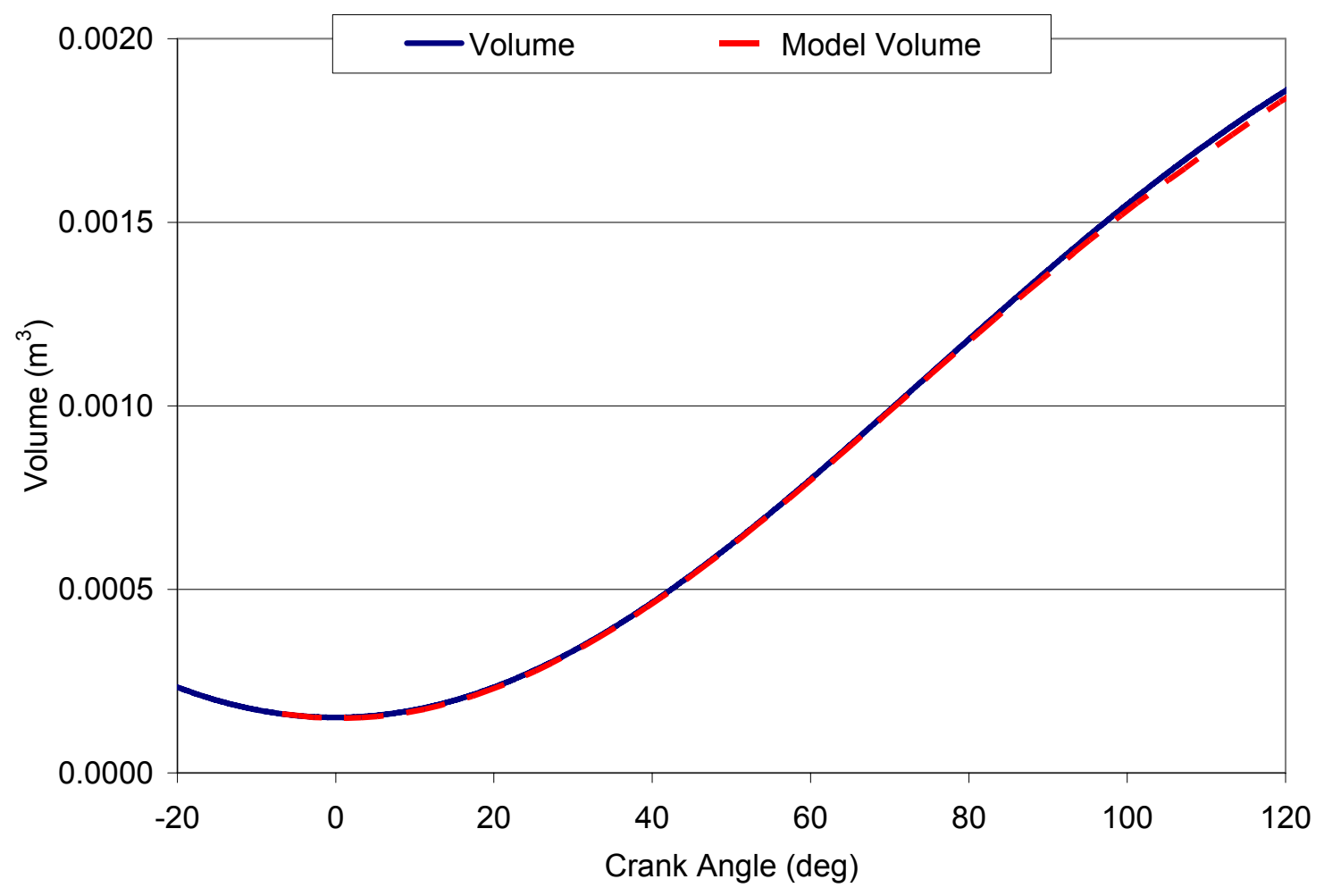

Figure 4-33 Cylinder Volume Predicted by Combustion Model and Actual

The combustion model parameters of mixing constant, local equivalence ratio at initial combustion, and internal EGR were varied for mode 8. With increasing mixing (a higher mixing constant), the predicted exhaust NOx generally decreased (Figure 4-34). The predicted $\mathrm{CO}_{2}$ was insensitive to the mixing constant in the studied range of 1.5 to 2.5 . A lower mixing constant would result in a richer fuel package for a longer duration, but as long as the burned zone reached the global equivalence ratio, all $\mathrm{CO}$ was converted to $\mathrm{CO}_{2}$, since equilibrium was assumed and the global equivalence ratio was lean. Higher internal EGR decreased the predicted NOx as expected. Three percent internal EGR was assumed since Heywood [60] states the residual gas fraction has an order of a few percent for diesel engines. 


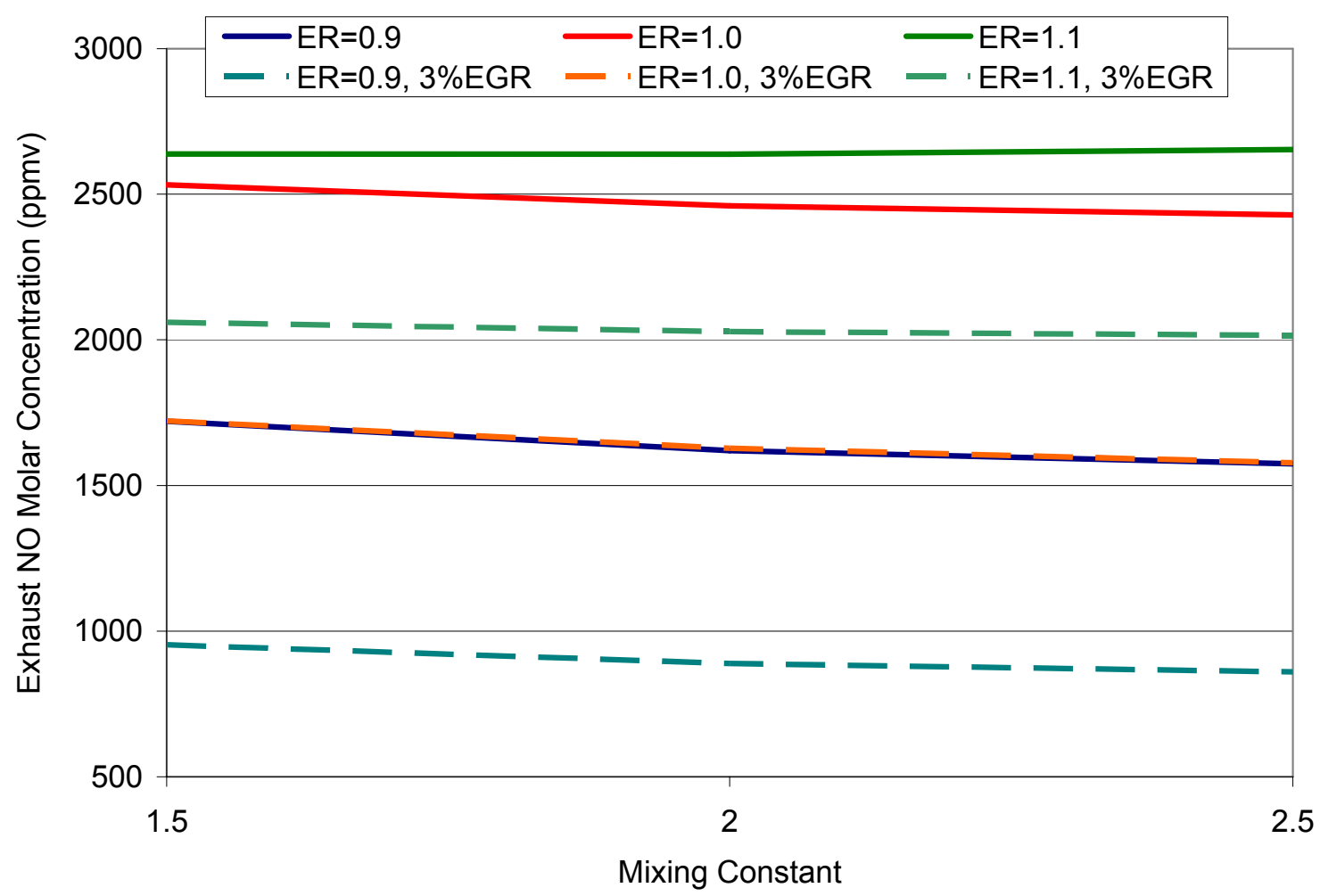

Figure 4-34 Influence of Mixing Constant and Local Equivalence Ratio on NOx

With 3\% internal EGR, the calculated $\mathrm{CO}_{2}$ had better agreement with the experimental $\mathrm{CO}_{2}$ (Figure 4-35). It should be noted that the assumed internal EGR and local equivalence ratio at combustion did not affect the predicted NOx percent increase/reduction with and without additive. The assumptions only changed the predicted NOx concentration levels. That is, the absolute NOx concentration was sensitive to the values selected for internal EGR and local equivalence ratio, but the percent difference between a neat fuel and an additized fuel were not influenced by the selection of these values. The mixing constant changed the predicted NOx increase/decrease due to the increased quenching affect on NOx with greater mixing. A mixing constant of two had better agreement in the predicted cylinder temperature and cylinder volume. In addition, as stated earlier, another NOx research study [68] with a more detailed kinetic NOx mechanism, having the same mixing relation, used a value of two for the mixing constant. 


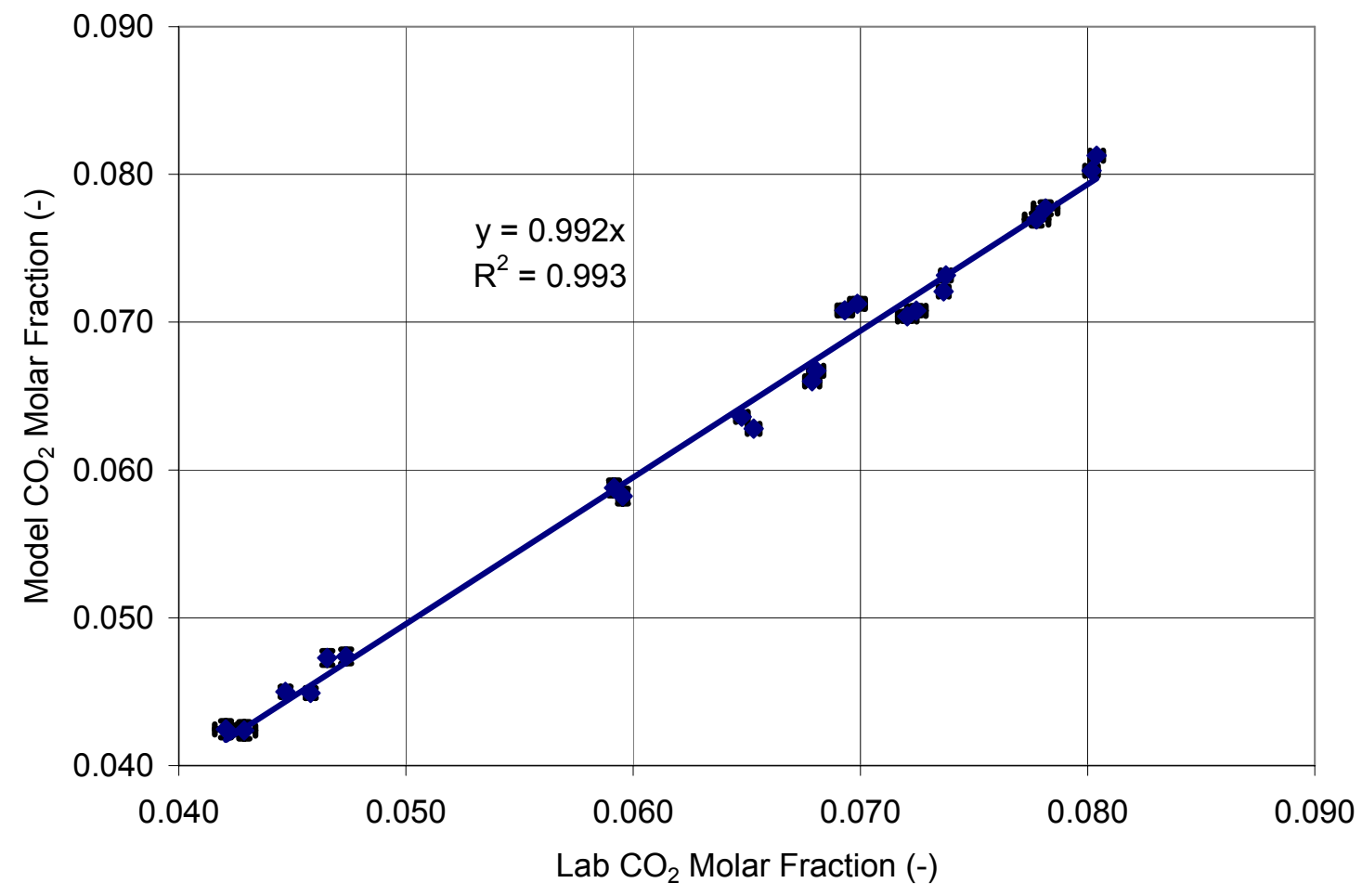

Figure 4-35 Model $\mathrm{CO}_{2}$ and Laboratory Based $\mathrm{CO}_{2}$ for Low Cetane Fuel with and without Additive

Utilizing the combustion model for modes 3-13, the NOx was predicted for the base (Low Cetane) and additized ( $8 \mathrm{ml} / \mathrm{gal}$ 2-EHN) fuels. Figure 4-36 shows the exhaust NOx concentrations from the laboratory and the combustion model. The agreement in the predicted NOx to the experimental NOx was $17 \%$ to $59 \%$. If the average predicted NOx level was adjusted to the average experimental NOx level using a constant factor, the agreement would be $\pm 21 \%$. Better agreement would be shown with fewer modes studied due to easier adjustment of model parameters. Three-dimensional CFD combustion models utilizing more reactions and kinetic mechanisms have shown NOx agreement with a difference as high as $44 \%$ [95], where fewer modes are typically analyzed than the 11 modes at different engine load and speeds investigated here. The bars depicted in Figure 4-36 are from a study utilizing the Guttman fuel with four repeat SET tests. The predicted range over the average (similar to a covariance) and the experiment NOx were computed utilizing the four repeat tests. The range over average from the Guttman fuel was then multiplied by NOx from the additized and unadditized Low Cetane fuels. The range was used instead of the standard deviation because the additized and unadditized Low Cetane fuels had no repeats, and the range would give a better indication of 
variability from repeat tests. As shown in Figure 4-36, test-to-test variability was only a few percent. The combustion model was shown to predict NOx trends. Research in the literature with similar agreement to the experimental NOx has also been used to predict NOx trends $[65$, $66,68]$.



Figure 4-36 Model NOx and Laboratory Based NOx for Low Cetane Fuel with and without Additive

\subsubsection{Steady State}

The agreement between experimental and model predicted percent NOx increase/reduction is shown as Figure 4-37. Good agreement was obtained, particularly between the 25-75\% loads. At $100 \%$ load, the combustion model predicted a NOx decrease. The model constituents of $\mathrm{CO}_{2}$, $\mathrm{H}_{2} \mathrm{O}, \mathrm{N}_{2}, \mathrm{O}_{2}, \mathrm{O}, \mathrm{CO}, \mathrm{H}_{2}, \mathrm{H}$, and $\mathrm{OH}$ are a function of pressure and temperature due to the assumed equilibrium reactions. A decrease in temperature decreases NOx formation, but an increase in pressure at the same temperature decreases the formation of $\mathrm{O}$ and $\mathrm{OH}$, which leads to lower NOx. For the equilibrium reaction of dioxygen and oxygen, $\mathrm{O}_{2} \rightarrow 2 \mathrm{O}$, at higher pressures, Le Chatelier's principle indicates the reaction is forced to the left due to the lower number of moles. At $100 \%$ load, the temperature profiles were very similar between the additized and unadditized fuel, but the pressure was slightly higher with the additized fuel, which 
therefore reduced NOx. For the other loads (25-75\%), the temperature profile changed significantly between fuels and offset the influence of pressure on NOx. The bars indicate the percent difference ranges from repeat SET tests utilizing the Guttman fuel.

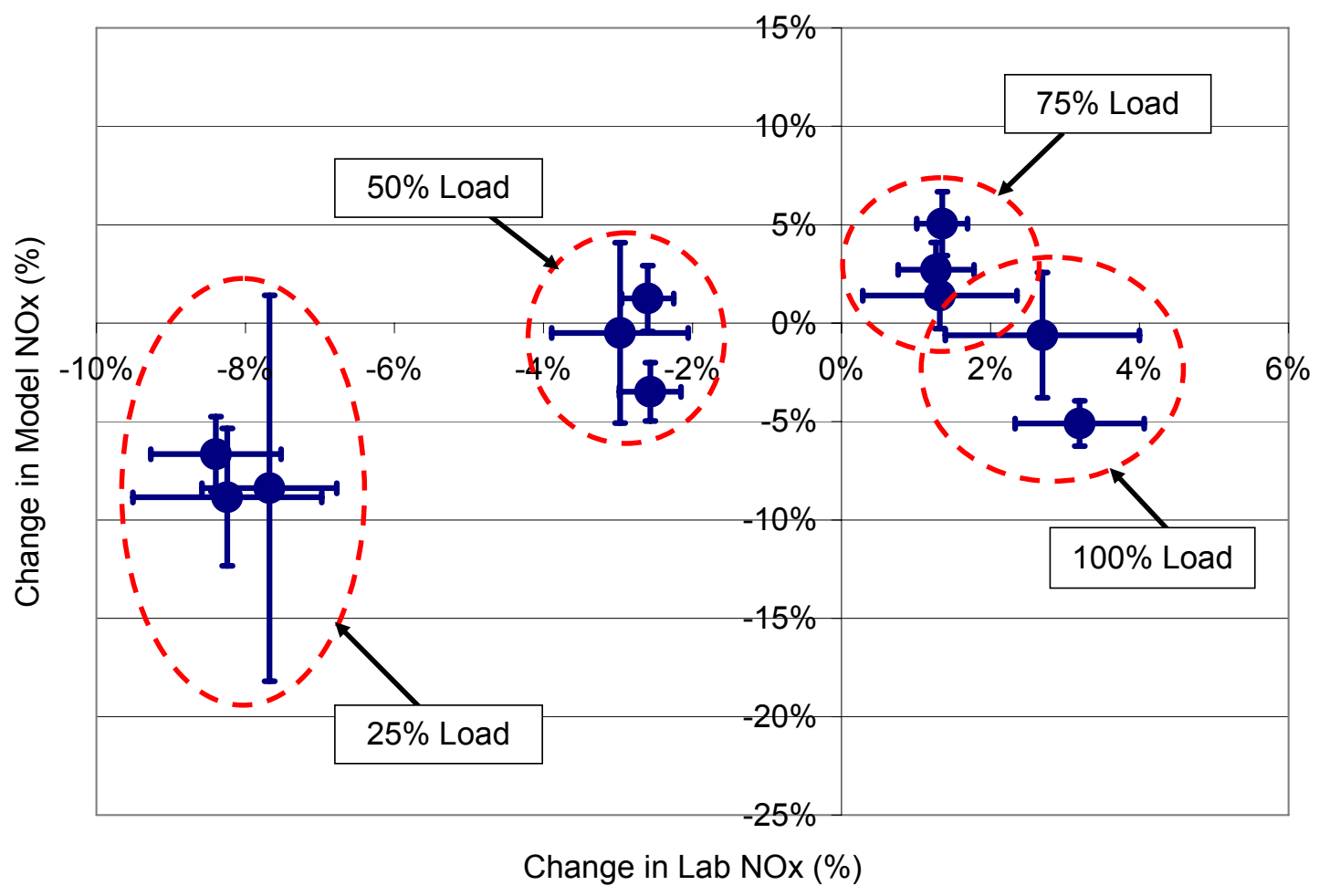

Figure 4-37 Percent Reduction in Exhaust NOx with Additized Low Cetane Fuel from Model and Laboratory For Mode 7, the model NOx and experimental NOx showed a NOx reduction of $8.8 \%$ and $8.2 \%$, respectively. The NOx reduction was due to a lower NOx formation rate (Figure 4-38) caused by a cetane improver. With a reduced ignition delay due to the cetane improver, less fuel was injected before the start of combustion creating lower heat release rates during the premix portion of the heat release and greater heat release rates during the diffusion portion. The high premix fraction (50-70\%) of the heat release at $25 \%$ load increased the significance of the NOx formed due to the premix portion of the heat release rather than the diffusion portion of the heat release. The diffusion portion occurred later in the expansion stoke with the cylinder volume expanding, which caused lower combustion temperatures and hence lower NOx formation. The low equivalence ratio ( $\sim 0.30$ to 0.34 ) of the $25 \%$ loads, compared to high loads, provided a greater amount of unburned air for quenching the combustion packages and reducing the cylinder temperature. 


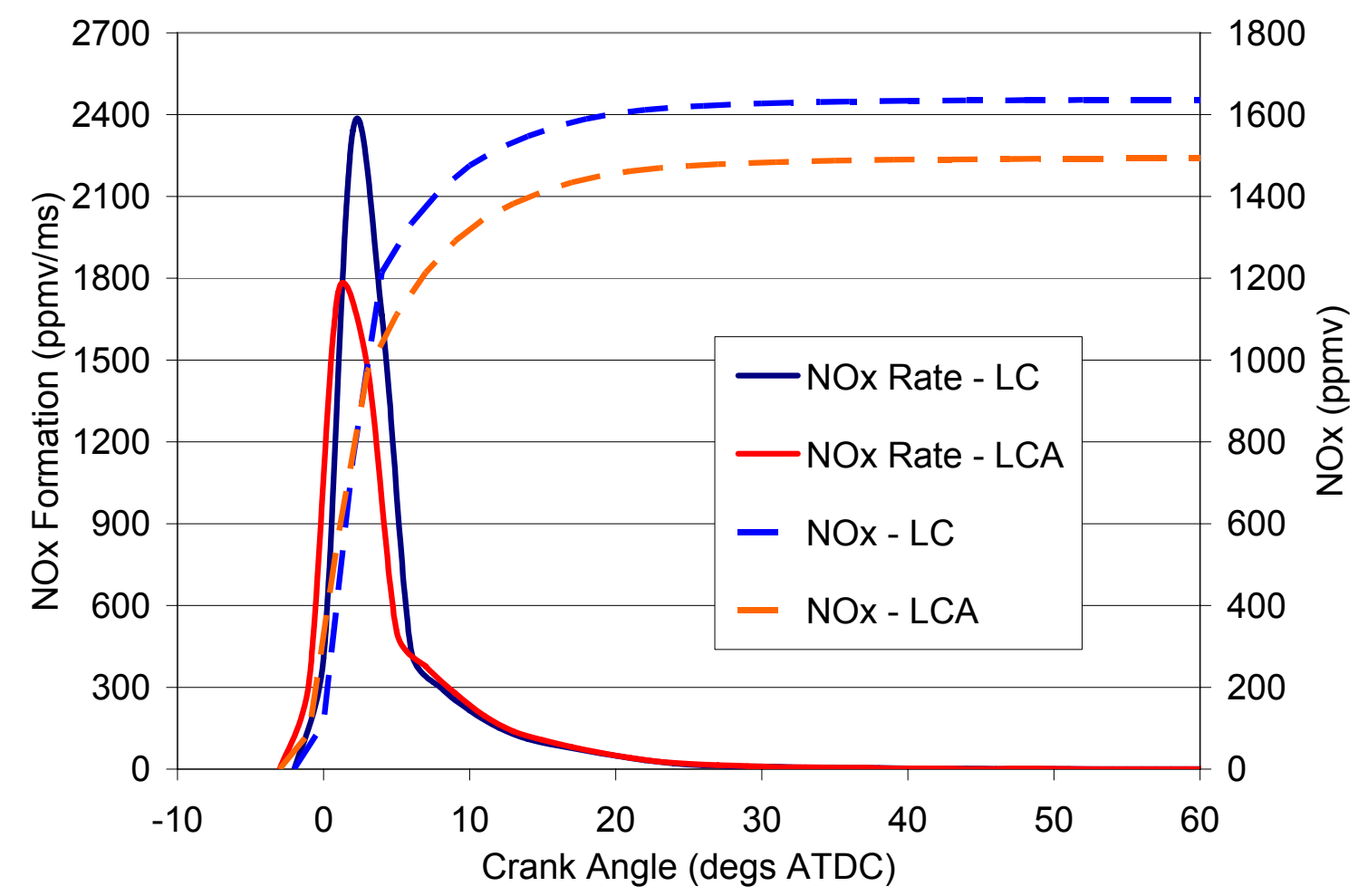

Figure 4-38 NOx Formation Between Low Cetane Fuel (LC) and Additized Low Cetane Fuel (LCA) for Mode 7 (25\% Load)

The low premix fraction (6-15\%) at 75-100\% load increased the significance of the NOx formed during the diffusion portion of the heat release more than during the premix portion. The large amount of fuel energy released during the diffusion section at high load created higher local temperatures and NOx formations than during the premixed section of the heat release. The large quantity of fuel energy released more than offset the reduced energy created by the expanding cylinder volume. As the duration of combustion increased, the contents of the unburned air in the cylinder heated up due to heat transfer, which created higher combustion temperatures for the later burning fuel packages. During Mode 4 ( $75 \%$ load), the experimental NOx and combustion model predicted NOx increased $1.4 \%$ and $5.1 \%$, receptively, with $8 \mathrm{ml} / \mathrm{gal}$ 2-EHN added to the Low Cetane fuel. The combustion during the premix portion of the heat release, at high load, increased the cylinder gas temperature creating greater combustion temperatures for the diffusion portion. Therefore, the premix portion of the heat release was reduced, and the additive generated higher NOx formation rates during the diffusion portion 
(Figure 4-39) and more than offset the lower NOx formation rates during the premix portion of the heat release.

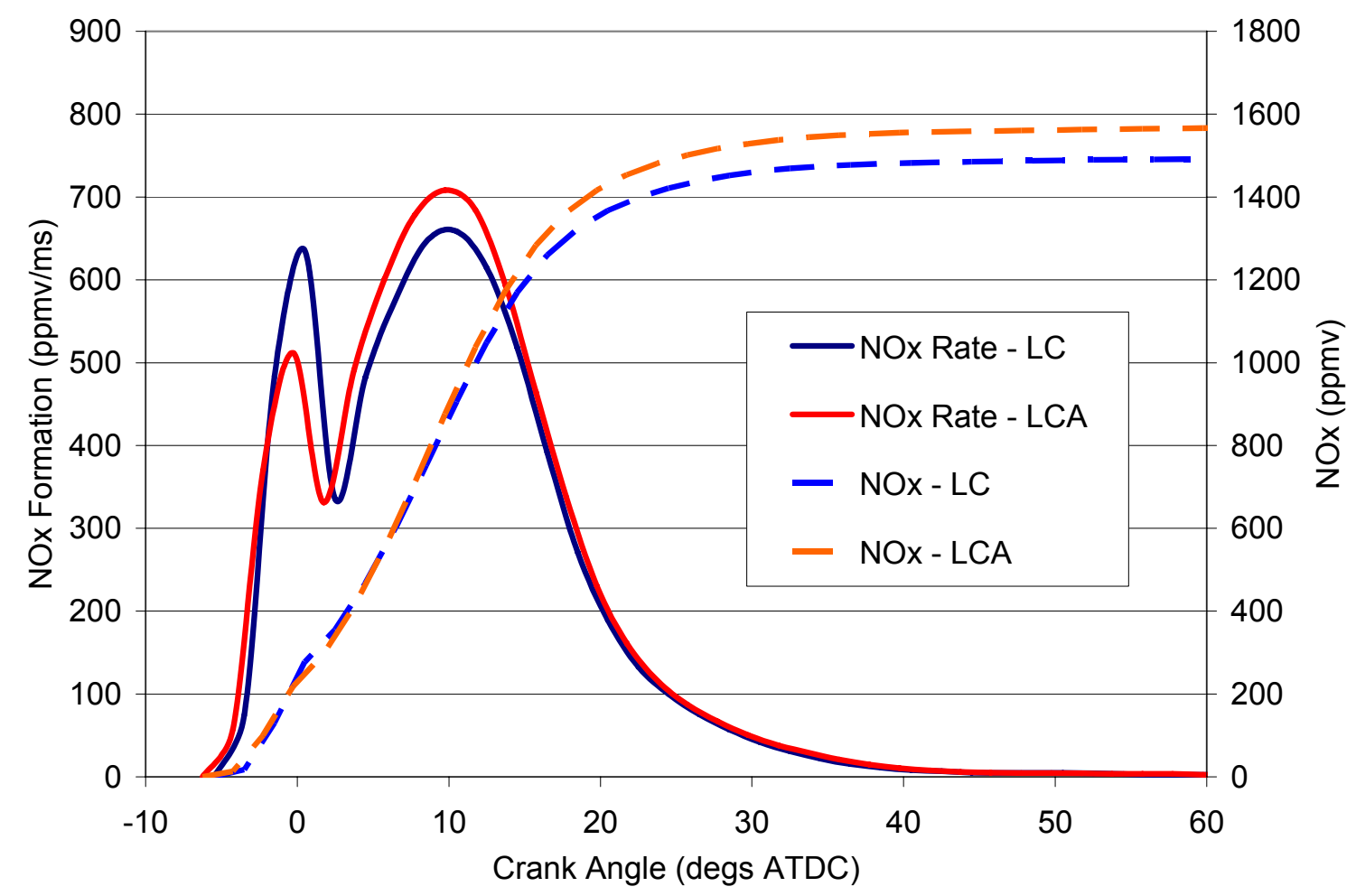

Figure 4-39 NOx Formation Between Low Cetane Fuel (LC) and Additized Low Cetane Fuel (LCA) for Mode 4 (75\% Load)

\subsubsection{Transient}

To understand whether the combustion model NOx from steady state correlated to the transient tests, the last portion of the first NYNF section of the FTP was investigated. Every tenth combustion cycle was solved with the combustion model to minimize computation time, since each combustion cycle takes 20 minutes for a solution, and this 45 -second interval of the FTP had 495 combustion cycles. The experimental heat release for each combustion cycle was fitted to the double Weibe function before use in the combustion model to minimize the variability.

The mass emissions of $\mathrm{CO}_{2}$ and NOx were calculated from the combustion model using the exhaust constituents and the in-cylinder pressure-based intake flow rate as the exhaust flow rate. Figure 4-40 and Figure 4-41 show the unadditized and additized (8ml/gal 2-EHN) Low Cetane fuels for experimental and model predicted $\mathrm{CO}_{2}$ and $\mathrm{NOx}$ during the third hot-start FTP. The 
response of the combustion model predicted $\mathrm{CO}_{2}$ and $\mathrm{NOx}$ was greater than experimental values due to the dilution tunnel having mass diffusion effects; although the trend was similar between predicted and experimental values. Integrating the mass emissions of $\mathrm{CO}_{2}$ over this 45 -second interval, the experimental and model $\mathrm{CO}_{2}$ showed a $0.6 \%$ and a $0.8 \%$ increase, respectively, between unadditized and additized fuels. The integrated NOx emissions resulted in an $8.1 \%$ and $6.0 \%$ reduction in NOx between unadditized and additized fuels for the experimental and model predicted NOx, respectively.

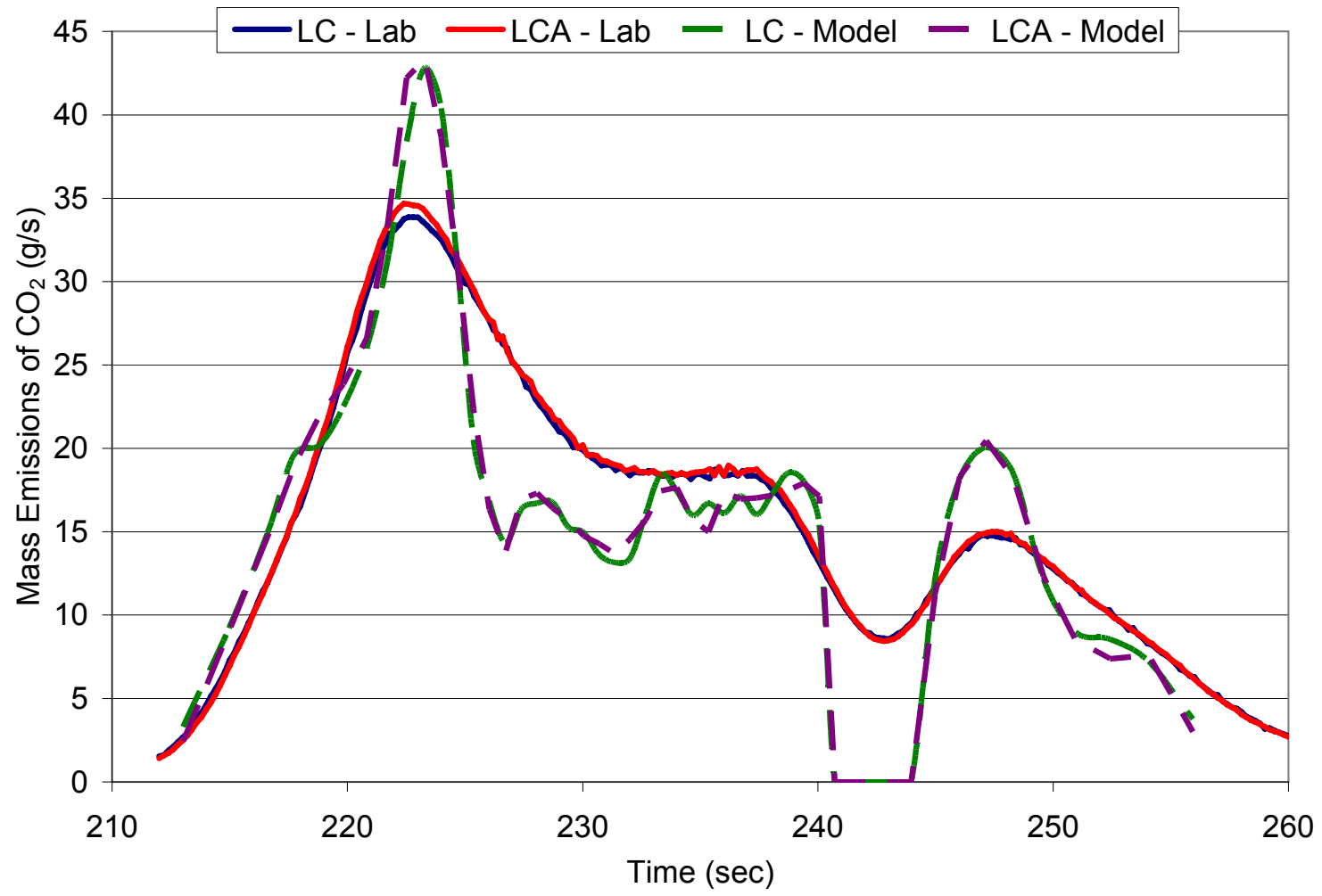

Figure 4-40 Mass Emissions of the Experimental $\mathrm{CO}_{2}$ and Combustion Model $\mathrm{CO}_{2}$ for a 45-second Section of the FTP 


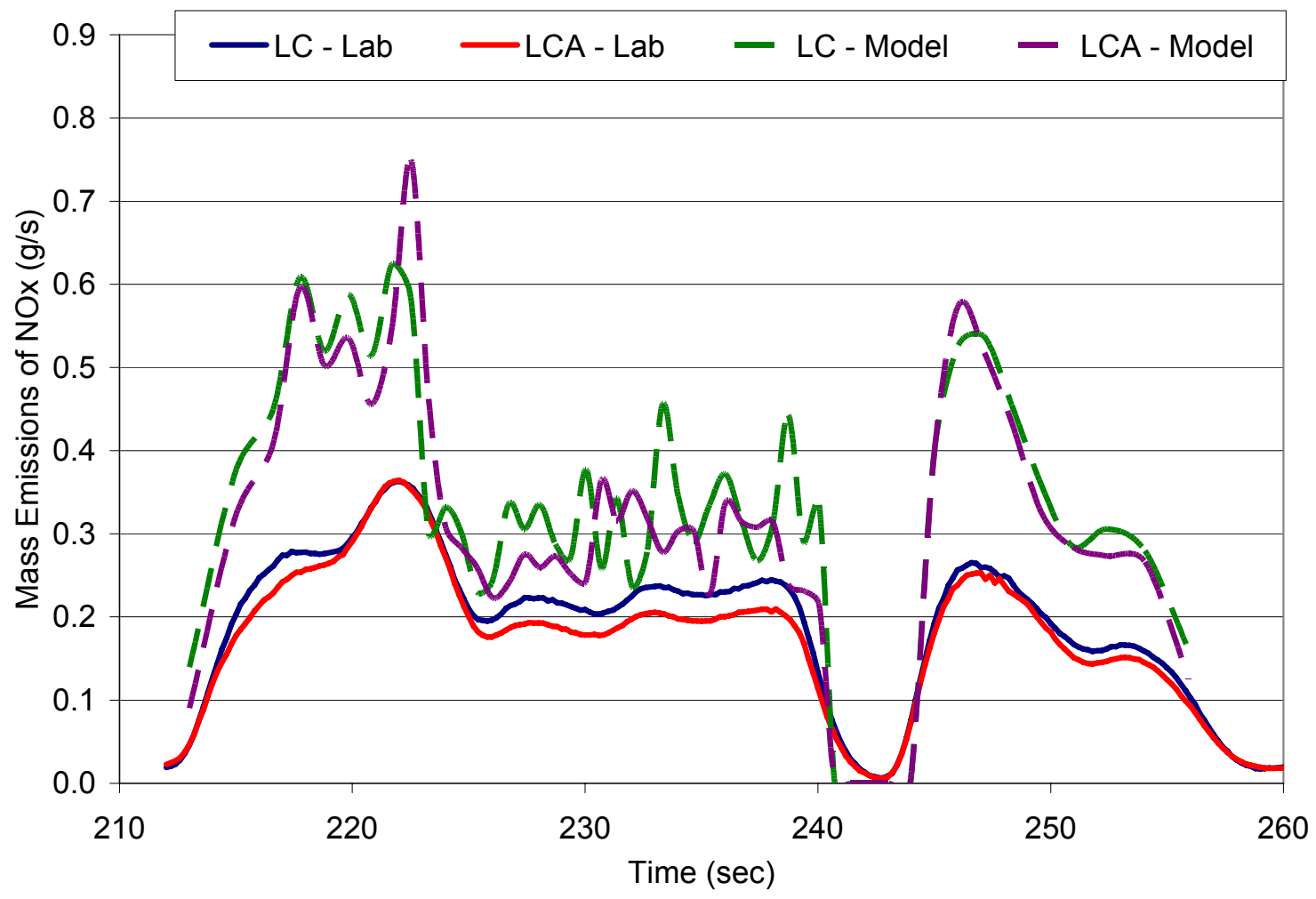

Figure 4-41 Mass Emissions of the Experimental NOx and Combustion Model NOx for a 45-second Section of the FTP

Figure 4-42 shows the NOx formation rate during the 45 crank angle degrees after the SOC for the 45 -second section of the FTP. The NOx formation rate during the first 10 degrees after the SOC was decreased with the additive, but the second portion of the NOx formation rate from the diffusion burning (occurred after initial $10 \mathrm{deg}$ after the SOC) tended to increase at higher load. The interval of 220-225 seconds on the FTP demonstrates the increase due to the additive during diffusion burning for the NOx formation at high load. 


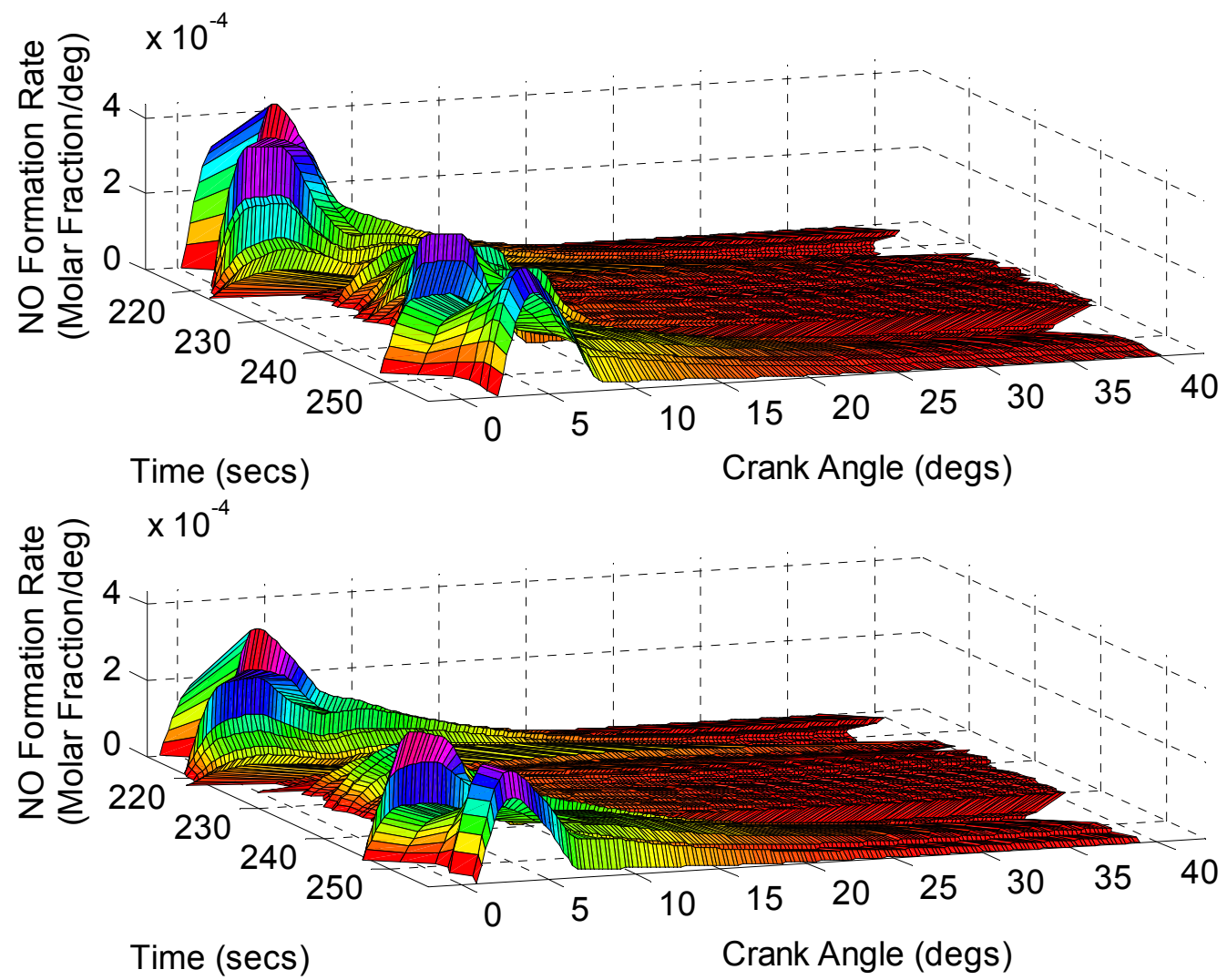

Figure 4-42 NO Formation Rates for a 45-second Section of the FTP (Top: Low Cetane Fuel, Bottom: Low Cetane Fuel with $8 \mathrm{ml} /$ gal 2-EHN)

An argument could be made that the transient nature of the turbocharger more strongly influences NOx emissions during transient operation than during steady state operation. The study by Assanis and coworkers [63] showed that during a load change, the turbocharger lag produced more prominent premix combustion due to the relatively high equivalence ratio. Typical diesel acceleration does not simply have a load change. Both load and engine speed change during acceleration. Figure 4-43 shows the 45 -second interval during the FTP for the cylinder fuel flow rate, air flow rate, and ratio of cylinder pressure at EVO to IVC. As the engine accelerates, the air flow and the fuel flow follow each other. From 218-222 seconds, the pressure ratio stays relatively constant during acceleration, but the change in NOx goes from a reduction to no NOx change or a NOx increase (Figure 4-41). 

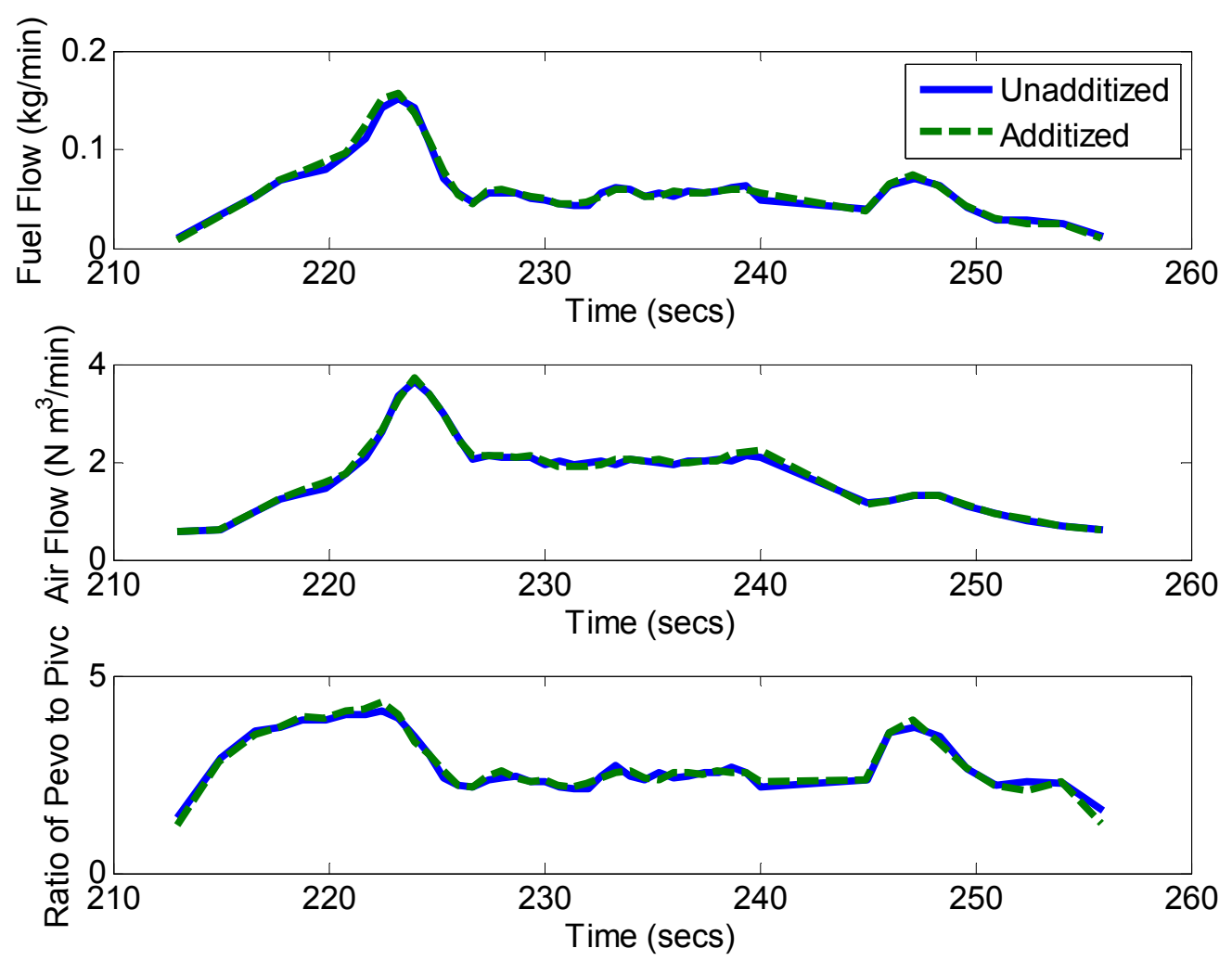

Figure 4-43 Cylinder Fuel Flow Rate (Top), Air Flow Rate (Middle), and Ratio of Cylinder Pressure at EVO to IVO for a 45 -second Section of the FTP

As mentioned in Section 4.2.5, the behavior of the fuel injection timing changed between steady state and transient operation. The combustion model was able to predict the reduction of the integrated NOx with $8 \mathrm{ml} / \mathrm{gal} 2-\mathrm{EHN}$ added to the Low Cetane fuel during transient operation. With the additive, the reduction of the NOx formation rate during the premix combustion and the increase of the NOx formation rate during diffusion combustion were evident. During steady state, the combustion model inaccurately predicted a NOx decrease with the additive at $100 \%$ load. This inaccurate NOx prediction at $100 \%$ load was not evident, or occurred for only a short period during the transient combustion modeling and therefore did not greatly influence the integrated NOx emissions. 


\subsection{Significance}

The effectiveness of the cetane improvers on NOx were engine, load, neat fuel, and additive concentration dependent (Figure 4-44). A $6^{\text {th }}$ order polynomial was fit to the continuous NOx mass rate as a function of power from the FTP test for additized and neat fuel on the 1992 DDC and 2004 Cummins. Using these $6^{\text {th }}$ order polynomials, a percent reduction in NOx with additive trend was calculated. For more details on the percent reduction of NOx versus power for these additives and engines, see reference [69]. It should be noted that the base fuels and concentrations of 2-EHN shown in Figure 4-44 are different for the two engines shown, but represent the general trend that older engines have a greater NOx reduction using cetane improvers.

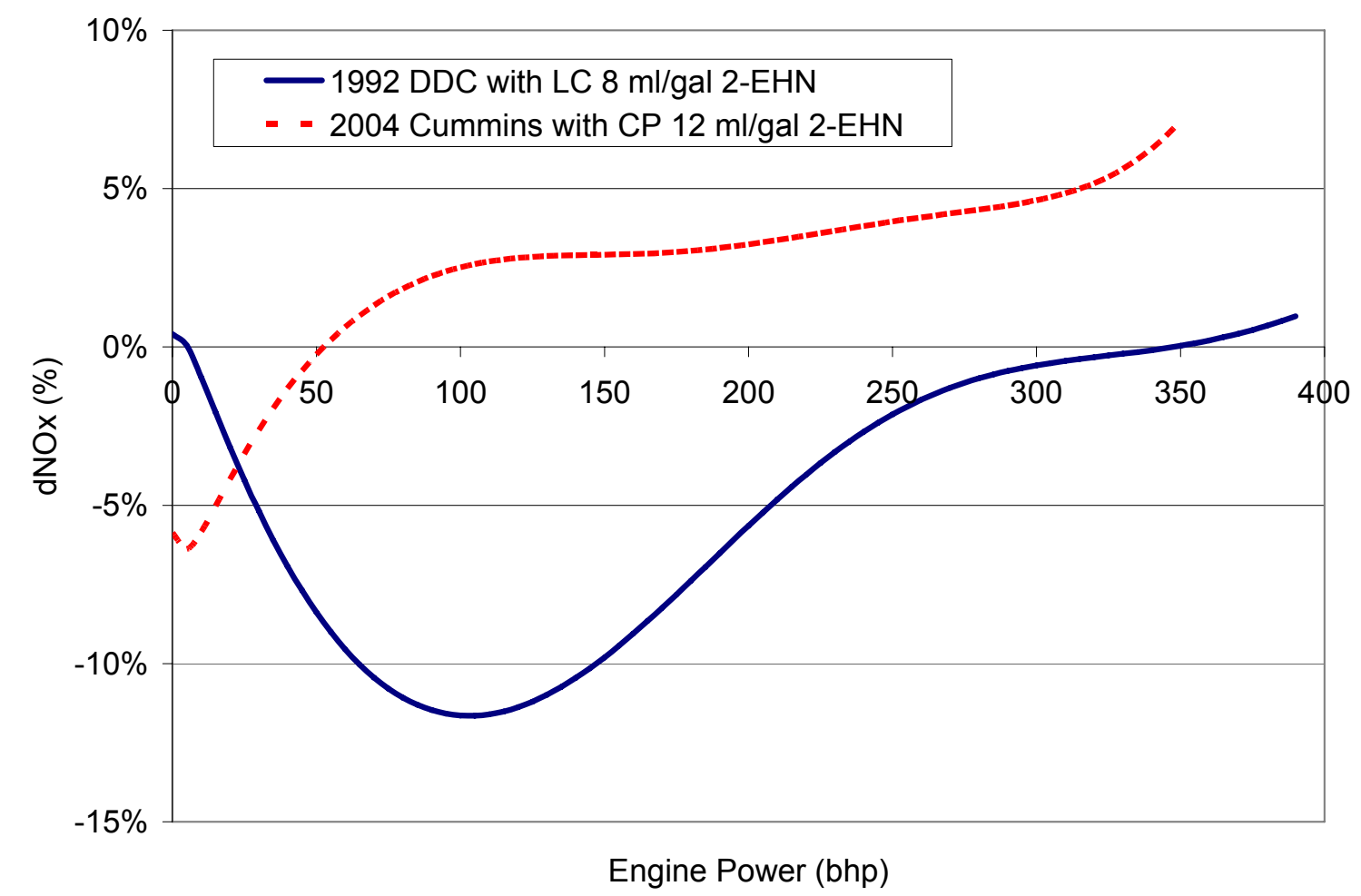

Figure 4-44 NOx Reduction from the FTP cycle with 2-EHN on the 1992 DDC and 2004 Cummins

An ideal candidate for cetane improvers would be a legacy on-road heavy-duty diesel engine operating in urban areas, such as refuse trucks and buses, because the engine operates primarily at low horsepower (Figure 4-44). The high horsepower operation of an on-road diesel truck engine operating in rural conditions may not have a significant benefit from a cetane improver. 
Modern engines with higher compression ratios and/or EGR may not benefit from a cetane improver at higher average engine loads. 


\section{Conclusions and Recommendations}

\subsection{Conclusions}

Three cetane improver additives of DTBP, 2-EHN, and ODA (proprietary) were investigated with a variety of base fuels on 1992 DDC and 2004 Cummins engines. The engines were exercised over the transient heavy-duty FTP cycle and the steady state SET test, with in-cylinder pressure collected. A zero-dimensional heat release model was applied to an averaged pressure trace for the steady state modes and cycle-by-cycle during transient testing. The emissions of $\mathrm{CO}, \mathrm{CO}_{2}$, THC, NOx, and TPM were collected. A phenomenological combustion model was developed to investigate the influence of the shift in global heat release due to the additives on the NOx emissions.

On the FTP cycle, the cetane improvers showed a statistically significant NOx decrease of 2.2$4.9 \%$ with the 1992 DDC engine and a $0-1.4 \%$ increase of NOx with the 2004 Cummins engine compared to the base fuels (excluding biodiesel blends). The emissions of CO, THC, and TPM showed percent reductions of $4.6-8.9 \%, 10.9-37.0 \%$, and 6.6 to $-1.0 \%$ (increase), respectively, on the 1992 DDC engine. On the 2004 Cummins engine, the emissions of CO with the cetane improvers either showed no significant difference or reductions of up to $14.7 \%$ compared to the base fuels (excluding biodiesel blends), while THC and TPM had no significant difference.

Compared to the base fuel (excluding biodiesel blends) during steady state testing, the emissions of NOx showed up to a $1.8 \%$ increase at $100 \%$ load and up to an $8 \%$ decrease at $25 \%$ load on the 1992 DDC engine. The emissions of CO reduced (up to 26\%) for all modes, and THC had no change for some modes and reductions (up to 39\%) for others when compared to the base fuels (excluding biodiesel blends). For the 2004 Cummins engine, no change in NOx or a $6 \%$ NOx increase with additives was noticed during SET tests when compared to the base fuel (excluding biodiesel blends).

For both engines on the FTP cycle, the B20 biodiesel blends of soy, tallow, and cottonseed fuels significantly reduced CO (9.8-14.4\%), THC (12-34.2\%), and TPM (23.2-34.7\%) compared to the 
neat fuel. The NOx emissions significantly decreased (2.1-2.2\%) on the 1992 DDC engine and significantly increased (2.8-4.3\%) on the 2004 Cummins engine compared to the neat fuel. The neat fuel used for the biodiesel blends on the 1992 DDC engine was of lower cetane (46.2) than the neat fuel (49.9) on the 2004 Cummins engine. The addition of a cetane improver to the biodiesel blends resulted in no significant difference on the 2004 Cummins, while the NOx emissions were reduced (0.7-0.9\%) on the 1992 DDC engine. During the SET tests, the biodiesel blends showed similar trends as the additized neat fuel with reduced NOx at low load and increased NOx at high load on the 1992 DDC engine, suggesting a cetane effect created by the biodiesel.

The fuel additives reduced the premix fraction of the heat release for all loads on the 1992 DDC engine and low load on the 2004 Cummins engine. The reduction of the premix fraction with the cetane improvers on the 1992 DDC engine correlated with NOx change, although the premix fraction was a function of injection timing. The change in peak cylinder gas temperature and the change in NOx with the cetane improvers showed consistent correlations between steady state and transient testing on the 1992 DDC engine.

The 2004 Cummins engine had higher boost pressure, MAT, and intake air flow, which may have reduced the premix fraction. Disabling the EGR had no effect on the ability of the cetane improvers to reduce NOx on the 2004 Cummins engine. More control over the 2004 Cummins engine is needed to determine cetane improver effects, since large variations in the steady state emissions were noticed for repeat tests. These variations were attributed to changes in the ECU engine control.

On the transient heat release cycles, a similar change in heat release was obtained with the use of fuel additives as in the steady state modes. As the engine accelerated from low load to high load, the NOx decreased then had no change or a NOx increase with the premix fraction being high at low load and low at high load.

The phenomenological combustion model showed that the change in global heat release by the cetane improvers on the 1992 DDC engine was the cause of the fuel additives' changes in NOx. 
The combustion model was applied to the steady state modes and a 45-second section of the FTP cycle. The steady state percent change in NOx trend with the cetane improvers agreed with the experimental values, except at $100 \%$ load. The percent reduction of the integrated NOx from the combustion model for the base and additized fuels agreed within $1.1 \%$ of the experimental NOx over the 45-second section of the FTP.

The strong correlations between the change in NOx and the change in heat release parameters showed that cetane improvers shift the heat release profile creating reduced NOx at low load and increased NOx at high load. The phenomenological combustion model related the shifted heat release profile to the change in NOx, thereby solidifying that the reduced ignition delay creates the conditions for both reduced NOx at low load and increased NOx at high load. The tools of analyzing the heat release parameters and the phenomenological combustion model provided a technique to separate the influence of a shifted heat release profile (and therefore, a shifted cylinder temperature and pressure) from other effects (chemical formation, lower adiabatic flame temperature, and increased EGR). The application of the heat release analysis and combustion model was able to distinguish differences between steady state and transient operation.

\subsection{Recommendations}

Emissions testing, a detailed heat release analysis, and a NOx combustion model were used to determine the influence of cetane improvers on emissions. The heat release analysis and combustion model were applied to steady state and transient testing. The analysis methods (heat release parameters and combustion model) could be applied to any number of fuel studies including biodiesel, combustion improver additives, or oxygenates. A change in the fuel may create a chemical formation effect and a shifted heat release rate profile. Correlating the change in heat release parameters to the change in emissions would help determine how much a shifted global heat release effects the emissions. The NOx combustion model provides more understanding of how a shifted global heat release rate effects emissions.

These methodologies could be applied in engine control studies to help adjust fuel injection characteristics. With engine control dependent on operating conditions (steady state or 
transient), applying the heat release analysis and combustion model to transient conditions could be used to improve engine tuning.

Some recommendations for further studying of the effect of fuel additives on diesel engine emissions and performance are:

- The use of a more complex combustion model, with full kinetics, may improve the correlation with experimental results.

- The SET tests, especially on the 2004 Cummins engine or newer engines, should have multiple tests for statistical significance.

- Based on the results of the 1992 DDC engine, the use of a fuel additive that ignites early after injection, but slows burning (low premix spike and high diffusion) may provide maximum NOx reduction.

- Due to the nature of how cetane improvers cause increased NOx at high load, a fuel additive that reduces ignition delay at low load, but increases the ignition delay at high load may provide the most NOx reduction for the 1992 DDC engine.

- A greater number of additives varieties could be investigated, such as metal-based additives (platinum/cerium).

- Increasing levels of nitrogen in the fuel might be interesting to investigate since very little, if any, literature has looked into fuel-borne NOx for diesel engines. However, nitrogen levels in present United States on-road fuels are typically low ( $<300 \mathrm{ppmw})$. A $100 \%$ fuel-borne nitrogen conversion rate from $24 \mathrm{ml} / \mathrm{gal} 2$-EHN on the 2004 Cummins engine would be up to $6 \%$ of the total NOx mass produced by the engine. 


\section{References}

1. September 2003 Report: National Air Quality and Emissions Trends Report, 2003 Special Studies Edition, Environmental Protection Agency, Washington, DC, USEPA \#454/R-03005, 2003.

2. Pope, C. III, "Air Pollution and Health -- Good News and Bad," The New England Journal of Medicine, Vol. 351, pgs. 1132-1134, 2004.

3. Maitre, A., Bonneterre, V., Huillard, L., Sabatier, P., and de Gaudemaris, R., "Impact of Urban Atmospheric Pollution on Coronary Disease," Vol. 27, pgs. 2275-2284, European Heart Journal, 2006.

4. Frey, H., Unal, A., Rouphall, N., and Colyar, J., "On-Road Measurement of Vehicle Tailpipe Emissions Using a Portable Instrument," Journal of the Air \& Waste Management Association, Vol. 53, pgs. 992-1002, 2003.

5. "Notice of Filing of Consent Decree under the Clean Air Act," Office of the Federal Register National Archives and Records Administration, Vol. 63, No. 212, Washington, D.C, 1998.

6. Seneczko, M., "Quest for a Million-Mile Vehicle," Machine Design, Vol. 55, No. 21, pgs. 40-48, 1983.

7. The California Diesel Fuel Regulations, in Title 13, California Code of Regulations, 2004.

8. Kullnowski, A., Henly, T., and Growcott, P., "Diesel Fuel Additives to Meet Worldwide Performance and Emissions Requirements," Warrendale, PA, SAE Paper No. 932737, 1993.

9. Lange, W., Cooke, J., Gadd, P., Zurner, H., Schlogl, H., and Richter, K., "Influence of Fuel Properties on Exhaust Emissions from Advanced Heavy-Duty Engines Considering the Effect of Natural and Additive Enhanced Cetane Number," Warrendale, PA, SAE Paper No. 972894, 1997.

10. Ryan III, T., Buckingham, J., Dodge, L., and Olikara, C., "The Effects of Fuel Properties on Emissions from a 2.5gm NOx Heavy-Duty Diesel Engine," Warrendale, PA, SAE Paper No. 982491, 1998.

11. Barbier, P., "Evaluation of Cetane Improver Effects on Regulated Emissions from a Passenger Car Equipped with a Common Rail Diesel Engine," Warrendale, PA, SAE Paper No. 2000-01-1853, 2000. 
12. Wong, C. and Gilbert, J., "Investigation of the Performance of a Heavy Duty Diesel Truck Engine Operating on Low Cetane Diesel Fuel," Warrendale, PA, SAE Paper No. 881647, 1988.

13. McMillan, M. and Halsall, R., "Fuel Effects on Combustion and Emissions in a Direct Injection Diesel Engine,” Warrendale, PA, SAE Paper No. 881650, 1988.

14. Sienicki, E., Jass, R., Slodowske, W., McCarthy, C., and Krodel, A., "Diesel Fuel Aromatic and Cetane Number Effects on Combustion and Emissions From a Prototype 1991 Diesel Engine," Warrendale, PA, SAE Paper No. 902172, 1990.

15. Li, X., Chippior, W., and Gülder, Ö., "Effects of Cetane Enhancing Additives and Ignition Quality on Diesel Engine Emissions,” Warrendale, PA, SAE Paper No. 972968, 1992.

16. Code of Federal Regulations, "Control of Emissions from New and In-Use Highway Vehicles and Engines," CFR Title 40 Part 86, Office of the Federal Register National Archives and Records Administration, Washington, DC, 2004.

17. "Standard Test Method for Cetane Number of Diesel Fuel Oil," American Society for Testing and Materials, West Conshohocken, PA, ASTM-D613-05, 2005.

18. Lange, W., "The Effect of Fuel Properties on Particulates Emissions in Heavy-Duty Truck Engines Under Transient Operating Conditions," Warrendale, PA, SAE Paper No. 912425, 1991.

19. McCarthy, C., Slodowske, W., Sien.0icki, E., and Jass, R., "Diesel Fuel Property Effects on Exhaust Emissions from a Heavy Duty Diesel Engine that Meets 1994 Emissions Requirements,” Warrendale, PA, SAE Paper No. 922267, 1992.

20. Singal, S. and Pundir, B., "Diesel Fuel Quality and Particulate Emissions: An Overview," Warrendale, PA, SAE Paper No. 961185, 1996.

21. Reddy, V., "Evaluation of Current and Early Production Electronically Controlled HeavyDuty Diesel Engine Emissions Based on Fuel Property Differences,” Master's Thesis, West Virginia University, 2006.

22. Ochoterena, R., Larsson, M., Andersson, S., and Denbratt, I., "Optical Studies of Spray Development and Combustion Characterisation of Oxygenated and Fischer-Tropsch FuelsGTL Fuels,” Warrendale, PA, SAE Paper No. 2008-01-1393, 2008.

23. Wall, J. and Hoekman, S., "Fuel Composition Effects on Heavy-Duty Diesel Particulate Emissions," Warrendale, PA, SAE Paper No. 841364, 1984. 
24. Bello, A., Torres, J., Herrera J., and Sarmiento, J., "Effect of the Diesel Properties on the Emissions of Particulate Matter," Warrendale, PA, SAE Paper No. 2000-01-2888, 2000.

25. Ullman, T., "Investigation of the Effects of Fuel Composition on Heavy-Duty Diesel Engine Emissions," Warrendale, PA, SAE Paper No. 892072, 1989.

26. Signer, M., Heinze, P., Mercogliano, R., and Stein H., "European Programme on Emissions, Fuels and Engine Technologies (EPEFE) - Heavy Duty Diesel Study," Warrendale, PA, SAE Paper No. 961074, 1996.

27. Den Ouden, C., Clark, R., Cowley, L., Stradling R., Lange, W., and Maillard, C., "Fuel Quality Effects on Particulate Matter Emissions from Light-and Heavy-Duty Diesel Engines,” Warrendale, PA, SAE Paper No. 942022, 1994.

28. Flanigan, C., Litzinger, T., and Graves, R. "The Effect of Aromatics and Cycloparaffins on DI Diesel Emissions,” Warrendale, PA, SAE Paper No. 892130, 1989.

29. Bertoli, C., Giacomo, N., Iorio, B., and Prati, M., "The Influence of Fuel Composition on Particulate Emissions of DI Diesel Engines,” Warrendale, PA, SAE Paper No. 932733, 1993.

30. Kidoguchi, Y., Yang, C., and Miwa, K., "Effects of Fuel Properties on Combustion and Emission Characteristics of a Direct-Injection Diesel Engine," Warrendale, PA, SAE Paper No. 2000-01-1851, 2000.

31. Baranescu, R., "Influence of Fuel Sulfur on Diesel Particulate Emissions," Warrendale, PA, SAE Paper No. 881174, 1988.

32. Higgins, B., Siebers, D., Mueller, C., and Aradi, A., "Effects of an Ignition-Enhancing, Diesel-Spray Evaporation, Mixing, Ignition, and Combustion,” Twenty-Seventh Symposium (International) on Combustion, The Combustion Institute, pgs.1873-1880, 1998.

33. McCormick, R., Alvarez, J., Graboski, M., Tyson, K., and Vertin, K., "Fuel Additive and Blending Approaches to Reducing NOx Emissions from Biodiesel," Warrendale, PA, SAE Paper No. 2002-01-1658, 2002.

34. Hess, H., Boehman, A., Tijm, P., and Waller, F., "Experimental Studies of the Impact of CETANER on Diesel Combustion and Emissions," Warrendale, PA, SAE Paper No. 200001-2886, 2000.

35. Liotta, F. and Mantalvo, D., "The Effect of Oxygenated Fuels on Emissions from a Modern Heavy-Duty Diesel Engine," Warrendale, PA, SAE Paper No. 932734, 1993. 
36. Ullman, T., Spreen, K., and Mason, R., "Effects of Cetane Number, Cetane Improver, Aromatics, and Oxygenates on 1994 Heavy Duty Diesel Engine Emissions," Warrendale, PA, SAE Paper No. 941020, 1994.

37. Zannis, T., Hountalas, D., and Kouremenos, D., "Experimental Investigation to Specify the Effect of Oxygenated Additive Content and Type on DI Diesel Engine Performance and Emissions" Warrendale, PA, SAE Paper No. 2004-01-0097, 2004.

38. Lu, X., Yang, J., Zhang, W., and Huang, Z., "Improving Combustion and Emissions of Direct Injection Compression and Emissions of Direct Injection Compression Ignition Engines Using Oxygenated Fuel Additives Combined with a Cetane Improver," Energy \& Fuels, Vol. 19 No. 5, pgs. 1879 -1888, 2005.

39. Song, J., Zello, V., Boehman, A., and Waller, F., "Comparison of the Impact of Intake Oxygen Enrichment and Fuel Oxygenation on Diesel Combustion and Emissions," Energy \& Fuels, Vol. 18 No. 5, 2004.

40. Bertola, A. and Boulouchos, K., "Oxygenated Fuels for Particulate Emissions Reduction in Heavy-Duty DI-Diesel Engines with Common-Rail Fuel Injection," Warrendale, PA, SAE Paper No. 2000-01-2885, 2000.

41. Nylund, N. and Aakko, P., "Characterization of New Fuel Qualities," Warrendale, PA, SAE Paper No. 2000-01-2009, 2000.

42. Caton, J., Ruemmele, W., Kelso, D., and Epperly, W., "Performance and Fuel Consumption of a Single-Cylinder, Direct-Injection Diesel Engine Using a Platinum Fuel Additive," Warrendale, PA, SAE Paper No. 910229, 1991.

43. Valentine, J., Peter-Hoblyn, J., and Acres, G., "Emissions Reduction and Improved Fuel Economy Performance from a Bimetallic Paltinum/Cerium Diesel Fuel Additive at UltraLow Dose Rates," Warrendale, PA, SAE Paper No. 2000-01-1934, 2000.

44. "Standard Specification for Diesel Fuel Oils," American Society for Testing and Materials, West Conshohocken, PA, ASTM-D975-06, 2006.

45. Langer, D., Petek, N., and Schiferl, E., "Maximizing the Effectiveness of Water Blended Fuel in Reducing Emissions by Varying Injection Timing or Using Aftertreatment Device," Warrendale, PA, SAE Paper No. 2001-01-0513, 2001.

46. Kowalewicz, A. and Wojtyniak, M., "Alternative Fuels and their Application to Combustion Engines," Journal of Automobile Engineering, Vol. 219, pgs. 103-125, 2005. 
47. Canakci, M., "Performance and Emissions Characteristics of Biodiesel from Soybean Oil," Journal of Automobile Engineering, Vol. 219, pgs. 915-922, 2005.

48. Szybist, J., Kirby, S., and Boehman, A., "NOx Emissions of Alternative Diesel Fuels: A Comparative Analysis of Biodiesel and FT Diesel," Energy \& Fuels, Vol. 19 No. 4, pgs. 1484-1492, 2005.

49. Bari, S., Yu, C., and Lim, T., "Filter Clogging and Power Loss Issues while Running a Diesel Engine with Waste Cooking Oil," Journal of Automobile Engineering, Vol. 216, pgs. 9931001, 2002.

50. Atkinson, C., Thompson, G., Traver, M., and Clark, N., "In-Cylinder Combustion Pressure Characteristics of Fischer-Tropsch and Conventional Diesel Fuels in a Heavy Duty CI Engine," Warrendale, PA, SAE Paper No. 1999-01-1472, 1999.

51. Yongcheng, H., Longbao, Z., Shangxue, W., and Shenghua, L., "Study on the Performance and Emissions of a Compression Ignition Engine Fuelled with Fischer-Tropsch Diesel Fuel," Journal of Automobile Engineering, Vol. 220, pgs. 827-835 2006.

52. Warnatz, J., Maas, U., and Dibble, R. W., Combustion, Physical and Chemical Fundamentals, Modeling and Simulation, Springer-Verlag, New York City, NY, 1996.

53. Dec, J.., "A Conceptual Model of DI Diesel Combustion Based on Laser-Sheet Imaging," Warrendale, PA, SAE Paper No. 970873, 1997.

54. Dec, J. and Canaan, R., "PLIF Imaging of NO Formation in a DI Diesel Engine," Warrendale, PA, SAE Paper No. 980147, 1998.

55. Aceves, S., Flowers, D., Martinez-Frias, J., Smith, J., Dibble, R., Au, M., and Girard, J., "HCCI Combustion: Analysis and Experiments," Warrendale, PA, SAE Paper No. 2001-012077, 2001.

56. Alkidas, A., "On the Premixed Combustion in a Direct Injection Diesel Engine," Journal of Engineering for Gas Turbines and Power, Vol. 109, pgs.187-192, 1987.

57. “Emission Formation in Diesel Engines,” DieselNet, Brampton, ON, Canada, 2006. http://www.dieselnet.com/tech/diesel emiform.html (accessed June 24, 2008).

58. Health Effects Institute, "Diesel Exhaust: Critical Analysis of Emissions, Exposure, and Health Effects," Health Effects Institute, Cambridge, MA, 1995.

59. Inventory of U.S. Greenhouse Gas Emissions and Sinks: 1990-2004, Environmental Protection Agency, Washington, DC, USEPA \#430-R-06-002, 2006. 
60. Heywood, J.B., Internal Combustion Engine Fundamentals, McGraw-Hill, New York City, NY, 1988.

61. Woshni, G., "A Universally Applicable Equation for the Instantaneous Heat Transfer Coefficient in the Internal Combustion Engine," Warrendale, PA, SAE Paper No. 670931, 1967.

62. Brunt, M. and Platts, K., "Calculation of Heat Release in Direct Injection Diesel Engines," Warrendale, PA, SAE Paper No. 1999-01-0187, 1999.

63. Assanis, D., Filipi, Z., Fiveland, S., and Syrimis, M., "A Methodology for Cycle-By-Cycle Transient Heat Release Analysis in a Turbocharged Direct Injection Diesel Engine," Warrendale, PA, SAE Paper No. 2000-01-1185, 2000.

64. Galindo, J., Bermudez, V., Serrano, J., and Lopez, J., "Cycle to Cycle Diesel Combustion Characterization during Engine Transient Operation," Warrendale, PA, SAE Paper No. 200101-3262, 2001.

65. Stiesch, G., Modeling Engine Spray and Combustion Processes, Springer, New York City, NY, 2003.

66. Singh, S., Reitz, R., and Musculus, M., "Comparison of the Characteristic Time (CTC), Representative Interactive Flamelet (RIF), and Direct Integration with Detailed Chemistry Combustion Models against Optical Diagnostic Data for Multi-Mode in a Heavy-Duty DI Diesel Engine,” Warrendale, PA, SAE Paper No. 2006-01-0055, 2006.

67. Turns, S.R., An Introduction to Combustion: Concepts and Applications, Second Edition, McGraw-Hill, New York City, NY, 2000.

68. Hernandez, J., Lapuerta, M., and Perez-Collado, J., A Combustion Kinetic Model for Estimating Diesel Engine NOx Emissions," Combustion Theory and Modeling, Vol. 10, pgs. 639-657, 2006.

69. Tincher, R., "Evaluation of Heavy Duty Diesel Engines Regulated Emissions Based on Variation of Fuel Properties by Use of Additives," M.S. Thesis, Department of Mechanical and Aerospace Engineering, West Virginia University, Morgantown, WV, 2007.

70. Nandi, M. and Jacobs, D., “Cetane Response of Di-tertiary-butyl Peroxide in Different Diesel Fuels,” Warrendale, PA, SAE Paper No. 952368, 1995.

71. "Fuel Additive Packages Containing 2-Ethylhexyl Nitrate (2-EHN) - Best Practices Manual," Additives Technical Committee, Europe, 2004. 
72. “Material Safety Data Sheet - NOROX DTBP,” Norac Inc., Azusa, CA, 2006.

73. "DI-tert-BUTYL PEROXIDE," International Programme on Chemical Safety, CAS No. 110-05-4, Switzerland, 1999.

74. "6125B Specifications", Kistler Instrumentation Corporation, Amherst, NY, 2008.

75. “6061B Specifications”, Kistler Instrumentation Corporation, Amherst, NY, 2008.

76. Brunt, M. and Pond, C., "Evaluation of Techniques for Absolute Cylinder Pressure Correction,” Warrendale, PA, SAE Paper No. 970036, 1997.

77. Lyn, W. and Valdmanis, E., "The Effects of Physical Factors on Ignition Delay," Warrendale, PA, SAE Paper No. 680102, 1968.

78. Brunt, M. and Emtage, A., "Evaluation of Burn Rate Routines and Analysis Errors," Warrendale, PA, SAE Paper No. 970037, 1997.

79. Brunt, M. and Emtage, A., "Evaluation of IMEP Routines and Analysis Errors," Warrendale, PA, SAE Paper No. 960609, 1996.

80. Park, S. and Sunwoo, M., "Torque Estimation of Spark Ignition Engines via Cylinder Pressure Measurement," Journal of Automobile Engineering, Vol. 217, pgs. 809-817, 2003.

81. Miyamoto, N., Chikahisa, T., Murayama, T., and Sawyer, R., "Description and Analysis of Diesel Engine Rate of Combustion and Performance Using Weibe's Functions," Warrendale, PA, SAE Paper No. 850107, 1985.

82. Schreiner, K., "Equivalent Combustion Rate with the Polygon-Hyperbola Function: Investigations into the Dependence of the Parameters in the Performance Map," Proc 5th Symposium, "The Working Process of the Internal Combustion Engine," Technical University Graz, Austria, pgs. 239-257, 1995.

83. Ceviz, M., Kaymaz, İ., "Temperature and air-fuel ratio dependent specific heat ratio functions for lean burned and unburned mixture," Energy Conversion and Management, Vol. 46, pp. 2387-2404, 2005.

84. Lanzafame, R. and Messina, M., "ICE Gross Heat Release Strongly Influenced by Specific Heat Ratio Values," International Journal of Automotive Technology, Vol. 4, No. 3, pp. 1251333, 2003.

85. Klein, M. and Eriksson, L., "A Specific Heat Ratio Model for Single-Zone Heat Release Models,” SAE International, Warrendale, PA, SAE Paper No. 2004-01-1464, 2004. 
86. Brunt, M. and Platts, K., "Calculation of Heat Release in Direct Injection Diesel Engines," SAE International, Warrendale, PA, SAE Paper No. 1999-01-0187, 1999.

87. Arrègle, J., López, J., García, J., and Fenollosa, C., "Development of a Zero-Dimensional Diesel Combustion Model. Part 1: Analysis of the Quasi-Steady Diffusion Combustion Phase,” Applied Thermal Engineering, Vol. 23, pp 1301-1317, 2003.

88. Arrègle, J., López, J., García, J., and Fenollosa, C., "Development of a Zero-Dimensional Diesel Combustion Model. Part 2: Analysis of the Transient Initial and Final Diffusion Combustion Phases," Applied Thermal Engineering, Vol. 23, pgs. 1319-1331, 2003.

89. Ferguson, C. and Kirkpatrick, A., Internal Combustion Engines, John Wiley \& Sons, Inc., Hoboken, NJ, 2000.

90. Miller, R., Davis, G., Lavoie, G., Newman, C., and Gardner, T., "A Super-Extended Zeldovich Mechanism and Engine Calibration," SAE International, Warrendale, PA, SAE Paper No. 980781, 1998.

91. Kobori, S., Kamimoto, T., and Aradi, A., "A Study of Ignition Delay of Diesel Fuel Sprays," International Journal of Engine Research, Vol. 1, pgs.29-39, 2000.

92. Aoyagi, Y., Kunishima, E., Asaumi, Y., Aihara, Y., Odaka, M. and Goto, Y., "Diesel Combustion and Emission Using High Boost and High Injection Pressure in a Single Cylinder Engine," JSME International Journal, Series B: Fluids and Thermal Engineering, Vol. 48, pgs.648-655, 2006.

93. Kim, S., Wakisaka, T., and Aoyagi, Y., "A Numerical Study of the Effects of Boost Pressure and Exhaust Gas Recirculation Ratio on the Combustion Process and Exhaust Emissions in a Diesel Engine," International Journal of Engine Research, Vol. 8, pgs.147-162, 2007.

94. Clark, N., Jarrett, R., and Atkinson, C., "Field Measurements of Particulate Matter Emissions, Carbon Monoxide, and Exhaust Opacity from Heavy-Duty Diesel Vehicles," Journal of the Air \& Waste Management Assoc., Vol. 49, pgs.76-84, 1999.

95. Brakora, J., Ra, Y., Reitz, R., Mcfarlane, J., and Daw, C., "Development and Validation of a Reduced Reaction Mechanism for Biodiesel Fueled Engine Simulations," SAE International, Warrendale, PA, SAE Paper No. 2008-01-1378, 2008. 


\section{Appendices}

Table 7-1 Fuel Properties

\begin{tabular}{|c|c|c|c|c|c|c|c|c|}
\hline $\begin{array}{r}\text { Test } \\
\text { Method }\end{array}$ & Fuel Property & Units & $\begin{array}{c}\text { Grad } \\
\text { Ref }\end{array}$ & $\begin{array}{l}\text { Grad } \\
\text { Cand }\end{array}$ & $\begin{array}{l}\text { CP } \\
\text { Cert } \\
\end{array}$ & $\begin{array}{l}\text { CP } \\
\text { Cert } \\
\text { B20 } \\
\text { Soy } \\
\end{array}$ & $\begin{array}{c}\text { CP } \\
\text { Cert } \\
\text { B20 } \\
\text { Mineral } \\
\end{array}$ & $\begin{array}{c}\text { CP Cert } \\
\text { B20 } \\
\text { Cottonseed }\end{array}$ \\
\hline \multirow[t]{3}{*}{ D4052s } & API Gravity @60F & - & 38.5 & 38.2 & 35.3 & 33.8 & 34.2 & 33.9 \\
\hline & $\begin{array}{c}\text { Specific Gravity } \\
\text { @60F }\end{array}$ & - & 0.8323 & 0.834 & 0.8486 & 0.8558 & 0.854 & 0.8553 \\
\hline & Density @15C & $g / L$ & 831.8 & 833.5 & 848.1 & 855.3 & 853.5 & 854.8 \\
\hline D445 40c & Viscosity & cSt & 2.669 & 2.471 & 2.61 & 2.914 & 2.986 & 2.949 \\
\hline \multirow[t]{3}{*}{ D5186 } & Total Aromatics & $\begin{array}{c}\operatorname{mass} \\
\%\end{array}$ & 7.4 & 27.1 & 33 & 33.3 & 33.4 & 36.7 \\
\hline & Mono Aromatics & $\begin{array}{c}\operatorname{mass} \\
\%\end{array}$ & 6.5 & 21.2 & 25.7 & 23.6 & 23.6 & 22.1 \\
\hline & Poly Aromatics & $\begin{array}{c}\text { mass } \\
\%\end{array}$ & 0.9 & 5.9 & 7.3 & 9.7 & 9.7 & 14.6 \\
\hline \multirow[t]{2}{*}{ D5291 } & Carbon & wt $\%$ & 85.02 & 85.9 & 86.01 & 84.24 & 84.05 & 83.94 \\
\hline & Hydrogen & wt \% & 14 & 13.23 & 12.97 & 12.66 & 12.68 & 12.44 \\
\hline \multirow[t]{3}{*}{ Calculated } & Oxygen $^{a}$ & wt $\%$ & 0 & 0 & 0 & 2.08 & 2.25 & 2.6 \\
\hline & HtoC & - & 1.96 & 1.84 & 1.80 & 1.79 & 1.80 & 1.77 \\
\hline & OtoC & - & 0.000 & 0.000 & 0.000 & 0.019 & 0.020 & 0.023 \\
\hline D4629 & Nitrogen & ppmw & 13.8 & 6.4 & 68.4 & 66.7 & 66.9 & 69.3 \\
\hline D5453 & Sulfur & ppmw & 3.3 & 3.7 & 319.5 & 274.4 & 275.9 & 280.3 \\
\hline D613 & Cetane Number & - & 60.8 & 51.7 & 49.9 & 52.8 & 54.6 & 53.4 \\
\hline D4737A & Cetane Index & - & 52.7 & 50.9 & 47.3 & 48.3 & 48.7 & 48.0 \\
\hline D976 & Cetane Index & - & 51.4 & 50.9 & 47.3 & 49.3 & 49.6 & 49.2 \\
\hline \multirow[t]{17}{*}{ D86 } & Distillation - IBP & ${ }^{\circ} \mathrm{F}$ & 383.9 & 349.0 & 350.1 & 360.5 & 339.0 & 362.4 \\
\hline & Distillation - $5 \%$ & ${ }^{\circ} \mathrm{F}$ & 406.9 & 374.9 & 359.5 & 397.3 & 383.4 & 396.1 \\
\hline & Distillation - $10 \%$ & ${ }^{\circ} \mathrm{F}$ & 426.2 & 398.7 & 408.7 & 430.4 & 420.7 & 428.5 \\
\hline & Distillation - $15 \%$ & ${ }^{\circ} \mathrm{F}$ & 438.0 & 411.6 & 427.9 & 449.1 & 443.9 & 451.3 \\
\hline & Distillation - $20 \%$ & ${ }^{\circ} \mathrm{F}$ & 447.0 & 426.4 & 441.3 & 466.8 & 464.2 & 468.7 \\
\hline & Distillation - $\mathbf{3 0} \%$ & ${ }^{\circ} \mathrm{F}$ & 463.2 & 452.5 & 464.8 & 496.2 & 492.7 & 497.3 \\
\hline & Distillation - $40 \%$ & ${ }^{\circ} \mathrm{F}$ & 479.4 & 475.7 & 483.9 & 519.4 & 516.2 & 521.2 \\
\hline & Distillation - $50 \%$ & ${ }^{\circ} \mathrm{F}$ & 493.8 & 494.2 & 501.8 & 542.5 & 539.8 & 543.4 \\
\hline & Distillation - $60 \%$ & ${ }^{\circ} \mathrm{F}$ & 509.2 & 512.1 & 520.1 & 566.7 & 562.5 & 565.5 \\
\hline & Distillation $-70 \%$ & ${ }^{\circ} \mathrm{F}$ & 525.2 & 529.6 & 539.6 & 590.8 & 586.7 & 588.6 \\
\hline & Distillation - $80 \%$ & ${ }^{\circ} \mathrm{F}$ & 545.4 & 550.7 & 562.1 & 613.4 & 609.0 & 610.3 \\
\hline & Distillation - $90 \%$ & ${ }^{\circ} \mathrm{F}$ & 575.0 & 581.7 & 592.6 & 633.9 & 629.8 & 630.6 \\
\hline & Distillation - 95\% & ${ }^{\circ} \mathrm{F}$ & 600.3 & 609.5 & 617.3 & 647.6 & 644.1 & 644.7 \\
\hline & Distillation - FBP & ${ }^{\circ} \mathrm{F}$ & 624.1 & 640.5 & 643.0 & 657.0 & 662.0 & 661.2 \\
\hline & Recovered & $\mathrm{mL}$ & 97.3 & 98.3 & 96.1 & 97.3 & 97.2 & 98.5 \\
\hline & Residue & $\mathrm{mL}$ & 1.1 & 0.1 & 1.1 & 1.2 & 1 & 1 \\
\hline & Loss & $\mathrm{mL}$ & 1.6 & 1.6 & 2.8 & 1.5 & 1.8 & 0.5 \\
\hline D93 & Flash Point & ${ }^{\circ} \mathrm{F}$ & 104 & 154 & 162 & 164 & 168 & 167 \\
\hline D2500 & Cloud Point & ${ }^{\circ} \mathrm{C}$ & -24 & -15 & -20 & -10 & -9 & -12 \\
\hline wvU & LHV & $\mathrm{MJ} / \mathbf{k g}$ & 42.81 & 42.59 & 42.45 & 41.23 & 41.24 & 41.25 \\
\hline
\end{tabular}


Table 7-2 Fuel Properties Continued

\begin{tabular}{|c|c|c|c|c|c|c|c|}
\hline $\begin{array}{r}\text { Test } \\
\text { Method }\end{array}$ & Fuel Property & Units & LC & $\begin{array}{l}\text { LC } \\
\text { B20 } \\
\text { Soy }\end{array}$ & $\begin{array}{l}\text { LC B20 } \\
\text { Mineral }\end{array}$ & $\begin{array}{c}\text { LC B20 } \\
\text { Cottonseed }\end{array}$ & Guttman \\
\hline \multirow{3}{*}{ D4052s } & API Gravity @60F & - & 33.1 & 31.6 & 31.7 & 31.5 & 44.7 \\
\hline & $\begin{array}{c}\text { Specific Gravity } \\
\text { @60F }\end{array}$ & - & 0.8598 & 0.8675 & 0.8668 & 0.8682 & 0.8032 \\
\hline & Density@15C & $g / L$ & 859.3 & 867 & 866.3 & 867.7 & 802.8 \\
\hline D445 40c & Viscosity & cSt & 2.67 & 2.847 & 2.888 & 2.848 & 2.091 \\
\hline \multirow[t]{3}{*}{ D5186 } & Total Aromatics & $\begin{array}{c}\operatorname{mass} \\
\%\end{array}$ & 39.3 & 38.5 & 39.4 & 40.4 & 9.3 \\
\hline & Mono Aromatics & $\underset{\%}{\operatorname{mass}}$ & 31.2 & 34 & 35 & 34.1 & 8.8 \\
\hline & Poly Aromatics & $\begin{array}{c}\operatorname{mass} \\
\%\end{array}$ & 8.1 & 4.5 & 4.4 & 6.3 & 5.6 \\
\hline \multirow[t]{2}{*}{ D5291 } & Carbon & wt \% & 85.23 & 83.77 & 84.11 & 83.59 & 85.35 \\
\hline & Hydrogen & wt \% & 12.56 & 12.31 & 12.22 & 12.32 & 14 \\
\hline \multirow[t]{3}{*}{ Calculated } & Oxygen $^{a}$ & wt $\%$ & 0 & 1.71 & 1.46 & 1.88 & 0 \\
\hline & HtoC & - & 1.76 & 1.75 & 1.73 & 1.76 & 1.95 \\
\hline & Otoc & - & 0.000 & 0.015 & 0.013 & 0.017 & 0.000 \\
\hline D4629 & Nitrogen & ppmw & 16.5 & 27.5 & 31.4 & 31.7 & 5.6 \\
\hline D5453 & Sulfur & ppmw & 8 & 5.1 & 5.6 & 5.2 & 13.9 \\
\hline D613 & Cetane Number & - & 46.2 & 48.8 & 48.9 & 47.7 & 58.3 \\
\hline D4737A & Cetane Index & - & 43.0 & 42.7 & 42.7 & 42.3 & 58.7 \\
\hline D976 & Cetane Index & - & 43.4 & 43.8 & 43.7 & 43.3 & 57.9 \\
\hline \multirow[t]{17}{*}{ D86 } & Distillation - IBP & ${ }^{\circ} \mathrm{F}$ & 354.1 & 360.7 & 370.9 & 366.5 & 321.7 \\
\hline & Distillation - $5 \%$ & ${ }^{\circ} \mathrm{F}$ & 381.2 & 410.1 & 409.6 & 406.6 & 352.1 \\
\hline & Distillation - $10 \%$ & ${ }^{\circ} \mathrm{F}$ & 414.2 & 432.1 & 432.6 & 431.7 & 365.8 \\
\hline & Distillation - $15 \%$ & ${ }^{\circ} \mathrm{F}$ & 431.5 & 445.2 & 446.5 & 445.2 & 374.9 \\
\hline & Distillation - $20 \%$ & ${ }^{\circ} \mathrm{F}$ & 441.8 & 457.6 & 459.3 & 458.0 & 385.9 \\
\hline & Distillation - $\mathbf{3 0} \%$ & ${ }^{\circ} \mathrm{F}$ & 463.5 & 480.7 & 480.6 & 481.2 & 408.7 \\
\hline & Distillation - $40 \%$ & ${ }^{\circ} \mathrm{F}$ & 482.8 & 504.4 & 502.4 & 501.2 & 434.2 \\
\hline & Distillation - $50 \%$ & ${ }^{\circ} \mathrm{F}$ & 500.8 & 526.2 & 524.0 & 523.3 & 464.5 \\
\hline & Distillation - $60 \%$ & ${ }^{\circ} \mathrm{F}$ & 520.8 & 550.9 & 547.8 & 547.5 & 498.8 \\
\hline & Distillation - $70 \%$ & ${ }^{\circ} \mathrm{F}$ & 542.0 & 578.2 & 574.2 & 573.2 & 536.0 \\
\hline & Distillation - $80 \%$ & ${ }^{\circ} \mathrm{F}$ & 565.5 & 604.7 & 600.0 & 599.4 & 570.7 \\
\hline & Distillation - $90 \%$ & ${ }^{\circ} \mathrm{F}$ & 595.2 & 627.7 & 622.9 & 623.4 & 600.1 \\
\hline & Distillation - 95\% & ${ }^{\circ} \mathrm{F}$ & 619.3 & 640.4 & 636.7 & 636.7 & 616.6 \\
\hline & Distillation - FBP & ${ }^{\circ} \mathrm{F}$ & 641.7 & 655.1 & 654.1 & 654.4 & 631.8 \\
\hline & Recovered & $\mathrm{mL}$ & 96.9 & 97.9 & 98.4 & 98.1 & 98.3 \\
\hline & Residue & $\mathrm{mL}$ & 1 & 1.2 & 1 & 0.9 & 1.0 \\
\hline & Loss & $\mathrm{mL}$ & 2.1 & 0.9 & 0.6 & 1.0 & 0.7 \\
\hline D93 & Flash Point & ${ }^{\circ} \mathrm{F}$ & 151 & 167 & 173 & 173 & 127 \\
\hline D2500 & Cloud Point & ${ }^{\circ} \mathrm{C}$ & -20 & -15 & -10 & -14 & -16 \\
\hline wVU & LHV & $\mathrm{MJ} / \mathrm{kg}$ & 42.31 & 41.05 & 41.17 & 41.11 & 42.81 \\
\hline
\end{tabular}


Table 7-3 In-Cylinder Pressure Transducer Specifications

\begin{tabular}{|c|c|c|c|c|}
\hline \multicolumn{2}{|c|}{ Specification } & Units & 6125B & 6061B \\
\hline \multicolumn{2}{|l|}{ Range } & bar & 0 to 250 & 0 to 250 \\
\hline \multicolumn{2}{|l|}{ Overload } & bar & 300 & 300 \\
\hline \multicolumn{2}{|l|}{ Sensitivity } & $\mathrm{pC} / \mathrm{bar}$ & $\approx-16$ & $\approx-25$ \\
\hline \multicolumn{2}{|c|}{ Natural Frequency } & $\mathrm{kHz}$ & $\approx 75$ & $\approx 90$ \\
\hline \multicolumn{2}{|c|}{ Linearity } & $\% \mathrm{FSO}$ & $\leq \pm 0.5$ & $\leq \pm 0.5$ \\
\hline \multicolumn{2}{|c|}{$\begin{array}{l}\text { Operating Temperature } \\
\text { Range }\end{array}$} & ${ }^{\circ} \mathrm{C}$ & $\begin{array}{l}-50 \text { to } \\
350\end{array}$ & $\begin{array}{l}-50 \text { to } \\
350\end{array}$ \\
\hline \multirow[t]{4}{*}{$\begin{array}{l}\text { Sensitivity } \\
\text { Shift }\end{array}$} & $\begin{array}{l}200 \ldots \pm \\
150^{\circ} \mathrm{C}\end{array}$ & $\%$ & $\leq \pm 2$ & - \\
\hline & $\begin{array}{l}200 \ldots \pm \\
50^{\circ} \mathrm{C}\end{array}$ & $\%$ & $\leq \pm 1$ & - \\
\hline & $50 \pm 150^{\circ} \mathrm{C}$ & $\%$ & - & $\leq \pm 0.5$ \\
\hline & 50 to $350^{\circ} \mathrm{C}$ & $\% /{ }^{\circ} \mathrm{C}$ & - & $\leq 0.01$ \\
\hline \multirow{3}{*}{$\begin{array}{l}\text { Thermal } \\
\text { Shock at } \\
1500 \text { min-1, } 9 \\
\text { bar IMEP }\end{array}$} & $\Delta p$ & bar & $\leq-0.3$ & $< \pm 0.2$ \\
\hline & $\triangle \mathrm{IMEP}$ & $\%$ & $<-2$ & $\leq \pm 1$ \\
\hline & $\Delta p_{\max }$ & $\%$ & $<-1$ & - \\
\hline
\end{tabular}


Table 7-4 The Average Combustion Parameter Correlation Coefficients for NOx and CO from 12 SET Tests on the 1992 DDC Engine

\begin{tabular}{|c|c|c|c|c|c|c|c|c|}
\hline Parameter & $\begin{array}{c}\text { NOx } \\
\text { (g/bhp-hr) }\end{array}$ & $\begin{array}{l}\text { NOx } \\
(g / s)\end{array}$ & EINOx & $\begin{array}{c}\text { NOx } \\
(\text { ppmv) }\end{array}$ & $\begin{array}{c}\text { CO } \\
\text { (g/bhp-hr) }\end{array}$ & $\begin{array}{l}\text { co } \\
(g / s)\end{array}$ & EICO & $\begin{array}{c}\text { Co } \\
\text { (ppmv) }\end{array}$ \\
\hline Heat Released-Net (kJ) & -0.96 & 0.91 & -0.97 & 0.37 & 0.79 & 0.88 & 0.81 & 0.81 \\
\hline Heat Released-Gross (kJ) & -0.96 & 0.90 & -0.97 & 0.39 & 0.80 & 0.88 & 0.82 & 0.82 \\
\hline Max Heat Release Rate (kJ/deg) & 0.88 & -0.93 & 0.90 & -0.22 & -0.55 & -0.64 & -0.56 & -0.57 \\
\hline $\begin{array}{l}\text { Location of Max Heat Release Rate } \\
\text { (ms) }\end{array}$ & -0.52 & 0.69 & -0.55 & -0.04 & 0.58 & 0.75 & 0.60 & 0.58 \\
\hline Max Pressure (kPa) & -0.95 & 0.94 & -0.96 & 0.35 & 0.75 & 0.85 & 0.77 & 0.77 \\
\hline Location of Maximum Pressure (deg) & -0.99 & 0.86 & -0.98 & 0.56 & 0.70 & 0.74 & 0.72 & 0.73 \\
\hline Max Pressure Rise (kPa/deg) & 0.85 & -0.94 & 0.88 & -0.13 & -0.58 & -0.69 & -0.59 & -0.59 \\
\hline Location of Max Pressure Rise (ms) & 0.17 & -0.29 & 0.18 & 0.10 & -0.08 & -0.13 & -0.08 & -0.08 \\
\hline Start of Combustion (deg) & 0.91 & -0.99 & 0.91 & -0.27 & -0.58 & -0.71 & -0.60 & -0.61 \\
\hline End of Combustion (deg) & -0.92 & 0.88 & -0.94 & 0.30 & 0.74 & 0.82 & 0.76 & 0.76 \\
\hline $\begin{array}{l}\text { Indicated Mean Effective Pressure } \\
\text { (kPa) }\end{array}$ & -0.96 & 0.91 & -0.97 & 0.38 & 0.78 & 0.87 & 0.80 & 0.81 \\
\hline Location of $10 \%$ MFB (ms) & -0.83 & 0.84 & -0.86 & 0.18 & 0.84 & 0.95 & 0.86 & 0.85 \\
\hline Location of $50 \%$ MFB (ms) & -0.98 & 0.84 & -0.99 & 0.52 & 0.79 & 0.83 & 0.81 & 0.82 \\
\hline Location of $90 \%$ MFB (ms) & -0.91 & 0.64 & -0.91 & 0.63 & 0.80 & 0.78 & 0.81 & 0.83 \\
\hline Max Gas Temperature (K) & -0.96 & 0.72 & -0.94 & 0.69 & 0.71 & 0.72 & 0.73 & 0.75 \\
\hline $\begin{array}{l}\begin{array}{l}\text { Location of Max Gas Temperature } \\
\text { (ms) }\end{array} \\
\end{array}$ & -0.95 & 0.74 & -0.95 & 0.56 & 0.83 & 0.84 & 0.84 & 0.86 \\
\hline Average Temperature (K) & -0.99 & 0.81 & -0.97 & 0.62 & 0.72 & 0.75 & 0.74 & 0.76 \\
\hline Engine Speed (rpm) & -0.02 & 0.41 & -0.05 & -0.45 & -0.27 & -0.12 & -0.26 & -0.27 \\
\hline Exhaust Temperature (degC) & -1.00 & 0.88 & -0.99 & 0.53 & 0.73 & 0.79 & 0.75 & 0.76 \\
\hline Location of Premix Fraction (ms) & 0.86 & -0.89 & 0.85 & -0.38 & -0.50 & -0.62 & -0.52 & -0.53 \\
\hline Premix Fraction & 0.99 & -0.87 & 0.96 & -0.63 & -0.63 & -0.69 & -0.65 & -0.67 \\
\hline Flow Rate (m3/min) & -0.76 & 0.97 & -0.77 & 0.03 & 0.47 & 0.64 & 0.49 & 0.49 \\
\hline Pressure at SOC (kPa) & -0.90 & 0.95 & -0.92 & 0.24 & 0.74 & 0.86 & 0.76 & 0.76 \\
\hline Temperature at SOC $(\mathrm{K})$ & 0.65 & -0.60 & 0.66 & -0.29 & -0.31 & -0.34 & -0.32 & -0.33 \\
\hline Fuel Flow (kg/min) & -0.91 & 0.98 & -0.92 & 0.26 & 0.66 & 0.79 & 0.68 & 0.68 \\
\hline Fuel-to-Air Ratio & -0.97 & 0.74 & -0.95 & 0.67 & 0.73 & 0.74 & 0.75 & 0.77 \\
\hline Manifold Air Pressure (kPa) & -0.89 & 0.96 & -0.91 & 0.22 & 0.72 & 0.85 & 0.74 & 0.73 \\
\hline Ratio of EVO to IVC Pressure (-) & -0.99 & 0.83 & -0.98 & 0.58 & 0.73 & 0.77 & 0.74 & 0.76 \\
\hline Ratio of Qw-to-Qg & 0.77 & -0.94 & 0.78 & -0.11 & -0.40 & -0.55 & -0.42 & -0.42 \\
\hline Polytropic Compression & -0.54 & 0.80 & -0.57 & -0.16 & 0.30 & 0.45 & 0.31 & 0.30 \\
\hline Ignition Delay (ms) & 0.95 & -0.96 & 0.96 & -0.32 & -0.68 & -0.78 & -0.70 & -0.71 \\
\hline Injection Duration (deg) & -0.94 & 0.97 & -0.95 & 0.30 & 0.71 & 0.82 & 0.72 & 0.73 \\
\hline Brake Torque (N-m) & -0.96 & 0.91 & -0.97 & 0.39 & 0.79 & 0.87 & 0.81 & 0.81 \\
\hline Fuel Conversion Efficiency (\%) & -0.96 & 0.88 & -0.91 & 0.65 & 0.54 & 0.63 & 0.56 & 0.58 \\
\hline Pressure at SOI (kPa) & -0.91 & 0.94 & -0.92 & 0.25 & 0.76 & 0.87 & 0.78 & 0.78 \\
\hline Temperature at SOI (K) & -0.66 & 0.75 & -0.69 & 0.02 & 0.66 & 0.77 & 0.67 & 0.66 \\
\hline Premix Length (deg) & 0.37 & 0.03 & 0.33 & -0.70 & -0.45 & -0.34 & -0.45 & -0.47 \\
\hline Diffusion Length (deg) & -0.29 & 0.43 & -0.35 & -0.23 & 0.52 & 0.62 & 0.53 & 0.50 \\
\hline Premix Heat Released (kJ) & 0.99 & -0.87 & 0.96 & -0.62 & -0.65 & -0.72 & -0.67 & -0.68 \\
\hline Diffusion Heat Released (kJ) & -0.96 & 0.90 & -0.97 & 0.40 & 0.79 & 0.87 & 0.81 & 0.81 \\
\hline Premix Shape Factor (-) & -0.52 & 0.27 & -0.46 & 0.72 & 0.16 & 0.14 & 0.17 & 0.20 \\
\hline Diffusion Shape Factor (-) & -0.93 & 0.96 & -0.94 & 0.29 & 0.63 & 0.72 & 0.65 & 0.65 \\
\hline
\end{tabular}


Table 7-5 Correlation Coefficients for Change in Combustion Parameters and Change in NOx and CO Emissions for Low Cetane Fuel with 8ml/gal 2-EHN Fuel Compared to Low Cetane Fuel

\begin{tabular}{|c|c|c|c|c|c|c|c|c|}
\hline Parameter & $\begin{array}{c}\text { NOx } \\
\text { (g/bhp-hr) }\end{array}$ & $\begin{array}{l}\text { NOx } \\
(g / s)\end{array}$ & EINOx & $\begin{array}{c}\text { NOx } \\
(\text { ppmv) }\end{array}$ & $\begin{array}{c}\text { CO } \\
\text { (g/bhp-hr) }\end{array}$ & $\begin{array}{l}\text { CO } \\
(g / s)\end{array}$ & EICO & $\begin{array}{c}\text { CO } \\
\text { (ppmv) }\end{array}$ \\
\hline Heat Released-Net (kJ) & 0.64 & 0.56 & 0.63 & 0.61 & -0.16 & -0.42 & -0.24 & -0.36 \\
\hline Heat Released-Gross (kJ) & 0.52 & 0.47 & 0.52 & 0.54 & -0.36 & -0.51 & -0.42 & -0.49 \\
\hline Max Heat Release Rate (kJ/deg) & 0.55 & 0.73 & 0.59 & 0.66 & -0.29 & -0.66 & -0.36 & -0.34 \\
\hline $\begin{array}{l}\text { Location of Max Heat Release Rate } \\
\text { (ms) }\end{array}$ & 0.34 & 0.52 & 0.36 & 0.41 & -0.05 & -0.33 & -0.10 & -0.09 \\
\hline Max Pressure (kPa) & 0.92 & 0.96 & 0.94 & 0.97 & -0.39 & -0.82 & -0.51 & -0.60 \\
\hline Location of Maximum Pressure (deg) & -0.51 & -0.44 & -0.50 & -0.44 & 0.12 & 0.36 & 0.21 & 0.32 \\
\hline Max Pressure Rise (kPa/deg) & 0.39 & 0.52 & 0.43 & 0.51 & -0.19 & -0.43 & -0.22 & -0.15 \\
\hline Location of Max Pressure Rise (ms) & 0.26 & 0.40 & 0.29 & 0.37 & -0.27 & -0.41 & -0.29 & -0.25 \\
\hline Start of Combustion (deg) & 0.76 & 0.85 & 0.78 & 0.82 & -0.50 & -0.83 & -0.60 & -0.67 \\
\hline End of Combustion (deg) & 0.13 & 0.09 & 0.12 & 0.16 & -0.20 & -0.21 & -0.21 & -0.23 \\
\hline \begin{tabular}{|l|} 
Indicated Mean Effective \\
Pressure $(\mathrm{kPa})$
\end{tabular} & 0.63 & 0.57 & 0.62 & 0.59 & 0.05 & -0.33 & -0.04 & -0.14 \\
\hline Location of $10 \%$ MFB (ms) & 0.71 & 0.79 & 0.74 & 0.78 & -0.73 & -0.90 & -0.80 & -0.85 \\
\hline Location of $\mathbf{5 0 \%}$ MFB (ms) & -0.07 & -0.33 & -0.13 & -0.24 & 0.28 & 0.37 & 0.26 & 0.12 \\
\hline Location of $90 \%$ MFB (ms) & -0.81 & -0.84 & -0.82 & -0.81 & 0.14 & 0.59 & 0.26 & 0.36 \\
\hline Max Gas Temperature (K) & 0.93 & 0.81 & 0.92 & 0.89 & -0.23 & -0.63 & -0.35 & -0.50 \\
\hline \begin{tabular}{|l|} 
Location of Max Gas \\
Temperature (ms) \\
\end{tabular} & -0.84 & -0.83 & -0.85 & -0.86 & 0.07 & 0.54 & 0.18 & 0.27 \\
\hline Average Temperature (K) & 0.53 & 0.29 & 0.51 & 0.44 & -0.02 & -0.19 & -0.09 & -0.19 \\
\hline Engine Speed (rpm) & -0.08 & -0.08 & -0.10 & -0.10 & 0.49 & 0.32 & 0.48 & 0.46 \\
\hline Exhaust Temperature (degC) & -0.66 & -0.40 & -0.63 & -0.53 & -0.25 & 0.06 & -0.15 & 0.00 \\
\hline Location of Premix Fraction (ms) & 0.05 & 0.04 & 0.04 & 0.05 & 0.02 & 0.01 & 0.00 & -0.03 \\
\hline Premix Fraction & 0.94 & 0.99 & 0.96 & 0.98 & -0.46 & -0.86 & -0.58 & -0.68 \\
\hline Flow Rate (m3/min) & -0.57 & -0.55 & -0.59 & -0.60 & 0.54 & 0.65 & 0.60 & 0.65 \\
\hline Pressure at SOC $(\mathrm{kPa})$ & -0.82 & -0.92 & -0.84 & -0.89 & 0.36 & 0.77 & 0.47 & 0.54 \\
\hline Temperature at SOC $(\mathrm{K})$ & -0.06 & -0.31 & -0.09 & -0.16 & 0.15 & 0.28 & 0.18 & 0.14 \\
\hline Fuel Flow (kg/min) & 0.52 & 0.49 & 0.50 & 0.53 & 0.08 & -0.28 & 0.00 & -0.08 \\
\hline Fuel-to-Air Ratio & 0.66 & 0.59 & 0.66 & 0.68 & -0.42 & -0.62 & -0.49 & -0.57 \\
\hline Manifold Air Pressure (kPa) & -0.73 & -0.72 & -0.75 & -0.78 & 0.44 & 0.71 & 0.53 & 0.60 \\
\hline Ratio of EVO to IVC Pressure (-) & -0.09 & -0.35 & -0.13 & -0.24 & 0.48 & 0.48 & 0.49 & 0.43 \\
\hline Ratio of Qw-to-Qg & 0.00 & -0.01 & -0.01 & 0.03 & -0.35 & -0.22 & -0.33 & -0.32 \\
\hline Polytropic Compression & 0.26 & 0.35 & 0.24 & 0.23 & -0.08 & -0.28 & -0.15 & -0.25 \\
\hline Ignition Delay (ms) & 0.65 & 0.80 & 0.69 & 0.74 & -0.47 & -0.75 & -0.55 & -0.57 \\
\hline Injection Duration (deg) & -0.28 & -0.22 & -0.30 & -0.29 & 0.29 & 0.36 & 0.31 & 0.32 \\
\hline Brake Torque (N-m) & 0.59 & 0.55 & 0.59 & 0.56 & -0.01 & -0.34 & -0.09 & -0.18 \\
\hline Fuel Conversion Efficiency (\%) & -0.02 & -0.04 & -0.02 & -0.10 & 0.37 & 0.25 & 0.36 & 0.34 \\
\hline Pressure at SOI (kPa) & -0.51 & -0.71 & -0.55 & -0.61 & 0.52 & 0.72 & 0.59 & 0.60 \\
\hline Temperature at SOI (K) & -0.12 & -0.39 & -0.15 & -0.22 & 0.12 & 0.31 & 0.15 & 0.11 \\
\hline Premix Length (deg) & -0.14 & 0.03 & -0.10 & -0.02 & -0.23 & -0.15 & -0.20 & -0.09 \\
\hline Diffusion Length (deg) & 0.79 & 0.66 & 0.75 & 0.69 & 0.05 & -0.37 & -0.09 & -0.29 \\
\hline Premix Heat Released (kJ) & 0.91 & 0.88 & 0.93 & 0.92 & -0.35 & -0.73 & -0.46 & -0.55 \\
\hline Diffusion Heat Released (kJ) & -0.29 & -0.35 & -0.34 & -0.36 & 0.29 & 0.39 & 0.30 & 0.24 \\
\hline Premix Shape Factor (-) & 0.04 & -0.04 & 0.02 & 0.02 & 0.27 & 0.20 & 0.25 & 0.21 \\
\hline Diffusion Shape Factor (-) & -0.27 & -0.37 & -0.26 & -0.29 & 0.02 & 0.24 & 0.09 & 0.17 \\
\hline
\end{tabular}


Table 7-6 The Average Combustion Parameter Correlation Coefficients for NOx and CO from 1 SET Tests on the 2004 Cummins Engine

\begin{tabular}{|c|c|c|c|c|c|c|c|c|}
\hline Parameter & $\begin{array}{c}\text { NOx } \\
\text { (g/bhp-hr) }\end{array}$ & $\begin{array}{l}\text { NOx } \\
(g / s)\end{array}$ & EINOx & $\begin{array}{c}\text { NOx } \\
\text { (ppmv) }\end{array}$ & $\begin{array}{c}\text { CO } \\
\text { (g/bhp-hr) }\end{array}$ & $\begin{array}{l}\text { co } \\
(g / s)\end{array}$ & EICO & $\begin{array}{c}\text { CO } \\
\text { (ppmv) }\end{array}$ \\
\hline Heat Released-Net (kJ) & 0.39 & 0.88 & 0.63 & 0.86 & -0.80 & 0.20 & -0.83 & -0.67 \\
\hline Heat Released-Gross (kJ) & 0.40 & 0.89 & 0.65 & 0.87 & -0.81 & 0.19 & -0.83 & -0.68 \\
\hline Max Heat Release Rate (kJ/deg) & 0.24 & 0.67 & 0.60 & 0.79 & -0.88 & -0.31 & -0.86 & -0.70 \\
\hline $\begin{array}{l}\text { Location of Max Heat Release Rate } \\
\text { (ms) }\end{array}$ & 0.52 & 0.78 & 0.69 & 0.80 & -0.80 & -0.01 & -0.87 & -0.86 \\
\hline Max Pressure $(\mathrm{kPa})$ & 0.67 & 0.96 & 0.80 & 0.89 & -0.70 & 0.28 & -0.76 & -0.71 \\
\hline Location of Maximum Pressure (deg) & 0.83 & 0.85 & 0.92 & 0.88 & -0.44 & 0.04 & -0.47 & -0.46 \\
\hline Max Pressure Rise (kPa/deg) & 0.53 & 0.91 & 0.68 & 0.81 & -0.71 & 0.30 & -0.76 & -0.68 \\
\hline Location of Max Pressure Rise (ms) & 0.32 & 0.47 & 0.38 & 0.39 & -0.17 & 0.21 & -0.15 & -0.06 \\
\hline Start of Combustion (deg) & -0.74 & -0.99 & -0.86 & -0.91 & 0.65 & -0.26 & 0.70 & 0.65 \\
\hline End of Combustion (deg) & 0.10 & 0.59 & 0.27 & 0.49 & -0.64 & 0.33 & -0.66 & -0.51 \\
\hline $\begin{array}{l}\text { Indicated Mean Effective Pressure } \\
(\mathrm{kPa})\end{array}$ & 0.45 & 0.91 & 0.69 & 0.89 & -0.81 & 0.17 & -0.84 & -0.70 \\
\hline Location of $10 \%$ MFB (ms) & 0.41 & 0.82 & 0.66 & 0.84 & -0.87 & 0.01 & -0.90 & -0.81 \\
\hline Location of $50 \%$ MFB (ms) & 0.30 & 0.76 & 0.58 & 0.82 & -0.83 & -0.01 & -0.85 & -0.70 \\
\hline Location of $90 \%$ MFB (ms) & 0.12 & 0.61 & 0.46 & 0.73 & -0.79 & -0.18 & -0.77 & -0.57 \\
\hline Max Gas Temperature (K) & 0.15 & 0.70 & 0.52 & 0.80 & -0.85 & -0.13 & -0.83 & -0.60 \\
\hline Location of Max Gas Temperature (ms) & 0.12 & 0.62 & 0.45 & 0.73 & -0.80 & -0.11 & -0.80 & -0.61 \\
\hline Average Temperature (K) & 0.21 & 0.81 & 0.52 & 0.80 & -0.85 & 0.12 & -0.85 & -0.64 \\
\hline Engine Speed (rpm) & 0.35 & 0.23 & 0.06 & -0.06 & 0.22 & 0.72 & 0.12 & -0.01 \\
\hline Exhaust Temperature (degC) & - & - & - & - & - & - & - & - \\
\hline Location of Premix Fraction (ms) & -0.42 & -0.70 & -0.57 & -0.66 & 0.70 & -0.12 & 0.74 & 0.69 \\
\hline Premix Fraction & -0.43 & -0.73 & -0.57 & -0.67 & 0.80 & -0.11 & 0.87 & 0.87 \\
\hline Flow Rate (m3/min) & 0.55 & 0.80 & 0.54 & 0.58 & -0.46 & 0.57 & -0.55 & -0.54 \\
\hline Pressure at SOC (kPa) & 0.47 & 0.81 & 0.58 & 0.70 & -0.71 & 0.32 & -0.78 & -0.74 \\
\hline Temperature at SOC (K) & -0.06 & -0.27 & -0.38 & -0.52 & 0.43 & 0.50 & 0.36 & 0.20 \\
\hline Fuel Flow (kg/min) & 0.46 & 0.91 & 0.60 & 0.77 & -0.68 & 0.45 & -0.72 & -0.60 \\
\hline Fuel-to-Air Ratio & 0.03 & 0.65 & 0.41 & 0.72 & -0.84 & -0.08 & -0.81 & -0.55 \\
\hline Manifold Air Pressure (kPa) & 0.58 & 0.92 & 0.71 & 0.82 & -0.72 & 0.31 & -0.78 & -0.73 \\
\hline Ratio of EVO to IVC Pressure (-) & 0.15 & 0.73 & 0.48 & 0.76 & -0.87 & 0.04 & -0.87 & -0.67 \\
\hline Ratio of Qw-to-Qg & 0.24 & 0.12 & 0.41 & 0.36 & -0.10 & -0.57 & -0.03 & 0.02 \\
\hline Polytropic Compression & 0.51 & 0.38 & 0.44 & 0.33 & -0.07 & 0.07 & -0.11 & -0.21 \\
\hline Ignition Delay (ms) & -0.68 & -0.81 & -0.68 & -0.67 & 0.52 & -0.37 & 0.61 & 0.66 \\
\hline Injection Duration (deg) & - & - & - & - & - & - & - & - \\
\hline Brake Torque (N-m) & 0.41 & 0.88 & 0.68 & 0.90 & -0.82 & 0.10 & -0.84 & -0.69 \\
\hline Fuel Conversion Efficiency (\%) & 0.20 & 0.62 & 0.59 & 0.78 & -0.90 & -0.43 & -0.87 & -0.72 \\
\hline Pressure at SOI (kPa) & - & - & - & - & - & - & - & - \\
\hline Temperature at SOI (K) & - & - & - & - & - & - & - & - \\
\hline Premix Length (deg) & 0.28 & 0.14 & 0.19 & 0.09 & 0.13 & 0.14 & 0.11 & 0.06 \\
\hline Diffusion Length (deg) & 0.30 & 0.84 & 0.48 & 0.73 & -0.67 & 0.44 & -0.70 & -0.51 \\
\hline Premix Heat Released (kJ) & -0.51 & -0.60 & -0.52 & -0.53 & 0.52 & -0.20 & 0.62 & 0.70 \\
\hline Diffusion Heat Released (kJ) & 0.40 & 0.88 & 0.64 & 0.86 & -0.80 & 0.20 & -0.83 & -0.67 \\
\hline Premix Shape Factor (-) & -0.29 & -0.69 & -0.48 & -0.62 & 0.73 & -0.15 & 0.74 & 0.63 \\
\hline Diffusion Shape Factor (-) & 0.67 & 0.62 & 0.60 & 0.49 & -0.48 & 0.17 & -0.58 & -0.75 \\
\hline EGR Mass Fraction (-) & -0.37 & -0.84 & -0.61 & -0.82 & 0.84 & -0.14 & 0.88 & 0.75 \\
\hline
\end{tabular}


Table 7-7 Correlation Coefficients for Change in Combustion Parameters and Change in NOx and CO Emissions for CP Cert Fuel with 12ml/gal 2-EHN Fuel Compared to CP Cert Fuel

\begin{tabular}{|c|c|c|c|c|c|c|c|c|}
\hline Parameter & $\begin{array}{c}\text { NOx } \\
\text { (g/bhp-hr) }\end{array}$ & $\begin{array}{l}\text { NOx } \\
\text { (g/s) }\end{array}$ & EINOx & $\begin{array}{c}\text { NOx } \\
\text { (ppmv) }\end{array}$ & $\begin{array}{c}\text { CO } \\
\text { (g/bhp-hr) }\end{array}$ & $\begin{array}{c}\text { CO } \\
\text { (g/s) }\end{array}$ & EICO & $\begin{array}{c}\text { CO } \\
\text { (ppmv) }\end{array}$ \\
\hline Heat Released-Net (kJ) & 0.23 & 0.62 & 0.39 & 0.63 & 0.23 & 0.11 & 0.19 & 0.15 \\
\hline Heat Released-Gross (kJ) & 0.29 & 0.59 & 0.44 & 0.61 & 0.18 & 0.06 & 0.14 & 0.10 \\
\hline Max Heat Release Rate (kJ/deg) & 0.36 & 0.60 & 0.43 & 0.67 & 0.69 & 0.59 & 0.76 & 0.83 \\
\hline Location of Max Heat Release Rate (ms) & -0.10 & -0.58 & -0.08 & -0.56 & -0.70 & -0.62 & -0.75 & -0.77 \\
\hline Max Pressure (kPa) & 0.43 & -0.20 & 0.40 & -0.30 & -0.38 & -0.36 & -0.38 & -0.36 \\
\hline Location of Maximum Pressure (deg) & 0.04 & -0.30 & -0.10 & -0.36 & -0.28 & -0.11 & -0.24 & -0.17 \\
\hline Max Pressure Rise (kPa/deg) & 0.37 & 0.56 & 0.43 & 0.64 & 0.64 & 0.55 & 0.72 & 0.79 \\
\hline Location of Max Pressure Rise (ms) & 0.41 & 0.57 & 0.46 & 0.65 & 0.62 & 0.52 & 0.70 & 0.77 \\
\hline Start of Combustion (deg) & -0.39 & 0.50 & -0.18 & 0.57 & 0.89 & 0.88 & 0.88 & 0.86 \\
\hline End of Combustion (deg) & 0.59 & -0.16 & 0.51 & -0.10 & -0.41 & -0.55 & -0.35 & -0.32 \\
\hline Indicated Mean Effective Pressure (kPa) & 0.57 & 0.31 & 0.55 & 0.26 & -0.23 & -0.32 & -0.22 & -0.20 \\
\hline Location of $10 \%$ MFB (ms) & 0.65 & -0.03 & 0.65 & 0.07 & -0.42 & -0.54 & -0.42 & -0.42 \\
\hline Location of $50 \%$ MFB (ms) & 0.17 & -0.31 & 0.15 & -0.31 & -0.72 & -0.72 & -0.76 & -0.80 \\
\hline Location of $90 \%$ MFB (ms) & 0.25 & 0.43 & 0.31 & 0.49 & 0.08 & -0.02 & 0.06 & 0.04 \\
\hline Max Gas Temperature (K) & 0.25 & -0.44 & 0.11 & -0.51 & -0.44 & -0.30 & -0.40 & -0.34 \\
\hline Location of Max Gas Temperature (ms) & 0.19 & -0.50 & 0.23 & -0.49 & -0.77 & -0.79 & -0.81 & -0.85 \\
\hline Average Temperature (K) & 0.58 & -0.23 & 0.25 & -0.35 & -0.55 & -0.53 & -0.46 & -0.36 \\
\hline Engine Speed (rpm) & 0.27 & -0.28 & 0.05 & -0.36 & -0.38 & -0.43 & -0.34 & -0.30 \\
\hline Exhaust Temperature (degC) & - & - & - & - & - & - & - & - \\
\hline Location of Premix Fraction (ms) & -0.44 & -0.28 & -0.65 & -0.25 & -0.13 & -0.07 & -0.12 & -0.09 \\
\hline Premix Fraction & -0.10 & 0.73 & 0.01 & 0.77 & 0.94 & 0.86 & 0.95 & 0.95 \\
\hline Flow Rate (m3/min) & -0.12 & 0.11 & 0.08 & 0.18 & 0.06 & -0.08 & 0.01 & -0.06 \\
\hline Pressure at SOC (kPa) & 0.28 & -0.73 & 0.18 & -0.73 & -0.84 & -0.79 & -0.83 & -0.80 \\
\hline Temperature at SOC (K) & 0.25 & -0.65 & 0.01 & -0.71 & -0.69 & -0.58 & -0.65 & -0.58 \\
\hline Fuel Flow (kg/min) & 0.35 & 0.61 & 0.50 & 0.63 & 0.19 & 0.05 & 0.16 & 0.11 \\
\hline Fuel-to-Air Ratio & 0.39 & 0.46 & 0.47 & 0.44 & 0.06 & 0.03 & 0.04 & 0.04 \\
\hline Manifold Air Pressure (kPa) & -0.01 & 0.44 & 0.15 & 0.46 & 0.25 & 0.10 & 0.20 & 0.15 \\
\hline Ratio of EVO to IVC Pressure (-) & 0.55 & -0.10 & 0.24 & -0.22 & -0.44 & -0.47 & -0.35 & -0.25 \\
\hline Ratio of Qw-to-Qg & 0.33 & -0.65 & 0.08 & -0.70 & -0.71 & -0.65 & -0.65 & -0.57 \\
\hline Polytropic Compression & 0.13 & -0.58 & -0.17 & -0.68 & -0.50 & -0.41 & -0.43 & -0.34 \\
\hline Ignition Delay (ms) & -0.20 & 0.58 & -0.06 & 0.62 & 0.89 & 0.86 & 0.92 & 0.93 \\
\hline Injection Duration (deg) & - & - & - & - & - & - & - & - \\
\hline Brake Torque (N-m) & 0.58 & 0.30 & 0.54 & 0.24 & -0.23 & -0.31 & -0.21 & -0.19 \\
\hline Fuel Conversion Efficiency (\%) & 0.41 & -0.47 & 0.07 & -0.57 & -0.63 & -0.61 & -0.55 & -0.44 \\
\hline Pressure at SOI (kPa) & - & - & - & - & - & - & - & - \\
\hline Temperature at SOI (K) & - & - & - & - & - & - & - & - \\
\hline Premix Length (deg) & -0.53 & -0.21 & -0.17 & 0.00 & 0.25 & 0.23 & 0.21 & 0.13 \\
\hline Diffusion Length (deg) & 0.05 & 0.62 & 0.20 & 0.63 & 0.57 & 0.57 & 0.56 & 0.55 \\
\hline Premix Heat Released (kJ) & 0.10 & 0.78 & 0.21 & 0.81 & 0.92 & 0.83 & 0.95 & 0.97 \\
\hline Diffusion Heat Released (kJ) & -0.05 & -0.38 & -0.10 & -0.47 & -0.62 & -0.51 & -0.67 & -0.70 \\
\hline Premix Shape Factor (-) & 0.22 & -0.49 & -0.06 & -0.56 & -0.72 & -0.67 & -0.66 & -0.57 \\
\hline Diffusion Shape Factor (-) & 0.53 & -0.42 & 0.28 & -0.47 & -0.69 & -0.77 & -0.63 & -0.58 \\
\hline EGR Mass Fraction (-) & 0.38 & 0.83 & 0.30 & 0.73 & 0.57 & 0.45 & 0.62 & 0.68 \\
\hline
\end{tabular}


Table 7-8 Repeatability of Heat Release Parameters from 11 SET Tests: Parameters (range/average), Ratios (range/average), Time (range in ms), and Crank Angle (range in deg)

\begin{tabular}{|c|c|c|c|c|c|c|c|c|c|c|c|c|c|}
\hline & \multicolumn{13}{|c|}{ Mode } \\
\hline Parameters (range/average) & 1 & 2 & 3 & 4 & 5 & 6 & 7 & 8 & 9 & 10 & 11 & 12 & 13 \\
\hline Heat Released-Net (kJ) & $30.9 \%$ & $0.7 \%$ & $0.8 \%$ & $0.6 \%$ & $1.6 \%$ & $0.8 \%$ & $2.0 \%$ & $0.7 \%$ & $1.0 \%$ & $0.8 \%$ & $0.5 \%$ & $0.5 \%$ & $0.8 \%$ \\
\hline Heat Released-Gross (kJ) & $34.7 \%$ & $1.1 \%$ & $1.1 \%$ & $1.1 \%$ & $1.7 \%$ & $0.9 \%$ & $2.0 \%$ & $1.1 \%$ & $1.1 \%$ & $0.7 \%$ & $0.6 \%$ & $0.8 \%$ & $1.0 \%$ \\
\hline Max Heat Release Rate (kJ/deg) & $48.5 \%$ & $2.1 \%$ & $2.7 \%$ & $1.9 \%$ & $3.6 \%$ & $2.7 \%$ & $4.3 \%$ & $1.7 \%$ & $2.3 \%$ & $1.3 \%$ & $2.6 \%$ & $2.4 \%$ & $3.1 \%$ \\
\hline Max Pressure $(\mathrm{kPa})$ & $8.6 \%$ & $0.8 \%$ & $1.3 \%$ & $0.6 \%$ & $1.2 \%$ & $0.5 \%$ & $0.8 \%$ & $0.5 \%$ & $1.1 \%$ & $0.7 \%$ & $0.7 \%$ & $0.5 \%$ & $1.2 \%$ \\
\hline Max Pressure Rise (kPa/deg) & $49.5 \%$ & $2.1 \%$ & $2.9 \%$ & $1.7 \%$ & $2.4 \%$ & $2.5 \%$ & $3.9 \%$ & $1.9 \%$ & $2.8 \%$ & $4.0 \%$ & $2.9 \%$ & $1.8 \%$ & $2.8 \%$ \\
\hline $\begin{array}{l}\text { Indicated Mean Effective Pressure } \\
(\mathrm{kPa})\end{array}$ & $36.8 \%$ & $1.0 \%$ & $1.0 \%$ & $0.9 \%$ & $1.7 \%$ & $0.7 \%$ & $2.2 \%$ & $0.8 \%$ & $1.2 \%$ & $1.0 \%$ & $1.0 \%$ & $0.9 \%$ & $0.7 \%$ \\
\hline Max Gas Temperature (K) & $8.9 \%$ & $2.1 \%$ & $2.0 \%$ & $2.0 \%$ & $1.7 \%$ & $1.7 \%$ & $1.6 \%$ & $2.2 \%$ & $1.8 \%$ & $1.7 \%$ & $1.6 \%$ & $1.5 \%$ & $1.5 \%$ \\
\hline Average Temperature $(\mathrm{K})$ & $5.1 \%$ & $1.6 \%$ & $1.6 \%$ & $1.1 \%$ & $1.3 \%$ & $1.1 \%$ & $1.4 \%$ & $1.6 \%$ & $0.9 \%$ & $1.2 \%$ & $1.3 \%$ & $1.0 \%$ & $1.2 \%$ \\
\hline Engine Speed (rpm) & $0.4 \%$ & $0.4 \%$ & $0.2 \%$ & $0.5 \%$ & $0.2 \%$ & $0.3 \%$ & $0.2 \%$ & $0.3 \%$ & $0.2 \%$ & $0.7 \%$ & $0.2 \%$ & $0.4 \%$ & $0.4 \%$ \\
\hline Exhaust Temperature (degC) & $15.0 \%$ & $1.0 \%$ & $1.4 \%$ & $1.0 \%$ & $1.3 \%$ & $0.9 \%$ & $1.7 \%$ & $0.5 \%$ & $0.7 \%$ & $1.1 \%$ & $1.1 \%$ & $0.7 \%$ & $1.2 \%$ \\
\hline Flow Rate $\left(\mathrm{m}^{3} / \mathrm{min}\right)$ & $2.6 \%$ & $1.6 \%$ & $1.5 \%$ & $1.1 \%$ & $1.0 \%$ & $1.2 \%$ & $1.1 \%$ & $1.4 \%$ & $1.1 \%$ & $1.6 \%$ & $1.7 \%$ & $0.6 \%$ & $1.1 \%$ \\
\hline Pressure at SOC $(\mathrm{kPa})$ & $44.8 \%$ & $0.5 \%$ & $1.2 \%$ & $0.6 \%$ & $0.7 \%$ & $1.4 \%$ & $1.5 \%$ & $0.9 \%$ & $1.5 \%$ & $1.2 \%$ & $0.9 \%$ & $0.7 \%$ & $0.5 \%$ \\
\hline Temperature at SOC (K) & $18.7 \%$ & $1.5 \%$ & $1.8 \%$ & $1.3 \%$ & $0.9 \%$ & $1.7 \%$ & $1.8 \%$ & $1.5 \%$ & $1.1 \%$ & $1.2 \%$ & $1.8 \%$ & $1.0 \%$ & $1.1 \%$ \\
\hline Fuel Flow (kg/min) & $34.7 \%$ & $0.9 \%$ & $1.3 \%$ & $1.3 \%$ & $1.7 \%$ & $1.1 \%$ & $2.1 \%$ & $1.2 \%$ & $1.4 \%$ & $0.7 \%$ & $0.8 \%$ & $0.7 \%$ & $0.9 \%$ \\
\hline Fuel-to-Air Ratio & $35.1 \%$ & $1.7 \%$ & $2.5 \%$ & $2.0 \%$ & $2.2 \%$ & $1.7 \%$ & $2.7 \%$ & $2.6 \%$ & $1.6 \%$ & $1.4 \%$ & $2.0 \%$ & $1.0 \%$ & $1.9 \%$ \\
\hline Manifold Air Pressure $(\mathrm{kPa})$ & $0.9 \%$ & $0.6 \%$ & $0.3 \%$ & $0.6 \%$ & $0.3 \%$ & $0.6 \%$ & $0.5 \%$ & $0.7 \%$ & $0.5 \%$ & $0.3 \%$ & $2.0 \%$ & $0.3 \%$ & $0.8 \%$ \\
\hline Brake Torque (N-m) & $3949 \%$ & $1.0 \%$ & $1.1 \%$ & $1.0 \%$ & $1.9 \%$ & $0.8 \%$ & $2.8 \%$ & $0.8 \%$ & $1.5 \%$ & $1.1 \%$ & $1.4 \%$ & $0.9 \%$ & $0.7 \%$ \\
\hline Pressure at SOI (kPa) & $0.8 \%$ & $1.0 \%$ & $1.1 \%$ & $2.1 \%$ & $1.2 \%$ & $0.9 \%$ & $1.1 \%$ & $0.6 \%$ & $1.0 \%$ & $0.4 \%$ & $0.4 \%$ & $1.1 \%$ & $0.9 \%$ \\
\hline Temperature at SOI $(\mathrm{K})$ & $2.4 \%$ & $1.8 \%$ & $1.6 \%$ & $1.5 \%$ & $1.1 \%$ & $1.3 \%$ & $1.2 \%$ & $1.3 \%$ & $1.2 \%$ & $1.1 \%$ & $1.6 \%$ & $0.9 \%$ & $1.2 \%$ \\
\hline Premix Heat Released $(\mathrm{kJ})$ & $197 \%$ & $3.5 \%$ & $6.7 \%$ & $4.4 \%$ & $11.9 \%$ & $9.2 \%$ & $9.7 \%$ & $11.4 \%$ & $5.7 \%$ & $12.5 \%$ & $3.4 \%$ & $3.9 \%$ & $11.6 \%$ \\
\hline Diffusion Heat Released (kJ) & $67.0 \%$ & $1.6 \%$ & $4.0 \%$ & $1.5 \%$ & $1.7 \%$ & $1.3 \%$ & $11.2 \%$ & $1.5 \%$ & $5.5 \%$ & $1.4 \%$ & $5.1 \%$ & $0.8 \%$ & $4.7 \%$ \\
\hline
\end{tabular}

\section{Ratios (range/average)}

\begin{tabular}{|c|c|c|c|c|c|c|c|c|c|c|c|c|c|}
\hline Premix Fraction & $222 \%$ & $4.5 \%$ & $2.8 \%$ & $2.7 \%$ & $4.4 \%$ & $4.9 \%$ & $2.7 \%$ & $5.7 \%$ & $3.2 \%$ & $7.3 \%$ & $2.4 \%$ & $4.5 \%$ & $4.8 \%$ \\
\hline Ratio of EVO to IVC Pressure (-) & $8.2 \%$ & $0.6 \%$ & $0.7 \%$ & $0.4 \%$ & $1.0 \%$ & $0.4 \%$ & $1.8 \%$ & $0.4 \%$ & $0.6 \%$ & $0.4 \%$ & $1.4 \%$ & $0.4 \%$ & $0.7 \%$ \\
\hline Fuel Conversion Efficiency (\%) & $-4922 \%$ & $0.8 \%$ & $0.4 \%$ & $0.3 \%$ & $0.7 \%$ & $0.6 \%$ & $0.7 \%$ & $0.4 \%$ & $0.3 \%$ & $0.9 \%$ & $1.0 \%$ & $0.8 \%$ & $0.3 \%$ \\
\hline Premix Shape Factor (-) & $235 \%$ & $7.0 \%$ & $6.5 \%$ & $7.8 \%$ & $9.3 \%$ & $12.1 \%$ & $9.5 \%$ & $13.0 \%$ & $7.4 \%$ & $14.9 \%$ & $4.7 \%$ & $3.5 \%$ & $5.5 \%$ \\
\hline Diffusion Shape Factor (-) & $188 \%$ & $1.5 \%$ & $4.6 \%$ & $3.3 \%$ & $6.8 \%$ & $2.3 \%$ & $12.2 \%$ & $1.7 \%$ & $7.4 \%$ & $2.4 \%$ & $2.9 \%$ & $2.3 \%$ & $6.6 \%$ \\
\hline
\end{tabular}




\begin{tabular}{|c|c|c|c|c|c|c|c|c|c|c|c|c|c|}
\hline \multirow[b]{2}{*}{ Time (ms) } & \multicolumn{13}{|c|}{ Mode } \\
\hline & 1 & 2 & 3 & 4 & 5 & 6 & 7 & 8 & 9 & 10 & 11 & 12 & 13 \\
\hline $\begin{array}{l}\text { Location of Max Gas Temperature } \\
(\mathrm{ms})\end{array}$ & 1.157 & 0.019 & 0.015 & 0.028 & 0.027 & 0.027 & 0.018 & 0.024 & 0.015 & 0.014 & 0.026 & 0.023 & 0.018 \\
\hline $\begin{array}{l}\text { Location of Max Heat Release } \\
\text { Rate }(\mathrm{ms})\end{array}$ & 1.089 & 0.017 & 0.000 & 0.000 & 0.009 & 0.009 & 0.009 & 0.016 & 0.007 & 0.009 & 0.000 & 0.000 & 0.000 \\
\hline $\begin{array}{l}\text { Location of Max Pressure Rise } \\
\text { (ms) }\end{array}$ & 1.089 & 0.000 & 0.007 & 0.000 & 0.009 & 0.009 & 0.009 & 0.007 & 0.007 & 0.006 & 0.006 & 0.006 & 0.007 \\
\hline Location of $10 \%$ MFB (ms) & 1.086 & 0.009 & 0.007 & 0.001 & 0.009 & 0.009 & 0.009 & 0.015 & 0.007 & 0.007 & 0.000 & 0.000 & 0.006 \\
\hline Location of $50 \%$ MFB (ms) & 1.089 & 0.010 & 0.015 & 0.007 & 0.010 & 0.011 & 0.009 & 0.009 & 0.007 & 0.008 & 0.006 & 0.008 & 0.007 \\
\hline Location of $90 \%$ MFB (ms) & 1.126 & 0.068 & 0.029 & 0.012 & 0.028 & 0.057 & 0.018 & 0.016 & 0.029 & 0.042 & 0.013 & 0.040 & 0.040 \\
\hline Location of Premix Fraction (ms) & 0.211 & 0.009 & 0.007 & 0.001 & 0.009 & 0.009 & 0.000 & 0.008 & 0.008 & 0.012 & 0.007 & 0.006 & 0.006 \\
\hline Ignition Delay (ms) & 0.193 & 0.009 & 0.008 & 0.015 & 0.009 & 0.009 & 0.009 & 0.007 & 0.008 & 0.007 & 0.000 & 0.007 & 0.007 \\
\hline
\end{tabular}

\section{Crank Angle (deg)}

\begin{tabular}{|c|c|c|c|c|c|c|c|c|c|c|c|c|c|}
\hline $\begin{array}{l}\text { Location of Maximum Pressure } \\
\text { (deg) }\end{array}$ & 0.50 & 0.00 & 0.00 & 0.25 & 0.25 & 0.25 & 0.25 & 0.25 & 0.50 & 0.25 & 0.25 & 0.00 & 0.25 \\
\hline Start of Combustion (deg) & 15.75 & 0.00 & 0.25 & 0.00 & 0.00 & 0.25 & 0.25 & 0.25 & 0.25 & 0.25 & 0.00 & 0.00 & 0.00 \\
\hline End of Combustion (deg) & 6.75 & 8.75 & 1.25 & 5.50 & 8.00 & 4.50 & 0.75 & 3.75 & 1.50 & 10.75 & 4.25 & 12.00 & 2.00 \\
\hline Injection Duration (deg) & 0.25 & 0.50 & 0.50 & 0.50 & 0.25 & 0.25 & 0.50 & 0.25 & 0.25 & 0.25 & 0.25 & 0.25 & 0.25 \\
\hline Premix Length (deg) & 25.97 & 0.23 & 0.15 & 0.14 & 0.23 & 0.26 & 0.19 & 0.13 & 0.21 & 0.33 & 0.06 & 0.13 & 0.20 \\
\hline Diffusion Length (deg) & 43.19 & 0.55 & 4.18 & 1.80 & 4.17 & 0.92 & 14.12 & 1.48 & 6.26 & 1.50 & 2.17 & 0.83 & 3.44 \\
\hline
\end{tabular}


Table 7-9 January 2007 FTP Results for the 1992 Detroit Diesel Series 60

\begin{tabular}{|c|c|c|c|c|c|c|c|c|c|c|c|c|c|c|c|c|c|c|c|}
\hline \multirow[b]{2}{*}{$\begin{array}{l}\text { Additive I } \\
\text { Condition }\end{array}$} & \multirow[b]{2}{*}{ Base } & \multicolumn{2}{|c|}{ Work } & \multicolumn{2}{|c|}{ BSFC } & \multicolumn{2}{|c|}{$\mathrm{CO}_{2}$} & \multicolumn{2}{|c|}{ co } & \multicolumn{2}{|c|}{ NOx } & \multicolumn{2}{|c|}{ NOX2 } & \multicolumn{2}{|c|}{ No } & \multicolumn{2}{|c|}{$\mathrm{HC}$} & \multicolumn{2}{|c|}{ TPM } \\
\hline & & $\begin{array}{c}\text { bhp- } \\
\text { hr }\end{array}$ & $\begin{array}{l}\text { Diff } \\
(\%)\end{array}$ & $\begin{array}{c}\text { Ib/bhp- } \\
\text { hr }\end{array}$ & $\begin{array}{l}\text { Diff } \\
(\%)\end{array}$ & $\begin{array}{c}\text { g/bhp- } \\
\text { hr }\end{array}$ & $\begin{array}{l}\text { Diff } \\
(\%)\end{array}$ & $\begin{array}{c}\text { g/bhp- } \\
\mathrm{hr}\end{array}$ & $\begin{array}{l}\text { Diff } \\
(\%)\end{array}$ & $\begin{array}{c}\text { g/bhp- } \\
\mathrm{hr}\end{array}$ & $\begin{array}{l}\text { Diff } \\
(\%)\end{array}$ & $\begin{array}{c}\text { g/bhp- } \\
\mathrm{hr}\end{array}$ & $\begin{array}{l}\text { Diff } \\
(\%)\end{array}$ & $\begin{array}{c}\text { g/bhp- } \\
\mathrm{hr}\end{array}$ & $\begin{array}{l}\text { Diff } \\
(\%)\end{array}$ & $\begin{array}{c}\text { g/bhp- } \\
\text { hr }\end{array}$ & $\begin{array}{l}\text { Diff } \\
(\%)\end{array}$ & $\begin{array}{c}\text { g/bhp- } \\
\mathrm{hr}\end{array}$ & $\begin{array}{l}\text { Diff } \\
(\%)\end{array}$ \\
\hline- & $\begin{array}{l}\text { CP } \\
\text { Cert } \\
\end{array}$ & 25.45 & - & 0.3741 & - & 530.7 & - & 3.977 & - & 5.144 & - & 5.213 & - & 4.877 & - & 0.1134 & - & 0.2762 & - \\
\hline \begin{tabular}{|l|}
$12 \mathrm{ml} / \mathrm{gal}$ \\
ODA \\
\end{tabular} & $\begin{array}{l}\mathrm{CP} \\
\text { Cert } \\
\end{array}$ & 25.51 & $0.2 \%$ & 0.3747 & * & 528.8 & * & 3.748 & $-5.8 \%$ & 4.957 & $-3.6 \%$ & 5.010 & $-3.9 \%$ & 4.732 & $-3.0 \%$ & 0.1010 & $-10.9 \%$ & 0.2791 & $1.0 \%$ \\
\hline- & $\begin{array}{c}\text { Grad } \\
\text { Ref }\end{array}$ & 24.71 & - & 0.3723 & - & 517.7 & - & 3.335 & - & 4.702 & $=$ & 4.722 & - & 4.430 & - & 0.1134 & - & 0.2514 & - \\
\hline $\begin{array}{l}16 \mathrm{ml} / \mathrm{gal} \\
\text { ODA }\end{array}$ & $\begin{array}{c}\text { Grad } \\
\text { Ref }\end{array}$ & 24.74 & $0.1 \%$ & 0.3721 & * & 517.7 & * & 3.138 & $-5.9 \%$ & 4.593 & $-2.3 \%$ & 4.578 & $-3.1 \%$ & 4.310 & $-2.7 \%$ & 0.0961 & $-15.2 \%$ & 0.2383 & $-5.2 \%$ \\
\hline- & $\begin{array}{l}\text { Grad } \\
\text { Cand }\end{array}$ & 24.70 & - & 0.3745 & - & 523.0 & - & 3.275 & - & 5.041 & - & 5.040 & - & 4.741 & - & 0.1137 & . & 0.2445 & - \\
\hline \begin{tabular}{|l|}
$8 \mathrm{ml} / \mathrm{gal}$ \\
$2 \mathrm{EHN}$ \\
\end{tabular} & $\begin{array}{l}\text { Grad } \\
\text { Cand }\end{array}$ & 24.73 & $0.1 \%$ & 0.3733 & * & 520.0 & * & 3.031 & $-7.4 \%$ & 4.887 & $-3.1 \%$ & 4.903 & $-2.7 \%$ & 4.615 & $-2.6 \%$ & 0.0986 & $-13.3 \%$ & 0.2338 & $-4.3 \%$ \\
\hline $\begin{array}{l}16 \mathrm{ml} / \mathrm{gal} \\
\text { ODA }\end{array}$ & $\begin{array}{l}\text { Grad } \\
\text { Cand }\end{array}$ & 24.77 & $0.3 \%$ & 0.3748 & * & 516.5 & $-1.2 \%$ & 2.970 & $-9.3 \%$ & 4.914 & $-2.5 \%$ & 4.904 & $-2.7 \%$ & 4.618 & $-2.6 \%$ & 0.0989 & $-13.0 \%$ & 0.2311 & $-5.5 \%$ \\
\hline $\begin{array}{l}16 \mathrm{ml} / \mathrm{gal} \\
\text { ODA } 2 \mathrm{x}\end{array}$ & $\begin{array}{l}\text { Grad } \\
\text { Cand }\end{array}$ & 24.77 & $0.3 \%$ & 0.3749 & * & 521.9 & * & 2.971 & $-9.3 \%$ & 4.925 & $-2.3 \%$ & 4.925 & $-2.3 \%$ & 4.639 & $-2.2 \%$ & 0.0984 & $-13.5 \%$ & 0.2284 & $-6.6 \%$ \\
\hline- & $\begin{array}{l}\text { Grad } \\
\text { Cand }\end{array}$ & 24.76 & $0.3 \%$ & 0.3757 & * & 519.0 & * & 3.193 & $-2.5 \%$ & 5.064 & * & 5.058 & * & 4.764 & * & 0.1058 & $-6.9 \%$ & 0.2415 & $-1.2 \%$ \\
\hline \begin{tabular}{|l|}
$10 \mathrm{ml} / \mathrm{gal}$ \\
DTBP
\end{tabular} & $\begin{array}{l}\text { Grad } \\
\text { Cand }\end{array}$ & 24.74 & $0.2 \%$ & 0.3754 & * & 523.2 & * & 3.023 & $-7.7 \%$ & 4.889 & $-3.0 \%$ & 4.871 & $-3.4 \%$ & 4.598 & $-3.0 \%$ & 0.0911 & $-19.8 \%$ & 0.2318 & $-5.2 \%$ \\
\hline $\begin{array}{l}6 \mathrm{ml} / \mathrm{gal} \\
\text { ODA }\end{array}$ & $\begin{array}{l}\text { Grad } \\
\text { Cand }\end{array}$ & 24.76 & $0.2 \%$ & 0.3754 & * & 525.0 & * & 3.065 & $-6.4 \%$ & 4.929 & $-2.2 \%$ & 4.958 & $-1.6 \%$ & 4.663 & $-1.6 \%$ & 0.0959 & $-15.6 \%$ & 0.2301 & $-5.9 \%$ \\
\hline
\end{tabular}


Table 7-10 June 2007 FTP Results for the 1992 Detroit Diesel Series 60

\begin{tabular}{|c|c|c|c|c|c|c|c|c|c|c|c|c|c|c|c|c|c|c|c|}
\hline \multirow[b]{2}{*}{$\begin{array}{l}\text { Additive I } \\
\text { Condition }\end{array}$} & \multirow[b]{2}{*}{ Base } & \multicolumn{2}{|c|}{ Work } & \multicolumn{2}{|c|}{ BSFC } & \multicolumn{2}{|c|}{$\mathrm{CO}_{2}$} & \multicolumn{2}{|c|}{ co } & \multicolumn{2}{|c|}{ NOx } & \multicolumn{2}{|c|}{ NOx2 } & \multicolumn{2}{|c|}{ NO } & \multicolumn{2}{|c|}{$\mathrm{HC}$} & \multicolumn{2}{|c|}{ TPM } \\
\hline & & $\begin{array}{c}\text { bhp- } \\
\text { hr }\end{array}$ & $\begin{array}{l}\text { Diff } \\
(\%)\end{array}$ & $\begin{array}{c}\text { Ib/bhp- } \\
\text { hr }\end{array}$ & $\begin{array}{l}\text { Diff } \\
(\%)\end{array}$ & $\begin{array}{c}\text { g/bhp- } \\
\mathrm{hr}\end{array}$ & $\begin{array}{l}\text { Diff } \\
(\%)\end{array}$ & $\begin{array}{c}\text { g/bhp- } \\
\text { hr }\end{array}$ & $\begin{array}{l}\text { Diff } \\
(\%)\end{array}$ & $\begin{array}{c}\text { g/bhp- } \\
\text { hr }\end{array}$ & $\begin{array}{l}\text { Diff } \\
(\%)\end{array}$ & $\begin{array}{c}\text { g/bhp- } \\
\text { hr }\end{array}$ & $\begin{array}{l}\text { Diff } \\
(\%)\end{array}$ & $\begin{array}{c}\text { g/bhp- } \\
\text { hr }\end{array}$ & $\begin{array}{l}\text { Diff } \\
(\%)\end{array}$ & $\begin{array}{c}\text { g/bhp- } \\
\text { hr }\end{array}$ & $\begin{array}{l}\text { Diff } \\
(\%)\end{array}$ & $\begin{array}{c}\text { g/bhp- } \\
\text { hr }\end{array}$ & $\begin{array}{l}\text { Diff } \\
(\%)\end{array}$ \\
\hline- & $\begin{array}{c}\text { Low } \\
\text { Cetane } \\
\end{array}$ & 24.36 & - & 0.3807 & - & 528.6 & - & 4.369 & - & 5.457 & - & 5.502 & - & 5.152 & - & 0.1306 & - & 0.3342 & - \\
\hline \begin{tabular}{|l|}
$7.5 \mathrm{ml} / \mathrm{gal}$ \\
DTBP \\
\end{tabular} & \begin{tabular}{|c|} 
Low \\
Cetane
\end{tabular} & 24.41 & $0.2 \%$ & 0.3791 & $-0.4 \%$ & 528.9 & * & 4.151 & $-5.0 \%$ & 5.219 & $-4.4 \%$ & 5.258 & $-4.4 \%$ & 4.941 & $-4.1 \%$ & 0.1088 & $-16.7 \%$ & 0.3087 & * \\
\hline $\begin{array}{l}3 \mathrm{ml} / \mathrm{gal} 2- \\
\mathrm{EHN}\end{array}$ & $\begin{array}{c}\text { Low } \\
\text { Cetane }\end{array}$ & 24.44 & $0.3 \%$ & 0.3797 & $-0.3 \%$ & 529.4 & * & 4.099 & $-6.2 \%$ & 5.315 & $-2.6 \%$ & 5.333 & $-3.1 \%$ & 5.068 & $-1.6 \%$ & 0.1072 & $-18.0 \%$ & 0.3072 & * \\
\hline $\begin{array}{l}6 \mathrm{ml} / \mathrm{gal} 2- \\
\mathrm{EHN} \\
\end{array}$ & $\begin{array}{c}\text { Low } \\
\text { Cetane } \\
\end{array}$ & 24.43 & $0.3 \%$ & 0.3796 & $-0.3 \%$ & 527.8 & * & 4.017 & $-8.1 \%$ & 5.249 & $-3.8 \%$ & 5.281 & $-4.0 \%$ & 4.966 & $-3.6 \%$ & 0.1016 & $-22.2 \%$ & 0.3056 & * \\
\hline $\begin{array}{l}8 \mathrm{ml} / \mathrm{gal} 2- \\
\mathrm{EHN}\end{array}$ & $\begin{array}{c}\text { Low } \\
\text { Cetane }\end{array}$ & 24.42 & $0.2 \%$ & 0.3797 & $-0.2 \%$ & 526.6 & $-0.4 \%$ & 3.979 & $-8.9 \%$ & 5.190 & $-4.9 \%$ & 5.246 & $-4.6 \%$ & 4.941 & $-4.1 \%$ & 0.0947 & $-27.5 \%$ & 0.3035 & * \\
\hline \begin{tabular}{|l|}
$6 \mathrm{ml} / \mathrm{gal}$ \\
ODA3
\end{tabular} & $\begin{array}{c}\text { Low } \\
\text { Cetane } \\
\end{array}$ & 24.45 & $0.4 \%$ & 0.3798 & $-0.2 \%$ & 527.8 & * & 4.037 & $-7.6 \%$ & 5.240 & $-4.0 \%$ & 5.323 & $-3.3 \%$ & 5.019 & $-2.6 \%$ & 0.1003 & $-23.2 \%$ & 0.3049 & * \\
\hline $\begin{array}{l}12 \mathrm{ml} / \mathrm{gal} \\
\text { ODA3 }\end{array}$ & $\begin{array}{c}\text { Low } \\
\text { Cetane }\end{array}$ & 24.43 & $0.3 \%$ & 0.3800 & $-0.2 \%$ & 527.6 & * & 4.003 & $-8.4 \%$ & 5.244 & $-3.9 \%$ & 5.260 & $-4.4 \%$ & 4.960 & $-3.7 \%$ & 0.0916 & $-29.9 \%$ & 0.3051 & * \\
\hline \begin{tabular}{|l|}
$16 \mathrm{ml} / \mathrm{gal}$ \\
ODA3
\end{tabular} & $\begin{array}{c}\text { Low } \\
\text { Cetane }\end{array}$ & 24.41 & $0.2 \%$ & 0.3800 & * & 525.4 & $-0.6 \%$ & 4.040 & $-7.5 \%$ & 5.200 & $-4.7 \%$ & 5.240 & $-4.8 \%$ & 4.941 & $-4.1 \%$ & 0.0888 & $-32.0 \%$ & 0.3115 & ${ }^{*}$ \\
\hline \begin{tabular}{|l|}
$3.88 \mathrm{ml} / \mathrm{gal}$ \\
ODANS \\
\end{tabular} & $\begin{array}{c}\text { Low } \\
\text { Cetane } \\
\end{array}$ & 24.45 & $0.4 \%$ & 0.3788 & $-0.5 \%$ & 527.0 & $-0.3 \%$ & 3.985 & $-8.8 \%$ & 5.276 & $-3.3 \%$ & 5.332 & $-3.1 \%$ & 5.038 & $-2.2 \%$ & 0.0950 & $-27.3 \%$ & 0.3019 & * \\
\hline \begin{tabular}{|l|}
$7.75 \mathrm{ml} / \mathrm{gal}$ \\
ODANS \\
\end{tabular} & $\begin{array}{c}\text { Low } \\
\text { Cetane } \\
\end{array}$ & 24.44 & $0.3 \%$ & 0.3796 & $-0.3 \%$ & 526.6 & $-0.4 \%$ & 3.987 & $-8.7 \%$ & 5.230 & $-4.2 \%$ & 5.281 & $-4.0 \%$ & 4.975 & $-3.4 \%$ & 0.0862 & $-34.0 \%$ & 0.3049 & * \\
\hline \begin{tabular}{|l|}
$10.33 \mathrm{ml} / \mathrm{gal}$ \\
ODANS
\end{tabular} & $\begin{array}{c}\text { Low } \\
\text { Cetane }\end{array}$ & 24.42 & $0.3 \%$ & 0.3799 & * & 526.3 & $-0.4 \%$ & 4.021 & $-8.0 \%$ & 5.199 & $-4.7 \%$ & 5.221 & $-5.1 \%$ & 4.922 & $-4.5 \%$ & 0.0823 & $-37.0 \%$ & 0.3100 & * \\
\hline
\end{tabular}


Table 7-11 July 2007 FTP Results for the 1992 Detroit Diesel Series 60

\begin{tabular}{|c|c|c|c|c|c|c|c|c|c|c|c|c|c|c|c|c|c|c|c|}
\hline \multirow[b]{2}{*}{$\begin{array}{l}\text { Additive I } \\
\text { Condition }\end{array}$} & \multirow[b]{2}{*}{ Base } & \multicolumn{2}{|c|}{ Work } & \multicolumn{2}{|c|}{ BSFC } & \multicolumn{2}{|c|}{$\mathrm{CO}_{2}$} & \multicolumn{2}{|c|}{ co } & \multicolumn{2}{|c|}{ NOx } & \multicolumn{2}{|c|}{ NOx2 } & \multicolumn{2}{|c|}{ NO } & \multicolumn{2}{|c|}{$\mathrm{HC}$} & \multicolumn{2}{|c|}{ TPM } \\
\hline & & \begin{tabular}{|c|} 
bhp- \\
hr
\end{tabular} & $\begin{array}{l}\text { Diff } \\
(\%)\end{array}$ & $\begin{array}{c}\text { Ib/bhp- } \\
\mathrm{hr}\end{array}$ & $\begin{array}{l}\text { Diff } \\
(\%)\end{array}$ & $\begin{array}{c}\text { g/bhp- } \\
\text { hr }\end{array}$ & $\begin{array}{l}\text { Diff } \\
(\%)\end{array}$ & $\begin{array}{c}\text { g/bhp- } \\
\mathrm{hr}\end{array}$ & $\begin{array}{l}\text { Diff } \\
(\%)\end{array}$ & $\begin{array}{c}\text { g/bhp- } \\
\mathrm{hr}\end{array}$ & $\begin{array}{l}\text { Diff } \\
(\%)\end{array}$ & $\begin{array}{c}\text { g/bhp- } \\
\text { hr }\end{array}$ & $\begin{array}{l}\text { Diff } \\
(\%)\end{array}$ & $\begin{array}{c}\text { g/bhp- } \\
\mathrm{hr}\end{array}$ & $\begin{array}{l}\text { Diff } \\
(\%) \\
\end{array}$ & $\begin{array}{c}\text { g/bhp- } \\
\text { hr }\end{array}$ & $\begin{array}{l}\text { Diff } \\
(\%)\end{array}$ & $\begin{array}{c}\text { g/bhp- } \\
\mathrm{hr}\end{array}$ & $\begin{array}{l}\text { Diff } \\
(\%)\end{array}$ \\
\hline- & CP Cert & 25.25 & - & 0.3704 & - & 519.9 & - & 3.440 & - & 5.102 & - & 5.214 & - & - & - & 0.1112 & - & 0.2649 & - \\
\hline $\begin{array}{l}12 \mathrm{ml} / \mathrm{gal} \\
\text { ODA }\end{array}$ & CP Cert & 25.26 & * & 0.3716 & * & 519.9 & * & 3.250 & $-5.5 \%$ & 4.968 & $-2.6 \%$ & 4.955 & * & -- & -- & 0.0858 & $-22.8 \%$ & 0.2618 & * \\
\hline- & Low Cetane & 25.30 & - & 0.3728 & - & 522.2 & - & 3.643 & - & 5.379 & - & 5.374 & - & -- & -- & 0.1155 & - & 0.2655 & - \\
\hline $\begin{array}{l}6 \mathrm{ml} / \mathrm{gal} 2- \\
\mathrm{EHN}\end{array}$ & Low Cetane & 25.32 & $0.1 \%$ & 0.3722 & * & 519.5 & * & 3.464 & $-4.9 \%$ & 5.171 & $-3.9 \%$ & 5.192 & $-3.4 \%$ & -- & -- & 0.0953 & $-17.4 \%$ & 0.2662 & * \\
\hline $\begin{array}{l}12 \mathrm{ml} / \mathrm{gal} \\
\text { ODA3 }\end{array}$ & Low Cetane & 25.32 & $0.1 \%$ & 0.3720 & $-0.2 \%$ & 521.4 & * & 3.476 & $-4.6 \%$ & 5.151 & $-4.2 \%$ & 5.138 & $-4.4 \%$ & -- & -- & 0.0898 & $-22.3 \%$ & 0.2631 & * \\
\hline \begin{tabular}{|l|}
$12 \mathrm{ml} / \mathrm{gal}$ \\
$\mathrm{ODA} 3+12$ \\
$\mathrm{ml} / \mathrm{gal}$ \\
Ethanol \\
\end{tabular} & Low Cetane & 25.31 & * & 0.3726 & * & 520.2 & * & 3.451 & $-5.3 \%$ & 5.178 & $-3.7 \%$ & 5.145 & $-4.3 \%$ & -- & -- & 0.0894 & $-22.6 \%$ & 0.2598 & * \\
\hline B20 Soy & Low Cetane & 25.28 & * & 0.3806 & $2.1 \%$ & 521.6 & * & 3.141 & $-13.8 \%$ & 5.363 & * & 5.388 & * & -- & -- & 0.0882 & $-23.6 \%$ & 0.2018 & $-24.0 \%$ \\
\hline B20 Mineral & Low Cetane & 25.28 & * & 0.3801 & $2.0 \%$ & 521.5 & * & 3.120 & $-14.4 \%$ & 5.266 & $-2.1 \%$ & 5.243 & $-2.4 \%$ & -- & -- & 0.0794 & $-31.2 \%$ & 0.2033 & $-23.4 \%$ \\
\hline \begin{tabular}{|l|} 
B20 \\
Cottonseed
\end{tabular} & Low Cetane & 25.28 & $-0.1 \%$ & 0.3809 & $2.2 \%$ & 519.5 & * & 3.119 & $-14.4 \%$ & 5.260 & $-2.2 \%$ & 5.245 & $-2.4 \%$ & -- & -- & 0.0760 & $-34.2 \%$ & 0.2020 & $-23.9 \%$ \\
\hline Low Cetane & Low Cetane & 25.31 & $0.1 \%$ & 0.3719 & $-0.2 \%$ & 519.3 & * & 3.613 & $-0.8 \%$ & 5.411 & $0.6 \%$ & 5.381 & * & -- & -- & 0.0988 & $-14.5 \%$ & 0.2499 & $-5.9 \%$ \\
\hline $\begin{array}{l}6 \mathrm{ml} / \mathrm{gal} 2- \\
\mathrm{EHN}\end{array}$ & $\begin{array}{c}\text { B20 } \\
\text { Cottonseed }\end{array}$ & 25.29 & * & 0.3810 & * & 521.8 & * & 3.051 & $-2.2 \%$ & 5.221 & $-0.7 \%$ & 5.230 & * & -- & -- & 0.0696 & * & 0.2035 & * \\
\hline $\begin{array}{l}12 \mathrm{ml} / \mathrm{gal} \\
\text { ODA3 }\end{array}$ & $\begin{array}{c}\text { B20 } \\
\text { Cottonseed }\end{array}$ & 25.28 & * & 0.3815 & $0.2 \%$ & 520.8 & $0.2 \%$ & 3.059 & $-1.9 \%$ & 5.214 & $-0.9 \%$ & 5.242 & * & -- & -- & 0.0692 & $-8.9 \%$ & 0.2019 & * \\
\hline
\end{tabular}


Table 7-12 February 2007 FTP Results for the 2004 Cummins ISM 370

\begin{tabular}{|c|c|c|c|c|c|c|c|c|c|c|c|c|c|c|c|c|c|c|c|c|}
\hline \multirow[b]{2}{*}{$\begin{array}{l}\text { Additive I } \\
\text { Condition }\end{array}$} & \multirow[b]{2}{*}{ Base } & \multirow[b]{2}{*}{$\begin{array}{c}\text { Engine } \\
\text { MAP }\end{array}$} & \multicolumn{2}{|c|}{ Work } & \multicolumn{2}{|c|}{ BSFC } & \multicolumn{2}{|c|}{$\mathrm{CO}_{2}$} & \multicolumn{2}{|c|}{ co } & \multicolumn{2}{|c|}{ NOx } & \multicolumn{2}{|c|}{ NOx2 } & \multicolumn{2}{|c|}{ No } & \multicolumn{2}{|c|}{$\mathrm{HC}$} & \multicolumn{2}{|c|}{ TPM } \\
\hline & & & $\begin{array}{c}\text { bhp- } \\
\text { hr }\end{array}$ & Diff (\%) & $\begin{array}{c}\text { Ib/bhp- } \\
\mathrm{hr}\end{array}$ & $\begin{array}{l}\text { Diff } \\
(\%)\end{array}$ & $\begin{array}{c}\text { g/bhp- } \\
\mathrm{hr}\end{array}$ & $\begin{array}{l}\text { Diff } \\
(\%)\end{array}$ & $\begin{array}{c}\text { g/bhp- } \\
\mathrm{hr}\end{array}$ & Diff (\%) & $\begin{array}{c}\text { g/bhp- } \\
\text { hr }\end{array}$ & $\begin{array}{l}\text { Diff } \\
(\%)\end{array}$ & $\begin{array}{c}\text { g/bhp- } \\
\mathrm{hr}\end{array}$ & $\begin{array}{l}\text { Diff } \\
(\%)\end{array}$ & $\begin{array}{c}\text { g/bhp- } \\
\text { hr }\end{array}$ & $\begin{array}{l}\text { Diff } \\
(\%)\end{array}$ & $\begin{array}{c}\text { g/bhp- } \\
\text { hr }\end{array}$ & Diff (\%) & $\begin{array}{c}\text { g/bhp- } \\
\mathrm{hr}\end{array}$ & Diff (\%) \\
\hline- & $\mathrm{CP}$ & $\mathrm{CP}$ & 25.65 & - & 0.4238 & - & 601.5 & - & 0.6162 & - & 2.353 & - & 2.333 & - & 2.070 & - & 0.1999 & - & 0.0744 & - \\
\hline $12 \mathrm{ml} / \mathrm{gal}$ ODA & $\mathrm{CP}$ & $\mathrm{CP}$ & 25.55 & * & 0.4215 & * & 601.5 & * & 0.5705 & $-7.4 \%$ & 2.350 & * & 2.332 & * & 2.075 & * & 0.2033 & * & 0.0745 & * \\
\hline $6 \mathrm{ml} / \mathrm{gal} 2 \mathrm{EHN}$ & $\mathrm{CP}$ & $\mathrm{CP}$ & 25.64 & * & 0.4225 & * & 599.6 & $-0.3 \%$ & 0.5712 & $-7.3 \%$ & 2.364 & * & 2.358 & * & 2.094 & $1.2 \%$ & 0.2036 & * & 0.0731 & * \\
\hline $\begin{array}{l}12 \mathrm{ml} / \mathrm{gal} \\
2 \mathrm{EHN} \\
\end{array}$ & $\mathrm{CP}$ & $\mathrm{CP}$ & 25.64 & * & 0.4214 & * & 600.2 & * & 0.5430 & $-11.9 \%$ & 2.383 & $1.3 \%$ & 2.367 & $1.4 \%$ & 2.104 & $1.6 \%$ & 0.2042 & * & 0.0719 & * \\
\hline $24 \mathrm{ml} / \mathrm{gal}$ ODA & $\mathrm{CP}$ & $\mathrm{CP}$ & 25.65 & * & 0.4161 & * & 600.6 & * & 0.5565 & $-9.7 \%$ & 2.385 & $1.4 \%$ & 2.361 & * & 2.094 & * & 0.2057 & * & 0.0719 & * \\
\hline \begin{tabular}{|l|}
$15 \mathrm{ml} / \mathrm{gal}$ \\
DTBP
\end{tabular} & $\mathrm{CP}$ & $\mathrm{CP}$ & 25.59 & * & 0.4191 & * & 601.3 & * & 0.5257 & $-14.7 \%$ & 2.363 & * & 2.355 & * & 2.098 & * & 0.1992 & * & 0.0721 & * \\
\hline & $\begin{array}{l}\text { Grad } \\
\text { Cand } \\
\end{array}$ & $\begin{array}{c}\text { Grad } \\
\text { Ref } \\
\end{array}$ & 25.22 & - & 0.4094 & - & 596.1 & - & 0.5600 & - & 2.347 & - & 2.329 & - & 2.047 & - & 0.2139 & - & 0.0548 & - \\
\hline $6 \mathrm{ml} / \mathrm{gal}$ ODA & $\begin{array}{l}\text { Grad } \\
\text { Cand }\end{array}$ & $\begin{array}{c}\text { Grad } \\
\text { Ref }\end{array}$ & 25.22 & * & 196 & * & 598.3 & $0.4 \%$ & 0.5575 & * & 2.349 & * & 2.324 & * & 2.041 & * & 0.2165 & * & 0.0550 & * \\
\hline B20 Soy & $\mathrm{CP}$ & $\begin{array}{c}\text { Grad } \\
\text { Ref }\end{array}$ & 25.23 & * & 0.4229 & * & 604.7 & * & 0.5485 & $-9.8 \%$ & 2.479 & $4.3 \%$ & 2.460 & $4.2 \%$ & 2.188 & $5.4 \%$ & 0.1854 & $-12.0 \%$ & 0.0562 & $-23.2 \%$ \\
\hline B20 Mineral & $\mathrm{CP}$ & $\begin{array}{c}\text { Grad } \\
\text { Ref }\end{array}$ & 25.20 & * & 0.4268 & * & 602.0 & $-0.5 \%$ & 0.5430 & $-10.7 \%$ & 2.441 & $2.8 \%$ & 2.406 & $1.9 \%$ & 2.139 & $3.1 \%$ & 0.1806 & $-14.3 \%$ & 0.0532 & $-27.3 \%$ \\
\hline \begin{tabular}{|l} 
B20 \\
Cottonseed
\end{tabular} & $\mathrm{CP}$ & $\begin{array}{c}\text { Grad } \\
\text { Ref }\end{array}$ & 25.21 & * & 0.4328 & $1.7 \%$ & 601.9 & $-0.5 \%$ & 0.5450 & $-10.4 \%$ & 2.466 & $3.8 \%$ & 2.435 & $3.2 \%$ & 2.166 & $4.4 \%$ & 0.1812 & $-14.0 \%$ & 0.0478 & $-34.7 \%$ \\
\hline \begin{tabular}{|l|}
$10 \mathrm{ml} / \mathrm{gal}$ \\
DTBP \\
\end{tabular} & B20 Soy & $\begin{array}{c}\text { Grad } \\
\text { Ref }\end{array}$ & 25.17 & $-0.3 \%$ & 0.4376 & * & 604.4 & * & 0.5260 & $-4.1 \%$ & 2.418 & * & 2.435 & * & 2.166 & * & 0.1838 & * & 0.0563 & * \\
\hline- & $\mathrm{CP}$ & $\mathrm{CP}$ & 25.60 & $-0.2 \%$ & 0.4250 & * & 603.4 & * & 0.5915 & $-4.0 \%$ & 2.364 & * & 2.346 & * & 2.076 & * & 0.2060 & * & 0.0691 & * \\
\hline$E$ & $\mathrm{CP}$ & $\begin{array}{c}\text { Grad } \\
\text { Ref }\end{array}$ & 25.10 & - & 0.4258 & - & 604.9 & - & 0.6081 & - & 2.376 & - & 2.360 & - & 2.075 & - & 0.2106 & - & 0.0732 & - \\
\hline \begin{tabular}{|l|} 
Grad Ref \\
Fuel, w EGR \\
\end{tabular} & \begin{tabular}{|c|} 
Grad Ref \\
Fuel, w/o \\
EGR \\
\end{tabular} & $\begin{array}{c}\text { Grad } \\
\text { Ref }\end{array}$ & 25.25 & * & 0.4223 & $6.5 \%$ & 590.7 & $4.8 \%$ & 0.5675 & $-11.9 \%$ & 2.181 & $-54.1 \%$ & 2.161 & $-54.9 \%$ & 1.884 & $-57.9 \%$ & 0.1913 & $-3.6 \%$ & 0.0543 & $-12.8 \%$ \\
\hline & $\begin{array}{c}\text { Grad Ref } \\
\text { Fuel, w/o } \\
\text { EGR }\end{array}$ & $\begin{array}{c}\text { Grad } \\
\text { Ref }\end{array}$ & 25.24 & - & 0.3964 & - & 563.8 & - & 0.6440 & - & 4.750 & - & 4.789 & - & 4.472 & - & 0.1984 & - & 0.0623 & - \\
\hline
\end{tabular}


Table 7-13 January 2007 SET Results for the 1992 Detroit Diesel Series 60

\begin{tabular}{|c|c|c|c|c|c|c|c|c|c|c|c|c|c|c|c|c|c|c|}
\hline \multirow[b]{2}{*}{$\begin{array}{l}\text { Additive / } \\
\text { Condition }\end{array}$} & \multirow[b]{2}{*}{ Base } & \multirow[b]{2}{*}{ Mode } & \multicolumn{2}{|c|}{ Work } & \multicolumn{2}{|c|}{ BSFC } & \multicolumn{2}{|c|}{$\mathrm{CO}_{2}$} & \multicolumn{2}{|c|}{$\mathrm{CO}$} & \multicolumn{2}{|c|}{ NOx } & \multicolumn{2}{|c|}{ NOx2 } & \multicolumn{2}{|c|}{$\mathrm{HC}$} & \multicolumn{2}{|c|}{ TPM } \\
\hline & & & \begin{tabular}{|c|} 
bhp- \\
hr
\end{tabular} & $\begin{array}{l}\text { Diff } \\
(\%)\end{array}$ & $\begin{array}{c}\text { Ib/bhp- } \\
\text { hr }\end{array}$ & $\begin{array}{l}\text { Diff } \\
(\%)\end{array}$ & $\begin{array}{c}\text { g/bhp- } \\
\mathrm{hr}\end{array}$ & $\begin{array}{l}\text { Diff } \\
(\%)\end{array}$ & $\begin{array}{c}\text { g/bhp- } \\
\text { hr }\end{array}$ & $\begin{array}{l}\text { Diff } \\
(\%)\end{array}$ & $\begin{array}{c}\text { g/bhp- } \\
\text { hr }\end{array}$ & $\begin{array}{l}\text { Diff } \\
(\%)\end{array}$ & $\begin{array}{c}\text { g/bhp- } \\
\text { hr }\end{array}$ & \begin{tabular}{|l} 
Diff \\
$(\%)$
\end{tabular} & $\begin{array}{c}\text { g/bhp- } \\
\text { hr }\end{array}$ & $\begin{array}{l}\text { Diff } \\
(\%)\end{array}$ & $\begin{array}{c}\text { g/bhp- } \\
\text { hr }\end{array}$ & $\begin{array}{l}\text { Diff } \\
(\%)\end{array}$ \\
\hline \multirow[t]{14}{*}{-} & \multirow[t]{14}{*}{$\begin{array}{l}\text { CP } \\
\text { Cert }\end{array}$} & 0 & 4.084 & - & 0.3203 & - & 459.6 & - & 2.993 & - & 7.846 & - & 7.852 & - & 0.0442 & - & 0.5589 & - \\
\hline & & $1^{*}$ & 0.000 & - & 2.691 & - & 16350 & - & 171.8 & - & 380.2 & - & 350.8 & - & 13.5 & - & - & - \\
\hline & & 2 & 6.798 & - & 0.2678 & - & 451.8 & - & 10.27 & - & 5.857 & - & 5.874 & - & 0.0222 & - & - & - \\
\hline & & 3 & 3.794 & - & 0.3226 & - & 458.4 & - & 0.6842 & - & 9.156 & - & 9.190 & - & 0.0405 & - & - & - \\
\hline & & 4 & 5.706 & - & 0.3166 & - & 447.3 & - & 1.745 & - & 7.426 & - & 7.449 & - & 0.0238 & - & - & - \\
\hline & & 5 & 3.398 & - & 0.3231 & - & 460.5 & - & 0.9587 & - & 8.756 & - & 8.775 & - & 0.0388 & - & - & - \\
\hline & & 6 & 5.083 & - & 0.3257 & - & 455.3 & - & 4.067 & - & 6.862 & - & 6.869 & - & 0.0215 & - & - & - \\
\hline & & 7 & 1.698 & - & 0.3437 & - & 495.9 & - & 0.7202 & - & 11.93 & - & 11.93 & - & 0.124 & - & - & - \\
\hline & & 8 & 7.605 & - & 0.3186 & - & 440.7 & - & 3.430 & - & 6.615 & - & 6.629 & - & 0.0232 & - & - & - \\
\hline & & 9 & 1.900 & - & 0.3515 & - & 505.5 & - & 0.7661 & - & 11.89 & - & 11.91 & - & 0.124 & - & - & - \\
\hline & & 10 & 7.785 & - & 0.3185 & - & 441.4 & - & 1.583 & - & 6.996 & - & 7.005 & - & 0.0280 & - & - & - \\
\hline & & 11 & 1.946 & - & 0.3659 & - & 530.7 & - & 0.9683 & - & 12.20 & - & 12.21 & - & 0.191 & - & - & - \\
\hline & & 12 & 5.831 & - & 0.3194 & - & 448.4 & - & 0.8206 & - & 7.756 & - & 7.766 & - & 0.0370 & - & - & - \\
\hline & & 13 & 3.890 & - & 0.3277 & - & 465.6 & - & 0.4945 & - & 9.397 & - & 9.394 & - & 0.0701 & - & - & - \\
\hline \multirow[t]{14}{*}{$\begin{array}{c}\text { 12ml/gal } \\
\text { ODA }\end{array}$} & \multirow[t]{14}{*}{$\begin{array}{c}\text { CP } \\
\text { Cert }\end{array}$} & 0 & 4.084 & * & 0.3220 & * & 455.6 & $-0.9 \%$ & 2.877 & $-3.9 \%$ & 7.783 & * & 7.820 & * & 0.0399 & * & 0.5282 & * \\
\hline & & $1^{*}$ & 0.000 & * & 3.080 & $14.4 \%$ & 15950 & $-2.5 \%$ & 92.50 & $-46.2 \%$ & 416.7 & $9.6 \%$ & 383.1 & $9.2 \%$ & 5.75 & $-57.4 \%$ & - & * \\
\hline & & 2 & 6.801 & * & 0.2767 & $3.3 \%$ & 448.8 & * & 10.10 & * & 5.956 & * & 5.986 & * & 0.0230 & * & - & * \\
\hline & & 3 & 3.794 & * & 0.3186 & * & 454.0 & $-1.0 \%$ & 0.6198 & $-9.4 \%$ & 8.934 & $-2.4 \%$ & 8.975 & $-2.3 \%$ & 0.0377 & * & - & * \\
\hline & & 4 & 5.706 & * & 0.3187 & * & 442.7 & $-1.0 \%$ & 1.624 & $-6.9 \%$ & 7.470 & * & 7.517 & * & 0.0228 & * & - & * \\
\hline & & 5 & 3.396 & * & 0.3268 & * & 455.8 & $-1.0 \%$ & 0.8559 & $-10.7 \%$ & 8.575 & * & 8.627 & * & 0.0392 & * & - & * \\
\hline & & 6 & 5.078 & * & 0.3247 & * & 451.0 & $-0.9 \%$ & 3.733 & $-8.2 \%$ & 6.906 & * & 6.942 & * & 0.0221 & * & - & * \\
\hline & & 7 & 1.697 & * & 0.3466 & * & 488.7 & $-1.4 \%$ & 0.6342 & $-11.9 \%$ & 11.06 & $-7.3 \%$ & 11.12 & $-6.9 \%$ & 0.110 & * & - & * \\
\hline & & 8 & 7.610 & * & 0.3181 & * & 437.8 & * & 3.432 & * & 6.705 & * & 6.752 & * & 0.0235 & * & - & * \\
\hline & & 9 & 1.899 & * & 0.3489 & * & 499.1 & $-1.3 \%$ & 0.6915 & $-9.7 \%$ & 10.99 & $-7.6 \%$ & 11.05 & $-7.3 \%$ & 0.109 & * & - & * \\
\hline & & 10 & 7.786 & * & 0.3191 & * & 438.4 & * & 1.545 & * & 7.100 & * & 7.153 & * & 0.0290 & * & - & * \\
\hline & & 11 & 1.960 & $0.7 \%$ & 0.3642 & * & 523.5 & $-1.4 \%$ & 0.8091 & $-16.4 \%$ & 11.24 & $-7.8 \%$ & 11.30 & $-7.4 \%$ & 0.152 & $-20.2 \%$ & - & * \\
\hline & & 12 & 5.829 & * & 0.3196 & * & 445.3 & * & 0.7657 & $-6.7 \%$ & 7.773 & * & 7.833 & * & 0.0388 & * & - & * \\
\hline & & 13 & 3.892 & * & 0.3271 & * & 461.0 & $-1.0 \%$ & 0.4503 & $-8.9 \%$ & 9.041 & $-3.8 \%$ & 9.109 & $-3.0 \%$ & 0.0689 & * & - & * \\
\hline \multirow[t]{14}{*}{-} & \multirow[t]{14}{*}{$\begin{array}{c}\text { Grad } \\
\text { Ref }\end{array}$} & 0 & 4.063 & - & 0.3216 & - & 445.3 & - & 2.876 & - & 7.267 & - & 7.246 & - & 0.0404 & - & 0.4970 & - \\
\hline & & $1^{*}$ & 0.000 & - & 2.976 & - & 16170 & - & 86.53 & - & 389.4 & - & 361.3 & - & 7.50 & - & - & - \\
\hline & & 2 & 6.787 & - & 0.2829 & - & 435.3 & - & 9.764 & - & 5.604 & - & 5.592 & - & 0.0228 & - & - & - \\
\hline & & 3 & 3.785 & - & 0.3195 & - & 445.2 & - & 0.6629 & - & 8.299 & - & 8.292 & - & 0.0374 & - & - & - \\
\hline & & 4 & 5.672 & - & 0.3168 & - & 432.5 & - & 1.707 & - & 6.982 & - & 6.979 & - & 0.0225 & - & - & - \\
\hline & & 5 & 3.386 & - & 0.3212 & - & 447.6 & - & 0.9232 & - & 8.002 & - & 7.996 & - & 0.0360 & - & - & - \\
\hline & & 6 & 5.070 & - & 0.3232 & - & 439.2 & - & 3.928 & - & 6.458 & - & 6.451 & - & 0.0206 & - & - & - \\
\hline & & 7 & 1.694 & - & 0.3414 & - & 478.6 & - & 0.6476 & - & 10.27 & - & 10.23 & - & 0.113 & - & - & - \\
\hline & & 8 & 7.564 & - & 0.3177 & - & 427.2 & - & 3.452 & - & 6.287 & - & 6.276 & - & 0.0236 & - & - & - \\
\hline & & 9 & 1.894 & - & 0.3495 & - & 490.2 & - & 0.6761 & - & 10.18 & - & 10.14 & - & 0.116 & - & - & - \\
\hline & & 10 & 7.717 & - & 0.3168 & - & 428.7 & - & 1.559 & - & 6.614 & - & 6.604 & - & 0.0278 & - & - & - \\
\hline & & 11 & 1.932 & - & 0.3665 & - & 515.9 & - & 0.8225 & - & 10.47 & - & 10.43 & - & 0.165 & - & - & - \\
\hline & & 12 & 5.789 & - & 0.3179 & - & 435.0 & - & 0.8212 & - & 7.247 & - & 7.233 & - & 0.0374 & - & - & - \\
\hline & & 13 & 3.860 & - & 0.3267 & - & 450.2 & - & 0.4656 & - & 8.449 & - & 8.436 & - & 0.0649 & - & - & - \\
\hline
\end{tabular}




\begin{tabular}{|c|c|c|c|c|c|c|c|c|c|c|c|c|c|c|c|c|c|c|}
\hline \multirow{15}{*}{$\begin{array}{c}\text { Additive I } \\
\text { Condition } \\
16 \mathrm{ml} / \mathrm{gal} \\
\mathrm{ODA}\end{array}$} & \multirow{15}{*}{$\begin{array}{c}\text { Base } \\
\text { Grad } \\
\text { Ref }\end{array}$} & & \multicolumn{2}{|c|}{ Work } & \multicolumn{2}{|c|}{ BSFC } & \multicolumn{2}{|c|}{$\mathrm{CO}_{2}$} & \multicolumn{2}{|c|}{ co } & \multicolumn{2}{|c|}{ NOx } & \multicolumn{2}{|c|}{ NOx2 } & \multicolumn{2}{|c|}{$\mathrm{HC}$} & \multicolumn{2}{|c|}{ TPM } \\
\hline & & \begin{tabular}{|c} 
Mode \\
0 \\
\end{tabular} & \begin{tabular}{|c|} 
bhp- \\
hr \\
4.062 \\
\end{tabular} & $\begin{array}{c}\text { Diff } \\
(\%) \\
* \\
\end{array}$ & \begin{tabular}{|c|}
$\begin{array}{c}\text { Ib/bhp- } \\
\text { hr }\end{array}$ \\
0.3207 \\
\end{tabular} & $\begin{array}{c}\text { Diff } \\
(\%) \\
* \\
\end{array}$ & \begin{tabular}{|c|} 
g/bhp- \\
$\mathbf{h r}$ \\
445.0 \\
\end{tabular} & $\begin{array}{c}\text { Diff } \\
(\%) \\
* \\
\end{array}$ & \begin{tabular}{|c}
$\begin{array}{c}\text { g/bhp- } \\
\text { hr }\end{array}$ \\
2.793 \\
\end{tabular} & $\begin{array}{c}\text { Diff } \\
(\%) \\
* \\
\end{array}$ & $\begin{array}{c}\text { g/bhp- } \\
\text { hr } \\
7.279 \\
\end{array}$ & $\begin{array}{c}\text { Diff } \\
(\%) \\
*\end{array}$ & $\begin{array}{c}\text { g/bhp- } \\
\text { hr }\end{array}$ & \begin{tabular}{|c|}
$\begin{array}{c}\text { Diff } \\
(\%)\end{array}$ \\
$*$ \\
\end{tabular} & $\begin{array}{c}\text { g/bhp- } \\
\text { hr }\end{array}$ & $\begin{array}{c}\text { Diff } \\
(\%) \\
* \\
\end{array}$ & $\begin{array}{c}\text { g/bhp- } \\
\mathbf{~ h r} \\
0.4621 \\
\end{array}$ & $\begin{array}{l}\text { Diff } \\
\mathbf{( \% )} \\
-7.0 \% \\
\end{array}$ \\
\hline & & $1^{*}$ & 0.000 & - & 2.773 & * & 16300 & * & 50.61 & $-41.5 \%$ & 381.6 & * & 351.4 & * & 9.43 & * & - & - \\
\hline & & 2 & 6.790 & * & 0.2810 & * & 436.0 & * & 9.585 & * & 5.679 & $1.3 \%$ & 5.661 & $1.2 \%$ & 0.0227 & * & - & - \\
\hline & & 3 & 3.786 & * & 0.3221 & * & 443.7 & * & 0.5988 & $-9.7 \%$ & 8.291 & * & 8.271 & * & 0.0349 & * & - & - \\
\hline & & 4 & 5.673 & * & 0.3164 & * & 433.3 & * & 1.637 & * & 7.075 & * & 7.056 & $1.1 \%$ & 0.0210 & * & - & - \\
\hline & & 5 & 3.386 & * & 0.3210 & * & 445.4 & * & 0.8379 & $-9.2 \%$ & 8.034 & * & 8.004 & * & 0.0329 & * & - & - \\
\hline & & 6 & 5.073 & * & 0.3217 & $-0.5 \%$ & 439.4 & * & 3.768 & * & 6.516 & * & 6.494 & * & 0.0210 & * & - & - \\
\hline & & 7 & 1.697 & * & 0.3413 & * & 477.2 & * & 0.5823 & $-10.1 \%$ & 9.841 & $-4.2 \%$ & 9.768 & $-4.6 \%$ & 0.101 & * & - & - \\
\hline & & 8 & 7.561 & $0.0 \%$ & 0.3167 & * & 426.4 & * & 3.436 & * & 6.368 & $1.3 \%$ & 6.354 & $1.2 \%$ & 0.0218 & * & - & - \\
\hline & & 9 & 1.892 & * & 0.3459 & * & 488.6 & * & 0.5969 & $-11.7 \%$ & 9.712 & $-4.6 \%$ & 9.666 & $-4.7 \%$ & 0.0971 & * & - & - \\
\hline & & 10 & 7.717 & * & 0.3172 & * & 428.4 & * & 1.543 & * & 6.720 & $1.6 \%$ & 6.708 & $1.6 \%$ & 0.0254 & * & - & - \\
\hline & & 11 & 1.914 & * & 0.3630 & * & 516.3 & * & 0.7253 & $-11.8 \%$ & 9.883 & $-5.6 \%$ & 9.840 & $-5.6 \%$ & 0.142 & * & - & - \\
\hline & & 12 & 5.787 & * & 0.3182 & * & 435.1 & * & 0.7507 & $-8.6 \%$ & 7.332 & $1.2 \%$ & 7.316 & * & 0.0329 & * & - & - \\
\hline & & 13 & 3.857 & $-0.1 \%$ & 0.3260 & * & 450.8 & * & 0.4214 & $-9.5 \%$ & 8.379 & $-0.8 \%$ & 8.363 & * & 0.0592 & * & - & - \\
\hline- & $\begin{array}{l}\text { Grad } \\
\text { Cand }\end{array}$ & 0 & 4.059 & - & 0.3246 & - & 449.9 & - & 2.890 & - & 7.657 & - & 7.622 & - & 0.0414 & - & 0.4974 & - \\
\hline & & $1^{*}$ & 0.000 & - & 2.850 & - & 16220 & - & 136.5 & - & \begin{tabular}{|l|l}
403.6 \\
\end{tabular} & - & 374.8 & - & 13.7 & - & - & - \\
\hline & & 2 & 6.758 & - & 0.2859 & - & 439.9 & - & 9.756 & - & 5.824 & - & 5.802 & - & 0.0232 & - & - & - \\
\hline & & 3 & 3.778 & - & 0.3247 & - & 449.9 & - & 0.6659 & - & 8.800 & - & 8.772 & - & 0.0379 & - & - & - \\
\hline & & 4 & 5.669 & - & 0.3181 & - & 437.5 & - & 1.719 & - & 7.300 & - & 7.268 & - & 0.0229 & - & - & - \\
\hline & & 5 & 3.388 & - & 0.3244 & - & 449.4 & - & 0.9355 & - & 8.471 & - & 8.437 & - & 0.0369 & - & - & - \\
\hline & & 6 & 5.082 & - & 0.3257 & - & 444.1 & - & 3.958 & - & 6.724 & - & 6.702 & - & 0.0213 & - & - & - \\
\hline & & 7 & 1.694 & - & 0.3495 & - & 483.0 & - & 0.6967 & - & 11.30 & - & 11.25 & - & 0.122 & - & - & - \\
\hline & & 8 & 7.562 & - & 0.3207 & - & 432.4 & - & 464 & - & 6.511 & - & 6.495 & - & 0.0218 & - & - & - \\
\hline & & 9 & 1.902 & - & 0.3504 & - & 495.1 & - & 0.7012 & - & \begin{tabular}{|l}
11.22 \\
\end{tabular} & - & 11.17 & - & 0.113 & - & - & - \\
\hline & & 10 & 7.687 & - & 0.3219 & - & 433.1 & - & 1.519 & - & 6.900 & - & 6.876 & - & 0.0256 & - & - & - \\
\hline & & 11 & 1.931 & - & 0.3669 & - & 519.1 & - & 0.8876 & - & 11.57 & - & 11.54 & - & 0.161 & - & - & - \\
\hline & & 12 & 5.787 & - & 0.3212 & - & 439.7 & - & 0.8049 & - & 7.569 & - & 7.545 & - & 0.0337 & - & - & - \\
\hline & & 13 & 3.865 & - & 0.3293 & - & 455.0 & - & 0.4617 & - & 9.031 & - & 8.999 & - & 0.0597 & - & - & - \\
\hline $\begin{array}{l}8 \mathrm{ml} / \mathrm{gal} \\
2 \mathrm{EHN}\end{array}$ & $\begin{array}{l}\text { Grad } \\
\text { Cand }\end{array}$ & 0 & 4.061 & * & 0.3179 & * & 450.0 & * & 2.671 & $-7.6 \%$ & 7.638 & * & 7.602 & * & 0.0362 & * & 0.4489 & * \\
\hline & & $1^{*}$ & 0.000 & - & 3.124 & * & 17130 & * & 73.32 & $-46.3 \%$ & \begin{tabular}{|l|}
399.7 \\
\end{tabular} & * & 378.0 & * & 9.11 & * & - & - \\
\hline & & 2 & 6.785 & $0.4 \%$ & 0.2797 & * & \begin{tabular}{|l}
440.2 \\
\end{tabular} & * & 9.326 & $-4.4 \%$ & 5.915 & * & 5.887 & $1.5 \%$ & 0.0225 & * & - & - \\
\hline & & 3 & 3.779 & * & 0.3156 & * & 448.2 & $-0.4 \%$ & 0.5676 & * & 8.695 & * & 8.670 & * & 0.0339 & * & - & - \\
\hline & & 4 & 5.667 & * & 0.3125 & * & 436.8 & * & 1.514 & * & 7.367 & $0.9 \%$ & 7.348 & $1.1 \%$ & 0.0207 & * & - & - \\
\hline & & 5 & 3.390 & * & 0.3184 & * & 450.4 & * & 0.8017 & $-14.3 \%$ & 8.402 & * & 8.371 & $-0.8 \%$ & 0.0344 & * & - & - \\
\hline & & 6 & 5.073 & $-0.2 \%$ & 0.3188 & * & 444.5 & * & 3.596 & $-9.1 \%$ & 6.805 & $1.2 \%$ & 6.772 & * & 0.0214 & * & - & - \\
\hline & & 7 & 1.699 & * & 0.3355 & * & 481.5 & * & 0.5999 & * & 10.50 & $-7.1 \%$ & 10.46 & $-7.0 \%$ & 0.105 & * & - & - \\
\hline & & 8 & 7.554 & * & 0.3139 & * & 431.8 & * & 3.225 & * & 6.665 & $2.4 \%$ & 6.635 & $2.2 \%$ & 0.0212 & * & - & - \\
\hline & & 9 & 1.896 & * & 0.3449 & * & 491.9 & * & 0.5983 & * & 10.40 & $-7.3 \%$ & 10.36 & $-7.3 \%$ & 0.0891 & * & - & - \\
\hline & & 10 & 7.708 & * & 0.3141 & * & 433.8 & * & 1.400 & $-7.8 \%$ & 7.031 & $1.9 \%$ & 7.004 & * & 0.0234 & $-8.4 \%$ & - & - \\
\hline & & 11 & 1.924 & * & 0.3598 & * & 519.1 & * & 0.7546 & $-15.0 \%$ & 10.67 & $-7.8 \%$ & 10.62 & $-7.9 \%$ & 0.140 & $-13.4 \%$ & - & - \\
\hline & & 12 & 5.797 & * & 0.3128 & * & 440.2 & * & 0.7020 & $-12.8 \%$ & 7.669 & * & 7.635 & $1.2 \%$ & 0.0314 & * & - & - \\
\hline & & 13 & 3.861 & * & 0.3220 & * & 456.2 & * & 0.3979 & $-13.8 \%$ & 8.873 & * & 8.834 & $-1.8 \%$ & 0.0547 & * & - & - \\
\hline $\begin{array}{c}16 \mathrm{ml} / \mathrm{gal} \\
\mathrm{ODA}\end{array}$ & $\begin{array}{l}\text { Grad } \\
\text { Cand }\end{array}$ & 0 & 4.063 & * & 0.3244 & * & 445.3 & * & 2.581 & $-10.7 \%$ & 7.665 & * & 7.604 & * & 0.0347 & * & 0.4514 & * \\
\hline & & $1^{*}$ & 0.000 & - & 3.444 & * & 16560 & * & 70.06 & $-48.7 \%$ & 421.7 & * & 382.7 & * & 4.74 & * & - & - \\
\hline
\end{tabular}




\begin{tabular}{|c|c|c|c|c|c|c|c|c|c|c|c|c|c|c|c|c|c|c|}
\hline \multirow{14}{*}{$\begin{array}{l}\text { Additive / } \\
\text { Condition }\end{array}$} & \multirow{14}{*}{ Base } & & \multicolumn{2}{|c|}{ Work } & \multicolumn{2}{|c|}{ BSFC } & \multicolumn{2}{|c|}{$\mathrm{CO}_{2}$} & \multicolumn{2}{|c|}{ co } & \multicolumn{2}{|c|}{ NOx } & \multicolumn{2}{|c|}{ NOx 2} & \multicolumn{2}{|c|}{$\mathrm{HC}$} & \multicolumn{2}{|c|}{ TPM } \\
\hline & & Mode & $\begin{array}{c}\text { bhp- } \\
\text { hr }\end{array}$ & \begin{tabular}{|l|} 
Diff \\
$(\%)$
\end{tabular} & $\begin{array}{c}\text { Ib/bhp- } \\
\text { hr }\end{array}$ & $\begin{array}{l}\text { Diff } \\
(\%)\end{array}$ & $\begin{array}{c}\text { g/bhp- } \\
\text { hr }\end{array}$ & $\begin{array}{l}\text { Diff } \\
(\%)\end{array}$ & $\begin{array}{c}\text { g/bhp- } \\
\text { hr }\end{array}$ & $\begin{array}{l}\text { Diff } \\
(\%)\end{array}$ & $\begin{array}{c}\text { g/bhp- } \\
\mathrm{hr}\end{array}$ & $\begin{array}{l}\text { Diff } \\
\text { (\%) }\end{array}$ & $\begin{array}{c}\text { g/bhp- } \\
\text { hr }\end{array}$ & $\begin{array}{c}\text { Diff } \\
\text { (\%) } \\
*\end{array}$ & $\begin{array}{c}\text { g/bhp- } \\
\text { hr }\end{array}$ & $\begin{array}{c}\text { Diff } \\
(\%) \\
*\end{array}$ & $\begin{array}{c}\text { g/bhp- } \\
\mathrm{hr}\end{array}$ & $\begin{array}{l}\text { Diff } \\
(\%)\end{array}$ \\
\hline & & 2 & 6.788 & $0.4 \%$ & 0.2847 & * & 435.0 & * & 9.113 & $-6.6 \%$ & 5.926 & $1.8 \%$ & 5.878 & * & 0.0205 & * & - & - \\
\hline & & 3 & 3.784 & * & 0.3224 & * & 445.0 & * & 0.5399 & * & 8.743 & * & 8.691 & * & 0.0326 & * & - & - \\
\hline & & 4 & 5.671 & * & 0.3176 & * & 432.3 & * & 1.453 & $-11.9 \%$ & 7.397 & $0.9 \%$ & 7.360 & * & 0.0196 & * & - & - \\
\hline & & 5 & 3.387 & * & 0.3237 & * & 446.1 & * & 0.7707 & $-14.3 \%$ & 8.468 & * & 8.413 & * & 0.0338 & * & - & - \\
\hline & & 6 & 5.071 & $-0.2 \%$ & 0.3237 & * & 438.4 & * & 3.420 & $-9.1 \%$ & 6.836 & $1.2 \%$ & 6.789 & $1.0 \%$ & 0.0186 & * & - & - \\
\hline & & 7 & 1.698 & * & 0.3425 & * & 478.0 & * & 0.5936 & * & 10.53 & $-7.1 \%$ & 10.44 & $-7.0 \%$ & 0.102 & * & - & - \\
\hline & & 8 & 7.561 & * & \begin{tabular}{|l}
0.3187 \\
\end{tabular} & * & 426.9 & * & 3.079 & * & 6.668 & $2.4 \%$ & 6.626 & * & 0.0197 & * & - & - \\
\hline & & 9 & 1.896 & * & 0.3528 & * & 492.2 & * & 0.5956 & $-14.7 \%$ & 10.45 & $-7.3 \%$ & 10.36 & $-7.3 \%$ & 0.0950 & * & - & - \\
\hline & & 10 & 7.716 & $0.3 \%$ & 0.3205 & * & 428.0 & * & 1.334 & $-7.8 \%$ & 7.039 & * & 6.998 & $1.9 \%$ & 0.0246 & * & - & - \\
\hline & & 11 & 1.934 & * & 0.3675 & * & 517.5 & * & 0.7301 & $-15.0 \%$ & 10.68 & $-7.8 \%$ & 10.60 & $-7.9 \%$ & 0.142 & $-13.4 \%$ & - & - \\
\hline & & 12 & 5.797 & $0.2 \%$ & 0.3211 & * & 434.8 & * & 0.6749 & $-12.8 \%$ & 7.676 & * & 7.627 & * & 0.0315 & * & - & - \\
\hline & & 13 & 3.861 & $-0.1 \%$ & 0.3298 & * & 453.3 & * & 0.3956 & $-13.8 \%$ & 8.888 & $-1.8 \%$ & 8.838 & $-1.8 \%$ & 0.0616 & * & - & - \\
\hline \multirow[t]{14}{*}{$\begin{array}{l}16 \mathrm{ml} / \mathrm{gal} \\
\mathrm{ODA} 2 \mathrm{x}\end{array}$} & \multirow[t]{14}{*}{$\begin{array}{l}\text { Grad } \\
\text { Cand }\end{array}$} & 0 & 4.064 & $0.1 \%$ & 0.3242 & * & 451.1 & * & 2.576 & $-10.9 \%$ & 7.698 & * & 7.673 & * & 0.0351 & * & 0.4558 & * \\
\hline & & $1^{*}$ & 0.000 & - & 3.501 & * & 16980 & * & 72.91 & $-46.6 \%$ & 411.2 & * & 388.5 & * & 7.75 & * & - & - \\
\hline & & 2 & 6.789 & $0.5 \%$ & 0.2853 & * & 441.2 & * & 9.025 & $-7.5 \%$ & 5.967 & $2.5 \%$ & 5.950 & $2.6 \%$ & 0.0208 & * & - & - \\
\hline & & 3 & 3.787 & * & 0.3206 & * & 450.4 & * & 0.5253 & * & 8.810 & * & 8.790 & * & .0307 & * & - & - \\
\hline & & 4 & 5.672 & * & 0.3178 & * & 438.6 & * & 1.469 & $-11.9 \%$ & 7.450 & $0.9 \%$ & 7.439 & $1.1 \%$ & 0.0188 & * & - & - \\
\hline & & 5 & 3.384 & * & 0.3220 & $-1.8 \%$ & 452.4 & * & 0.7593 & $-14.3 \%$ & 8.523 & * & 8.502 & * & 0.0334 & * & - & - \\
\hline & & 6 & 5.071 & $-0.2 \%$ & 0.3231 & * & 444.8 & * & 3.371 & $-9.1 \%$ & 6.882 & $1.2 \%$ & 6.860 & $1.0 \%$ & 0.0190 & * & - & - \\
\hline & & 7 & 1.699 & * & 0.3412 & * & 483.9 & * & 0.6131 & $-13.9 \%$ & 10.50 & $-7.1 \%$ & 10.48 & $-7.0 \%$ & 0.105 & * & - & - \\
\hline & & 8 & 7.565 & * & 0.3190 & * & 431.9 & * & 3.111 & * & 6.687 & $2.4 \%$ & 6.673 & $2.2 \%$ & 0.0203 & * & - & - \\
\hline & & 9 & 1.894 & * & 0.3532 & * & 497.7 & * & 0.5959 & $-14.7 \%$ & 10.47 & $-7.3 \%$ & 10.45 & $-7.3 \%$ & 0.0906 & * & - & - \\
\hline & & 10 & 7.723 & $0.3 \%$ & 0.3201 & * & 433.5 & * & 1.349 & $-7.8 \%$ & 7.063 & $1.9 \%$ & 7.045 & $1.9 \%$ & 0.0230 & $-8.4 \%$ & - & - \\
\hline & & 11 & 1.926 & * & 0.3666 & * & 525.0 & $0.0 \%$ & 0.7397 & $-15.0 \%$ & 10.73 & $-7.8 \%$ & 0.70 & $-7.9 \%$ & 0.141 & * & - & - \\
\hline & & 12 & 5.793 & * & 0.3200 & * & 441.2 & * & 0.6770 & $-12.8 \%$ & 7.731 & $1.3 \%$ & 7.712 & $1.2 \%$ & 0.0328 & * & - & - \\
\hline & & 13 & 3.863 & * & 0.3294 & * & 456.6 & * & 0.3937 & $-13.8 \%$ & 8.881 & * & 8.867 & $-1.8 \%$ & 0.0602 & * & - & - \\
\hline \multirow[t]{14}{*}{ - } & \multirow[t]{14}{*}{$\begin{array}{l}\text { Grad } \\
\text { Cand }\end{array}$} & 0 & 4.061 & * & 0.3240 & * & 446.0 & $-0.9 \%$ & 2.709 & $-6.3 \%$ & 7.716 & * & 7.653 & * & 0.0401 & * & 0.4930 & * \\
\hline & & $1^{*}$ & 0.000 & * & 3.457 & $21.3 \%$ & 16260 & * & 129.4 & $-5.2 \%$ & 421.2 & $4.4 \%$ & 390.1 & $4.1 \%$ & 15.4 & * & - & - \\
\hline & & 2 & 6.787 & $0.4 \%$ & 0.2794 & * & 436.7 & * & 9.405 & $-3.6 \%$ & 5.850 & * & 5.803 & * & 0.0228 & * & - & - \\
\hline & & 3 & 3.778 & * & 0.3237 & * & 445.7 & $-0.9 \%$ & 0.5943 & $-10.8 \%$ & 8.926 & * & 8.871 & * & .0383 & * & - & - \\
\hline & & 4 & 5.665 & * & 0.3179 & * & 432.1 & $-1.2 \%$ & 1.548 & $-9.9 \%$ & 7.374 & * & 7.328 & * & 0.0211 & * & - & - \\
\hline & & 5 & 3.381 & $-0.2 \%$ & 0.3261 & * & 446.7 & * & 0.8583 & $-8.3 \%$ & 8.576 & * & 8.516 & * & 0.0417 & * & - & - \\
\hline & & 6 & 5.071 & $-0.2 \%$ & 0.3252 & * & 439.6 & $-1.0 \%$ & 3.555 & $-10.2 \%$ & 6.810 & * & 6.767 & * & 0.0204 & * & - & - \\
\hline & & 7 & 1.698 & $0.2 \%$ & 0.3447 & * & 478.4 & $-1.0 \%$ & 0.6644 & $-4.6 \%$ & 11.25 & * & 11.15 & * & 0.115 & * & - & - \\
\hline & & 8 & 7.566 & * & 0.3189 & * & 426.7 & $-1.3 \%$ & 3.190 & $-7.9 \%$ & 6.564 & * & 6.518 & * & 0.0198 & * & - & - \\
\hline & & 9 & 1.895 & $-0.3 \%$ & 0.3543 & * & 492.7 & * & 0.6473 & $-7.7 \%$ & 11.24 & * & 11.14 & * & 0.0979 & * & - & - \\
\hline & & 10 & 7.716 & $0.4 \%$ & 0.3195 & * & 430.0 & * & 1.386 & $-8.8 \%$ & 6.937 & * & 6.885 & * & 0.0228 & * & - & - \\
\hline & & 11 & 1.917 & $-0.7 \%$ & 0.3710 & * & 519.9 & * & 0.8502 & $-4.2 \%$ & 11.63 & * & 11.54 & * & 0.152 & * & - & - \\
\hline & & 12 & 5.792 & * & 0.3204 & * & 435.8 & $-0.9 \%$ & 0.7220 & $-10.3 \%$ & 7.634 & * & 7.585 & * & 0.0333 & * & - & - \\
\hline & & 13 & 3.866 & * & 0.3280 & * & 452.6 & * & 0.4554 & * & 9.023 & * & 8.976 & * & 0.0642 & * & - & - \\
\hline \multirow[t]{4}{*}{$\begin{array}{c}10 \mathrm{ml} / \mathrm{gal} \\
\text { DTBP }\end{array}$} & \multirow[t]{4}{*}{$\begin{array}{l}\text { Grad } \\
\text { Cand }\end{array}$} & 0 & 4.062 & * & 0.3263 & * & 451.5 & * & 2.641 & $-8.6 \%$ & 7.625 & * & 7.596 & * & 0.0335 & * & 0.4679 & * \\
\hline & & $1^{*}$ & 0.000 & - & 3.760 & * & 16740 & * & 83.60 & $-38.8 \%$ & 410.0 & * & 381.1 & * & 8.10 & * & - & - \\
\hline & & 2 & 6.787 & $0.4 \%$ & 0.2882 & * & 441.9 & * & 9.275 & * & 5.911 & * & 5.880 & * & 0.0213 & * & - & - \\
\hline & & 3 & 3.778 & * & \begin{tabular}{|l}
0.3252 \\
\end{tabular} & * & 452.3 & * & 0.5425 & * & 8.629 & * & 8.703 & * & 0.0292 & * & - & - \\
\hline
\end{tabular}




\begin{tabular}{|c|c|c|c|c|c|c|c|c|c|c|c|c|c|c|c|c|c|c|}
\hline \multirow{11}{*}{$\begin{array}{l}\text { Additive I } \\
\text { Condition }\end{array}$} & \multirow{11}{*}{ Base } & & \multicolumn{2}{|c|}{ Work } & \multicolumn{2}{|c|}{ BSFC } & \multicolumn{2}{|c|}{$\mathrm{CO}_{2}$} & \multicolumn{2}{|c|}{ co } & \multicolumn{2}{|c|}{ NOx } & \multicolumn{2}{|c|}{ NOX 2} & \multicolumn{2}{|c|}{$\mathrm{HC}$} & \multicolumn{2}{|c|}{ TPM } \\
\hline & & $\begin{array}{c}\text { Mode } \\
4\end{array}$ & $\begin{array}{c}\text { bhp- } \\
\text { hr }\end{array}$ & $\begin{array}{l}\text { Diff } \\
(\%)\end{array}$ & $\begin{array}{c}\text { Ib/bhp- } \\
\text { hr }\end{array}$ & $\begin{array}{l}\text { Diff } \\
(\%)\end{array}$ & $\begin{array}{c}\text { g/bhp- } \\
\mathrm{hr}\end{array}$ & $\begin{array}{l}\text { Diff } \\
(\%)\end{array}$ & $\begin{array}{c}\text { g/bhp- } \\
\text { hr }\end{array}$ & $\begin{array}{l}\text { Diff } \\
(\%)\end{array}$ & $\begin{array}{c}\text { g/bhp- } \\
\text { hr }\end{array}$ & $\begin{array}{l}\text { Diff } \\
(\%)\end{array}$ & $\begin{array}{c}\text { g/bhp- } \\
\text { hr }\end{array}$ & \begin{tabular}{|l} 
Diff \\
(\%)
\end{tabular} & $\begin{array}{c}\text { g/bhp- } \\
\text { hr }\end{array}$ & $\begin{array}{l}\text { Diff } \\
(\%)\end{array}$ & $\begin{array}{c}\text { g/bhp- } \\
\mathrm{hr}\end{array}$ & $\begin{array}{c}\text { Diff } \\
\text { (\%) }\end{array}$ \\
\hline & & 5 & 3.388 & * & 0.3239 & * & 453.1 & $0.2 \%$ & 0.7780 & $-14.3 \%$ & 8.420 & * & 8.389 & * & 0.0337 & * & - & - \\
\hline & & 6 & 5.076 & * & 0.3246 & * & 444.5 & * & 3.507 & $-9.1 \%$ & 6.800 & * & 6.772 & * & 0.0187 & * & - & - \\
\hline & & 7 & 1.696 & * & 0.3445 & * & 484.8 & * & 0.6088 & $-13.9 \%$ & 10.53 & $-7.1 \%$ & 10.48 & $-7.0 \%$ & 0.101 & $-13.9 \%$ & - & - \\
\hline & & 8 & 7.561 & * & 0.3202 & * & 432.0 & * & 3.165 & * & 6.642 & $2.4 \%$ & 6.617 & * & 0.0186 & * & - & - \\
\hline & & 9 & 1.898 & * & 0.3547 & * & 497.0 & * & 0.6041 & $-14.7 \%$ & 10.39 & $-7.3 \%$ & 10.34 & $-7.3 \%$ & 0.0857 & * & - & - \\
\hline & & 10 & 7.711 & * & 0.3219 & * & 434.1 & * & 1.371 & $-7.8 \%$ & 7.006 & * & 6.980 & * & 0.0219 & * & - & - \\
\hline & & 11 & 1.932 & * & 0.3710 & * & 523.8 & * & 0.7188 & $-15.0 \%$ & 10.65 & $-7.8 \%$ & 10.60 & $-7.9 \%$ & 0.128 & $-13.4 \%$ & - & - \\
\hline & & 12 & 5.793 & * & 0.3196 & * & 440.1 & * & 0.6785 & $-12.8 \%$ & 7.639 & * & 7.618 & * & 0.0278 & * & - & - \\
\hline & & 13 & 3.861 & * & 0.3257 & * & 455.9 & * & 0.3795 & $-13.8 \%$ & 8.867 & * & 8.849 & * & 0.0517 & $-8.4 \%$ & - & - \\
\hline \multirow[t]{14}{*}{$\begin{array}{c}6 \mathrm{ml} / \mathrm{gal} \\
\mathrm{ODA}\end{array}$} & \multirow[t]{14}{*}{$\begin{array}{l}\text { Grad } \\
\text { Cand }\end{array}$} & 0 & 4.063 & * & 0.3261 & * & 441.6 & * & 2.595 & $-10.2 \%$ & 7.433 & * & 7.430 & * & 0.0329 & * & 0.4671 & * \\
\hline & & $1^{*}$ & 0.000 & - & 3.693 & * & 16750 & * & 82.17 & $-39.8 \%$ & 415.8 & * & 394.7 & * & 7.78 & * & - & - \\
\hline & & 2 & 6.787 & $0.4 \%$ & 0.2893 & * & 443.2 & $0.8 \%$ & 9.165 & * & 5.889 & * & 5.880 & * & 0.0197 & * & - & - \\
\hline & & 3 & 3.781 & * & 0.3254 & * & 453.1 & * & 0.5452 & * & 8.740 & * & 8.744 & * & 0.0313 & * & - & - \\
\hline & & 4 & 5.669 & * & 0.3183 & * & 439.3 & * & 1.480 & $-11.9 \%$ & 7.361 & * & 7.358 & * & 0.0183 & * & - & - \\
\hline & & 5 & 3.385 & * & 0.3238 & * & 454.2 & * & 0.7888 & $-14.3 \%$ & 8.426 & * & 8.435 & * & 0.0358 & * & - & - \\
\hline & & 6 & 5.076 & * & 0.3240 & * & 445.6 & * & 3.460 & $-9.1 \%$ & 6.800 & $1.2 \%$ & 6.806 & $1.0 \%$ & 0.0186 & * & - & - \\
\hline & & 7 & 1.696 & * & 0.3461 & * & 484.3 & * & 0.6224 & $-13.9 \%$ & 10.59 & $-7.1 \%$ & 10.61 & $-7.0 \%$ & 0.107 & * & - & - \\
\hline & & 8 & 7.563 & * & 0.3193 & * & 434.1 & * & 3.103 & $-6.9 \%$ & 6.621 & $2.4 \%$ & 6.623 & * & 0.0195 & * & - & - \\
\hline & & 9 & 1.899 & * & 0.3529 & * & 498.5 & * & 0.5952 & $-14.7 \%$ & 10.58 & $-7.3 \%$ & 10.60 & $-7.3 \%$ & 0.0833 & $-21.3 \%$ & - & - \\
\hline & & 10 & 7.711 & * & 0.3215 & * & 431.8 & * & 1.355 & $-7.8 \%$ & 6.914 & * & 6.919 & * & 0.0217 & $-8.4 \%$ & - & - \\
\hline & & 11 & 1.938 & * & 0.3692 & * & 430.4 & * & 0.6351 & * & 8.963 & * & 8.974 & * & 0.120 & * & - & - \\
\hline & & 12 & 5.798 & $0.2 \%$ & 0.3207 & * & 377.5 & * & 0.5864 & * & 6.508 & * & 6.512 & * & 0.0264 & * & - & - \\
\hline & & 13 & 3.863 & * & 0.3283 & * & 382.0 & * & 0.3333 & * & 7.360 & * & 7.376 & * & 0.0497 & * & - & - \\
\hline
\end{tabular}


Table 7-14 June 2007 SET Results for the 1992 Detroit Diesel Series 60

\begin{tabular}{|c|c|c|c|c|c|c|c|c|c|c|c|c|c|c|c|c|c|c|}
\hline \multirow[b]{2}{*}{$\begin{array}{l}\text { Additive I } \\
\text { Condition }\end{array}$} & \multirow[b]{2}{*}{ Base } & \multirow[b]{2}{*}{ Mode } & \multicolumn{2}{|c|}{ Work } & \multicolumn{2}{|c|}{ BSFC } & \multicolumn{2}{|c|}{$\mathrm{CO}_{2}$} & \multicolumn{2}{|c|}{$\mathrm{CO}$} & \multicolumn{2}{|c|}{ NOx } & \multicolumn{2}{|c|}{ NOx2 } & \multicolumn{2}{|c|}{$\mathrm{HC}$} & \multicolumn{2}{|c|}{ TPM } \\
\hline & & & \begin{tabular}{|c|} 
bhp- \\
hr
\end{tabular} & $\begin{array}{l}\text { Diff } \\
(\%)\end{array}$ & \begin{tabular}{|c|}
$\begin{array}{c}\text { Ib/bhp- } \\
\text { hr }\end{array}$ \\
\end{tabular} & $\begin{array}{l}\text { Diff } \\
(\%)\end{array}$ & $\begin{array}{c}\text { g/bhp- } \\
\text { hr }\end{array}$ & $\begin{array}{l}\text { Diff } \\
(\%)\end{array}$ & $\begin{array}{c}\text { g/bhp- } \\
\text { hr }\end{array}$ & $\begin{array}{l}\text { Diff } \\
(\%)\end{array}$ & $\begin{array}{c}\text { g/bhp- } \\
\text { hr }\end{array}$ & $\begin{array}{l}\text { Diff } \\
(\%)\end{array}$ & $\begin{array}{c}\text { g/bhp- } \\
\text { hr }\end{array}$ & $\begin{array}{l}\text { Diff } \\
(\%)\end{array}$ & $\begin{array}{c}\text { g/bhp- } \\
\text { hr }\end{array}$ & $\begin{array}{l}\text { Diff } \\
(\%)\end{array}$ & $\begin{array}{c}\text { g/bhp- } \\
\text { hr }\end{array}$ & $\begin{array}{l}\text { Diff } \\
(\%)\end{array}$ \\
\hline \multirow[t]{14}{*}{-} & \multirow[t]{14}{*}{$\begin{array}{c}\text { Low } \\
\text { Cetane }\end{array}$} & 0 & 4.038 & - & 0.3335 & - & 455.0 & - & 3.761 & - & 7.597 & - & 8.017 & - & 0.0450 & - & 0.7453 & - \\
\hline & & $1^{*}$ & 0.000 & - & 3.014 & - & 15080 & - & 223.5 & - & -9.202 & - & 325.8 & - & 26.2 & - & - & - \\
\hline & & 2 & 6.728 & - & 0.3171 & - & 445.2 & - & 11.81 & - & 4.046 & - & 5.738 & - & 0.0198 & - & - & - \\
\hline & & 3 & 3.768 & - & 0.3266 & - & 454.8 & - & 0.7878 & - & 9.306 & - & 9.418 & - & 0.0342 & - & - & - \\
\hline & & 4 & 5.661 & - & 0.3257 & - & 442.7 & - & 2.443 & - & 7.406 & - & 7.475 & - & 0.0225 & - & - & - \\
\hline & & 5 & 3.355 & - & 0.3288 & - & 455.0 & - & 1.080 & - & 9.082 & - & 9.222 & - & 0.0427 & - & - & - \\
\hline & & 6 & 5.036 & - & 0.3309 & - & 449.0 & - & 5.001 & - & 6.865 & - & 6.960 & - & 0.0232 & - & - & - \\
\hline & & 7 & 1.675 & - & 0.3451 & - & 491.6 & - & 0.8093 & - & 12.99 & - & 13.26 & - & 0.137 & - & - & - \\
\hline & & 8 & 7.546 & - & 0.3272 & - & 436.5 & - & 4.815 & - & 6.545 & - & 6.602 & - & 0.0219 & - & - & - \\
\hline & & 9 & 1.884 & - & 0.3522 & - & 502.4 & - & 0.8368 & - & 12.80 & - & 13.05 & - & 0.120 & - & - & - \\
\hline & & 10 & 7.652 & - & 0.3283 & - & 439.0 & - & 2.304 & - & 6.977 & - & 7.037 & - & 0.0245 & - & - & - \\
\hline & & 11 & 1.918 & - & 0.3708 & - & 526.3 & - & 1.012 & - & 13.15 & - & 13.43 & - & 0.161 & - & - & - \\
\hline & & 12 & 5.738 & - & 0.3265 & - & 445.6 & - & 1.144 & - & 7.827 & - & 7.932 & - & 0.0321 & - & - & - \\
\hline & & 13 & 3.825 & - & 0.3327 & - & 460.4 & - & 0.5141 & - & 9.625 & - & 9.798 & - & 0.0591 & - & - & - \\
\hline \multirow[t]{14}{*}{$\begin{array}{l}7.5 \mathrm{ml} / \mathrm{gal} \\
\text { DTBP }\end{array}$} & \multirow[t]{14}{*}{$\begin{array}{c}\text { Low } \\
\text { Cetane }\end{array}$} & 0 & 4.034 & * & 0.3329 & * & 455.5 & * & 3.560 & $-5.4 \%$ & 7.872 & $3.6 \%$ & 7.939 & * & 0.0402 & * & 0.6373 & * \\
\hline & & $1^{*}$ & 0.000 & * & 2.971 & * & 14710 & * & 136.0 & $-39.2 \%$ & 352.1 & $-3926 \%$ & 340.5 & * & 19.3 & * & - & - \\
\hline & & 2 & 6.717 & * & 0.3167 & * & 446.4 & * & 11.56 & * & 5.771 & $42.6 \%$ & 5.788 & * & 0.0189 & * & - & - \\
\hline & & 3 & 3.772 & * & 0.3256 & * & 453.2 & * & 0.7287 & * & 9.093 & $-2.3 \%$ & 9.181 & $-2.5 \%$ & 0.0417 & * & - & - \\
\hline & & 4 & 5.656 & * & 0.3243 & * & 442.9 & * & 2.227 & $-8.8 \%$ & 7.438 & * & 7.484 & * & 0.0239 & * & - & - \\
\hline & & 5 & 3.357 & * & 0.3278 & * & 456.6 & * & 0.9707 & * & 8.886 & * & 8.998 & $-2.4 \%$ & 0.0377 & * & - & - \\
\hline & & 6 & 5.034 & * & 0.3322 & * & 450.8 & * & 4.706 & $-5.9 \%$ & 6.897 & * & 6.975 & * & 0.0221 & * & - & - \\
\hline & & 7 & 1.676 & * & 0.3494 & * & 488.1 & * & 0.6921 & $-14.5 \%$ & 12.22 & $-5.9 \%$ & 12.45 & $-6.1 \%$ & 0.113 & * & - & - \\
\hline & & 8 & 7.542 & * & 0.3274 & * & 438.0 & * & 4.597 & * & 6.645 & * & 6.686 & * & 0.0207 & * & - & - \\
\hline & & 9 & 1.869 & * & 0.3535 & * & 500.2 & * & 0.7250 & $-13.4 \%$ & 12.08 & $-5.6 \%$ & 12.31 & $-5.7 \%$ & 0.0971 & * & - & - \\
\hline & & 10 & 7.647 & * & 0.3258 & * & 441.1 & * & 2.149 & $-6.7 \%$ & 7.077 & * & 7.121 & * & 0.0234 & * & - & - \\
\hline & & 11 & 1.923 & * & 0.3723 & * & 524.2 & * & 0.8305 & $-17.9 \%$ & 12.37 & $-5.9 \%$ & 12.61 & $-6.1 \%$ & 0.120 & $-25.2 \%$ & - & - \\
\hline & & 12 & 5.729 & $-0.2 \%$ & 0.3265 & * & 446.2 & * & 1.022 & $-10.6 \%$ & 7.859 & * & 7.924 & * & 0.0309 & * & - & - \\
\hline & & 13 & 3.813 & * & 0.3318 & * & 461.9 & * & 0.4841 & * & 9.371 & * & 9.496 & $-3.1 \%$ & 0.0557 & * & - & - \\
\hline \multirow[t]{14}{*}{$\begin{array}{l}3 \mathrm{ml} / \mathrm{gal} 2- \\
\mathrm{EHN}\end{array}$} & \multirow[t]{14}{*}{$\begin{array}{c}\text { Low } \\
\text { Cetane }\end{array}$} & 0 & 4.034 & * & 0.3328 & * & 455.4 & * & 3.444 & $-8.4 \%$ & 7.949 & $4.6 \%$ & 7.967 & * & 0.0386 & * & 0.6203 & * \\
\hline & & $1^{*}$ & 0.000 & * & 3.028 & * & 15250 & * & 154.4 & * & 370.0 & $-4121 \%$ & 358.6 & $10.1 \%$ & 14.9 & * & - & - \\
\hline & & 2 & 6.716 & * & 0.3169 & * & 446.7 & * & 11.31 & * & 5.814 & $43.7 \%$ & 5.812 & * & 0.0176 & * & - & - \\
\hline & & 3 & 3.775 & * & 0.3258 & * & 453.5 & * & 0.6683 & $-15.2 \%$ & 9.146 & $-1.7 \%$ & 9.209 & $-2.2 \%$ & 0.0333 & * & - & - \\
\hline & & 4 & 5.658 & * & 0.3235 & * & 442.8 & * & 2.132 & $-12.7 \%$ & 7.484 & * & 7.504 & * & 0.0204 & * & - & - \\
\hline & & 5 & 3.359 & * & 0.3282 & * & 454.3 & * & 0.9218 & $-14.6 \%$ & 8.979 & * & 9.053 & * & 0.0370 & * & - & - \\
\hline & & 6 & 5.034 & * & 0.3316 & * & 448.9 & * & 4.435 & $-11.3 \%$ & 6.961 & * & 6.992 & * & 0.0194 & * & - & - \\
\hline & & 7 & 1.677 & * & 0.3505 & * & 487.7 & * & 0.7337 & * & 12.41 & $-4.5 \%$ & 12.54 & $-5.4 \%$ & 0.127 & * & - & - \\
\hline & & 8 & 7.541 & * & 0.3267 & * & 438.0 & * & 4.395 & $-8.7 \%$ & 6.671 & * & 6.659 & * & 0.0192 & $-12.2 \%$ & - & - \\
\hline & & 9 & 1.874 & * & 0.3572 & * & 499.6 & * & 0.7344 & * & 12.31 & $-3.8 \%$ & 12.44 & $-4.7 \%$ & 0.108 & * & - & - \\
\hline & & 10 & 7.635 & * & 0.3240 & * & 440.4 & * & 2.047 & $-11.2 \%$ & 7.139 & * & 7.121 & * & 0.0236 & * & - & - \\
\hline & & 11 & 1.916 & * & 0.3725 & * & 524.4 & * & 0.8961 & $-11.4 \%$ & 12.64 & $-3.9 \%$ & 12.75 & $-5.1 \%$ & 0.147 & * & - & - \\
\hline & & 12 & 5.723 & $-0.3 \%$ & 0.3271 & * & 446.4 & * & 1.003 & $-12.3 \%$ & 7.930 & * & 7.929 & * & 0.0328 & * & - & - \\
\hline & & 13 & 3.815 & * & 0.3326 & * & 462.5 & * & 0.4821 & * & 9.516 & * & 9.550 & * & 0.0561 & * & - & - \\
\hline
\end{tabular}




\begin{tabular}{|c|c|c|c|c|c|c|c|c|c|c|c|c|c|c|c|c|c|c|}
\hline & \multirow{2}{*}{\multicolumn{2}{|c|}{ Work }} & \multirow{2}{*}{\multicolumn{2}{|c|}{ BSFC }} & \multirow{2}{*}{\multicolumn{2}{|c|}{$\mathrm{CO}_{2}$}} & \multirow{2}{*}{\multicolumn{2}{|c|}{ co }} & \multirow{2}{*}{\multicolumn{2}{|c|}{ NOx }} & \multirow{2}{*}{\multicolumn{2}{|c|}{ NOx 2}} & \multirow{2}{*}{\multicolumn{2}{|c|}{$\mathrm{HC}$}} & & \\
\hline & & & & & & & & & & & & & & & & & \multicolumn{2}{|c|}{ TPM } \\
\hline \multirow[t]{15}{*}{$\begin{array}{c}\text { Additive I } \\
\text { Condition } \\
6 \mathrm{ml} / \mathrm{gal} 2 \mathrm{EHN}\end{array}$} & \multirow{15}{*}{$\begin{array}{l}\text { Base } \\
\text { Low } \\
\text { Cetane }\end{array}$} & Mode & $\begin{array}{c}\text { bhp- } \\
\text { hr }\end{array}$ & $\begin{array}{l}\text { Diff } \\
(\%)\end{array}$ & $\begin{array}{c}\text { Ib/bhp- } \\
\text { hr }\end{array}$ & $\begin{array}{l}\text { Diff } \\
\text { (\%) }\end{array}$ & $\begin{array}{c}\text { g/bhp- } \\
\text { hr }\end{array}$ & $\begin{array}{l}\text { Diff } \\
\text { (\%) }\end{array}$ & $\begin{array}{c}\text { g/bhp- } \\
\text { hr }\end{array}$ & $\begin{array}{l}\text { Diff } \\
(\%)\end{array}$ & $\begin{array}{c}\text { g/bhp- } \\
\text { hr }\end{array}$ & $\begin{array}{l}\text { Diff } \\
(\%)\end{array}$ & $\begin{array}{c}\text { g/bhp- } \\
\mathrm{hr}\end{array}$ & $\begin{array}{l}\text { Diff } \\
(\%)\end{array}$ & $\begin{array}{c}\text { g/bhp- } \\
\text { hr }\end{array}$ & $\begin{array}{l}\text { Diff } \\
(\%)\end{array}$ & $\begin{array}{c}\text { g/bhp- } \\
\text { hr }\end{array}$ & $\begin{array}{l}\text { Diff } \\
(\%)\end{array}$ \\
\hline & & 0 & 4.034 & * & 0.3331 & * & 454.0 & * & 3.480 & $-7.5 \%$ & 7.948 & $4.6 \%$ & 7.944 & * & 0.0360 & $-20.1 \%$ & 0.6451 & * \\
\hline & & $1^{*}$ & 0.000 & * & 3.112 & * & 15220 & * & 139.0 & $-37.8 \%$ & 369.0 & $-4110 \%$ & 352.2 & $8.1 \%$ & 15.9 & * & - & - \\
\hline & & 2 & 6.718 & * & 0.3123 & * & 446.1 & * & 11.37 & * & 5.856 & $44.7 \%$ & 5.848 & $1.9 \%$ & 0.0181 & * & - & - \\
\hline & & 3 & 3.765 & * & 0.3270 & * & 453.6 & * & 0.6934 & * & 9.176 & * & 9.213 & $-2.2 \%$ & 0.0349 & * & - & - \\
\hline & & 4 & 5.656 & * & 0.3251 & * & 441.9 & * & 2.185 & $-10.5 \%$ & 7.515 & * & 7.515 & * & 0.0209 & * & - & - \\
\hline & & 5 & 3.359 & * & 0.3268 & * & \begin{tabular}{|l}
452.7 \\
\end{tabular} & * & 0.9300 & $-13.9 \%$ & 8.957 & * & 9.008 & * & 0.0383 & * & - & - \\
\hline & & 6 & 5.037 & * & 0.3314 & * & 447.5 & * & 4.562 & $-8.8 \%$ & 6.981 & * & 6.995 & * & 0.0190 & * & - & - \\
\hline & & 7 & 1.677 & * & 0.3444 & * & 486.5 & * & 0.6293 & $-22.2 \%$ & 12.23 & $-5.9 \%$ & 12.32 & $-7.1 \%$ & 0.0924 & $-32.3 \%$ & - & - \\
\hline & & 8 & 7.544 & * & 0.3279 & * & 436.0 & * & 4.475 & $-7.1 \%$ & 6.700 & * & 6.672 & * & 0.0174 & $-20.5 \%$ & - & - \\
\hline & & 9 & 1.875 & * & 0.3554 & * & 496.6 & $-1.2 \%$ & 0.6838 & $-18.3 \%$ & 12.00 & $-6.2 \%$ & 12.08 & $-7.4 \%$ & 0.0878 & $-26.5 \%$ & - & - \\
\hline & & 10 & 7.643 & * & 0.3269 & * & 438.8 & * & 2.100 & $-8.9 \%$ & 7.180 & * & 7.143 & * & 0.0229 & * & - & - \\
\hline & & 11 & 1.913 & * & 0.3784 & * & 522.1 & * & 0.8306 & $-17.9 \%$ & 12.44 & $-5.4 \%$ & 12.50 & $-6.9 \%$ & 0.122 & $-23.9 \%$ & - & - \\
\hline & & 12 & 5.723 & $-0.3 \%$ & 0.3262 & * & 444.8 & * & 0.9786 & $-14.5 \%$ & 7.967 & * & 7.946 & * & 0.0271 & $-15.6 \%$ & - & - \\
\hline & & 13 & 3.819 & * & 0.3330 & * & 460.0 & * & 0.4594 & * & 9.438 & * & 9.445 & $-3.6 \%$ & 0.0516 & * & - & - \\
\hline \multirow[t]{14}{*}{$8 \mathrm{ml} / \mathrm{gal} 2 \mathrm{EHN}$} & \multirow[t]{14}{*}{$\begin{array}{l}\text { Low } \\
\text { Cetane }\end{array}$} & 0 & 4.035 & * & 0.3334 & * & 453.9 & * & 3.467 & $-7.8 \%$ & 7.917 & $4.2 \%$ & 7.933 & * & 0.0335 & $-25.7 \%$ & 0.6265 & * \\
\hline & & $1^{*}$ & 0.000 & * & 3.166 & * & 14910 & * & 126.2 & $-43.5 \%$ & 367.2 & $-4091 \%$ & 355.3 & $9.1 \%$ & 14.8 & * & - & - \\
\hline & & 2 & 6.719 & * & 0.3136 & * & 445.8 & * & 11.35 & * & 5.843 & $44.4 \%$ & 5.843 & $1.8 \%$ & 0.0173 & * & - & - \\
\hline & & 3 & 3.767 & * & 0.3277 & * & 452.9 & * & 0.6697 & $-15.0 \%$ & 9.124 & $-2.0 \%$ & 9.182 & $-2.5 \%$ & 0.0318 & * & - & - \\
\hline & & 4 & 5.659 & * & 0.3255 & * & 441.5 & * & 2.169 & $1.2 \%$ & 7.494 & * & 7.503 & * & 0.0190 & * & - & - \\
\hline & & 5 & 3.355 & * & 0.3264 & * & 453.0 & * & 0.9248 & $-14.3 \%$ & 8.905 & * & 8.972 & $-2.7 \%$ & 0.0360 & * & - & - \\
\hline & & 6 & 5.036 & * & 0.3321 & * & 448.5 & * & 4.554 & $-8.9 \%$ & 6.948 & * & 6.981 & * & 0.0188 & * & - & - \\
\hline & & 7 & 1.679 & * & 0.3508 & * & 485.1 & * & 0.6600 & $-18.4 \%$ & 12.01 & $-7.6 \%$ & 12.15 & $-8.4 \%$ & 0.104 & * & - & - \\
\hline & & 8 & 7.545 & * & 0.3274 & * & 436.4 & * & 4.509 & $-6.4 \%$ & 6.703 & * & 6.689 & * & 0.0179 & $-18.3 \%$ & - & - \\
\hline & & 9 & 1.876 & * & 0.3549 & * & 495.9 & $-1.3 \%$ & 0.6215 & $-25.7 \%$ & \begin{tabular}{|l}
11.88 \\
\end{tabular} & $-7.1 \%$ & 11.99 & $-8.1 \%$ & 0.0729 & $-39.0 \%$ & - & - \\
\hline & & 10 & 7.640 & * & 0.3267 & * & 439.0 & * & 2.077 & $-9.8 \%$ & 7.180 & * & 7.164 & * & 0.0201 & $-18.1 \%$ & - & - \\
\hline & & 11 & 1.915 & * & 0.3730 & * & 520.4 & * & 0.7721 & $-23.7 \%$ & 12.27 & $-6.7 \%$ & 12.39 & $-7.8 \%$ & 0.112 & $-30.5 \%$ & - & - \\
\hline & & 12 & 5.724 & $-0.2 \%$ & 0.3276 & * & 445.8 & * & 1.003 & $-12.4 \%$ & 7.929 & * & 7.939 & * & 0.0271 & $-15.5 \%$ & - & - \\
\hline & & 13 & 3.824 & * & 316 & * & 459.5 & * & 0.4382 & $-14.8 \%$ & 9.405 & * & 443 & $-3.6 \%$ & 0.0442 & * & - & - \\
\hline \multirow[t]{14}{*}{$\begin{array}{c}\text { 6ml/gal } \\
\text { ODA3 }\end{array}$} & \multirow[t]{14}{*}{$\begin{array}{c}\text { Low } \\
\text { Cetane }\end{array}$} & 0 & 4.035 & * & 0.3305 & * & 455.5 & * & 3.562 & $-5.3 \%$ & 7.949 & $4.6 \%$ & 7.968 & * & 0.0374 & * & 0.6434 & * \\
\hline & & $1^{*}$ & 0.000 & * & 3.593 & * & 15220 & * & 170.4 & * & 358.0 & $-3990 \%$ & 337.7 & * & 16.5 & * & - & - \\
\hline & & 2 & 6.714 & * & 0.2971 & $6.3 \%$ & 447.5 & * & 11.60 & * & 5.804 & $43.4 \%$ & 5.802 & * & 0.0328 & * & - & - \\
\hline & & 3 & 3.772 & * & 0.3225 & * & \begin{tabular}{|l}
454.4 \\
\end{tabular} & * & 0.6890 & $-12.5 \%$ & 9.184 & * & 9.241 & $-1.9 \%$ & 0.0331 & * & - & - \\
\hline & & 4 & 5.663 & * & 0.3214 & * & 443.5 & * & 2.184 & $-10.6 \%$ & 7.513 & * & 7.534 & * & 0.0216 & * & - & - \\
\hline & & 5 & 3.358 & * & 0.3278 & * & \begin{tabular}{|l}
454.4 \\
\end{tabular} & * & 0.9407 & $-12.9 \%$ & 8.990 & * & 9.066 & * & 0.0348 & * & - & - \\
\hline & & 6 & 5.037 & * & 0.3298 & * & 448.9 & * & 4.610 & $-7.8 \%$ & 6.942 & * & 6.983 & * & 0.0183 & * & - & - \\
\hline & & 7 & 1.677 & * & 0.3420 & * & 487.1 & * & 0.7372 & * & 12.45 & $-4.2 \%$ & 12.58 & $-5.1 \%$ & 0.107 & * & - & - \\
\hline & & 8 & 7.542 & * & 0.3265 & * & 437.7 & * & 4.581 & * & 6.671 & * & 6.662 & * & 0.0186 & $-14.9 \%$ & - & - \\
\hline & & 9 & 1.870 & * & 0.3568 & * & 499.1 & * & 0.7312 & * & 12.36 & * & 12.48 & $-4.4 \%$ & 0.0852 & $-28.8 \%$ & - & - \\
\hline & & 10 & 7.645 & * & 0.3262 & * & 440.3 & * & 2.182 & * & 7.116 & * & 7.105 & * & 0.0201 & $-18.0 \%$ & - & - \\
\hline & & 11 & 1.917 & * & 0.3676 & * & 523.8 & * & 0.8809 & $-12.9 \%$ & 12.69 & $-3.5 \%$ & 12.82 & $-4.5 \%$ & 0.115 & $-28.5 \%$ & - & - \\
\hline & & 12 & 5.732 & * & 0.3268 & * & 446.2 & * & 1.043 & $-8.8 \%$ & 7.914 & * & 7.922 & * & 0.0258 & $-19.7 \%$ & - & - \\
\hline & & 13 & 3.822 & * & 0.3362 & * & 460.8 & * & 0.4690 & * & 9.495 & * & 9.547 & * & 0.0480 & * & - & - \\
\hline \multirow[t]{2}{*}{$\begin{array}{c}12 \mathrm{ml} / \mathrm{gal} \\
\text { ODA3 }\end{array}$} & \multirow[t]{2}{*}{$\begin{array}{l}\text { Low } \\
\text { Cetane }\end{array}$} & 0 & 4.034 & * & 0.3329 & * & \begin{tabular}{|l|}
453.7 \\
\end{tabular} & * & 3.450 & $-8.3 \%$ & 7.931 & $4.4 \%$ & 7.935 & * & 0.0326 & $-27.6 \%$ & 0.6501 & * \\
\hline & & $1^{*}$ & 0.000 & * & 3.136 & * & 14740 & * & 134.2 & $-40.0 \%$ & 361.7 & $-4031 \%$ & 348.1 & * & 11.3 & * & - & - \\
\hline
\end{tabular}




\begin{tabular}{|c|c|c|c|c|c|c|c|c|c|c|c|c|c|c|c|c|c|c|}
\hline \multirow{14}{*}{$\begin{array}{l}\text { Additive / } \\
\text { Condition }\end{array}$} & \multirow{14}{*}{ Base } & & \multicolumn{2}{|c|}{ Work } & \multicolumn{2}{|c|}{ BSFC } & \multicolumn{2}{|c|}{$\mathrm{CO}_{2}$} & \multicolumn{2}{|c|}{ co } & \multicolumn{2}{|c|}{ NOx } & \multicolumn{2}{|c|}{ NOX2 } & \multicolumn{2}{|c|}{$\mathrm{HC}$} & \multicolumn{2}{|c|}{ TPM } \\
\hline & & Mode & $\begin{array}{c}\text { bhp- } \\
\text { hr }\end{array}$ & $\begin{array}{l}\text { Diff } \\
(\%)\end{array}$ & $\begin{array}{c}\text { Ib/bhp- } \\
\text { hr }\end{array}$ & $\begin{array}{l}\text { Diff } \\
\text { (\%) }\end{array}$ & $\begin{array}{c}\text { g/bhp- } \\
\mathrm{hr}\end{array}$ & $\begin{array}{l}\text { Diff } \\
(\%)\end{array}$ & $\begin{array}{c}\text { g/bhp- } \\
\text { hr }\end{array}$ & $\begin{array}{l}\text { Diff } \\
(\%)\end{array}$ & $\begin{array}{c}\text { g/bhp- } \\
\text { hr }\end{array}$ & $\begin{array}{l}\text { Diff } \\
(\%)\end{array}$ & $\begin{array}{c}\text { g/bhp- } \\
\text { hr }\end{array}$ & $\begin{array}{l}\text { Diff } \\
(\%)\end{array}$ & $\begin{array}{c}\text { g/bhp- } \\
\text { hr }\end{array}$ & $\begin{array}{l}\text { Diff } \\
(\%)\end{array}$ & $\begin{array}{c}\text { g/bhp- } \\
\mathrm{hr}\end{array}$ & $\begin{array}{l}\text { Diff } \\
(\%)\end{array}$ \\
\hline & & 2 & 6.719 & * & 0.3148 & * & 446.3 & * & 11.33 & * & 5.859 & $44.8 \%$ & 5.844 & $1.9 \%$ & 0.0160 & * & - & - \\
\hline & & 3 & 3.767 & * & 0.3244 & * & 452.7 & * & 0.6663 & $-15.4 \%$ & 9.164 & $-1.5 \%$ & 9.196 & $-2.4 \%$ & 0.0292 & * & - & - \\
\hline & & 4 & 5.659 & * & 0.3257 & * & 441.9 & * & 2.136 & $-12.5 \%$ & 7.514 & * & 7.512 & * & 0.0184 & * & - & - \\
\hline & & 5 & 3.358 & * & 0.3277 & * & 452.7 & * & 0.9389 & $-13.0 \%$ & 8.934 & * & 8.975 & $-2.7 \%$ & 0.0344 & * & - & - \\
\hline & & 6 & 5.035 & * & 0.3309 & * & 447.9 & * & 4.537 & $-9.3 \%$ & 6.932 & * & 6.951 & * & 0.0173 & * & - & - \\
\hline & & 7 & 1.676 & * & 0.3518 & * & 485.1 & * & 0.6485 & $-19.9 \%$ & 12.19 & $-6.2 \%$ & 12.30 & $-7.2 \%$ & 0.101 & * & - & - \\
\hline & & 8 & 7.541 & * & 0.3264 & * & 436.2 & * & 4.425 & $-8.1 \%$ & 6.706 & * & 6.680 & * & 0.0187 & $-14.5 \%$ & - & - \\
\hline & & 9 & 1.870 & * & 0.3562 & * & 497.3 & * & 0.6838 & $-18.3 \%$ & 12.04 & $-5.9 \%$ & 12.15 & $-6.9 \%$ & 0.0818 & $-31.6 \%$ & - & - \\
\hline & & 10 & 7.650 & * & 0.3254 & * & 438.0 & * & 2.066 & $-10.3 \%$ & 7.129 & * & 7.105 & * & 0.0215 & * & - & - \\
\hline & & 11 & 1.912 & * & 0.3687 & * & 523.2 & * & 0.8230 & $-18.6 \%$ & 12.43 & $-5.4 \%$ & 12.55 & $-6.6 \%$ & 0.116 & $-28.0 \%$ & - & - \\
\hline & & 12 & 5.724 & $-0.2 \%$ & 0.3268 & * & 444.1 & * & \begin{tabular}{|l}
1.002 \\
\end{tabular} & $-12.4 \%$ & 7.918 & * & 7.919 & * & 0.0265 & $-17.5 \%$ & - & - \\
\hline & & 13 & 3.819 & * & 0.3334 & * & 459.5 & * & 0.4471 & $-13.0 \%$ & 9.436 & * & .478 & $-3.3 \%$ & 0.0471 & * & - & - \\
\hline \multirow[t]{14}{*}{$\begin{array}{c}\text { 16ml/gal } \\
\text { ODA3 }\end{array}$} & \multirow[t]{14}{*}{$\begin{array}{c}\text { Low } \\
\text { Cetane }\end{array}$} & 0 & 4.034 & * & 0.3327 & * & 452.5 & * & 3.506 & $-6.8 \%$ & 7.844 & $3.2 \%$ & 7.893 & * & 0.0326 & $-27.6 \%$ & 0.6489 & * \\
\hline & & $1^{*}$ & 0.000 & * & 3.035 & * & 14330 & * & 122.5 & $-45.2 \%$ & 348.9 & $-3892 \%$ & 338.3 & * & 14.5 & * & - & - \\
\hline & & 2 & 6.719 & * & 0.3083 & * & 445.2 & * & 11.50 & * & 5.801 & $43.4 \%$ & 5.820 & * & 0.0167 & * & - & - \\
\hline & & 3 & 3.767 & * & 0.3255 & * & 451.4 & * & 0.6769 & $-14.1 \%$ & 9.062 & $-2.6 \%$ & 9.147 & $-2.9 \%$ & 0.0276 & * & - & - \\
\hline & & 4 & 5.660 & * & 0.3260 & * & 440.7 & * & 2.164 & $-11.4 \%$ & 7.432 & * & 7.469 & * & 0.0172 & * & - & - \\
\hline & & 5 & 3.359 & * & 0.3272 & * & 451.6 & * & 0.9758 & * & 8.810 & $-3.0 \%$ & 8.909 & $-3.4 \%$ & 0.0347 & * & - & - \\
\hline & & 6 & 5.038 & * & 0.3308 & * & 446.3 & * & 4.586 & $-8.3 \%$ & 6.884 & * & 6.938 & * & 0.0182 & * & - & - \\
\hline & & 7 & 1.678 & * & 0.3435 & * & 484.3 & * & 0.6392 & $-21.0 \%$ & 11.98 & $-7.8 \%$ & 12.16 & $-8.3 \%$ & 0.0987 & * & - & - \\
\hline & & 8 & 7.544 & * & 0.3285 & * & 435.3 & * & 4.512 & $-6.3 \%$ & 6.636 & * & 654 & * & 0.0172 & $-21.4 \%$ & - & - \\
\hline & & 9 & 1.870 & * & 0.3567 & * & 495.9 & $-1.3 \%$ & 0.6625 & $-20.8 \%$ & 1.85 & $-7.4 \%$ & 2.02 & $-7.9 \%$ & 0.0759 & $-36.5 \%$ & - & - \\
\hline & & 10 & 7.646 & * & 0.3277 & * & 438.0 & * & 2.149 & $-6.7 \%$ & 7.082 & * & .100 & * & 0.0197 & $-19.4 \%$ & - & - \\
\hline & & 11 & 1.916 & * & 0.3693 & * & 520.5 & * & 0.8065 & $-20.3 \%$ & 12.21 & $-7.1 \%$ & 12.39 & $-7.7 \%$ & 0.115 & $-28.8 \%$ & - & - \\
\hline & & 12 & 5.722 & $-0.3 \%$ & 0.3284 & * & 443.0 & * & 1.027 & $-10.3 \%$ & 7.861 & * & 7.912 & * & 0.0263 & $-18.2 \%$ & - & - \\
\hline & & 13 & \begin{tabular}{|l|}
3.817 \\
\end{tabular} & * & 0.3339 & * & 457.3 & * & 0.4559 & * & 9.316 & $-3.2 \%$ & 9.412 & $-3.9 \%$ & 0.0476 & * & - & - \\
\hline \multirow[t]{14}{*}{$\begin{array}{c}3.88 \mathrm{ml} / \mathrm{gal} \\
\text { ODANS }\end{array}$} & \multirow[t]{14}{*}{$\begin{array}{l}\text { Low } \\
\text { Cetane }\end{array}$} & 0 & 4.036 & * & 0.3310 & * & 455.1 & * & 3.464 & $-7.9 \%$ & 7.957 & $4.7 \%$ & 7.943 & * & 0.0331 & $-26.5 \%$ & 0.6293 & * \\
\hline & & $1^{*}$ & 0.000 & * & 3.167 & * & 15380 & * & 141.1 & * & 367.9 & $-4098 \%$ & 342.4 & * & 13.4 & * & - & - \\
\hline & & 2 & 6.717 & * & 0.2992 & $\begin{array}{c}- \\
5.6 \%\end{array}$ & 447.6 & * & 11.41 & * & 5.815 & $43.7 \%$ & 5.801 & * & 0.0169 & * & - & - \\
\hline & & 3 & 3.773 & * & 0.3263 & * & 453.8 & * & 0.6781 & $-13.9 \%$ & 9.161 & $-1.6 \%$ & 9.191 & $-2.4 \%$ & 0.0271 & * & - & - \\
\hline & & 4 & 5.660 & * & 0.3244 & * & 443.5 & * & \begin{tabular}{|l}
2.121 \\
\end{tabular} & $-13.1 \%$ & 7.501 & * & 7.490 & * & 0.0182 & * & - & - \\
\hline & & 5 & 3.357 & * & 0.3301 & * & 455.1 & * & 0.9396 & $-13.0 \%$ & 8.959 & * & 9.001 & $-2.4 \%$ & 0.0343 & * & - & - \\
\hline & & 6 & 5.037 & * & 0.3313 & * & 449.3 & * & 4.497 & $-10.1 \%$ & 6.975 & * & 6.976 & * & 0.0187 & * & - & - \\
\hline & & 7 & 1.678 & * & 0.3480 & * & 488.8 & * & 0.7003 & $-13.5 \%$ & 12.40 & $-4.6 \%$ & 12.47 & $-6.0 \%$ & 0.102 & * & - & - \\
\hline & & 8 & 7.536 & * & 0.3264 & * & 437.0 & * & 4.382 & $-9.0 \%$ & 6.715 & * & 6.677 & * & 0.0165 & $-24.6 \%$ & - & - \\
\hline & & 9 & 1.873 & * & 0.3520 & * & 498.0 & * & 0.7341 & * & 12.26 & $-4.2 \%$ & 12.33 & $-5.5 \%$ & 0.0895 & $-25.1 \%$ & - & - \\
\hline & & 10 & 7.645 & * & 0.3274 & * & 439.5 & * & 2.111 & $-8.4 \%$ & 7.142 & * & 7.104 & * & 0.0195 & $-20.3 \%$ & - & - \\
\hline & & 11 & 1.923 & * & 0.3657 & * & 523.2 & * & 0.8511 & $-15.9 \%$ & 12.63 & $-3.9 \%$ & 12.68 & $-5.5 \%$ & 0.118 & $-26.3 \%$ & - & - \\
\hline & & 12 & 5.746 & $0.1 \%$ & 0.3271 & * & 444.7 & * & 1.022 & $-10.7 \%$ & 7.934 & * & 7.907 & * & 0.0261 & $-18.8 \%$ & - & - \\
\hline & & 1 & 3.815 & * & 48 & * & 459.8 & * & 0.4614 & * & 9.500 & * & 9.503 & $-3.0 \%$ & 0.0490 & * & - & - \\
\hline \multirow[t]{4}{*}{$\begin{array}{c}7.75 \mathrm{ml} / \mathrm{gal} \\
\text { ODANS }\end{array}$} & \multirow[t]{4}{*}{$\begin{array}{c}\text { Low } \\
\text { Cetane }\end{array}$} & 0 & 4.035 & * & 0.3308 & * & 453.1 & * & 3.486 & $-7.3 \%$ & 7.621 & * & .934 & * & 0.0308 & $-31.6 \%$ & 0.6504 & * \\
\hline & & $1^{*}$ & 0.000 & * & 3.126 & * & 14700 & * & 127.1 & $-43.1 \%$ & 349.8 & $-3901 \%$ & 29.1 & * & 11.4 & * & - & - \\
\hline & & 2 & 6.716 & * & 0.2980 & $6 . \overline{\%}$ & 445.9 & * & 11.41 & * & 5.613 & $38.7 \%$ & 5.836 & * & 0.0157 & * & - & - \\
\hline & & 3 & 3.768 & * & 0.3257 & * & 451.9 & * & 0.6750 & $-14.3 \%$ & 8.780 & $-5.7 \%$ & 9.180 & $-2.5 \%$ & 0.0278 & * & - & - \\
\hline
\end{tabular}




\begin{tabular}{|c|c|c|c|c|c|c|c|c|c|c|c|c|c|c|c|c|c|c|}
\hline \multirow[b]{2}{*}{$\begin{array}{l}\text { Additive I } \\
\text { Condition }\end{array}$} & \multirow[b]{2}{*}{ Base } & \multirow{3}{*}{$\begin{array}{c}\text { Mode } \\
4 \\
\end{array}$} & \multicolumn{2}{|c|}{ Work } & \multicolumn{2}{|c|}{ BSFC } & \multicolumn{2}{|c|}{$\mathrm{CO}_{2}$} & \multicolumn{2}{|c|}{$\mathrm{co}$} & \multicolumn{2}{|c|}{ NOx } & \multicolumn{2}{|c|}{ NOx2 } & \multicolumn{2}{|c|}{$\mathrm{HC}$} & \multicolumn{2}{|c|}{ TPM } \\
\hline & & & $\begin{array}{c}\text { bhp- } \\
\text { hr }\end{array}$ & $\begin{array}{l}\text { Diff } \\
(\%)\end{array}$ & $\begin{array}{c}\text { Ib/bhp- } \\
\text { hr }\end{array}$ & $\begin{array}{l}\text { Diff } \\
(\%)\end{array}$ & $\begin{array}{c}\text { g/bhp- } \\
\text { hr }\end{array}$ & $\begin{array}{c}\begin{array}{c}\text { Diff } \\
(\%)\end{array} \\
*\end{array}$ & $\begin{array}{c}\text { g/bhp- } \\
\text { hr }\end{array}$ & $\begin{array}{c}\text { Diff } \\
(\%)\end{array}$ & $\begin{array}{c}\text { g/bhp- } \\
\text { hr }\end{array}$ & $\begin{array}{l}\text { Diff } \\
(\%)\end{array}$ & $\begin{array}{c}\text { g/bhp- } \\
\text { hr }\end{array}$ & $\begin{array}{c}\text { Diff } \\
(\%) \\
*\end{array}$ & $\begin{array}{c}\text { g/bhp- } \\
\text { hr }\end{array}$ & $\begin{array}{c}\text { Diff } \\
(\%) \\
*\end{array}$ & $\begin{array}{c}\text { g/bhp- } \\
\text { hr }\end{array}$ & $\begin{array}{l}\text { Diff } \\
(\%)\end{array}$ \\
\hline & & & 5.658 & * & & * & 441.8 & * & 2.150 & $-12.0 \%$ & 7.224 & $-2.5 \%$ & 7.527 & * & 0.0171 & * & - & - \\
\hline & & 5 & 3.360 & * & 0.3301 & * & 452.5 & * & 0.9462 & $-12.4 \%$ & 8.541 & $-6.0 \%$ & 8.938 & $-3.1 \%$ & 0.0358 & * & - & - \\
\hline & & 6 & 5.040 & * & 0.3324 & * & 447.0 & * & 4.634 & $-7.3 \%$ & 6.672 & $-2.8 \%$ & 6.970 & * & 0.0171 & * & - & - \\
\hline & & 7 & 1.679 & * & 0.3426 & * & 484.5 & * & 0.6609 & $-18.3 \%$ & 11.65 & $-10.3 \%$ & 12.22 & $-7.8 \%$ & 0.0988 & * & - & - \\
\hline & & 8 & 7.538 & * & 0.3271 & * & 436.2 & * & 4.496 & $-6.6 \%$ & 6.460 & * & 6.706 & * & 0.0170 & $-22.5 \%$ & - & - \\
\hline & & 9 & 1.871 & * & 0.3533 & * & 494.9 & $-1.5 \%$ & 0.6675 & $-20.2 \%$ & 11.50 & $-10.2 \%$ & 12.05 & $-7.7 \%$ & 0.0752 & $-37.1 \%$ & - & - \\
\hline & & 10 & 7.649 & * & 0.3265 & * & 437.9 & * & 2.118 & $-8.1 \%$ & 6.898 & * & 7.163 & * & 0.0198 & $-19.0 \%$ & - & - \\
\hline & & 11 & 1.920 & * & 0.3697 & * & 520.3 & * & 0.7894 & $-22.0 \%$ & 11.83 & $-10.0 \%$ & 12.40 & $-7.7 \%$ & 0.108 & $-33.0 \%$ & - & - \\
\hline & & 12 & 5.738 & * & 0.3278 & * & 443.3 & * & 1.020 & $-10.9 \%$ & 7.634 & $-2.5 \%$ & 7.950 & * & 0.0248 & $-22.7 \%$ & - & - \\
\hline & & 13 & 3.815 & * & 0.3329 & * & 457.6 & * & 0.4290 & $-16.6 \%$ & 9.057 & $-5.9 \%$ & 9.464 & $-3.4 \%$ & 0.0398 & * & - & - \\
\hline \multirow[t]{14}{*}{$\begin{array}{c}10.33 \mathrm{ml} / \mathrm{gal} \\
\text { ODANS }\end{array}$} & \multirow[t]{14}{*}{$\begin{array}{l}\text { Low } \\
\text { Cetane }\end{array}$} & 0 & 4.036 & * & 0.3301 & * & 453.1 & * & 3.447 & $-8.4 \%$ & 7.908 & $4.1 \%$ & 7.917 & * & 0.0306 & $-32.1 \%$ & 0.6830 & * \\
\hline & & $1^{*}$ & 0.000 & * & 3.064 & * & 14890 & * & 115.4 & $-48.3 \%$ & 364.1 & $-4056 \%$ & 345.1 & * & 9.81 & * & - & - \\
\hline & & 2 & 6.718 & * & 0.2932 & $7.5 \%$ & 445.8 & * & \begin{tabular}{|l}
11.24 \\
\end{tabular} & * & 5.840 & $44.3 \%$ & 5.836 & * & 0.0155 & * & - & - \\
\hline & & 3 & 3.773 & * & 0.3244 & * & 452.0 & * & 0.6747 & $-14.4 \%$ & 9.092 & $-2.3 \%$ & 9.141 & $-2.9 \%$ & 0.0272 & * & - & - \\
\hline & & 4 & 5.659 & * & 0.3244 & * & 441.7 & * & 2.140 & $-12.4 \%$ & 7.496 & * & 7.504 & * & 0.0167 & * & - & - \\
\hline & & 5 & 3.358 & * & 0.3287 & * & 452.1 & * & 0.9338 & $-13.5 \%$ & 8.871 & * & 8.930 & $-3.2 \%$ & 0.0347 & * & - & - \\
\hline & & 6 & 5.037 & * & 0.3330 & * & 446.8 & * & 4.589 & $-8.2 \%$ & 6.940 & * & 6.971 & * & 0.0169 & * & - & - \\
\hline & & 7 & 1.679 & * & 0.3490 & * & 484.4 & * & 0.6604 & $-18.4 \%$ & 11.93 & $-8.2 \%$ & 12.04 & $-9.2 \%$ & 0.104 & * & - & - \\
\hline & & 8 & 7.542 & * & 0.3269 & * & 435.7 & * & 4.507 & $-6.4 \%$ & 6.715 & * & 6.697 & * & 0.0171 & $-22.0 \%$ & - & - \\
\hline & & 9 & 1.870 & * & 0.3550 & * & 494.9 & $-1.5 \%$ & 0.6512 & $-22.2 \%$ & 11.87 & $-7.3 \%$ & 11.98 & $-8.2 \%$ & 0.0763 & $-36.2 \%$ & - & - \\
\hline & & 10 & 7.647 & * & 0.3264 & * & 438.4 & * & 2.072 & $-10.0 \%$ & 7.180 & * & 7.157 & * & 0.0195 & $-20.5 \%$ & - & - \\
\hline & & 11 & 1.928 & * & 0.3672 & * & 518.0 & * & 0.7678 & $-24.1 \%$ & 12.13 & $-7.8 \%$ & 12.23 & $-8.9 \%$ & 0.109 & $-32.3 \%$ & - & - \\
\hline & & 12 & 5.743 & * & 0.3275 & * & 442.6 & * & 0.9997 & $-12.6 \%$ & 7.944 & * & 7.945 & * & 0.0262 & $-18.4 \%$ & - & - \\
\hline & & 13 & 3.816 & * & 0.3355 & * & 457.5 & * & 0.4334 & $-15.7 \%$ & 9.392 & * & 9.436 & $-3.7 \%$ & 0.0448 & * & - & - \\
\hline
\end{tabular}


Table 7-15 July 2007 SET Results for the 1992 Detroit Diesel Series 60

\begin{tabular}{|c|c|c|c|c|c|c|c|c|c|c|c|c|c|c|c|c|c|c|}
\hline \multirow[b]{2}{*}{$\begin{array}{l}\text { Additive / } \\
\text { Condition }\end{array}$} & \multirow[b]{2}{*}{ Base } & \multirow[b]{2}{*}{ Mode } & \multicolumn{2}{|c|}{ Work } & \multicolumn{2}{|c|}{ BSFC } & \multicolumn{2}{|c|}{$\mathrm{CO}_{2}$} & \multicolumn{2}{|c|}{ co } & \multicolumn{2}{|c|}{ NOx } & \multicolumn{2}{|c|}{ NOx2 } & \multicolumn{2}{|c|}{$\mathrm{HC}$} & \multicolumn{2}{|c|}{ TPM } \\
\hline & & & \begin{tabular}{|c|} 
bhp- \\
hr
\end{tabular} & $\begin{array}{l}\text { Diff } \\
(\%)\end{array}$ & $\begin{array}{c}\text { lb/bhp- } \\
\text { hr }\end{array}$ & \begin{tabular}{|l|} 
Diff \\
$(\%)$
\end{tabular} & $\begin{array}{c}\text { g/bhp- } \\
\text { hr }\end{array}$ & \begin{tabular}{|l|} 
Diff \\
$(\%)$ \\
\end{tabular} & $\begin{array}{c}\text { g/bhp- } \\
\text { hr }\end{array}$ & $\begin{array}{l}\text { Diff } \\
(\%)\end{array}$ & $\begin{array}{c}\text { g/bhp- } \\
\mathrm{hr}\end{array}$ & \begin{tabular}{|l|} 
Diff \\
$(\%)$
\end{tabular} & $\begin{array}{c}\text { g/bhp- } \\
\mathrm{hr}\end{array}$ & $\begin{array}{l}\text { Diff } \\
(\%)\end{array}$ & $\begin{array}{c}\text { g/bhp- } \\
\mathrm{hr}\end{array}$ & $\begin{array}{l}\text { Diff } \\
(\%)\end{array}$ & $\begin{array}{c}\text { g/bhp- } \\
\text { hr }\end{array}$ & $\begin{array}{l}\text { Diff } \\
(\%)\end{array}$ \\
\hline \multirow[t]{14}{*}{-} & \multirow[t]{14}{*}{ CP Cert } & 0 & 4.113 & - & 0.3276 & - & 445.5 & - & 2.855 & - & 7.750 & - & 7.774 & - & 0.0394 & - & 0.5327 & - \\
\hline & & $1^{*}$ & 0.000 & - & 2.500 & - & 15410 & - & 151.2 & - & 359.8 & - & 332.5 & - & 13.7 & - & - & - \\
\hline & & 2 & 6.712 & - & 0.3037 & - & 436.1 & - & 10.18 & - & 5.874 & - & 5.868 & - & 0.0269 & - & - & - \\
\hline & & 3 & 3.860 & - & 0.3238 & - & 446.5 & - & 0.6752 & - & 9.009 & - & 9.032 & - & 0.0354 & - & - & - \\
\hline & & 4 & 5.783 & - & 0.3175 & - & 432.2 & - & 1.624 & - & 7.367 & - & 7.398 & - & 0.0226 & - & - & - \\
\hline & & 5 & 3.350 & - & 0.3212 & - & 447.4 & - & 0.8537 & - & 8.693 & - & 8.716 & - & 0.0429 & - & - & - \\
\hline & & 6 & 5.027 & - & 0.3228 & - & 439.4 & - & 3.743 & - & 6.825 & - & 6.852 & - & 0.0228 & - & - & - \\
\hline & & 7 & 1.683 & - & 0.3478 & - & 484.3 & - & 0.6572 & - & 11.62 & - & 11.65 & - & 0.104 & - & - & - \\
\hline & & 8 & 7.721 & - & 0.3297 & - & 426.0 & - & 3.225 & - & 6.663 & - & 6.700 & - & 0.0221 & - & - & - \\
\hline & & 9 & 1.928 & - & 0.3546 & - & 494.4 & - & 0.6958 & - & 11.50 & - & 11.56 & - & 0.103 & - & - & - \\
\hline & & 10 & 7.874 & - & 0.3229 & - & 429.5 & - & 1.549 & - & 6.918 & - & 6.959 & - & 0.0235 & - & - & - \\
\hline & & 11 & 1.972 & - & 0.3594 & - & 518.7 & - & 0.8080 & - & 11.69 & - & 11.75 & - & 0.122 & - & - & - \\
\hline & & 12 & 5.913 & - & 0.3221 & - & 434.4 & - & 0.7987 & - & 7.582 & - & 7.635 & - & 0.0312 & - & - & - \\
\hline & & 13 & 3.934 & - & 0.3274 & - & 451.0 & - & 0.4175 & - & 9.071 & - & 9.130 & - & 0.0551 & - & - & - \\
\hline \multirow[t]{14}{*}{$\begin{array}{l}12 \mathrm{ml} / \mathrm{gal} \\
\text { ODA }\end{array}$} & \multirow[t]{14}{*}{ CP Cert } & 0 & 4.115 & * & 0.3245 & * & 445.8 & * & 2.757 & * & 7.754 & * & 7.717 & * & 0.0331 & * & 0.4937 & * \\
\hline & & $1^{*}$ & 0.000 & * & 2.433 & * & 14460 & * & 79.98 & $-47.1 \%$ & 370.8 & * & 339.9 & * & 6.57 & * & - & - \\
\hline & & 2 & 6.708 & * & 0.2963 & * & 438.8 & * & 9.997 & * & 5.992 & $2.0 \%$ & 5.944 & * & 0.0214 & * & - & - \\
\hline & & 3 & 3.857 & * & 0.3217 & * & 446.0 & * & 0.6014 & * & 8.888 & * & 8.848 & $-2.0 \%$ & 0.0312 & * & - & - \\
\hline & & 4 & 5.796 & * & 0.3175 & * & 433.0 & * & 1.589 & * & 7.466 & * & 7.440 & * & 0.0208 & * & - & - \\
\hline & & 5 & 3.350 & * & 0.3220 & * & 447.3 & * & 0.7873 & * & 8.635 & * & 8.590 & * & 0.0346 & * & - & - \\
\hline & & 6 & 5.025 & * & 0.3247 & * & 440.2 & * & 3.609 & * & 6.924 & * & 6.899 & * & 0.0235 & * & - & - \\
\hline & & 7 & 1.681 & * & 0.3485 & * & 481.7 & * & 0.6393 & * & 10.83 & $-6.8 \%$ & 10.76 & $-7.6 \%$ & 0.109 & * & - & - \\
\hline & & 8 & 7.723 & * & 0.3208 & $-2.7 \%$ & 427.8 & * & 3.182 & * & 6.821 & * & 6.804 & * & 0.0205 & * & - & - \\
\hline & & 9 & 1.927 & * & 0.3486 & * & 490.5 & * & 0.6174 & * & 10.72 & $-6.8 \%$ & 10.68 & $-7.6 \%$ & 0.0865 & * & - & - \\
\hline & & 10 & 7.873 & * & 0.3223 & * & 430.7 & * & 1.504 & * & 7.079 & * & 7.065 & * & 0.0218 & * & - & - \\
\hline & & 11 & 1.987 & * & 0.3627 & * & 514.7 & * & 0.6965 & $-13.8 \%$ & 10.81 & $-7.5 \%$ & 10.79 & $-8.2 \%$ & 0.107 & * & - & - \\
\hline & & 12 & 5.914 & * & 0.3193 & * & 435.1 & * & 0.7342 & $-8.1 \%$ & 7.691 & * & 7.678 & * & 0.0277 & * & - & - \\
\hline & & 13 & 3.950 & $0.4 \%$ & 0.3267 & * & 450.8 & * & 0.3635 & $-12.9 \%$ & 8.920 & * & 8.897 & * & 0.0420 & * & - & - \\
\hline & \multirow[t]{14}{*}{ Low Cetane } & 0 & 4.109 & - & 0.3264 & - & 448.1 & - & 2.922 & - & 7.987 & - & 7.978 & - & 0.0434 & - & 0.5469 & - \\
\hline & & $1^{*}$ & 0.000 & - & 2.612 & - & 16080 & - & 274.3 & - & 338.9 & - & 304.6 & - & 22.5 & - & - & - \\
\hline & & 2 & 6.699 & - & 0.2991 & - & 441.7 & - & 10.23 & - & 5.956 & - & 5.941 & - & 0.0273 & - & - & - \\
\hline & & 3 & 3.865 & - & 0.3221 & - & 446.5 & - & 0.6662 & - & 9.320 & - & 9.316 & - & 0.0353 & - & - & - \\
\hline & & 4 & 5.780 & - & 0.3185 & - & 434.8 & - & 1.652 & - & 7.528 & - & 7.528 & - & 0.0235 & - & - & - \\
\hline & & 5 & 3.356 & - & 0.3217 & - & 449.2 & - & 0.8737 & - & 9.065 & - & 9.060 & - & 0.0432 & - & - & - \\
\hline & & 6 & 5.021 & - & 0.3248 & - & 442.4 & - & 3.752 & - & 7.000 & - & 6.999 & - & 0.0229 & - & - & - \\
\hline & & 7 & 1.677 & - & 0.3542 & - & 484.8 & - & 0.8597 & - & 12.71 & - & 12.69 & - & 0.130 & - & - & - \\
\hline & & 8 & 7.718 & - & 0.3223 & - & 428.9 & - & 3.207 & - & 6.737 & - & 6.743 & - & 0.0211 & - & - & - \\
\hline & & 9 & 1.927 & - & 0.3474 & - & 493.5 & - & 0.8301 & - & 12.58 & - & 12.57 & - & 0.116 & - & - & - \\
\hline & & 10 & 7.862 & - & 0.3249 & - & 432.3 & - & 1.580 & - & 7.005 & - & 7.022 & - & 0.0242 & - & - & - \\
\hline & & 11 & 1.969 & - & 0.3634 & - & 518.7 & - & 0.9917 & - & 12.73 & - & 12.73 & - & 0.129 & - & - & - \\
\hline & & 12 & 5.888 & - & 0.3229 & - & 437.2 & - & 0.8124 & - & 7.729 & - & 7.739 & - & 0.0297 & - & - & - \\
\hline & & 13 & 3.935 & - & 0.3284 & - & 451.9 & - & 0.4562 & - & 9.494 & - & 9.494 & - & 0.0552 & - & - & - \\
\hline $6 \mathrm{ml} / \mathrm{gal}$ & Low Cetane & 0 & 4.109 & * & 0.3257 & * & 447.9 & * & 2.731 & $-6.5 \%$ & 7.914 & * & 7.927 & * & 0.0343 & $-21.0 \%$ & 0.4893 & * \\
\hline
\end{tabular}




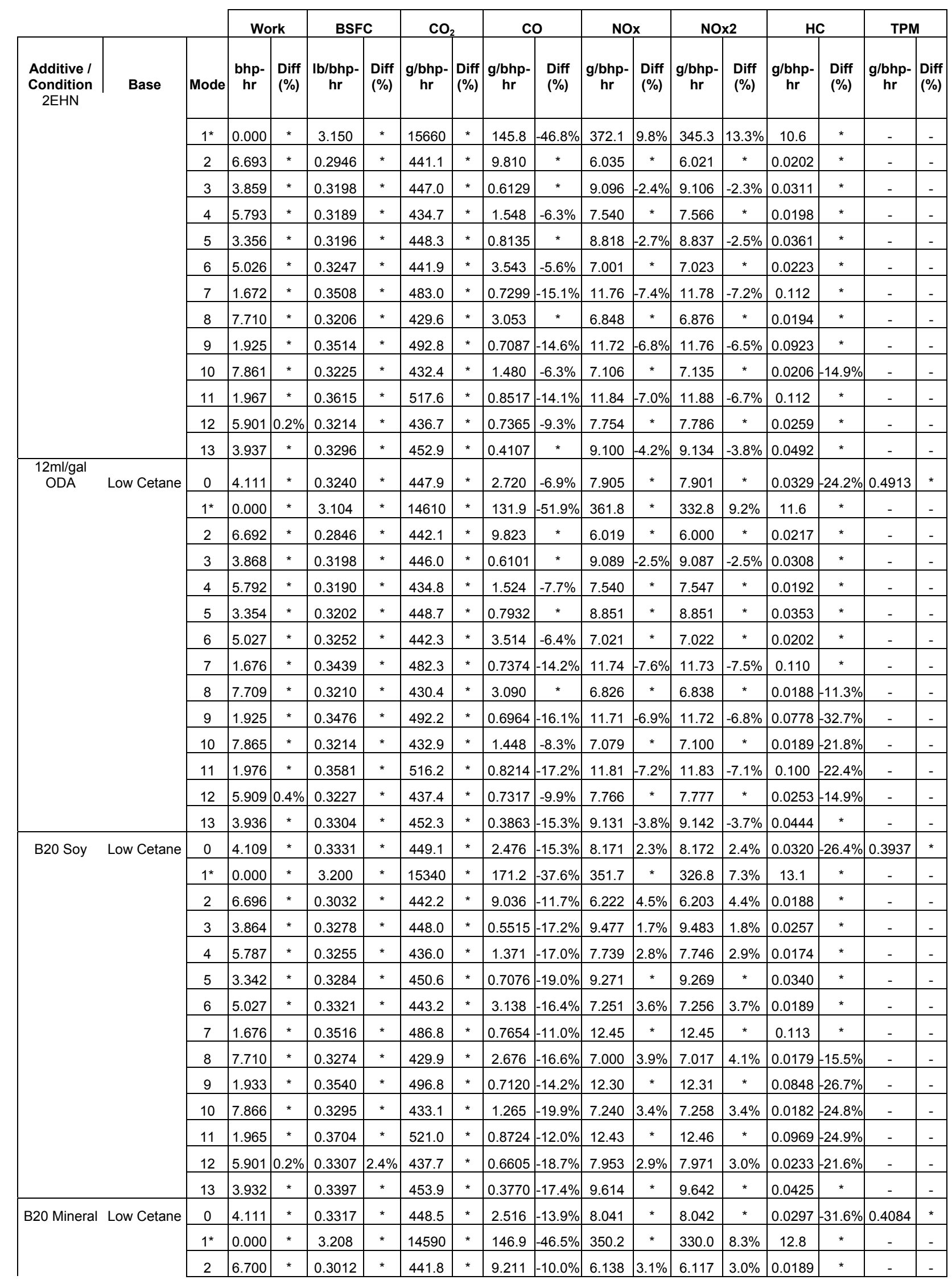




\begin{tabular}{|c|c|c|c|c|c|c|c|c|c|c|c|c|c|c|c|c|c|c|}
\hline \multirow{13}{*}{$\begin{array}{l}\text { Additive I } \\
\text { Condition }\end{array}$} & \multirow{13}{*}{ Base } & & \multicolumn{2}{|c|}{ Work } & \multicolumn{2}{|c|}{ BSFC } & \multicolumn{2}{|c|}{$\mathrm{CO}_{2}$} & \multicolumn{2}{|c|}{ co } & \multicolumn{2}{|c|}{ NOx } & \multicolumn{2}{|c|}{ NOx2 } & \multicolumn{2}{|c|}{$\mathrm{HC}$} & \multicolumn{2}{|c|}{ TPM } \\
\hline & & Mode & $\begin{array}{c}\text { bhp- } \\
\text { hr }\end{array}$ & $\begin{array}{l}\text { Diff } \\
(\%)\end{array}$ & $\begin{array}{c}\text { Ib/bhp- } \\
\text { hr }\end{array}$ & $\begin{array}{l}\text { Diff } \\
(\%)\end{array}$ & $\begin{array}{c}\text { g/bhp- } \\
\text { hr }\end{array}$ & $\begin{array}{l}\text { Diff } \\
(\%)\end{array}$ & $\begin{array}{c}\text { g/bhp- } \\
\text { hr }\end{array}$ & $\begin{array}{l}\text { Diff } \\
(\%)\end{array}$ & $\begin{array}{c}\text { g/bhp- } \\
\mathrm{hr}\end{array}$ & $\begin{array}{l}\text { Diff } \\
(\%)\end{array}$ & $\begin{array}{c}\text { g/bhp- } \\
\mathrm{hr}\end{array}$ & $\begin{array}{l}\text { Diff } \\
(\%)\end{array}$ & $\begin{array}{c}\text { g/bhp- } \\
\mathrm{hr}\end{array}$ & $\begin{array}{l}\text { Diff } \\
\text { (\%) }\end{array}$ & $\begin{array}{c}\text { g/bhp- } \\
\text { hr }\end{array}$ & $\begin{array}{l}\text { Diff } \\
(\%)\end{array}$ \\
\hline & & 3 & 3.858 & * & 0.3254 & * & 447.5 & * & 0.5489 & $-17.6 \%$ & 9.299 & * & 9.285 & * & 0.0249 & * & - & - \\
\hline & & 4 & 5.790 & * & 0.3232 & * & 435.2 & * & 1.409 & $-14.7 \%$ & 7.664 & * & 7.663 & * & 0.0163 & $-30.5 \%$ & - & - \\
\hline & & 5 & 3.351 & * & 0.3273 & * & 449.4 & * & 0.7247 & $-17.1 \%$ & 9.010 & * & 9.002 & * & 0.0318 & * & - & - \\
\hline & & 6 & 5.019 & * & 0.3351 & $3.2 \%$ & 443.5 & * & 3.249 & $-13.4 \%$ & 7.143 & * & 7.145 & * & 0.0178 & * & - & - \\
\hline & & 7 & 1.679 & * & 0.3506 & * & 484.8 & * & 0.7067 & $-17.8 \%$ & 12.00 & $-5.6 \%$ & 12.01 & $-5.4 \%$ & 0.103 & * & - & - \\
\hline & & 8 & 7.723 & * & 0.3270 & * & 430.3 & * & 2.735 & $-14.7 \%$ & 6.938 & * & 6.952 & * & 0.0165 & $-22.1 \%$ & - & - \\
\hline & & 9 & 1.939 & * & 0.3558 & * & 495.8 & * & 0.6647 & $-19.9 \%$ & 11.89 & $-5.5 \%$ & 11.91 & $-5.3 \%$ & 0.0708 & $-38.7 \%$ & - & - \\
\hline & & 10 & 7.861 & * & 0.3276 & * & 432.8 & * & 1.309 & $-17.1 \%$ & 7.195 & * & 7.223 & * & 0.0169 & $-30.3 \%$ & - & - \\
\hline & & 11 & 1.961 & * & 0.3723 & * & 521.6 & * & 0.8163 & $-17.7 \%$ & 12.01 & $-5.7 \%$ & 12.04 & $-5.4 \%$ & 0.0865 & $-33.0 \%$ & - & - \\
\hline & & 12 & 5.904 & $0.3 \%$ & 0.3283 & $1.7 \%$ & 437.7 & * & 0.6591 & $-18.9 \%$ & 7.863 & * & 7.886 & * & 0.0219 & $-26.4 \%$ & - & - \\
\hline & & 13 & 3.937 & * & 0.3334 & * & 453.6 & * & 0.3618 & $-20.7 \%$ & 9.371 & * & 9.397 & * & 0.0393 & * & - & - \\
\hline \multirow[t]{14}{*}{$\begin{array}{c}\text { B20 } \\
\text { Cottonseed }\end{array}$} & \multirow[t]{14}{*}{ Low Cetane } & 0 & 4.111 & * & 0.3313 & * & 446.9 & * & 2.542 & $-13.0 \%$ & 8.083 & * & 8.080 & * & 0.0291 & $-33.1 \%$ & 0.4141 & * \\
\hline & & $1^{*}$ & 0.000 & * & 3.212 & * & 14900 & * & 137.0 & $-50.1 \%$ & 358.9 & * & 332.3 & $9.1 \%$ & 12.0 & * & - & - \\
\hline & & 2 & 6.705 & * & 0.2955 & * & 440.7 & * & 9.554 & $-6.6 \%$ & 6.148 & $3.2 \%$ & 6.123 & $3.1 \%$ & 0.0192 & * & - & - \\
\hline & & 3 & 3.859 & * & 0.3277 & * & 445.4 & * & 0.5359 & $-19.6 \%$ & 9.335 & * & 9.330 & * & 0.0238 & * & - & - \\
\hline & & 4 & 5.788 & * & 0.3246 & * & 433.8 & * & 1.372 & $-16.9 \%$ & 7.735 & $2.7 \%$ & 7.742 & $2.8 \%$ & 0.0161 & $-31.4 \%$ & - & - \\
\hline & & 5 & 3.350 & * & 0.3286 & * & 448.6 & * & 0.7099 & $-18.7 \%$ & 9.101 & * & 9.094 & * & 0.0337 & * & - & - \\
\hline & & 6 & 5.020 & * & 0.3316 & * & 440.7 & * & 3.201 & $-14.7 \%$ & 7.211 & $3.0 \%$ & 7.209 & $3.0 \%$ & 0.0185 & * & - & - \\
\hline & & 7 & 1.675 & * & 0.3484 & * & 482.8 & * & 0.6918 & $-19.5 \%$ & 12.05 & $-5.2 \%$ & 12.03 & $-5.2 \%$ & 0.0962 & * & - & - \\
\hline & & 8 & 7.720 & * & 0.3268 & * & 428.8 & * & 2.726 & $-15.0 \%$ & 6.982 & $3.6 \%$ & 6.997 & $3.8 \%$ & 0.0163 & $-22.8 \%$ & - & - \\
\hline & & 9 & 1.940 & * & 0.3556 & * & 491.4 & * & 0.6409 & $-22.8 \%$ & 11.87 & $-5.7 \%$ & 11.87 & $-5.6 \%$ & 0.0716 & $-38.1 \%$ & - & - \\
\hline & & 10 & 7.861 & * & 0.3282 & * & 431.6 & * & 1.294 & $-18.1 \%$ & 7.240 & $3.3 \%$ & 7.258 & $3.4 \%$ & 0.0166 & $-31.3 \%$ & - & - \\
\hline & & 11 & 1.958 & * & 0.3731 & * & 519.0 & * & 0.8037 & $-19.0 \%$ & 11.99 & $-5.8 \%$ & 12.01 & $-5.7 \%$ & 0.0902 & $-30.1 \%$ & - & - \\
\hline & & 12 & 5.903 & $0.3 \%$ & 0.3277 & $1.5 \%$ & 435.9 & * & 0.6591 & $-18.9 \%$ & 7.923 & $2.5 \%$ & 7.943 & $2.6 \%$ & 0.0209 & $-29.6 \%$ & - & - \\
\hline & & 13 & 3.933 & * & 0.3348 & * & 451.7 & * & 0.3463 & $-24.1 \%$ & 9.357 & * & 9.373 & * & 0.0341 & * & - & - \\
\hline \multirow[t]{14}{*}{-} & \multirow[t]{14}{*}{ Low Cetane } & 0 & 4.108 & * & 0.3235 & * & 447.5 & * & 2.846 & * & 8.089 & * & 8.086 & * & 0.0349 & $-19.7 \%$ & 0.5264 & * \\
\hline & & $1^{*}$ & 0.000 & * & 2.580 & * & 14640 & * & 208.1 & * & 337.3 & * & 310.2 & * & 19.4 & * & - & - \\
\hline & & 2 & 6.696 & * & 0.2942 & * & 441.0 & * & 10.25 & * & 6.031 & * & 6.013 & * & 0.0203 & * & - & - \\
\hline & & 3 & 3.863 & * & 0.3190 & * & 445.9 & * & 0.6390 & * & 9.422 & * & 9.421 & * & 0.0287 & * & - & - \\
\hline & & 4 & 5.779 & * & 0.3166 & * & 434.8 & * & 1.580 & * & 7.633 & * & 7.639 & * & 0.0194 & * & - & - \\
\hline & & 5 & 3.347 & * & 0.3204 & * & 448.9 & * & 0.7940 & * & 9.181 & * & 9.187 & * & 0.0364 & * & - & - \\
\hline & & 6 & 5.026 & * & 0.3250 & * & 441.7 & * & 3.642 & * & 7.091 & * & 7.097 & * & 0.0185 & * & - & - \\
\hline & & 7 & 1.672 & * & 0.3419 & * & 482.9 & * & 0.8280 & * & 12.97 & * & 12.96 & * & 0.111 & * & - & - \\
\hline & & 8 & 7.712 & * & 0.3194 & * & 429.5 & * & \begin{tabular}{|l}
3.103 \\
\end{tabular} & * & 6.839 & * & 6.849 & * & 0.0181 & $-14.4 \%$ & - & - \\
\hline & & 9 & 1.922 & * & 0.3458 & * & 492.1 & * & 0.8196 & * & 12.84 & * & 12.84 & * & 0.0833 & $-28.0 \%$ & - & - \\
\hline & & 10 & 7.859 & * & 0.3222 & * & 432.4 & * & 1.497 & * & 7.076 & * & 7.096 & * & 0.0183 & $-24.5 \%$ & - & - \\
\hline & & 11 & 1.982 & * & 0.3604 & * & 517.0 & * & 0.9874 & * & 12.85 & * & 12.88 & * & 0.106 & $-18.0 \%$ & - & - \\
\hline & & 12 & 5.905 & $0.3 \%$ & 0.3204 & * & 437.0 & * & 0.7859 & * & 7.817 & * & 7.831 & * & 0.0232 & $-21.9 \%$ & - & - \\
\hline & & 13 & 3.934 & * & 0.3260 & * & 451.8 & * & 0.4052 & * & 9.549 & * & 9.564 & * & 0.0428 & * & - & - \\
\hline \multirow[t]{6}{*}{$\begin{array}{l}6 \mathrm{ml} / \mathrm{gal} \\
2 \mathrm{EHN}\end{array}$} & \multirow[t]{6}{*}{$\begin{array}{c}\text { B20 } \\
\text { Cottonseed }\end{array}$} & 0 & 4.112 & * & 0.3304 & * & 448.2 & * & 2.549 & * & 8.079 & * & 8.099 & * & 0.0283 & * & 0.4134 & * \\
\hline & & $1^{*}$ & 0.000 & * & 2.567 & * & 15770 & * & 135.9 & * & 371.4 & * & 346.2 & * & 9.70 & * & - & - \\
\hline & & 2 & 6.719 & * & 0.2977 & * & 440.0 & * & 9.417 & * & 6.146 & * & 6.139 & * & 0.0199 & * & - & - \\
\hline & & 3 & 3.864 & * & 0.3259 & * & 447.1 & * & 0.5426 & * & 9.311 & * & 9.313 & * & 0.0246 & * & - & - \\
\hline & & 4 & 5.792 & * & 0.3236 & * & 434.4 & * & 1.338 & * & 7.745 & * & 7.782 & * & 0.0165 & * & - & - \\
\hline & & 5 & 3.349 & * & 0.3297 & * & 450.1 & * & 0.6924 & * & 9.097 & * & 9.120 & * & 0.0278 & * & - & - \\
\hline
\end{tabular}




\begin{tabular}{|c|c|c|c|c|c|c|c|c|c|c|c|c|c|c|c|c|c|c|}
\hline \multirow[b]{2}{*}{$\begin{array}{l}\text { Additive / } \\
\text { Condition }\end{array}$} & \multirow[b]{2}{*}{ Base } & \multirow{3}{*}{\begin{tabular}{|c|} 
Mode \\
6 \\
\end{tabular}} & \multicolumn{2}{|c|}{ Work } & \multicolumn{2}{|c|}{ BSFC } & \multicolumn{2}{|c|}{$\mathrm{CO}_{2}$} & \multicolumn{2}{|c|}{ co } & \multicolumn{2}{|c|}{ NOx } & \multicolumn{2}{|c|}{ NOx2 } & \multicolumn{2}{|c|}{$\mathrm{HC}$} & \multicolumn{2}{|c|}{ TPM } \\
\hline & & & $\begin{array}{c}\text { bhp- } \\
\text { hr }\end{array}$ & $\begin{array}{l}\text { Diff } \\
\text { (\%) }\end{array}$ & $\begin{array}{c}\text { Ib/bhp- } \\
\text { hr }\end{array}$ & $\begin{array}{l}\text { Diff } \\
(\%)\end{array}$ & $\begin{array}{c}\text { g/bhp- } \\
\text { hr }\end{array}$ & $\begin{array}{c}\text { Diff } \\
(\%) \\
*\end{array}$ & $\begin{array}{c}\text { g/bhp- } \\
\text { hr }\end{array}$ & $\begin{array}{c}\text { Diff } \\
(\%)\end{array}$ & $\begin{array}{c}\text { g/bhp- } \\
\text { hr }\end{array}$ & $\begin{array}{c}\text { Diff } \\
(\%) \\
*\end{array}$ & $\begin{array}{c}\text { g/bhp- } \\
\text { hr }\end{array}$ & $\begin{array}{c}\text { Diff } \\
(\%) \\
*\end{array}$ & $\begin{array}{c}\text { g/bhp- } \\
\text { hr }\end{array}$ & $\begin{array}{c}\text { Diff } \\
(\%) \\
*\end{array}$ & $\begin{array}{c}\text { g/bhp- } \\
\mathrm{hr}\end{array}$ & $\begin{array}{l}\text { Diff } \\
(\%)\end{array}$ \\
\hline & & & 5.018 & * & 0.3311 & * & 442.9 & * & 3.225 & * & 7.238 & * & 7.259 & * & 0.0169 & * & - & - \\
\hline & & 7 & 1.676 & * & 0.3578 & * & 485.3 & * & 0.6460 & * & 11.76 & * & 11.78 & * & 0.0880 & * & - & - \\
\hline & & 8 & 7.727 & * & 0.3261 & * & 429.6 & * & 2.866 & * & 7.033 & * & 7.069 & * & 0.0163 & * & - & - \\
\hline & & 9 & 1.931 & * & 0.3522 & * & 495.2 & * & 0.6298 & * & 11.59 & * & 11.64 & * & 0.0675 & * & - & - \\
\hline & & 10 & 7.857 & * & 0.3280 & * & 432.0 & * & 1.332 & * & 7.297 & * & 7.337 & * & 0.0179 & * & - & - \\
\hline & & 11 & 1.960 & * & 0.3760 & * & 522.2 & * & 0.7429 & $-7.6 \%$ & 11.72 & * & 11.78 & * & 0.0848 & * & - & - \\
\hline & & 12 & 5.900 & * & 0.3287 & * & 437.0 & * & 0.6474 & * & 7.959 & * & 7.999 & * & 0.0215 & * & - & - \\
\hline & & 13 & 3.933 & * & 0.3359 & * & 453.3 & * & 0.3533 & * & 9.325 & * & 9.369 & * & 0.0405 & * & - & - \\
\hline \multirow[t]{14}{*}{$\begin{array}{c}\text { 12ml/gal } \\
\text { ODA3 }\end{array}$} & \multirow[t]{14}{*}{$\begin{array}{c}\mathrm{B} 20 \\
\text { Cottonseed }\end{array}$} & 0 & 4.113 & * & 0.3296 & * & 447.2 & * & 2.498 & * & 8.088 & * & 8.084 & * & 0.0260 & * & 0.4332 & * \\
\hline & & $1^{*}$ & 0.000 & * & 3.266 & * & 15510 & * & 123.9 & * & 378.3 & * & 354.1 & * & 10.0 & * & - & - \\
\hline & & 2 & 6.705 & * & 0.2848 & * & 440.7 & * & 9.244 & * & 6.175 & * & 6.147 & * & 0.0174 & * & - & - \\
\hline & & 3 & 3.870 & * & 0.3242 & * & 446.7 & * & 0.5388 & * & 9.287 & * & 9.274 & * & 0.0221 & * & - & - \\
\hline & & 4 & 5.792 & * & 0.3244 & * & 433.7 & * & \begin{tabular}{|l}
1.360 \\
\end{tabular} & * & 7.766 & * & 7.768 & * & 0.0155 & * & - & - \\
\hline & & 5 & 3.353 & * & 0.3279 & * & 447.8 & * & 0.6761 & * & 9.059 & * & 9.058 & * & 0.0285 & * & - & - \\
\hline & & 6 & 5.022 & * & 0.3304 & * & 441.0 & * & 3.103 & * & 7.218 & * & 7.218 & * & 0.0165 & * & - & - \\
\hline & & 7 & 1.676 & * & 0.3492 & * & 482.2 & * & 0.5796 & $-16.2 \%$ & 11.73 & * & 11.72 & * & 0.0721 & * & - & - \\
\hline & & 8 & 7.724 & * & 0.3276 & * & 429.3 & * & 2.827 & * & 7.031 & * & 7.051 & * & 0.0162 & * & - & - \\
\hline & & 9 & 1.932 & * & 0.3559 & * & 494.3 & * & 0.6026 & * & 11.64 & * & 11.64 & * & 0.0585 & * & - & - \\
\hline & & 10 & 7.861 & * & 0.3283 & * & 431.0 & * & 1.305 & * & 7.293 & * & 7.309 & * & 0.0165 & * & - & - \\
\hline & & 11 & 1.970 & * & 0.3714 & * & 517.8 & * & 0.7175 & $-10.7 \%$ & 11.73 & * & 11.73 & * & 0.0783 & * & - & - \\
\hline & & 12 & 5.903 & * & 0.3271 & * & 435.5 & * & 0.6334 & * & 7.988 & * & 8.010 & * & 0.0186 & * & - & - \\
\hline & & 13 & 3.934 & * & 0.3344 & * & 451.9 & * & 0.3246 & * & 9.333 & * & 9.356 & * & 0.0326 & * & - & - \\
\hline
\end{tabular}


Table 7-16 February 2007 SET Results for the 2004 Cummins ISM 370

\begin{tabular}{|c|c|c|c|c|c|c|c|c|c|c|c|c|c|c|c|c|c|c|}
\hline \multirow[b]{2}{*}{$\begin{array}{l}\text { Additive I } \\
\text { Condition }\end{array}$} & \multirow[b]{2}{*}{ Base } & \multirow[b]{2}{*}{ Mode } & \multicolumn{2}{|c|}{ Work } & \multicolumn{2}{|c|}{ BSFC } & \multicolumn{2}{|c|}{$\mathrm{CO}_{2}$} & \multicolumn{2}{|c|}{$\mathrm{Co}$} & \multicolumn{2}{|c|}{ NOx } & \multicolumn{2}{|c|}{ NOx2 } & \multicolumn{2}{|c|}{$\mathrm{HC}$} & \multicolumn{2}{|c|}{ TPM } \\
\hline & & & $\begin{array}{c}\text { bhp- } \\
\text { hr }\end{array}$ & \begin{tabular}{|l} 
Diff \\
$(\%)$
\end{tabular} & $\begin{array}{c}\text { Ib/bhp- } \\
\text { hr }\end{array}$ & $\begin{array}{l}\text { Diff } \\
(\%)\end{array}$ & $\begin{array}{c}\text { g/bhp- } \\
\text { hr }\end{array}$ & $\begin{array}{l}\text { Diff } \\
(\%)\end{array}$ & $\begin{array}{c}\text { g/bhp- } \\
\text { hr }\end{array}$ & Diff (\%) & $\begin{array}{c}\text { g/bhp- } \\
\mathrm{hr}\end{array}$ & $\begin{array}{l}\text { Diff } \\
(\%)\end{array}$ & $\begin{array}{c}\text { g/bhp- } \\
\mathrm{hr}\end{array}$ & $\begin{array}{l}\text { Diff } \\
(\%) \\
\end{array}$ & $\begin{array}{c}\text { g/bhp- } \\
\text { hr }\end{array}$ & $\begin{array}{l}\text { Diff } \\
(\%)\end{array}$ & $\begin{array}{c}\text { g/bhp- } \\
\mathrm{hr}\end{array}$ & $\begin{array}{l}\text { Diff } \\
(\%)\end{array}$ \\
\hline \multirow[t]{14}{*}{ 然 } & \multirow[t]{14}{*}{$\begin{array}{c}\text { Grad } \\
\text { Ref }\end{array}$} & 0 & 3.741 & - & 0.3804 & - & 525.0 & - & 0.5238 & - & 1.769 & - & 1.761 & - & 0.108 & - & 0.2434 & - \\
\hline & & $1^{*}$ & 0.000 & - & 0.000 & - & 15690 & - & 78.11 & - & 156.0 & - & 135.7 & - & 17.7 & - & - & - \\
\hline & & 2 & 5.989 & - & 0.3831 & - & 514.9 & - & 1.212 & - & 0.7848 & - & 0.7717 & - & 0.0420 & - & - & - \\
\hline & & 3 & 3.519 & - & 0.3751 & - & 523.1 & - & 0.3404 & - & 1.815 & - & 1.805 & - & 0.117 & - & - & - \\
\hline & & 4 & 5.286 & - & 0.3478 & - & 485.4 & - & 0.2374 & - & 2.294 & - & 2.303 & - & 0.0865 & - & - & - \\
\hline & & 5 & 3.156 & - & 0.3726 & - & 507.2 & - & 0.3382 & - & 1.385 & - & 1.364 & - & 0.0908 & - & - & - \\
\hline & & 6 & 4.746 & - & 0.3622 & - & 501.6 & - & 0.3226 & - & 1.490 & - & 1.482 & - & 0.0693 & - & - & - \\
\hline & & 7 & 1.584 & - & 0.4028 & - & 539.2 & - & 0.7592 & - & 1.170 & - & 1.117 & - & 0.172 & - & - & - \\
\hline & & 8 & 7.038 & - & 0.3581 & - & 480.0 & - & 0.2797 & - & 2.257 & - & 2.279 & - & 0.0745 & - & - & - \\
\hline & & 9 & 1.765 & - & 0.4536 & - & 593.4 & - & 0.8894 & - & 1.619 & - & 1.577 & - & 0.270 & - & - & - \\
\hline & & 10 & 7.068 & - & 0.3889 & - & 524.6 & - & 0.3853 & - & 1.625 & - & 1.637 & - & 0.0731 & - & - & - \\
\hline & & 11 & 1.775 & - & 0.5020 & - & 691.2 & - & 1.236 & - & 1.850 & - & 1.806 & - & 0.388 & - & - & - \\
\hline & & 12 & 5.302 & - & 0.3898 & - & 539.8 & - & 0.3227 & - & 1.637 & - & 1.643 & - & 0.114 & - & - & - \\
\hline & & 13 & 3.550 & - & 0.4077 & - & 592.2 & - & 0.5544 & - & 1.671 & - & 1.666 & - & 0.166 & - & - & - \\
\hline \multirow[t]{14}{*}{ - } & \multirow[t]{14}{*}{$\mathrm{CP}$} & 0 & 3.805 & - & 0.3810 & - & 534.4 & - & 0.4639 & - & 1.964 & - & 1.955 & - & 0.109 & - & 0.2615 & - \\
\hline & & $1^{*}$ & 0.000 & - & 0.000 & - & 17070 & - & 99.44 & - & 190.3 & - & 175.5 & - & 19.5 & - & - & - \\
\hline & & 2 & 6.061 & - & 0.3746 & - & 525.9 & - & 0.9830 & - & 0.8966 & - & 0.8858 & - & 0.0412 & - & - & - \\
\hline & & 3 & 3.577 & - & 0.4071 & - & 531.6 & - & 0.2967 & - & 1.964 & - & 1.953 & - & 0.112 & - & - & - \\
\hline & & 4 & 5.368 & - & 0.3519 & - & 495.5 & - & 0.2069 & - & 2.530 & - & 2.539 & - & 0.0877 & - & - & - \\
\hline & & 5 & 3.225 & - & 0.3616 & - & 518.4 & - & 0.2866 & - & 1.535 & - & 1.514 & - & 0.0979 & - & - & - \\
\hline & & 6 & 4.835 & - & 0.3615 & - & 511.4 & - & 0.2889 & - & 1.681 & - & 1.675 & - & 0.0735 & - & - & - \\
\hline & & 7 & 1.615 & - & 0.3849 & - & 550.4 & - & 0.7607 & - & 1.383 & - & 1.341 & - & 0.167 & - & - & - \\
\hline & & 8 & 7.153 & - & 0.3506 & - & 487.7 & - & 0.2419 & - & 2.518 & - & 2.523 & - & 0.0779 & - & - & - \\
\hline & & 9 & 1.790 & - & 0.4126 & - & 602.3 & - & 0.8513 & - & 1.788 & - & 1.750 & - & 0.252 & - & - & - \\
\hline & & 10 & 7.210 & - & 0.3679 & - & 532.4 & - & 0.3387 & - & 1.776 & - & 1.781 & - & 0.0762 & - & - & - \\
\hline & & 11 & 1.810 & - & 0.4808 & - & 699.1 & - & 1.195 & - & 2.008 & - & 1.977 & - & 0.388 & - & - & - \\
\hline & & 12 & 5.427 & - & 0.3833 & - & 546.5 & - & 0.2737 & - & 1.824 & - & 1.825 & - & 0.121 & - & - & - \\
\hline & & 13 & 3.614 & - & 0.5406 & - & 602.3 & - & 0.4630 & - & 1.852 & - & 1.844 & - & 0.167 & - & - & - \\
\hline \multirow[t]{14}{*}{$\begin{array}{c}12 \mathrm{ml} / \mathrm{gal} \\
\mathrm{ODA}\end{array}$} & \multirow[t]{14}{*}{$\mathrm{CP}$} & 0 & 3.806 & * & 0.3780 & * & 534.8 & * & 0.4249 & * & 1.985 & * & 1.983 & * & 0.109 & * & 0.2625 & * \\
\hline & & $1^{*}$ & 0.000 & - & 0.000 & * & 17040 & * & 81.03 & $-18.5 \%$ & 160.8 & $-15.5 \%$ & 151.3 & $-13.8 \%$ & 16.3 & * & - & * \\
\hline & & 2 & 6.091 & * & 0.3832 & * & 524.6 & * & 0.8762 & * & 0.9413 & * & 0.9275 & * & 0.0399 & * & - & * \\
\hline & & 3 & 3.574 & * & 0.3898 & * & 531.6 & * & 0.2755 & $-7.1 \%$ & 1.982 & * & 1.976 & * & 0.108 & $-3.9 \%$ & - & * \\
\hline & & 4 & 5.359 & * & 0.3478 & * & 495.2 & * & 0.2026 & * & 2.588 & * & 2.602 & * & 0.0850 & $-3.1 \%$ & - & * \\
\hline & & 5 & 3.225 & * & 0.3666 & * & 520.1 & * & 0.2651 & $-7.5 \%$ & 1.544 & * & 1.526 & * & 0.0953 & * & - & * \\
\hline & & 6 & 4.844 & * & 0.3639 & * & 511.7 & * & 0.2803 & * & 1.653 & $-1.7 \%$ & 1.648 & $-1.6 \%$ & 0.0702 & * & - & * \\
\hline & & 7 & 1.616 & * & 0.3850 & * & 552.3 & * & 0.6389 & $-16.0 \%$ & 1.355 & * & 1.327 & * & 0.164 & * & - & * \\
\hline & & 8 & 7.154 & * & 0.3499 & * & 487.9 & * & 0.2189 & $-9.5 \%$ & 2.555 & * & 2.573 & * & 0.0801 & * & - & * \\
\hline & & 9 & 1.788 & * & 0.4158 & * & 601.5 & * & 0.7813 & $-8.2 \%$ & 1.789 & * & 1.761 & * & 0.263 & * & - & * \\
\hline & & 10 & 7.218 & * & 0.3893 & $5.8 \%$ & 534.9 & * & 0.3312 & * & 1.812 & $2.1 \%$ & 1.823 & $2.3 \%$ & 0.0811 & * & - & * \\
\hline & & 11 & 1.801 & $-0.5 \%$ & 0.5029 & * & 699.4 & * & 1.092 & $-8.6 \%$ & 2.030 & * & 2.009 & * & 0.388 & * & - & * \\
\hline & & 12 & 5.415 & * & 0.3863 & * & 549.6 & * & 0.2648 & $-3.3 \%$ & 1.861 & * & 1.866 & * & 0.125 & * & - & * \\
\hline & & 13 & 3.610 & * & 0.4087 & * & 601.5 & * & 0.4310 & $-6.9 \%$ & 1.906 & * & 1.901 & * & 0.170 & * & - & * \\
\hline
\end{tabular}









\begin{tabular}{|c|c|c|c|c|c|c|c|c|c|c|c|c|c|c|c|c|c|c|}
\hline \multirow{14}{*}{$\begin{array}{l}\text { Additive I } \\
\text { Condition }\end{array}$} & \multirow{14}{*}{ Base } & & \multicolumn{2}{|c|}{ Work } & \multicolumn{2}{|c|}{ BSFC } & \multicolumn{2}{|c|}{$\mathrm{CO}_{2}$} & \multicolumn{2}{|c|}{$\mathrm{co}$} & \multicolumn{2}{|c|}{ NOx } & \multicolumn{2}{|c|}{ NOX 2} & \multicolumn{2}{|c|}{$\mathrm{HC}$} & \multicolumn{2}{|c|}{ TPM } \\
\hline & & Mode & $\begin{array}{c}\text { bhp- } \\
\text { hr }\end{array}$ & $\begin{array}{l}\text { Diff } \\
(\%)\end{array}$ & $\begin{array}{c}\text { Ib/bhp- } \\
\text { hr }\end{array}$ & $\begin{array}{l}\text { Diff } \\
(\%)\end{array}$ & $\begin{array}{c}\text { g/bhp- } \\
\mathrm{hr}\end{array}$ & $\begin{array}{l}\text { Diff } \\
(\%)\end{array}$ & $\begin{array}{c}\text { g/bhp- } \\
\text { hr }\end{array}$ & Diff (\%) & $\begin{array}{c}\text { g/bhp- } \\
\text { hr }\end{array}$ & $\begin{array}{l}\text { Diff } \\
\text { (\%) }\end{array}$ & $\begin{array}{c}\text { g/bhp- } \\
\text { hr }\end{array}$ & $\begin{array}{l}\text { Diff } \\
\text { (\%) }\end{array}$ & $\begin{array}{c}\text { g/bhp- } \\
\text { hr }\end{array}$ & $\begin{array}{l}\text { Diff } \\
(\%)\end{array}$ & $\begin{array}{c}\text { g/bhp- } \\
\text { hr }\end{array}$ & $\begin{array}{l}\text { Diff } \\
\text { (\%) }\end{array}$ \\
\hline & & & 6.027 & & 0.3737 & & 523.8 & & 0.7856 & * & & * & & * & & & - & * \\
\hline & & 3 & 3.572 & * & 0.3928 & * & 533.7 & * & 0.2792 & * & 2.032 & * & 2.012 & * & 0.113 & $0.5 \%$ & - & * \\
\hline & & 4 & 5.366 & * & 0.3549 & * & \begin{tabular}{|l|}
494.6 \\
\end{tabular} & * & 0.1911 & * & 2.605 & * & 2.602 & * & 0.0879 & * & - & * \\
\hline & & 5 & 3.225 & * & 0.3600 & * & 518.6 & * & 0.2747 & * & 1.551 & * & 1.522 & * & 0.103 & $5.7 \%$ & - & * \\
\hline & & 6 & 4.837 & * & 0.3614 & * & 510.5 & * & 0.2825 & * & 1.682 & * & 1.669 & $-0.4 \%$ & 0.0725 & * & - & * \\
\hline & & 7 & 1.610 & $-0.3 \%$ & 0.3817 & * & 555.6 & * & 0.6132 & $-19.4 \%$ & 1.371 & * & 1.328 & * & 0.165 & * & - & * \\
\hline & & 8 & 7.150 & * & 0.3603 & * & 488.9 & * & 0.2116 & $-12.5 \%$ & 2.599 & $3.2 \%$ & 2.601 & $3.1 \%$ & 0.0789 & * & - & * \\
\hline & & 9 & 1.787 & * & 0.4185 & * & 607.5 & * & 0.7423 & $-12.8 \%$ & 1.845 & * & 1.803 & * & 0.257 & * & - & * \\
\hline & & 10 & 7.211 & * & 0.3668 & * & 533.0 & * & 0.3224 & * & 1.839 & $3.6 \%$ & 1.836 & $3.1 \%$ & 0.0776 & * & - & * \\
\hline & & 11 & 1.801 & $-0.5 \%$ & 0.4815 & * & 703.0 & * & 1.054 & $-11.8 \%$ & 2.058 & * & 2.014 & * & 0.377 & * & - & * \\
\hline & & 12 & 5.418 & * & 0.3820 & * & 547.0 & * & 0.2649 & $-3.2 \%$ & 1.889 & * & 1.880 & * & 0.121 & * & - & * \\
\hline & & 13 & 3.625 & * & 0.4204 & * & 602.9 & * & 0.4309 & $-6.9 \%$ & 1.918 & * & 1.900 & * & 0.164 & * & - & * \\
\hline \multirow[t]{14}{*}{ - } & \multirow[t]{14}{*}{$\begin{array}{l}\text { Grad } \\
\text { Cand }\end{array}$} & 0 & 3.822 & - & 0.3812 & - & 530.9 & - & 0.3764 & - & 2.065 & - & 2.046 & - & 0.120 & - & 0.1754 & - \\
\hline & & $1^{*}$ & 0.000 & - & 0.000 & - & 16550 & - & 93.18 & - & 182.1 & - & 166.8 & - & 23.8 & - & - & - \\
\hline & & 2 & 6.418 & - & 0.3909 & - & 508.7 & - & 0.3310 & - & 1.664 & - & 1.653 & - & 0.0547 & - & - & - \\
\hline & & 3 & 3.573 & - & 0.3845 & - & 546.5 & - & 0.3314 & - & 1.867 & - & 1.843 & - & 0.128 & - & - & - \\
\hline & & 4 & 5.366 & - & 0.3522 & - & 492.9 & - & 0.1989 & - & 2.561 & - & 2.556 & - & 0.0967 & - & - & - \\
\hline & & 5 & 3.228 & - & 0.3762 & - & 514.7 & - & 0.2865 & - & 1.576 & - & 1.546 & - & 0.109 & - & - & - \\
\hline & & 6 & 4.836 & - & 0.3720 & - & 505.1 & - & 0.2927 & - & 1.641 & - & 1.624 & - & 0.0785 & - & - & - \\
\hline & & 7 & 1.614 & - & 0.3826 & - & 544.8 & - & 0.7203 & - & 1.379 & - & 1.330 & - & 0.184 & - & - & - \\
\hline & & 8 & 7.095 & - & 0.3522 & - & 485.7 & - & 0.2235 & - & 2.545 & - & 2.544 & - & 0.0814 & - & - & - \\
\hline & & 9 & 1.792 & - & 0.4292 & - & 599.8 & - & 0.8123 & - & 1.828 & - & 1.777 & - & 0.277 & - & - & - \\
\hline & & 10 & 7.140 & - & 0.3824 & - & 528.9 & - & 0.3382 & - & 1.800 & - & 1.793 & - & 0.0806 & - & - & - \\
\hline & & 11 & 1.810 & - & 0.5000 & - & 698.5 & - & 1.169 & - & 2.052 & - & 1.999 & - & 0.415 & - & - & - \\
\hline & & 12 & 5.414 & - & 0.3845 & - & 541.8 & - & 0.2803 & - & 1.875 & - & 1.864 & - & 0.127 & - & - & - \\
\hline & & 13 & 3.607 & - & 0.4361 & - & 601.7 & - & 0.4910 & - & 1.850 & - & 1.828 & - & 0.181 & - & - & - \\
\hline \multirow[t]{14}{*}{$6 \mathrm{ml} / \mathrm{gal}$ ODA } & \multirow[t]{14}{*}{$\begin{array}{l}\text { Grad } \\
\text { Cand }\end{array}$} & 0 & 3.781 & * & 0.3811 & * & 532.9 & * & 0.4062 & * & 2.010 & * & 1.994 & * & 0.119 & * & 0.0792 & -- \\
\hline & & $1^{*}$ & 0.000 & * & 0.000 & * & 15690 & $-5.2 \%$ & 70.38 & * & 176.1 & * & 162.1 & * & 24.1 & * & - & * \\
\hline & & 2 & 5.911 & $-7.9 \%$ & 0.3731 & $-4.6 \%$ & 519.8 & $2.2 \%$ & 0.6838 & $106.6 \%$ & 0.9896 & $-40.5 \%$ & 0.9719 & $-41.2 \%$ & 0.0470 & $-14.1 \%$ & - & * \\
\hline & & 3 & 3.575 & * & 0.4003 & $4.1 \%$ & 527.9 & $-3.4 \%$ & 0.2959 & * & 2.070 & * & 2.044 & * & 0.124 & * & - & * \\
\hline & & 4 & 5.364 & * & 0.3588 & * & 493.9 & * & 0.1992 & * & 2.578 & * & 2.578 & * & 0.0918 & $-5.1 \%$ & - & * \\
\hline & & 5 & 3.228 & * & 0.3676 & * & 516.3 & * & 0.2880 & * & 1.589 & * & 1.562 & * & 0.108 & * & - & * \\
\hline & & 6 & 4.839 & * & 0.3638 & * & 509.4 & * & 0.2933 & * & 1.649 & * & 1.635 & * & 0.0771 & * & - & * \\
\hline & & 7 & 1.612 & * & 0.3891 & * & 551.4 & * & 0.6505 & * & 1.388 & * & 1.340 & * & 0.183 & * & - & * \\
\hline & & 8 & 7.094 & * & 0.3504 & * & 488.9 & * & 0.2308 & * & 2.537 & * & 2.543 & * & 0.0826 & * & - & * \\
\hline & & 9 & 1.795 & * & 0.4376 & * & 604.0 & * & 0.7748 & * & 1.847 & * & 1.801 & * & 0.286 & * & - & * \\
\hline & & 10 & 7.131 & * & 0.3747 & * & 533.4 & * & 0.3454 & * & 1.803 & * & 1.802 & * & 0.0811 & * & - & * \\
\hline & & 11 & 1.801 & * & 0.5001 & * & 707.9 & * & 1.106 & * & 2.077 & * & 2.033 & * & 0.405 & * & - & * \\
\hline & & 12 & 5.418 & * & 0.4011 & $4.3 \%$ & 544.5 & * & 0.2718 & * & 1.894 & * & 1.886 & * & 0.126 & * & - & * \\
\hline & & 13 & 3.619 & * & 0.4441 & * & 601.9 & * & 0.4720 & * & 1.884 & * & 1.863 & * & 0.180 & * & - & * \\
\hline \multirow[t]{5}{*}{ B20 Soy } & \multirow[t]{5}{*}{$\mathrm{CP}$} & 0 & 3.795 & * & 0.3810 & * & 536.9 & * & 0.3839 & * & 2.121 & * & 2.114 & * & 0.102 & $-6.3 \%$ & 0.1838 & * \\
\hline & & $1^{*}$ & 0.000 & - & 0.000 & * & 16610 & * & \begin{tabular}{|l|} 
\\
104.1 \\
\end{tabular} & $4.6 \%$ & 186.5 & * & 167.9 & $-4.3 \%$ & 18.5 & * & - & * \\
\hline & & 2 & 5.978 & * & 0.3791 & * & 523.9 & * & 0.5814 & * & 1.028 & * & 1.013 & * & 0.0456 & * & - & * \\
\hline & & 3 & 3.585 & * & 0.3846 & * & 534.8 & * & 0.2763 & * & 2.147 & $9.3 \%$ & 2.131 & $9.1 \%$ & 0.0982 & $-12.4 \%$ & - & * \\
\hline & & 4 & 5.371 & * & 0.3543 & * & 498.1 & * & 0.1838 & $-11.2 \%$ & 2.707 & $7.0 \%$ & 2.722 & $7.2 \%$ & 0.0781 & $-11.0 \%$ & - & * \\
\hline
\end{tabular}




\begin{tabular}{|c|c|c|c|c|c|c|c|c|c|c|c|c|c|c|c|c|c|c|}
\hline \multirow{11}{*}{$\begin{array}{l}\text { Additive I } \\
\text { Condition }\end{array}$} & \multirow{11}{*}{ Base } & & \multicolumn{2}{|c|}{ Work } & \multicolumn{2}{|c|}{ BSFC } & \multicolumn{2}{|c|}{$\mathrm{CO}_{2}$} & \multicolumn{2}{|c|}{$\mathrm{co}$} & \multicolumn{2}{|c|}{ NOx } & \multicolumn{2}{|c|}{ NOX2 } & \multicolumn{2}{|c|}{$\mathrm{HC}$} & \multicolumn{2}{|c|}{ TPM } \\
\hline & & Mode & $\begin{array}{c}\text { bhp- } \\
\text { hr }\end{array}$ & \begin{tabular}{|c|} 
Diff \\
$(\%)$
\end{tabular} & $\begin{array}{c}\text { Ib/bhp- } \\
\text { hr }\end{array}$ & $\begin{array}{l}\text { Diff } \\
(\%)\end{array}$ & $\begin{array}{c}\text { g/bhp- } \\
\text { hr }\end{array}$ & $\begin{array}{l}\text { Diff } \\
(\%)\end{array}$ & $\begin{array}{c}\text { g/bhp- } \\
\mathrm{hr}\end{array}$ & Diff (\%) & $\begin{array}{c}\text { g/bhp- } \\
\mathrm{hr}\end{array}$ & $\begin{array}{l}\text { Diff } \\
\text { (\%) }\end{array}$ & $\begin{array}{c}\text { g/bhp- } \\
\text { hr }\end{array}$ & $\begin{array}{l}\text { Diff } \\
(\%)\end{array}$ & $\begin{array}{c}\text { g/bhp- } \\
\mathrm{hr}\end{array}$ & $\begin{array}{l}\text { Diff } \\
\text { (\%) }\end{array}$ & $\begin{array}{c}\text { g/bhp- } \\
\text { hr }\end{array}$ & $\begin{array}{l}\text { Diff } \\
(\%)\end{array}$ \\
\hline & & 5 & 3.230 & * & 0.4089 & $13.1 \%$ & 519.2 & * & 0.2790 & * & 1.661 & $8.2 \%$ & 1.642 & $8.5 \%$ & 0.0902 & $-7.8 \%$ & - & * \\
\hline & & 6 & 4.837 & * & 0.3668 & * & 511.0 & * & 0.2606 & $-9.8 \%$ & 1.813 & $7.8 \%$ & 1.810 & $8.0 \%$ & 0.0717 & * & - & * \\
\hline & & 7 & 1.613 & * & 0.3957 & * & 552.5 & * & 0.6826 & * & 1.479 & $6.9 \%$ & 1.429 & * & 0.148 & $-11.4 \%$ & - & * \\
\hline & & 8 & 7.125 & $-0.4 \%$ & 0.3566 & * & 492.6 & * & 0.1921 & $-20.6 \%$ & 2.729 & $8.4 \%$ & 2.751 & $9.0 \%$ & 0.0756 & * & - & * \\
\hline & & 9 & 1.790 & * & 0.4230 & * & 607.7 & * & 0.7959 & $-6.5 \%$ & 1.902 & * & 1.860 & * & 0.241 & * & - & * \\
\hline & & 10 & 7.198 & * & 0.3834 & * & 535.0 & * & 0.2995 & $-11.6 \%$ & 1.912 & $7.7 \%$ & 1.924 & $8.0 \%$ & 0.0752 & * & - & * \\
\hline & & 11 & 1.808 & $-0.1 \%$ & 0.5469 & * & 708.7 & * & 1.103 & * & 2.164 & * & 2.123 & * & 0.347 & $-10.6 \%$ & - & * \\
\hline & & 12 & 5.413 & * & 0.3628 & $-5.3 \%$ & 550.0 & * & 0.2577 & $-5.8 \%$ & 1.963 & $7.6 \%$ & 1.968 & $7.8 \%$ & 0.108 & $-10.5 \%$ & - & * \\
\hline & & 13 & 3.605 & * & 0.4266 & * & 606.2 & * & 0.4465 & $-3.6 \%$ & 1.975 & * & 1.967 & $6.7 \%$ & 0.150 & $-10.2 \%$ & - & * \\
\hline \multirow[t]{14}{*}{ B20 Mineral } & \multirow[t]{14}{*}{$\mathrm{CP}$} & 0 & 3.785 & * & 0.3904 & * & 536.8 & * & 0.3803 & * & 2.108 & * & 2.085 & * & 0.0959 & $-12.3 \%$ & 0.1809 & * \\
\hline & & $1^{*}$ & 0.000 & - & 0.000 & * & 16480 & * & 78.21 & $-21.4 \%$ & 179.5 & $-5.7 \%$ & 157.6 & $-10.2 \%$ & 17.4 & * & - & * \\
\hline & & 2 & 5.945 & * & 0.4049 & * & 526.6 & * & 0.6160 & * & 1.028 & * & 1.007 & * & 0.0391 & * & - & * \\
\hline & & 3 & 3.569 & * & 0.3783 & $-7.1 \%$ & 536.9 & * & 0.2887 & * & 2.157 & $9.8 \%$ & 2.128 & $9.0 \%$ & 0.0954 & $-14.9 \%$ & - & * \\
\hline & & 4 & 5.364 & * & 0.3554 & * & 497.7 & * & 0.1850 & $-10.6 \%$ & 2.695 & $6.5 \%$ & 2.692 & $6.0 \%$ & 0.0723 & $-17.6 \%$ & - & * \\
\hline & & 5 & 3.228 & * & 0.3729 & * & 519.3 & * & 0.2730 & * & 1.672 & $9.0 \%$ & 1.636 & $8.1 \%$ & 0.0814 & $-16.9 \%$ & - & * \\
\hline & & 6 & 4.839 & * & 0.3703 & * & 509.4 & * & 0.2543 & $-12.0 \%$ & 1.802 & $7.2 \%$ & 1.781 & $6.3 \%$ & 0.0613 & $-16.6 \%$ & - & * \\
\hline & & 7 & 1.610 & $-0.3 \%$ & 0.3957 & * & 550.7 & * & 0.6538 & * & 1.471 & $6.4 \%$ & 1.400 & * & 0.136 & $-18.7 \%$ & - & * \\
\hline & & 8 & 7.099 & $-0.8 \%$ & 0.3741 & $6.7 \%$ & 490.8 & * & 0.1964 & $-18.8 \%$ & 2.707 & $7.5 \%$ & 2.712 & $7.5 \%$ & 0.0698 & $-10.3 \%$ & - & * \\
\hline & & 9 & 1.788 & * & 0.4322 & * & 606.7 & * & 0.7664 & $-10.0 \%$ & 1.915 & * & 1.853 & * & 0.229 & * & - & * \\
\hline & & 10 & 7.161 & $-0.7 \%$ & 0.3817 & * & 536.6 & * & 0.3039 & $-10.3 \%$ & 1.889 & $6.4 \%$ & 1.886 & $5.9 \%$ & 0.0702 & * & - & * \\
\hline & & 11 & 1.802 & $-0.4 \%$ & 0.5566 & * & 708.2 & * & 1.101 & $-7.8 \%$ & 2.143 & * & 2.080 & * & 0.342 & $-12.0 \%$ & - & * \\
\hline & & 12 & 5.423 & * & 0.3950 & * & 546.8 & * & 0.2609 & $-4.7 \%$ & 1.953 & $7.1 \%$ & 1.944 & $6.5 \%$ & 0.104 & $-14.4 \%$ & - & * \\
\hline & & 13 & 3.610 & * & 0.4747 & * & 604.6 & * & 0.4524 & * & 1.946 & * & 1.917 & * & 0.145 & $-13.6 \%$ & - & * \\
\hline \multirow[t]{14}{*}{\begin{tabular}{|c|} 
B20 \\
Cottonseed
\end{tabular}} & \multirow[t]{14}{*}{$\mathrm{CP}$} & 0 & 3.794 & * & 0.3834 & * & 535.4 & * & 0.3745 & * & 2.142 & * & 2.124 & * & 0.0978 & \begin{tabular}{|l|}
$-10.5 \%$ \\
\end{tabular} & 0.1664 & $\begin{array}{c}- \\
36.4 \% \\
\end{array}$ \\
\hline & & $1^{*}$ & 0.000 & - & 0.000 & * & 15830 & $-7.3 \%$ & 85.83 & $-13.7 \%$ & 182.5 & $-4.1 \%$ & 165.0 & $-6.0 \%$ & 16.0 & * & - & * \\
\hline & & 2 & 5.956 & * & 0.3792 & * & 524.6 & * & 0.5506 & * & 1.054 & * & 1.035 & * & 0.0408 & * & - & * \\
\hline & & 3 & 3.584 & * & 0.3791 & $-6.9 \%$ & 533.1 & * & 0.2891 & * & 2.168 & $10.4 \%$ & 2.141 & $9.6 \%$ & 0.0925 & $-17.4 \%$ & - & * \\
\hline & & 4 & 5.371 & * & 0.3529 & * & 497.5 & * & 0.1811 & $-12.5 \%$ & 2.750 & $8.7 \%$ & 2.746 & $8.1 \%$ & 0.0763 & $-13.1 \%$ & - & * \\
\hline & & 5 & 3.227 & * & 0.3756 & $3.9 \%$ & 517.0 & * & 0.2772 & * & 1.681 & $9.5 \%$ & 1.648 & $8.9 \%$ & 0.0839 & $-14.3 \%$ & - & * \\
\hline & & 6 & 4.839 & * & 0.3706 & * & 509.0 & * & 0.2526 & $-12.6 \%$ & 1.806 & $7.4 \%$ & 1.791 & $6.9 \%$ & 0.0668 & $-9.1 \%$ & - & * \\
\hline & & 7 & 1.616 & * & 0.3928 & * & 550.7 & * & 0.6489 & $-14.7 \%$ & 1.477 & $6.8 \%$ & 1.422 & * & 0.137 & $-18.2 \%$ & - & * \\
\hline & & 8 & 7.138 & * & 0.3632 & * & 489.6 & * & 0.1847 & $-23.6 \%$ & 2.753 & $9.3 \%$ & 2.762 & $9.5 \%$ & 0.0722 & * & - & * \\
\hline & & 9 & 1.795 & * & 0.4579 & * & 605.7 & * & 0.7686 & $-9.7 \%$ & 1.931 & * & 1.878 & * & 0.229 & * & - & * \\
\hline & & 10 & 7.196 & * & 0.3853 & * & 534.1 & * & 0.3053 & $-9.9 \%$ & 1.925 & $8.4 \%$ & 1.925 & $8.1 \%$ & 0.0746 & * & - & * \\
\hline & & 11 & 1.809 & $-0.1 \%$ & 0.5406 & * & 706.4 & * & 1.113 & * & 2.168 & * & 2.113 & * & 0.349 & $-10.1 \%$ & - & * \\
\hline & & 12 & 5.403 & * & 0.3784 & * & 549.6 & * & 0.2703 & * & 1.996 & $9.5 \%$ & 1.990 & $9.1 \%$ & 0.106 & $-12.8 \%$ & - & * \\
\hline & & 13 & 3.606 & * & 0.4334 & * & 606.8 & * & 0.4792 & $3.5 \%$ & 1.991 & $7.5 \%$ & 1.974 & $7.0 \%$ & 0.147 & $-12.4 \%$ & - & * \\
\hline \multirow[t]{8}{*}{$\begin{array}{l}\text { 10ml/gal } \\
\text { DTBP }\end{array}$} & \multirow[t]{8}{*}{$\begin{array}{l}\text { B20 } \\
\text { Soy }\end{array}$} & 0 & 3.784 & * & 0.3998 & $4.9 \%$ & 537.4 & * & 0.3584 & * & 2.114 & * & 2.101 & * & 0.0938 & $-8.4 \%$ & - & - \\
\hline & & $1^{*}$ & 0.000 & - & 0.03236 & * & 16810 & * & 65.74 & $-36.8 \%$ & 173.7 & $-6.8 \%$ & 161.9 & $-3.6 \%$ & 18.4 & * & - & * \\
\hline & & 2 & 5.900 & * & 0.3745 & * & 526.8 & * & 0.5750 & * & 1.044 & * & 1.030 & * & 0.0382 & $-16.1 \%$ & - & * \\
\hline & & 3 & 3.567 & $-0.5 \%$ & 0.3939 & * & 536.0 & * & 0.2721 & * & 2.178 & * & 2.163 & * & 0.0874 & $-10.9 \%$ & - & * \\
\hline & & 4 & 5.368 & * & 0.3570 & * & 496.0 & * & 0.1686 & * & 2.709 & * & 2.712 & * & 0.0679 & $-13.1 \%$ & - & * \\
\hline & & 5 & 3.228 & * & 0.4788 & $17.1 \%$ & 516.4 & * & 0.2480 & $-11.1 \%$ & 1.696 & * & 1.677 & * & 0.0830 & $-8.0 \%$ & - & * \\
\hline & & 6 & 4.844 & * & 0.3757 & * & 509.3 & * & 0.2437 & $-6.5 \%$ & 1.795 & $-1.0 \%$ & 1.784 & $-1.4 \%$ & 0.0632 & $-11.9 \%$ & - & * \\
\hline & & 7 & 1.614 & * & 0.4022 & * & 552.9 & * & 0.5738 & $-15.9 \%$ & 1.432 & * & 1.391 & * & 0.139 & * & - & * \\
\hline
\end{tabular}




\begin{tabular}{|c|c|c|c|c|c|c|c|c|c|c|c|c|c|c|c|c|c|c|}
\hline \multirow{8}{*}{$\begin{array}{l}\text { Additive I } \\
\text { Condition }\end{array}$} & \multirow{8}{*}{ Base } & & \multicolumn{2}{|c|}{ Work } & \multicolumn{2}{|c|}{ BSFC } & \multicolumn{2}{|c|}{$\mathrm{CO}_{2}$} & \multicolumn{2}{|c|}{$\mathrm{co}$} & \multicolumn{2}{|c|}{ NOx } & \multicolumn{2}{|c|}{ NOx2 } & \multicolumn{2}{|c|}{$\mathrm{HC}$} & \multicolumn{2}{|c|}{ TPM } \\
\hline & & Mode & $\begin{array}{c}\text { bhp- } \\
\text { hr }\end{array}$ & $\begin{array}{l}\text { Diff } \\
(\%)\end{array}$ & $\begin{array}{c}\text { Ib/bhp- } \\
\text { hr }\end{array}$ & $\begin{array}{l}\text { Diff } \\
(\%)\end{array}$ & $\begin{array}{c}\text { g/bhp- } \\
\text { hr }\end{array}$ & $\begin{array}{l}\text { Diff } \\
(\%)\end{array}$ & $\begin{array}{c}\text { g/bhp- } \\
\text { hr }\end{array}$ & Diff (\%) & $\begin{array}{c}\text { g/bhp- } \\
\text { hr }\end{array}$ & $\begin{array}{l}\text { Diff } \\
(\%)\end{array}$ & $\begin{array}{c}\text { g/bhp- } \\
\text { hr }\end{array}$ & $\begin{array}{l}\text { Diff } \\
(\%)\end{array}$ & $\begin{array}{c}\text { g/bhp- } \\
\text { hr }\end{array}$ & $\begin{array}{l}\text { Diff } \\
(\%)\end{array}$ & $\begin{array}{c}\text { g/bhp- } \\
\text { hr }\end{array}$ & $\begin{array}{l}\text { Diff } \\
(\%)\end{array}$ \\
\hline & & 8 & 7.091 & $-0.5 \%$ & 0.3915 & $9.8 \%$ & 493.8 & * & 0.1926 & * & 2.700 & * & 2.701 & * & 0.0710 & * & - & * \\
\hline & & 9 & 1.799 & * & 0.4352 & * & 608.4 & * & 0.7089 & $-10.9 \%$ & 1.939 & * & 1.902 & * & 0.219 & * & - & * \\
\hline & & 10 & 7.177 & * & 0.4112 & $7.3 \%$ & 537.7 & * & 0.3086 & * & 1.877 & $-1.8 \%$ & 1.875 & $-2.5 \%$ & 0.0676 & * & - & * \\
\hline & & 11 & 1.808 & * & 0.5464 & * & 708.7 & * & 1.023 & * & 2.190 & * & 2.151 & * & 0.326 & $-6.1 \%$ & - & * \\
\hline & & 12 & 5.422 & * & 0.4003 & $10.3 \%$ & 548.0 & * & 0.2559 & * & 1.963 & * & 1.956 & * & 0.103 & * & - & * \\
\hline & & 13 & 3.608 & * & 0.4480 & * & 604.7 & * & 0.4458 & * & 1.968 & * & 1.952 & * & 0.141 & $-6.5 \%$ & - & * \\
\hline \multirow[t]{14}{*}{ - } & \multirow[t]{14}{*}{$\mathrm{CP}$} & 0 & 3.835 & * & 0.3758 & * & 539.8 & * & 0.3772 & * & 2.084 & * & 2.074 & * & 0.112 & * & 0.2162 & * \\
\hline & & $1^{*}$ & 0.000 & - & 0.000 & * & 16690 & * & 99.66 & * & \begin{tabular}{|l|}
187.2 \\
\end{tabular} & * & 173.4 & * & 25.7 & * & - & * \\
\hline & & 2 & 6.469 & * & 0.3281 & * & 519.0 & * & 0.3283 & * & 1.676 & * & 1.671 & * & 0.0446 & * & - & * \\
\hline & & 3 & 3.585 & * & 0.3947 & * & 554.5 & * & 0.3075 & * & 1.908 & * & 1.897 & * & 0.112 & * & - & * \\
\hline & & 4 & 5.355 & * & 0.3659 & * & 500.5 & * & 0.1960 & * & 2.602 & * & 2.608 & * & 0.0868 & * & - & * \\
\hline & & 5 & 3.230 & * & 0.3555 & * & 521.5 & * & 0.2789 & * & 1.559 & * & 1.536 & * & 0.100 & * & - & * \\
\hline & & 6 & 4.842 & * & 0.3541 & * & 514.0 & * & 0.2839 & * & 1.684 & * & 1.673 & * & 0.0716 & * & - & * \\
\hline & & 7 & 1.613 & * & 0.4403 & * & 555.5 & * & 0.7027 & * & 1.426 & * & 1.385 & * & 0.172 & * & - & * \\
\hline & & 8 & 7.144 & * & 0.3429 & * & 493.0 & * & 0.2379 & * & 2.540 & * & 2.549 & * & 0.0746 & * & - & * \\
\hline & & 9 & 1.797 & * & 0.4765 & * & 610.4 & * & 0.8387 & * & 1.868 & * & 1.832 & * & 0.288 & * & - & * \\
\hline & & 10 & 7.191 & * & 0.3767 & * & 539.5 & * & 0.3537 & * & 1.784 & * & 1.785 & * & 0.0697 & * & - & * \\
\hline & & 11 & 1.810 & * & 0.5351 & * & 709.9 & * & 1.148 & * & 2.126 & * & 2.089 & * & 0.397 & * & - & * \\
\hline & & 12 & 5.408 & * & 0.3893 & * & 552.8 & * & 0.2708 & * & 1.873 & * & 1.867 & * & 0.118 & * & - & * \\
\hline & & 13 & 3.607 & * & 0.4366 & * & 608.8 & * & 0.4568 & * & 1.914 & * & 1.899 & * & 0.173 & * & - & * \\
\hline \multirow[t]{14}{*}{ - } & \multirow[t]{14}{*}{$\begin{array}{c}\text { Grad } \\
\text { Ref } w / 0 \\
\text { EGR }\end{array}$} & 0 & 3.838 & - & 0.3563 & - & 497.3 & - & 0.2808 & - & 4.529 & - & 4.517 & - & 0.128 & - & 0.1242 & - \\
\hline & & $1^{*}$ & 0.000 & - & 0.000 & - & 17030 & - & 54.07 & - & 295.0 & - & 279.4 & - & 22.4 & - & - & - \\
\hline & & 2 & 6.450 & - & 0.3529 & - & 478.6 & - & 0.1629 & - & 4.263 & - & 4.258 & - & 0.0784 & - & - & - \\
\hline & & 3 & 3.583 & - & 0.3526 & - & 489.3 & - & 0.2311 & - & 4.435 & - & 4.427 & - & 0.127 & - & - & - \\
\hline & & 4 & 5.367 & - & 0.3419 & - & 470.5 & - & 0.1702 & - & 4.478 & - & 4.475 & - & 0.101 & - & - & - \\
\hline & & 5 & 3.227 & - & 0.3304 & - & 468.2 & - & 0.2075 & - & 4.726 & - & 4.718 & - & 0.101 & - & - & - \\
\hline & & 6 & 4.842 & - & 0.3288 & - & 457.7 & - & 0.1336 & - & 4.760 & - & 4.762 & - & 0.0912 & - & - & - \\
\hline & & 7 & 1.614 & - & 0.3767 & - & 505.7 & - & 0.4423 & - & 4.727 & - & 4.702 & - & 0.198 & - & - & - \\
\hline & & 8 & 7.146 & - & 0.3480 & - & 483.2 & - & 0.1712 & - & 4.225 & - & 4.220 & - & 0.0955 & - & - & - \\
\hline & & 9 & 1.798 & - & 0.3914 & - & 554.1 & - & 0.6231 & - & 4.061 & - & 4.029 & - & 0.312 & - & - & - \\
\hline & & 10 & 7.217 & - & 0.3589 & - & 500.8 & - & 0.2253 & - & 4.363 & - & 4.353 & - & 0.0907 & - & - & - \\
\hline & & 11 & 1.807 & - & 0.4570 & - & 624.7 & - & 0.8636 & - & 5.190 & - & 5.163 & - & 0.422 & - & - & - \\
\hline & & 12 & 5.418 & - & 0.3580 & - & 495.6 & - & 0.4545 & - & 4.652 & - & 4.646 & - & 0.111 & - & - & - \\
\hline & & 13 & 3.618 & - & 0.4007 & - & 525.1 & - & 0.5349 & - & 4.586 & - & 4.587 & - & 0.164 & - & - & - \\
\hline \multirow[t]{9}{*}{ - } & \multirow[t]{9}{*}{$\begin{array}{c}\text { Grad } \\
\text { Ref w/ } \\
\text { EGR }\end{array}$} & 0 & 3.787 & * & 0.3787 & $6.3 \%$ & 525.8 & $5.7 \%$ & 0.4613 & $64.3 \%$ & 1.849 & $-59.2 \%$ & 1.825 & $-59.6 \%$ & 0.108 & $-15.9 \%$ & 0.1986 & $59.9 \%$ \\
\hline & & $1^{*}$ & 0.000 & - & 0.000 & * & 16240 & $-4.6 \%$ & 70.29 & $30.0 \%$ & \begin{tabular}{|l|}
159.2 \\
\end{tabular} & $-46.0 \%$ & $\begin{array}{ll}146.3 \\
\end{array}$ & $-47.6 \%$ & $\begin{array}{ll}0 & 19.5 \\
\end{array}$ & * & - & * \\
\hline & & 2 & 5.970 & * & 0.3729 & * & 517.1 & $8.0 \%$ & 0.9119 & * & 0.8615 & $-79.8 \%$ & 0.8440 & $-80.2 \%$ & 0.0403 & $-48.6 \%$ & - & * \\
\hline & & 3 & 3.569 & * & 0.3856 & $9.4 \%$ & 523.2 & * & 0.3219 & $39.3 \%$ & 1.877 & $-57.7 \%$ & 1.851 & $-58.2 \%$ & 0.112 & $-11.6 \%$ & - & * \\
\hline & & 4 & 5.360 & * & 0.3538 & * & 486.9 & $3.5 \%$ & 0.2141 & $25.8 \%$ & 2.401 & $-46.4 \%$ & 2.388 & $-46.6 \%$ & 0.0825 & $-18.0 \%$ & - & * \\
\hline & & 5 & 3.231 & * & 0.3604 & $9.1 \%$ & 507.6 & $8.4 \%$ & 0.3140 & $51.3 \%$ & 1.420 & $-70.0 \%$ & 1.390 & $-70.5 \%$ & 0.0916 & $-9.3 \%$ & - & * \\
\hline & & 6 & 4.835 & * & 0.3604 & $9.6 \%$ & 503.4 & $10.0 \%$ & 0.3068 & $129.6 \%$ & 1.535 & $-67.8 \%$ & 1.516 & $-68.2 \%$ & 0.0665 & $-27.0 \%$ & - & * \\
\hline & & 7 & 1.614 & * & 0.3852 & * & 542.1 & $7.2 \%$ & 0.6735 & $52.3 \%$ & 1.248 & $-73.6 \%$ & 1.197 & $-74.6 \%$ & 0.176 & $-11.4 \%$ & - & * \\
\hline & & 8 & 7.118 & $-0.4 \%$ & 0.3582 & * & 480.5 & * & 0.2534 & $48.0 \%$ & 2.368 & $-43.9 \%$ & 2.355 & $-44.2 \%$ & 0.0762 & $-20.3 \%$ & - & * \\
\hline
\end{tabular}




\begin{tabular}{|c|c|c|c|c|c|c|c|c|c|c|c|c|c|c|c|c|c|c|}
\hline \multirow{7}{*}{$\begin{array}{l}\text { Additive I } \\
\text { Condition }\end{array}$} & \multirow{7}{*}{ Base } & & \multicolumn{2}{|c|}{ Work } & \multicolumn{2}{|c|}{ BSFC } & \multicolumn{2}{|c|}{$\mathrm{CO}_{2}$} & \multicolumn{2}{|c|}{ co } & \multicolumn{2}{|c|}{ NOx } & \multicolumn{2}{|c|}{ NOx2 } & \multicolumn{2}{|c|}{$\mathrm{HC}$} & \multicolumn{2}{|c|}{ TPM } \\
\hline & & Mode & $\begin{array}{c}\text { bhp- } \\
\text { hr }\end{array}$ & $\begin{array}{l}\text { Diff } \\
(\%)\end{array}$ & $\begin{array}{c}\text { Ib/bhp- } \\
\text { hr }\end{array}$ & $\begin{array}{l}\text { Diff } \\
(\%)\end{array}$ & $\begin{array}{c}\text { g/bhp- } \\
\text { hr }\end{array}$ & $\begin{array}{l}\text { Diff } \\
(\%)\end{array}$ & $\begin{array}{c}\text { g/bhp- } \\
\mathrm{hr}\end{array}$ & Diff (\%) & $\begin{array}{c}\text { g/bhp- } \\
\text { hr }\end{array}$ & $\begin{array}{l}\text { Diff } \\
(\%)\end{array}$ & $\begin{array}{c}\text { g/bhp- } \\
\text { hr }\end{array}$ & $\begin{array}{l}\text { Diff } \\
(\%)\end{array}$ & $\begin{array}{c}\text { g/bhp- } \\
\text { hr }\end{array}$ & $\begin{array}{l}\text { Diff } \\
(\%)\end{array}$ & $\begin{array}{c}\text { g/bhp- } \\
\text { hr }\end{array}$ & $\begin{array}{l}\text { Diff } \\
(\%)\end{array}$ \\
\hline & & 9 & 1.787 & * & 0.4224 & * & 591.6 & $6.8 \%$ & 0.8267 & $32.7 \%$ & 1.708 & $-58.0 \%$ & 1.653 & $-59.0 \%$ & 0.268 & * & - & * \\
\hline & & 10 & 7.140 & $-1.1 \%$ & 0.3863 & $7.6 \%$ & 526.1 & $5.1 \%$ & 0.3778 & $67.7 \%$ & 1.670 & $-61.7 \%$ & 1.658 & $-61.9 \%$ & 0.0739 & $-18.5 \%$ & - & * \\
\hline & & 11 & 1.815 & $0.4 \%$ & 0.4925 & * & 687.4 & $10.0 \%$ & 1.179 & $36.5 \%$ & 1.913 & $-63.1 \%$ & 1.864 & $-63.9 \%$ & 0.381 & $-9.8 \%$ & - & * \\
\hline & & 12 & 5.414 & * & 0.3904 & $9.0 \%$ & 537.4 & $8.4 \%$ & 0.3128 & $-31.2 \%$ & 1.737 & $-62.7 \%$ & 1.723 & $-62.9 \%$ & 0.113 & * & - & * \\
\hline & & 13 & 3.612 & * & 0.4231 & * & 591.3 & $12.6 \%$ & 0.5370 & * & 1.744 & $-62.0 \%$ & 1.722 & $-62.5 \%$ & 0.168 & * & - & * \\
\hline \multirow[t]{14}{*}{$\begin{array}{c}16 \mathrm{ml} / \mathrm{gal} \\
\mathrm{ODA}\end{array}$} & \multirow[t]{14}{*}{$\begin{array}{c}\text { Grad } \\
\text { Ref w/ } \\
\text { EGR }\end{array}$} & 0 & 3.784 & * & 0.3780 & * & 525.8 & * & 0.4533 & * & 1.864 & * & 1.851 & * & 0.0987 & $-8.2 \%$ & 0.2028 & * \\
\hline & & $1^{*}$ & 0.000 & - & 0.000 & * & 15650 & * & 59.48 & $-15.4 \%$ & 146.8 & $-7.8 \%$ & 136.3 & $-6.8 \%$ & 16.4 & * & - & * \\
\hline & & 2 & 5.947 & * & 0.3813 & * & 516.7 & * & 0.8882 & * & 0.8999 & * & 0.8867 & * & 0.0385 & * & - & * \\
\hline & & 3 & 3.584 & * & 0.3757 & * & 521.8 & * & 0.3195 & * & 1.919 & * & 1.902 & * & 0.0947 & $-15.6 \%$ & - & * \\
\hline & & 4 & 5.363 & * & 0.3503 & * & 486.1 & * & 0.2245 & * & 2.381 & * & 2.377 & * & 0.0767 & $-7.0 \%$ & - & * \\
\hline & & 5 & 3.230 & * & 0.3594 & * & 508.5 & * & 0.3135 & * & 1.460 & * & 1.437 & $3.4 \%$ & 0.0859 & $-6.2 \%$ & - & * \\
\hline & & 6 & 4.840 & * & 0.3589 & * & 501.6 & * & 0.3057 & * & 1.548 & $0.8 \%$ & 1.534 & $1.2 \%$ & 0.0657 & * & - & * \\
\hline & & 7 & 1.611 & * & 0.4163 & * & 542.6 & * & 0.6563 & * & 1.271 & * & 1.232 & * & 0.156 & $-10.9 \%$ & - & * \\
\hline & & 8 & 7.092 & $-0.4 \%$ & 0.3505 & * & 483.1 & * & 0.2643 & $4.3 \%$ & 2.367 & * & 2.368 & * & 0.0728 & * & - & * \\
\hline & & 9 & 1.799 & * & 0.4135 & * & 590.9 & * & 0.7917 & $-4.2 \%$ & 1.743 & * & 1.708 & * & 0.244 & * & - & * \\
\hline & & 10 & 7.125 & * & 0.3914 & * & 525.0 & * & 0.3739 & * & 1.688 & $1.1 \%$ & 1.688 & $1.8 \%$ & 0.0693 & * & - & * \\
\hline & & 11 & 1.805 & $-0.6 \%$ & 0.5114 & * & 691.9 & * & 1.150 & * & 1.972 & * & 1.940 & * & 0.340 & $-10.7 \%$ & - & * \\
\hline & & 12 & 5.415 & * & 0.3862 & * & 538.9 & * & 0.3093 & * & 1.770 & * & 1.767 & * & 0.108 & * & - & * \\
\hline & & 13 & 3.611 & * & 0.4226 & * & 594.0 & * & 0.5218 & $-2.8 \%$ & 1.774 & * & 1.762 & * & 0.152 & $-9.7 \%$ & - & * \\
\hline \multirow[t]{14}{*}{$\begin{array}{c}16 \mathrm{ml} / \mathrm{gal} \\
\mathrm{ODA}\end{array}$} & \multirow[t]{14}{*}{$\begin{array}{c}\text { Grad } \\
\text { Ref w/o } \\
\text { EGR }\end{array}$} & 0 & 3.834 & * & 0.3593 & * & 499.6 & * & 0.2828 & * & 4.515 & * & 4.515 & * & 0.119 & $-6.8 \%$ & 0.1151 & * \\
\hline & & $1^{*}$ & 0.000 & - & 0.000 & * & 16960 & * & 49.02 & $-9.3 \%$ & 263.1 & $-10.8 \%$ & 247.0 & $-11.6 \%$ & 18.8 & * & - & * \\
\hline & & 2 & 6.451 & * & 0.3502 & * & 482.2 & * & 0.1680 & * & 4.213 & * & 4.217 & * & 0.0690 & * & - & * \\
\hline & & 3 & 3.580 & * & 0.3661 & * & 490.5 & * & 0.2312 & * & 4.496 & * & 4.500 & * & 0.114 & $-10.2 \%$ & - & * \\
\hline & & 4 & 5.355 & * & 0.3447 & * & 472.2 & * & 0.1707 & * & 4.513 & * & 4.520 & * & 0.0941 & $-6.5 \%$ & - & * \\
\hline & & 5 & 3.234 & * & 0.3319 & * & 469.4 & * & 0.2214 & $6.7 \%$ & 4.709 & * & 4.715 & * & 0.0957 & $-5.2 \%$ & - & * \\
\hline & & 6 & 4.834 & * & 0.3309 & * & 461.7 & * & 0.1393 & $4.3 \%$ & 4.742 & $-0.4 \%$ & 4.753 & * & 0.0912 & * & - & * \\
\hline & & 7 & 1.614 & * & 0.4020 & * & 508.6 & * & 0.4686 & * & 4.692 & * & 4.671 & * & 0.187 & * & - & * \\
\hline & & 8 & 7.132 & * & 0.3510 & * & 484.1 & * & 0.1751 & * & 4.194 & * & 4.201 & * & 0.0911 & * & - & * \\
\hline & & 9 & 1.800 & * & 0.4034 & * & 559.8 & * & 0.6279 & * & 4.060 & * & 4.045 & * & 0.289 & * & - & * \\
\hline & & 10 & 7.219 & * & 0.3593 & * & 502.5 & * & 0.2346 & * & 4.337 & * & 4.344 & * & 0.0862 & * & - & * \\
\hline & & 11 & 1.797 & $-0.6 \%$ & 0.4789 & * & 629.0 & * & 0.8758 & * & 5.214 & * & 5.202 & * & 0.386 & $-8.5 \%$ & - & * \\
\hline & & 12 & 5.412 & * & 0.3545 & * & 499.6 & * & 0.4404 & $-3.1 \%$ & 4.674 & * & 4.685 & * & 0.110 & * & - & * \\
\hline & & 13 & 3.616 & * & 0.3912 & * & 525.7 & * & 0.5318 & * & 4.617 & * & 4.633 & * & 0.159 & * & - & * \\
\hline
\end{tabular}

